\title{
Behavioral Ecology of Coral Reef Fishes at Spawning Aggregation Sites
}

\author{
by \\ Gorka Sancho \\ "Licenciado" in Biological Sciences \\ Universidad Autonoma de Madrid, 1991
SUBMITTED IN PARTIAL FULFILLMENT OF THE REQUIREMENTS FOR THE DEGREE OF \\ DOCTOR OF PHILOSOPHY
}

at the

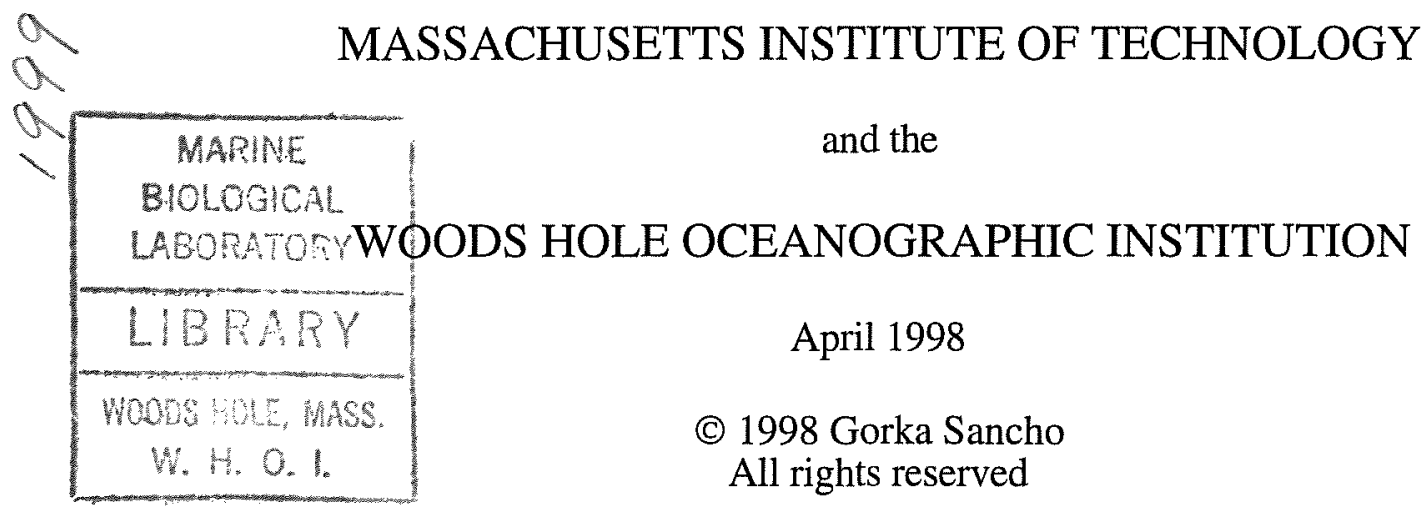

The author hereby grants to MIT and WHOI permission to reproduce paper and electronic copies of this thesis in whole, or in part, and to distribute them publicly.

Signature of Author

Joint Program in Biological Oceanography, Massachusetts Institute of Technology/

Woods Hole Oceanggraphic Institution

Certified by Thesis Supervisor

Accepted by

Dr. Mark Hahn Chairman, Joint Committee for Biological Oceanography, Massachusetts Institute of Technology/ Woods Hole Oceanographic Institution 
, 


\title{
BEHAVIORAL ECOLOGY OF CORAL REEF FISHES AT SPAWNING
}

\section{AGGREGATIONS SITES}

\author{
by \\ Gorka Sancho \\ Submitted to the Department of Biology in April 1998 in partial fulfillment of the \\ requirements for the degree of Doctor of Philosophy
}

\begin{abstract}
Coral reef fishes aggregate to spawn on certain locations of reefs. This thesis is an extensive investigation of the behavioral and ecological relations between spawning reef fishes, predators and their environment at a spawning aggregation site.

Many hypotheses have been proposed regarding the adaptive nature of different diel reproductive cycles observed in coral reef fishes. This study quantified the spawning patterns of eleven different reef fish species at one location (Johnston Atoll, Central Pacific), while making simultaneous measurements of the environmental factors likely to affect the spawning behavior of reef fishes. The environmental variables measured included time of day, tides, current velocity, current speed and abundance of piscivorous predators, and were correlated with observed spawning outputs through multifactorial analyses.

High interspecific variability in spawning patterns was found among the eleven monitored species. The majority of species spawned at a specific time of the day, in agreement with the timing of spawning described at other locations, indicative of a fixed general response by fishes across distribution areas. Spawning of most fishes with daytime spawning peaks was correlated with local changes in current direction and predatory risks, showing responses designed to reduce the mortality of propagules and adults. Dusk-spawning species generally did not respond to changes in flow direction and predator abundance, most likely due to their short spawning periods and the reduced predatory pressures that occurred at dusk. Tides did not seem to be used exclusively as synchronizing cues to adult fishes for spawning. The influence of current speed in determining diel timing of spawning varied among species, with some species showing responses to current speed while others showed no response.

Predation is a selective force hypothesized to influence the spawning behavior of coral reef fishes. This study describes and quantifies the predatory activities of two piscivorous and three planktivorous species at a coral reef fish spawning aggregation site in Johnston Atoll (Central Pacific). To characterize predator-prey relations, the spawning behavior of prey species was quantified simultaneously with measurements of predatory activity, current speed and substrate topography.

Diel activity patterns and predator-prey relations varied among the predatory species analyzed. The activity patterns of piscivores, measured both as abundance and attack rates, were high during the daytime, decreased during the late afternoon hours and reached a minimum at dusk. The abundance of piscivores was significantly correlated with the abundance of prey for only one (Caranx melampygus) of the two piscivorous species, while the other species (Aphareus furca) did not respond to prey abundance. The selection of certain prey species by piscivores was consistent with two different hypotheses: the
\end{abstract}


satiation of predators and the differences in spawning behaviors among prey species. Two of the three planktivorous species fed most actively at dusk, and selected as prey those species of reef fishes that produced eggs of large size. The third planktivorous species fed at all times of the day.

Spawning prey fishes were more abundant over substrates with complex topography where refuges from piscivores were abundant than over smooth substrates. Overall attack rates by piscivores on adult spawning fishes were higher than by planktivores feeding on recently released eggs. The diel spawning patterns displayed by reef fishes at the study site seem to be influenced by the diel activity and prey selection patterns of piscivores previously described. The highest diversity of prey species occurred at dusk, when piscivores were least abundant and overall abundance of prey fishes was lowest.

The behavioral strategies used by the piscivore Caranx melampygus (Carangidae) while feeding on spawning aggregations of coral reef fishes were studied for two years at Johnston Atoll (Central Pacific). Visual behavioral observations revealed the existence of two different hunting behaviors employed by this predator. A 'midwater' hunting behavior, which consisted of midwater high speed attacks on spawning fishes, is typical of large sized transient predators and yielded a low capture success rate (2\%). An 'ambush' hunting behavior consisted of attacks on spawning fishes from hiding locations in the substrate, and yielded a much higher capture success rate $(17 \%)$. While ambushing their prey, C. melampygus displayed territorial aggressive behaviors toward other intruding conspecifics, defending a specific section of the reef. This specialized ambushing behavior is atypical of fast swimming carangids, but illustrates the behavioral flexibility of this predator. I suggest that the use of these two hunting behaviors by $C$. melampygus can potentially cause density-dependent mortality rates in prey communities, a demographic consequence previously attributed to the simultaneous action of various guilds of predatory species.

Two species of trunkfishes (Ostraciidae) were observed spawning above a coral reef at Johnston Atoll (Central Pacific). This study analyzed the potential causes determining the difference in spawning ascent height in Ostracion meleagris $(3.3 \mathrm{~m}$ average) and $O$. whitleyi (1.5 $\mathrm{m}$ average). One hypothesis proposes that the risk of predation by piscivores influences how far each species can swim from the substrate, and that predation risk is greater for $O$. whitleyi than $O$. meleagris. Trunkfishes have an armoured exoskeleton and secrete an ichthyotoxic mucous under stress conditions, two defenses against predation. Because the two species used the same spawning grounds and spawned at approximately the same time, their size and toxicity levels were analyzed to assess their susceptibility to predation. Toxins were extracted from wild fishes and tested using a mosquitofish assay. Ostracion whitleyi was more toxic than $O$. meleagris, refuting the predation-risk hypothesis. A second hypothesis proposes that long ascents are a way for spawning pairs to avoid disturbances by other male conspecifics. Observations of the spawning behaviours of the two species showed that male $O$. meleagris were frequently involved in fighting episodes and showed high rates of male streaking (intruding nonpaired males attempting to fertilize eggs from spawning paired females), while none of these behaviours were observed in $O$. whitleyi. The larger spawning height from the substrate may be an attempt by pairs of $O$. meleagris to reduce the possibility of interference by other male conspecifics. Thus, the height of spawning ascents corresponds to the expectation from the male disturbance hypothesis, but not to the expectation of the predatory risk hypothesis.

Thesis Supervisor: Lauren S. Mullineaux

Title: Associate Scientist, Woods Hole Oceanographic Institution 


\section{Acknowledgments}

At the present time my thesis has been written, defended and corrected. Six years of hard work have come to an end, and it is time to look back and acknowledge all the people who helped me in one way or another with my research and my life. I hope to not miss too many people, since there were so many of you who helped me pursue my dreams of becoming a marine ecologist.

I have a large thesis committee, so bear with me. My advisor, Lauren Mullineaux, taught me all I know about the scientific method and encouraged me to move ahead with my research during obscure moments. Without her, I would have never finished this work. Phil Lobel gave me the opportunity of coming to WHOI, becoming a field ichthyologist and to work on Johnston Atoll. Judy McDowell was always a phone call away when I needed her, calm and optimistic. Andy Solow achieved what four different university courses were never able to accomplish, teach me statistics. Maybe the combination of infinite patience on his side and large doses of dark roasted coffee was the trick. Glenn Flierl graciously accepted being my MIT committee member, and greatly helped this thesis with most insightful comments of my work. Chris Petersen brought expertise on fish behavior to my committee, revised in detail all my manuscripts and always paid for our oriental food feasts. Two of my chapters are the result of conversations with him. I also wanted to thank to temporary members of my committee: Steve Bollens helped me pursue my interests in larval fish behavior, and Larry Madin, who's support as the head of the WHOI diving board was crucial for the completion of my field work.

My thesis was done in two different laboratories, so many people have shared my messy desks. My work was always influenced by my friend David Mann, also my colleague, officemate, diving buddy and writing consultant. We managed to help each other in rough moments, fuel our interests for the study of fishes and laugh as much as 
possible in the process. In the early days Erich Horgan and John Barimo completed ichthyology laboratory, it was a pleasure to work with such an enthusiastic bunch of friends. For brief moments Carla Curran, Diana Ma and Alistair Economakis coincided with me in this lab. Later on I moved across the hallway to share a space with Ewann Bernston and Susan Mills, which provided me with friendship, support and chocolate during the process of writing up my thesis. Laughs were also abundant.

David Mann, Gary Jaroslow, Deb Bidwell and Donald Kramer painfully read many rough drafts in Spanglish and improved my English. Conchita Avila and Annie Weisbrod helped me design the trunkfish toxicity protocol.

I spent most of my time in first floor of the Redfield building, where the organismal biologists of WHOI are most commonly found: Rudi and Ami Scheltema, Stacy Kim, Jesus Pineda, Peter Tyack, Rebecca Thomas, Patrick Miller, Pam Arnofsky, Mircea Podar, Molly and Winkle. Richard Harbison and Jim Craddock deserve special attention for great friendships and for transmitting to me their passion for science and the oceans. If they are not doing molecular biology because they are not interested, younger generations should drop by their offices to learn something about how science should be.

The WHOI education office always supported me, and I would like to specially thank Jake Peirson, Abbie Alvin and Julia Westwater, for dear friendships and support. Colleen Hurter from the MBL/WHOI library is one of the most hard working and efficient persons on this planet, and is a wonderful person, too. I believe it is very easy to obtain a Ph.D. with such a supporting team on your side.

But I also spent a lot of time at Johnston Atoll doing field work. Diving buddies were essential for my work with SCUBA, and I had the best ones: David Mann, Diana Ma, Alistair Economakis, Steve Oliver, John Barimo and Erich Horgan. Also a group of friends from Johnston Island, all excellent divers, was always ready to jump in the water if necessary, specially if it involved strong currents, sharks and spearing fishes: Gary 
McCloskey, GW, Kelly and Miguel Busquets, Dave Shogren, Jane Super and Mary Boyce. Roger DiRosa, Donna O'Daniel and Chris Depkin from the U.S. Fish \& Wildlife were our friends and colleagues, and we helped each other studying either fish or birds.

None of this work could have been possible without the help of vast amounts of money. A fellowship form La Fundacion "La Caixa" allowed me to come to the WHOI/MIT Joint Program and generously funded me for two years. Travel to Johnston Atoll, part of my salary and many oceanographical toys were funded by the following grants to P.S. Lobel: U.S. Army Chemical Material Destruction Agency (via NOAA Sea Grant NA90-AA-D-SG535 and the Office of Naval Research N00014-91-J-1591 and N00014-92-J-1969) and the U.S. Army Legacy Resource Management Program (DAMD 17-93-J-3052). Finally the WHOI education office covered my tuition for a few years and paid for my attendance to scientific meetings. Funds were also received from the Thomas F. Westcott Fund for WHOI / MIT Joint Program Students, WHOI Sea Grant project R/B134-PD, Coastal Research Center and Copeland Family Foundation.

I have left for now some of the most important people to me during these years, which were essential for my completion of my doctorate: my friends. You can easily recognize them, they are all fun loving open people with great hearts. I will first list Deb Bidwell, who recently entered my life like a hurricane and gave me the necessary energy to finish my thesis. She makes me happy and I am looking forward to many new adventures in her company. From my arrival to Woods Hole, Gary Jaroslow shared with me the good and bad moments, amplifying the first and soothing the last. I am honored we can call each other friends. In a similar role, I have to include the 'old guard' from Woods Hole: Javier Escartin, Dan Torres, The Weidmans, Joe \& Cecilia Lacasce, David \& Amy Mann, Miguel \& Kathleen Goni, Dan \& Haiga Lizarralde, Xavi Garcia, Connie Hart and Margie Oleksiak, the greatest group of friends a crazy paniard lost in New England could ask for. But I also want to thank Gaspar Taroncher, Ee Lin Lim, Nancy Parmentier, Rob \& 
Kahmla Evans, Deana Erdner, Jake, Anna Maria Peirson and family, Abbie Jackson, Julia Westwater, Rich \& Judy Harbison, \#2, Sonsoles Gonzalez, Ghislaine Llewelyn, Lisa \& Jason Moore, Gustavo \& Aria Arrizabalaga, David West, Nicole Duhamel, Kate Lindner, Christina Sun, Stacy Kim, Ewann Agenbroad, Dan Lindstrom, Ishi Buffin, Dana Stuart, Vicki Tauxe, Sheri Hall, Glenn Crossin, Lihini Aluwihare, Bill Shaw, Debbie Hassler, Karie Slavik, Pablo Canales, Shannon Wagner, Max, The Jovines, Rebecca Thomas, Flip Williams and the WHUF crowd, since they were all important friends to me at some point of my career, and still are. From Spain, I have to thank Carlos Hermida, Maite Cendan and Chema Velasco, que siempre me animaron a perseguir mis sueños pese que ello supusiese interponer un oceano entre nosotros. Espero pagarles con creces en el futuro proximo.

Finally I want to thank my family. I shared with them unique moments while diving in Menorca and fishing up the mountains of Spain, which obviously influenced the topic of this thesis. My mother, Elena Bizcarrondo, not only allowed me, but encouraged me to pursue my dreams and interests. My father, Jose Maria Sancho, is the one that took me to a fishing derby when I was 6 , and bought me a speargun at the age of 8 . I could have never asked for anything else. 


\section{Table of Contents}

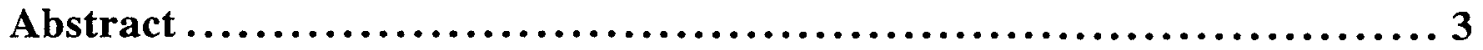

Acknowledgments .............................................. 5

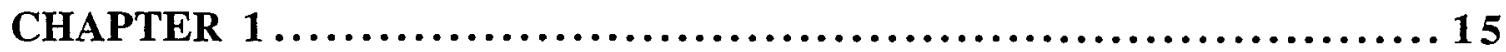

Introduction ....................................................... 15

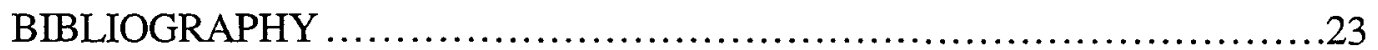

CHAPTER 2 ................................................. 25

Environmental influences on the diel timing of spawning in coral reef fishes.......................................................... 25

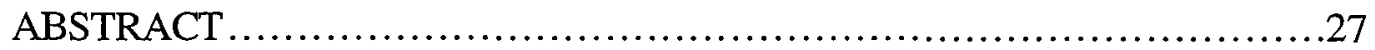

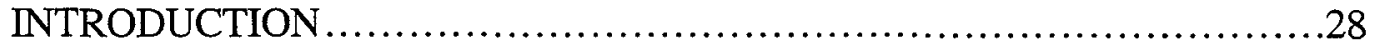

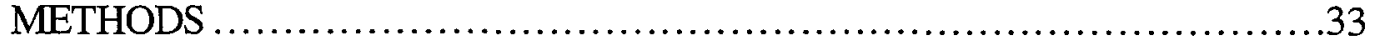

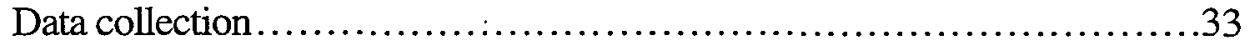

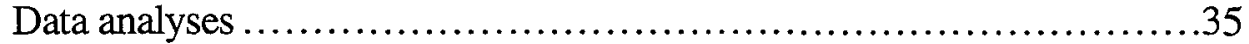

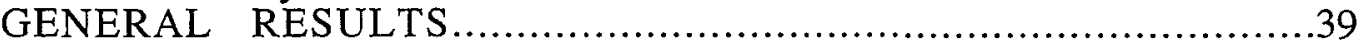

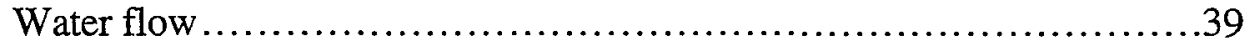

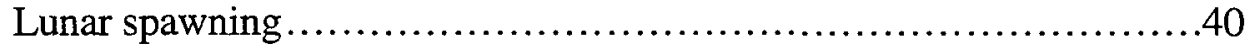

Relation of fish abundance and spawning with tides ..................41

Multifactorial analyses............................................42

Current reversal moments..........................................44

Dispersal of propagules ........................................45

RESULTS IN RELATION TO HYPOTHESES.................................46

Use of currents for maximum dispersal of larvae .....................46

Use of currents to minimize benthic egg predation ....................47

Use of tides as a synchronization cue by adults........................48

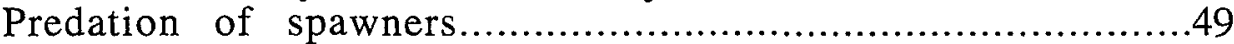

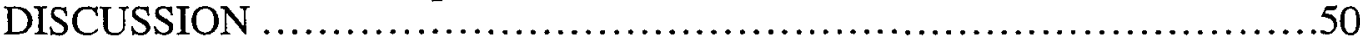

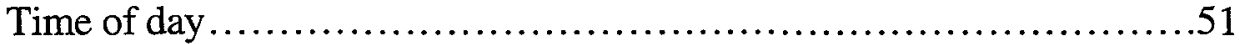

Current direction ................................................. 53

Current speed...................................................5

Tides........................................................... 55

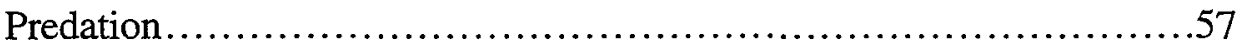

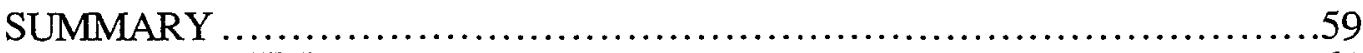

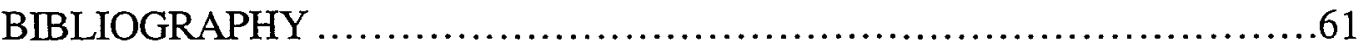

CHAPTER 3 ................................................ 101

Predator-prey relations at a spawning aggregation site of coral reef

fishes........................................................ 101

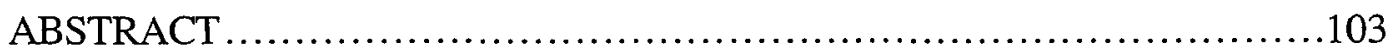

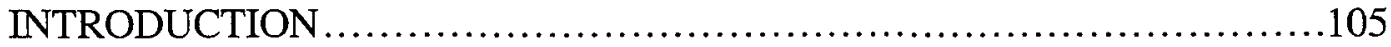

Background on predatory species.......................................111

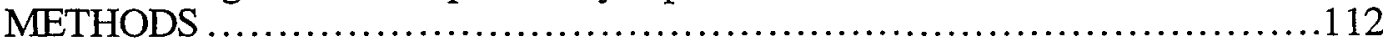

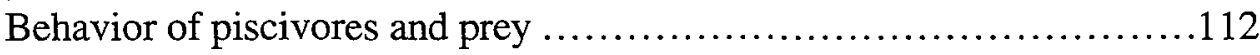


Behavior of planktivores........................................113

Topographical and current speed measurements .....................114

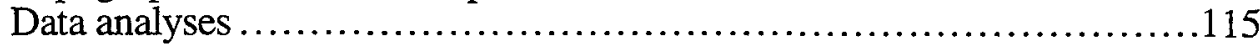

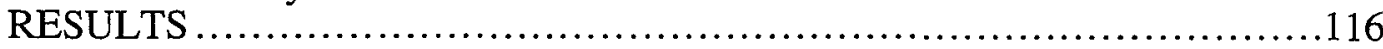

Piscivores........................................................... 116

Planktivores .......................................................119

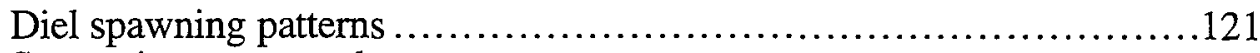

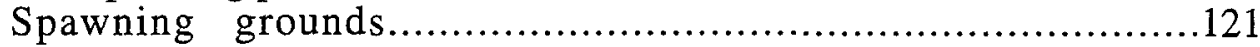

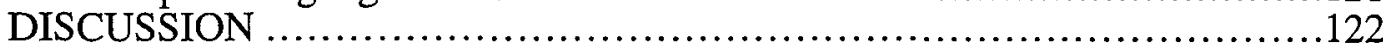

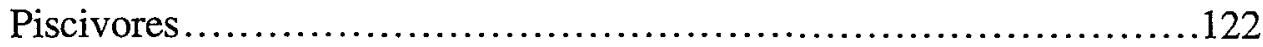

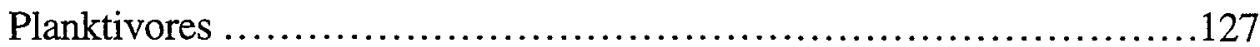

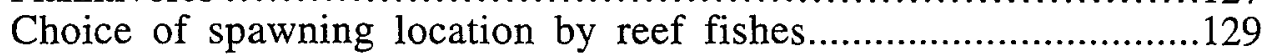

Effects of predation on reef fish populations ........................130

SUMMARY

Effects of predation on timing of spawning of reef fishes ..............131

BIBLIOGRAPHY

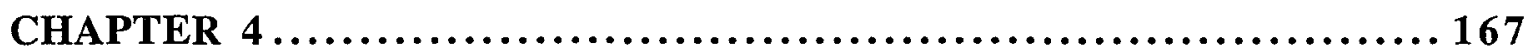

Novel territorial ambushing behavior of the transient predator Caranx

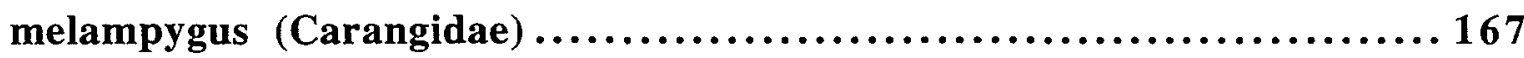

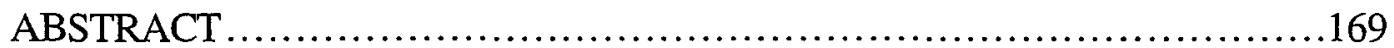

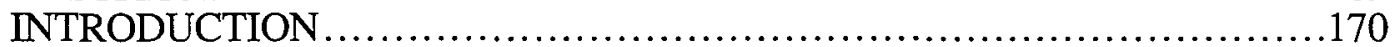

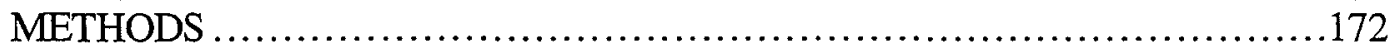

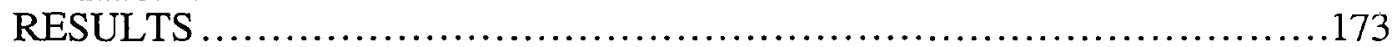

Midwater attacks ...............................................

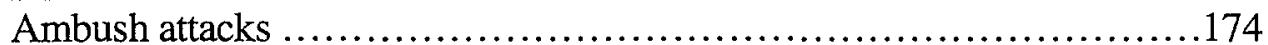

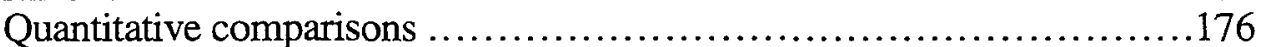

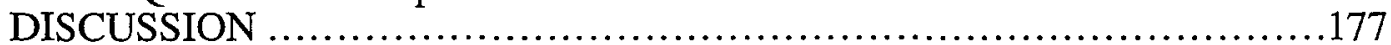

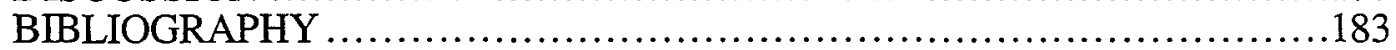

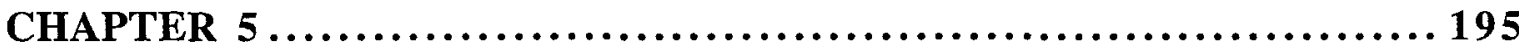

Influence of predation and male competition on the height of

spawning ascents in trunkfishes (Ostraciidae)................... 195

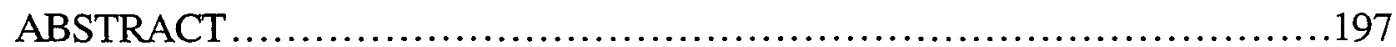

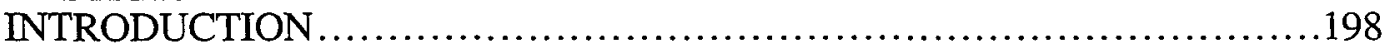

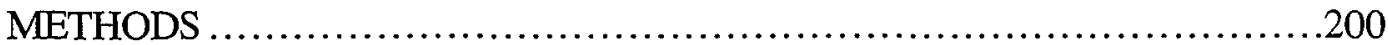

Behavior ............................................................. 200

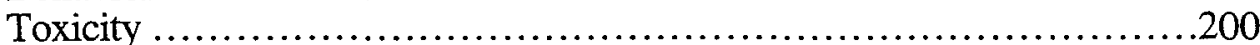

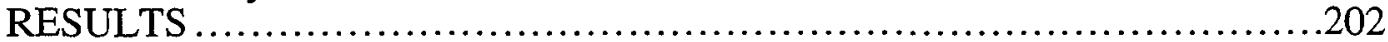

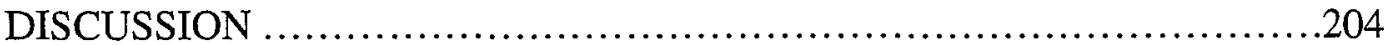

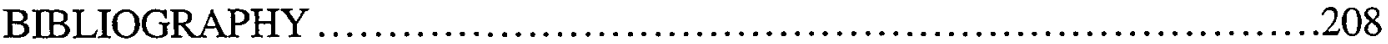

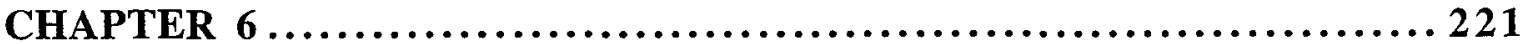

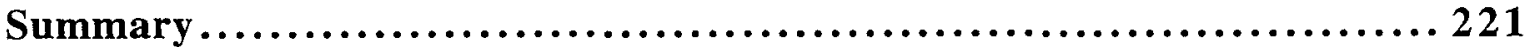

BIBLIOGRAPHY ................................................. 227

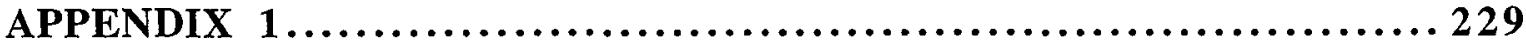


Reproductive seasonality of four reef fishes at Johnston Atoll

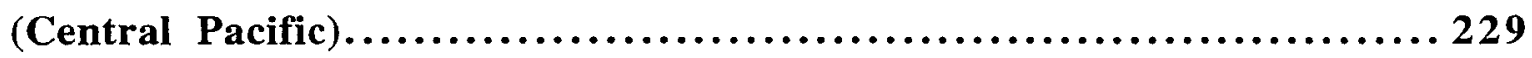

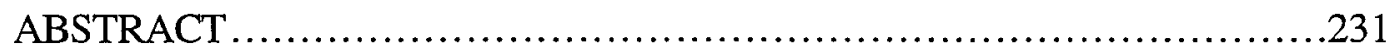

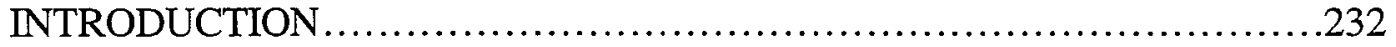

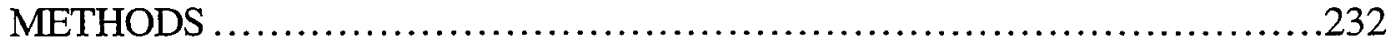

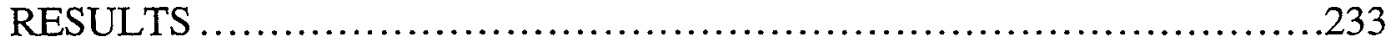

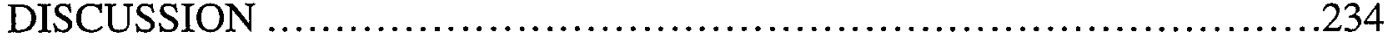

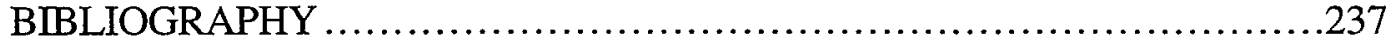

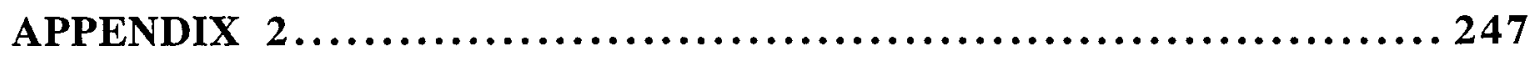

Graphic representations of some multifactorial analyses from Chapter

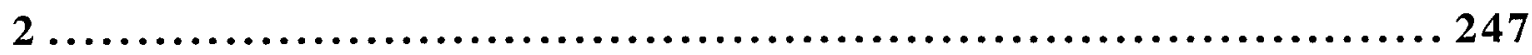




\section{List of Figures}

\section{Chapter 2}

Figure 1. Map of Johnston Atoll with locations of spawning aggregation sites.... 75

Figure 2. Current velocities and tidal heights at Mustin's Gap during

May 2, 1995.

Figure 3. Depth profile and current velocities at Mustin's Gap (May 3-8, 1995)

and Eastern Reef Edge (May 15-20)................................................ 79

Figure 4. Daily afternoon averages of current speed and spawning in 1995........ 81

Figure 5. Daily dusk averages of current speed and spawning in 1994................ 83

Figure 6. Daily dusk averages of current speed and spawning in 1995 ............... 85

Figure 7. Fish abundance and spawns of group-spawning species at different

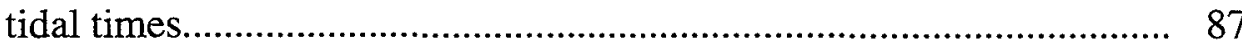

Figure 8. Spawns of pair-spawning species at different tidal times...................... 89

Figure 9. Abundance and spawning sequences of Chlorurus sordidus during days with current reversals (1995)........................................................ 91

Figure 10. Abundance and spawning sequence of Chlorurus sordidus on April 15, 1994.

Figure 11. Abundance and spawning sequences of Zebrasoma flavescens during days with current reversals (1995).

Figure 12. Abundance and spawning sequence of Ctenochaetus strigosus on

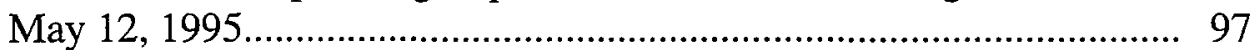

Figure 13. Distribution of spawns at different current speed categories.................. 99

\section{Chapter 3}

Figure 1. Hypotheses regarding the diel activity of predators in relation to their prey..

Figure 2. Map of Johnston Atoll with spawning aggregation sites and schematic representation of Mustin's Gap.

Figure 3. Diel distribution of piscivore presence and attacks (1994).

Figure 4. Distribution of piscivore presence and attacks at daytime and dusk periods (1995).

Figure 5. Distribution of triggerfish attacks at daytime and dusk periods (1995).. 155

Figure 6. Relation between egg volume of prey species and percentage of spawns attacked by triggerfishes.

Figure 7. Feeding heights of Dascyllus albisella versus current speed....

Figure 8. Diel distribution of abundance of spawning fishes, spawning rate and number of species.

Figure 9. Relation of density of spawning fishes and substrate topography. 163

Figure 10. Relationship between prey abundance and the presence of piscivores... 165 


\section{Chapter 4}

Figure 1. Schematic representation of a midwater attack sequence...................... 189

Figure 2. Schematic representation of an ambush attack sequence....................... 191

Figure 3. Diel distribution of midwater and ambush attacks by Jacks.................. 193

\section{Chapter 5}

Figure 1. Toxic effects of increasing amounts of toxic extracts of trunkfishes...... 213

Figure 2. Diel timing of spawning by trunkfishes............................................... 215

Figure 3. Comparison of spawning height, size and toxicity between Ostracion meleagris and Ostracion whitleyi.......................................................... 217

Figure 4. Diel timing of Ostracion meleagris behavioral events........................... 219

\section{Appendix 1}

Figure 1. Gonosomatic index for four reef fish species collected from

Johnston Atoll.

Figure 2. Condition factor for four reef fish species collected from

Johnston Atoll..

Figure 3. Condition factor for three reef fish species collected from Hawaii........ 245

\section{Appendix 2}

Figure 1. Regression curves of abundance of group-spawning fishes with significant independent variables.

Figure 2. Regression curves of number of spawns by group-spawning fishes with significant independent variables.

Figure 3. Regression curves of spawning intensity by group-spawning fishes with significant independent variables 253 


\section{List of Tables}

\section{Chapter 2}

Table 1. Spawning behavior of eleven reef fishes at Johnston Atoll...................... 66

Table 2. Multiple regression analyses of the abundance of group-spawning

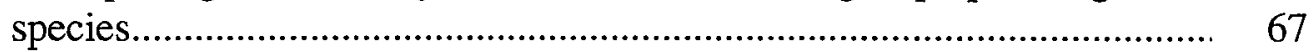

Table 3. Multiple regression analyses of the number of spawns of group-spawning species

Table 4. Multiple regression analyses of the spawning intensity of group-spawning species

Table 5. Multiple regression analyses of the number of spawns of dusk pair-spawning species.

Table 6. Multiple logistic model of the number of spawns of daytime pair-spawning species

Table 7. Summary table of analyses and results regarding number of spawns.......

\section{Chapter 3}

Table 1. Attacks by piscivores observed at Mustin's Gap.

Table 2. Duration of spawning rushes of prey and attack rates by piscivores........ 141

Table 3. Attack rates and success rates by piscivores in relation with prey spawning behavior

Table 4. Average feeding intensity and feeding height of Dascyllus albisella........ 143

Table 5. Current speed and topographical indices from two adjacent locations within the spawning grounds.

\section{Chapter 4}

Table 1. Success rates of midwater and ambush attack behaviors

Table 2. Description of successful attacks by Caranx melampygus.

\section{Chapter 5}

Table 1. Seize, sex and toxicity of individual trunkfishes used in toxicity tests.... 211 
CHAPTER 1

Introduction 
The purpose of this section is to introduce the reader to my thesis, the scientific questions it addresses and to review the previous work in the field. I will first state that the choice of the study organisms for my thesis was not based on any scientific principle, but was a result of my personal obsessive passion about fishes.

To a novice diver swimming over a coral reef, the first characteristic of the inhabiting fishes is their incredible diversity, which is most obviously expressed by the variety of colors, shapes and behaviors observed. But a behavior that few divers observe, probably because of their excitement and desire to touch every single critter they come across, is the process that distinguishes living organisms from non-living things: reproduction. If a diver moves swiftly across a reef and knows where to look, suddenly he or she will discover that the variety of colors, shapes and swimming behaviors of coral reef fishes is matched by the number of mating rituals and spawning tactics they display (Thresher 1984). This thesis is mainly based on observations of spawning events by reef fishes. When talking with colleagues and friends, after commenting that I work on coral reef fishes, the first question I inevitably get asked is "What fish species do you study?". This is a tough question to answer in my case, since I have attempted to use a comparative approach to study the mechanisms controlling spawning behavior of reef fishes, trying to find general principles that might explain the diverse behavioral patterns observed. My typical answer to the above question is "Any reef fish species that I could possibly observe spawning or interacting with spawning fishes". This response usually causes a certain degree of shock to the interrogator, I suppose because of the tendency of some modern biological fields to specialize on studying with scrutinizing detail a single species, a single strain or even a single gene. With slightly less enthusiasm, the second question I usually receive is "And where do you study all these fishes?". I usually exhale with relief, since there is a very straightforward answer, "Johnston Atoll". It is a small isolated coral reef atoll located in the Central Pacific Ocean at $16^{\circ} 45^{\prime} \mathrm{N} ; 169^{\circ} 30^{\prime} \mathrm{W}, 470$ miles south from 
French Frigate Shoals, the closest reef of the Hawaiian Archipelago. Even though Johnston Atoll has a low diversity of fish species with respect to Hawaiian and other IndoPacific reefs (Randall et al. 1985, Kosaki et al. 1991), fishes are very abundant due to the restrictive fishing regulations enforced in this U.S. Fish and Wildlife National Refuge. I still vividly remember the day in July of 1993, when diving along the NW reef edge of Johnston Atoll I encountered a spawning aggregation of reef fishes (Domeier \& Colin 1997). That day I observed thousands of fishes swimming against a strong current and rushing up to the surface to release clouds of eggs and sperm, large predators attacking spawning fishes, small predators feeding on drifting gametes and lines of fishes migrating in and out of the area. During that first dive at the spawning aggregation site my mind was spinning with questions and ideas for projects. Those initial ideas were polished with time and shared with colleagues, and with the help of approximately 400 more dives, became the core of the work you are about to read. This thesis is a study of some ecological and behavioral relations that occur among coral reef fishes when they aggregate to spawn.

Reproduction is a central feature in an animal's life history, since natural selection operates only by differential reproductive success. Differential mortality can be a selective force, but only to the degree that it creates differences between individuals in the number of progeny they produce. Darwin came to these conclusions mainly by observing terrestrial organisms and studying dead specimens of aquatic organisms. The study of natural reproductive behaviors of marine fishes did not advance until the development of diving technology which allowed scientists to routinely enter the marine environment. One of the first published articles describing the spawning behaviors of coral reef fishes concerned Indo-Pacific surgeonfishes (Randall 1961), one of the main groups of fishes I observed spawning at Johnston Atoll. During the 1970's and 1980's many descriptive studies were published regarding spawning behaviors of reef fishes, leading to the identification of some general patterns of behavior among species (for reviews see Johannes 1978, Robertson 
1991). Multiple hypotheses where proposed to explain the observed patterns of spawning timing and behavior (Johannes 1978, Barlow 1981, Doherty et al. 1985). These hypotheses argued for different effects of light levels, tides, currents and predators on the survivorship and dispersal of larvae, and on the biology of adult spawning fishes, but they were never rigorously tested (Shapiro et al. 1988). I have attempted in the 1990's to test a few of the hypotheses regarding the diel spawning patterns of reef fishes (Chapter 2), the role of predator-prey interactions at spawning aggregation sites (Chapters 3 and 4) and the mechanisms affecting rushing behaviors of spawning fishes (Chapter 5).

Many of the previous observations of spawning aggregations were opportunistic, often lacking standardized sampling procedures (see Shapiro et al. 1988, Domeier \& Colin 1997). Recent studies have evaluated hypotheses regarding annual and lunar timing patterns of spawning (Robertson 1990, Robertson et al. 1990), but have not addressed diel patterns of variability in spawning. In order to study the mechanisms influencing the diel timing of spawning of reef fishes, I quantified the spawning patterns of eleven different species while simultaneously measuring the environmental variables most likely to influence fish spawning patterns (Chapter 2). For the first time abundance and spawning of reef fishes were correlated in detail with tides, current direction, current speed, time of day and abundance of predators. The use of current meters permitted the measurement of current speed, a variable hypothesized to control spawning of fishes by affecting egg dispersal and survival, but that had not been studied in detail at spawning aggregation sites. Data were analyzed by multifactorial analysis techniques which helped to discern multiple correlational patterns among the different environmental variables.

Predation is one of the most important selective forces structuring communities of coral reef fishes, and by affecting the mortality rates of larvae, juveniles and adult fishes (for review see Hixon 1991). However, few studies have quantified predation rates at spawning aggregation sites, even though reef fishes can become more vulnerable to 
predation when spawning. Hypotheses proposing the importance of predation risks in determining spawning patterns of reef fishes were formulated decades ago (Johannes 1978), but testing them was impossible due to the little existent information on the activity patterns of predators at spawning locations (Robertson 1991). Predation events are rarely observed in natural circumstances, but the high levels of predatory activities observed at Johnston Atoll (by both piscivorous and plantkivorous fishes) allowed me to study specific predator-prey interactions occurring spawning aggregation sites (Chapter 3). Two large piscivorous species and three planktivorous species were monitored. Measurements of the diel activity patterns of predators were done for the first time at a spawning site, so hypotheses regarding the influence of predators on timing of spawning of reef fishes could be addressed. The simultaneous monitoring of multiple species of predator and prey permitted me to determine prey selection patterns of predators.

One of the piscivorous species studied, Caranx melampygus, was observed to display multiple hunting behaviors while attacking spawning fishes (Chapter 4). While generally being gregarious animals and attacking their prey from midwater positions, during moments of high abundance of spawning fishes $C$. melampygus could modify their behavior to increase prey capture rates. These behavioral changes involved becoming aggressive toward other conspecifics, defending a portion of reef, and hiding underneath coral heads while ambushing group-spawning fishes from this location. This species is considered to be one of the most important predators of reef fishes in the Indo-Pacific, since they are very abundant in shallow reefs and single individuals are estimated to consume $48 \mathrm{~kg}$ of fish per year (Sudekum et al. 1991). The combination of different feeding tactics by predators can cause density-dependent mortality in juvenile reef fishes (Hixon \& Carr 1997). Information on the hunting behaviors of C. melampygus is important to understand its potential effects on community regulation of reef fishes. 
A characteristic of the spawning behavior in most reef fishes is the existence of a spawning rush, during which reef fishes swim up into the water column to release their gametes (Thresher 1984). The selective mechanisms causing the evolution of this common spawning behavior have not been tested. Reef fishes are hypothesized to reduce egg predation by reef-based predators by releasing eggs above the substrate. Data on prey selection by predators indicate a strong preference of piscivores to attack their prey during spawning rushes (Moyer 1987), and predation risks of adult fishes are expected to influence the height of spawning (Robertson \& Hoffman 1977). To investigate which factors regulate the height of spawning ascent in reef fishes, I studied two similar species of trunkfishes: Ostracion meleagris and Ostracion whitleyi, which were observed spawning at two different heights. The relative susceptibility of the two trunkfish species to predation was estimated by measuring and comparing their overall size and toxicity levels, two characteristics hypothesized to influence their susceptibility to predation. Ostracion whitleyi had never been observed spawning before, and its mating behavior was compared to that of $O$. meleagris in order to determine if intraspecific social interactions could influence the height of spawning ascents.

The existence of strict limitations on fishing at Johnston Atoll was crucial for my observations of natural spawning and predatory events, because human fishing activities can alter and decimate spawning aggregations, as has occurred in many other locations (Sadovy 1994). More studies on the behavioral and ecological relations among fishes at spawning aggregations will help us to understand the complex selective factors influencing the reproduction of reef fishes and help elucidate the importance of spawning in aggregations to populations of reef fishes. This topic is important because commercial and recreational fishing practices quickly reduce the abundance of large predators, which can have effects on the mechanisms regulating other reef fish communities. Marine reserves are a effective way to reduce the general effects of fishing on reef fish populations (Roberts 
1997). Two of their most important functions are to protect large predators targeted by fishermen, and to increase the reproductive output of reef fishes so larvae will colonize reefs outside the reserves (Roberts 1997). Therefore, understanding the ecological and behavioral processes taking place at spawning aggregation of reef fishes sites should be crucial for the design of future marine reserves. 


\section{BIBLIOGRAPHY}

Barlow, G. W. (1981). Patterns of parental investment, dispersal and size among coralreef fishes. Env. Biol. Fish. 6: 65-85

Clifton, K. E., Robertson, D. R. (1993). Risks of alternative mating strategies. Nature. 366: 520

Doherty, P. J., Williams, D. M., Sale, P. F. (1985). The adaptive significance of larval dispersal in coral reef fishes. Env. Biol. Fish. 12: 81-90

Domeier, M. L., Colin, P. L. (1997). Tropical reef fish spawning aggregations: defined and reviewed. Bull. Mar. Sci. 60: 698-726

Hixon, M. A. (1991). Predation as a process structuring coral reef communities. In: Sale, P. F. (ed.) The ecology of fishes on coral reefs. Academic Press, San Diego, p. 475-508

Hixon, M. A., Carr, M. H. (1997). Synergistic predation, density dependence, and population regulation in marine fish. Science. 277: 946-949

Johannes, R. E. (1978). Reproductive strategies of coastal marine fishes in the tropics. Env. Biol. Fish. 3: 65-84

Kosaki, R. K., Pyle, R. L., Randall, J. E., Irons, D. K. (1991). New records of fishes from Johnston Atoll, with notes on biogeography. Pacific Science. 45: 186-203

Moyer, J. T. (1987). Quantitative observations of predation during spawning rushes of the labrid fish Thalassoma cupido at Miyake-jima, Japan. Japan. J. Ichthyol. 34: 7681

Randall, J. E. (1961). Observations on the spawning of surgeonfishes (Acanthuridae) in the Society Islands. Copeia. 2: 237-288

Randall, R. E., Lobel, P. S., Chave, E. H. (1985). Annotated checklist of the fishes of Johnston Island. Pacific Science. 39: 24-80

Roberts, C. M. (1997). Ecological advice for the global fisheries crisis. TREE. 12: 3538

Robertson, D. R. (1990). Differences in the seasonalities of spawning and recruitment of some small neotropical reef fishes. J. Exp. Mar. Biol. Ecol. 144: 49-62

Robertson, D. R. (1991). The role of adult biology in the timing of spawning of tropical reef fish. In: Sale, P. F. (ed.) The ecology of fishes on coral reefs. Academic Press, San Diego, p. 356-386

Robertson, D. R., Hoffman, S. G. (1977). The roles of female mate choice and predation in mating systems of some tropical labroid fishes. Z. Tierpsychol. 45: 298320 
Robertson, D. R., Petersen, C. W., Brawn, J. D. (1990). Lunar reproductive cycles of benthic-brooding reef fishes: reflections of larval biology or adult biology? Ecol. Monogr. 60: 311-329

Sadovy, Y. (1994). Grouper stocks of the western central Atlantic: the need for management and management needs. Proc. Gulf Carib. Fish. Inst. 43: 43-65

Sudekum, A. E., Parrish, J. D., Radtke, R. L., Ralston, S. (1991). Life history and ecology of large jacks in undisturbed, shallow, oceanic communities. Fish. Bull. 89: 493-513

Shapiro, D. Y., Hensley, D. A., Appledoorn, R. S. (1988). Pelagic spawning and egg transport in coral-reef fishes: a skeptical overview. Env. Biol. Fish. 22: 3-14

Thresher, R. E. (1984). Reproduction in reef fishes. T.F.H. Publications, Neptune City, New Jersey 


\section{CHAPTER 2}

Environmental influences on the diel timing of spawning in coral reef fishes 


\section{ABSTRACT}

Many hypotheses have been proposed regarding the adaptive nature of different diel reproductive cycles observed in coral reef fishes. This study quantified the spawning patterns of eleven different reef fish species at one location (Johnston Atoll, Central Pacific), while making simultaneous measurements of the environmental factors likely to affect the spawning behavior of reef fishes. The environmental variables measured included time of day, tides, current velocity, current speed and abundance of piscivorous predators, and were correlated with observed spawning outputs through multifactorial analyses.

High interspecific variability in spawning patterns was found among the eleven monitored species. The majority of species spawned at a specific time of the day, in agreement with the timing of spawning described at other locations, indicative of a fixed general response by fishes across distribution areas. Spawning of most fishes with daytime spawning peaks was correlated with local changes in current direction and predatory risks, showing responses designed to reduce the mortality of propagules and adults. Dusk-spawning species generally did not respond to changes in flow direction and predator abundance, most likely due to their short spawning periods and the reduced predatory pressures that occurred at dusk. Tides did not seem to be used exclusively as synchronizing cues to adult fishes for spawning. The influence of current speed in determining diel timing of spawning varied among species, with some species showing responses to current speed while others showed no response. 


\section{INTRODUCTION}

Since the first descriptive observations of coral reef fish spawning (Randall 1961), many studies have described the behavior of pelagic spawning reef fish (for reviews see Thresher 1984, Robertson 1991, Sadovy 1996). There is a great variability in spawning behaviors among reef fish, and many different hypotheses have been formulated to explain their reproductive patterns (Robertson et al. 1990, Robertson 1991). At the same time there is a clear lack of experimental studies designed to test these hypotheses (Shapiro et al. 1988, Robertson 1991). I attempted to address these hypotheses by performing a detailed quantification of spawning activities of various reef fish species and correlating these data with simultaneous measurements of environmental variables hypothesized to influence reproduction in reef fishes. I use these correlations to distinguish among alternative explanatory hypotheses and to provide information for the design of future experimental studies aimed at testing specific hypotheses.

One of the most variable and least understood aspects of reef fish reproduction is the diel pattern of spawning. Warner $(1991,1997)$ argued that phenotypic plasticity is more likely to occur in species with widely dispersed larvae and good sensory capabilities, such as coral reef fishes with pelagic spawning modes (Balon 1981). Focusing on these reef fishes, most observations have been done at daytime and during crepuscular periods. Coral reef fish seem follow two main rhythms for spawning: diel and tidal. The relative importance of these two environmental cues (time of day and tides) varies among species, and between different locations within a single species. Some species will spawn at a specific time of the day (circadian rhythm), which can vary from early morning to after sunset (Robertson \& Hoffman 1977, Lobel 1978, Robertson \& Warner 1978, Warner \& Robertson 1978, Kuwamura 1981, Robertson 1982, Thresher 1982, Clavijo 1983, Lobel \& Neudecker 1985, Thresher \& Brothers 1985, Colin \& Clavijo 1988, Myrberg et al. 
1989, Colin \& Bell 1991, Shibuno et al. 1993). In locations where tidal flows exist, certain species have been described on occasions to overlap a circatidal rhythm to their circadian rhythm, spawning at a specific time of the day, but only when the water flow is likely to sweep propagules away from the reef (Randall 1961, Robertson \& Hoffman 1977, Johannes 1978, Lobel 1978, Thresher 1979, Kuwamura 1981, Tribble 1982, Warner 1982, Robertson 1983, Ross 1983, Bell \& Colin 1986, Moyer 1989, Colin \& Bell 1991).

In addition to this interspecific variation, variation exists with single fish species with groups of individuals following two different spawning rhythms in different locations of the same reef system. On these occasions, a circatidal rhythm is followed by fish at the reef edge, where tidal currents sweep their propagules away from the reef, and a circadian rhythm is followed at locations where no currents off the reef are present (Robertson 1983, Colin \& Bell 1991). Also a single species has been described to follow, at the same spawning location, a circatidal spawning rhythm during certain part of the year and a circadian spawning rhythm during the rest of the spawning season (Tribble 1982). These observations indicate that certain decision mechanisms utilized by reef fish to establish diel spawning patterns are plastic and influenced by local environmental conditions (Warner 1997), possibly in a similar way as occurs in intertidal crabs (Morgan \& Christy 1994, Morgan 1996).

To achieve short-term behavioral control of spawning in relation to changing environmental conditions, the endocrine system controlling ovule maturation (Scott 1979) must be plastic enough to allow changes in a short period of time. The processes from the activation of resting ovarian cells to the appearance of hydrated fertile eggs in the ovarian lumen are poorly understood in tropical reef fishes, but can take place in 24 hours (Hoffman \& Grau 1989). Once eggs are hydrated, it is unclear how much time can they be retained in the ovary by a female before losing their competency. There are indications that 
female fish can release eggs for periods of 2 to 4 hours (Fischer \& Hardison 1987, Hoffman \& Grau 1989), and egg release can be delayed when fish are exposed experimentally to induced high predatory risks (Lobel \& Neudecker 1985, Nemtzov 1994). These data indicate the existence of a behavioral control by female fish on the release of hydrated eggs, probably up to a period of a few hours. This implies that coral reef fish have the potential to withhold their hydrated gametes if the spawning environment is inappropriate, and to wait up to a few hours for the conditions to change.

The variety of spawning patterns observed and the ability of fish to control the timing of spawning leads to the question of which are the selective forces determining spawning patterns in different reef fishes. Many different hypotheses have been proposed to explain the variety of diel and tidal spawning patterns observed, mostly based on predator-prey interactions involving spawners and eggs (Robertson 1991). Johannes (1978) developed the hypothesis that the avoidance of short-term predation on eggs over reef structures determines the spawning behavior of reef fishes. He predicted spawning at times of maximum current speeds in a direction away from the reef environment, since it would minimize benthic predation of propagules, and the appearance of a circatidal spawning rhythm in locations where currents are tidally controlled. Barlow (1981) proposed that coral reef fish select times for spawning that result in maximum egg transport away from their natal reef areas, hypothesizing that this behavior is adaptive because of patchy adult habitats. He argued that coral reefs are undergoing continual change, so the fish inhabiting them are selected to maximize the probability of their propagules colonizing different reef systems to insure the survivorship of species. On a spawning location across the reef edge with tidally driven circulation, the onset of outflowing currents should produce the maximum dispersal of eggs away from the reef. Colin and Clavijo (1988) proposed that tides are used as an arbitrary cue for adults to synchronize spawning, and therefore reduce the overall time spent in reproductive activities. Therefore the timing of 
reproduction should be independent of the survivorship and dispersal of eggs and larvae. Predation risks on the adult spawners and eggs have also been proposed as a way of explaining diel spawning patterns of reef fishes (Robertson \& Hoffman 1977, Johannes 1978, Lobel 1978, Thresher 1984, Robertson 1991), which should be a risk-minimizing response to feeding cycles of predatory fishes.

In spite of the abundance of explanatory hypotheses concerning diel spawning cycles of reef fishes, very few studies have been aimed at testing them (Shapiro et al. 1988). Of the above listing, only the dispersal hypothesis (Barlow 1981) has been tested in the field (Appeldoorn et al. 1994, Hensley et al. 1994). These authors showed that a comparison of estimated transport distances of eggs between spawning and non-spawning times and locations revealed no evidence that Thalassoma bifasciatum spawning behavior insures maximum transport of its propagules away from the natal reefs.

In order to evaluate the above hypotheses, there is a great need to measure current regimes at spawning sites in detail (Shapiro et al. 1988), since water flow is a crucial component of various hypotheses and it has rarely been measured in any detail at spawning grounds. From the only studies to date measuring currents at spawning grounds, a positive correlation between current speed and spawning has been described for $T$. bifasciatum over daily periods (Hunt von Herbing \& Hunte 1991) and seasonal periods (Appeldoorn et al. 1994). Colin (1995) stated that currents did not seem to influence timing of spawning of Epinephelus striatus, even though he did not specify the sampling period of his current speed measurements. There is also no information on predator diel activity patterns at spawning sites, so predatory risk reduction hypotheses cannot be effectively evaluated (Robertson 1991)

The objective of this paper is to compare observations of fish abundance and spawning intensity with detailed measurements of various local environmental factors to identify those factors correlated with spawning. Detailed measurements of current velocity 
and predator abundance concurrent with spawning counts allow the evaluation of some untested hypotheses regarding diel spawning cycles. The purpose of observing multiple species at the same spawning site is to assess the interspecific variability in spawning patterns under the same set of environmental conditions.

Based on the previous hypotheses regarding the importance of water flow, predation and use of tides by fish in establishing diel spawning times, the following predictions can be made:

Use of tidal currents for maximum dispersal of larvae. Fish should spawn at the onset of an outflowing current to maximize dispersal away from spawning grounds (Barlow 1981). A short spawning period after this moment would insure long distance transport for most of the propagules.

Use of currents to minimize benthic predation on eggs. Reduction of benthic egg predation can potentially occur under different environmental conditions, leading to the subsequent predictions: (1) fish should preferentially spawn in outflowing currents that carry propagules away from benthic predators; (2) fish should spawn at times when currents are fastest, to reduce the time that propagules spend exposed to benthic predators; and (3) daytime spawning species are more likely to use currents to minimize egg predation than dusk spawners. Dusk spawning species generally have a very short diel spawning window (Thresher 1984), and their timing of egg release seems strongly influenced by light intensity levels (Myrberg et al. 1989). They are expected to have less flexibility than daytime spawners to delay spawning when water flow conditions are inappropriate.

Use of tides as a synchronization cue by adults. The use of tides as arbitrary cues to synchronize the reproductive activities of conspecific fishes should lead to aggregation of fishes at spawning sites shortly after the moment of high or low tide (Colin \& Clavijo 1988). A selective advantage of synchronization is a reduction of time spent in spawning activities, time that would could otherwise be invested in feeding (Colin \& Clavijo 1988). 
The timing of these aggregations should occur independently of the existing currents at the spawning site.

Predation of spawners. Fish should show reduced spawning intensity activities during moments of high predatory activities by piscivorous species. This expectation is based on the observation that at spawning grounds, predators primarily attack spawning fishes during their spawning ascent (Moyer 1987, Chapter 3). Species of reef fishes with specific anti-predatory adaptations are more likely to have lower risks of predation and to spawn independently of the predatory activity of piscivores (Gladstone \& Westoby 1988). Large sizes, defensive spines and production of toxic substances are all examples of antipredatory adaptations used by coral reefs (Godin 1997, Smith 1977).

\section{METHODS}

\section{Data collection}

Reef fish spawning was monitored at two aggregation sites on Johnston Atoll (Central Pacific). This small isolated atoll has a maximum width of $20 \mathrm{~km}$ and a reef crest only along its N-NW edge (Figure 1). One of the spawning sites (Mustin's Gap) was the only significant channel that intersected the reef crest. It was approximately $28 \mathrm{~m}$ wide and $75 \mathrm{~m}$ long, with an average depth of $4.5 \mathrm{~m}$. The substrate consisted of a mix of live tabular coral formations (Acropora spp.), large dead coral boulders and fine coral rubble. The second spawning site (Eastern Reef Edge) was located inside the NE edge of the reef crest. It was a back reef location with an average depth ranging between 4 and $5 \mathrm{~m}$. The substrate consisted of dispersed live tabular coral formations and coral rubble. Other spawning aggregations were also discovered at Johnston Atoll, but difficult and undependable diving conditions did not permit their study.

Within each spawning site, a smaller representative sampling area was established to measure fish abundance and spawning intensity. At Mustin's Gap the sampling area 
consisted of a $170 \mathrm{~m}^{2}$ rectangle over a mixed substrate of live tabular coral formations and large dead coral boulders, located in the outer part of the reef channel. At the Eastern Reef Edge the sampling area was a $40 \mathrm{~m}^{2}$ tabular coral formation surrounded by coral rubble fields.

Observations while diving with SCUBA were always done by the same person (G. Sancho) to reduce inter-observer sampling bias. The diver's recording position was kept constant at both spawning grounds (always laying on the bottom and $5 \mathrm{~m}$ away from the edge of the sampling area). No modification of spawning or predatory behaviors because of diver presence were detected, and fish would on many occasions spawn a few centimeters away from the observer. No fish were speared at the spawning sites during the observation season. Sampling was done in 1994 and 1995 during the months of April and May, the peak spawning season at Johnston Atoll (Appendix 1). During 1994, 82 dives (105 hours) were done at Mustin's Gap from dawn though dusk, with the objective of quantifying the diel periodicity of spawning (G. Sancho in prep.). In 1995, 92 dives (86 hours) were done at Mustin's Gap from April 2 to May 20, with early afternoon (1300 through 1630) and dusk (1900 though 2000) dives attempted on alternate days. High surf across the reef crest sometimes made it impossible to dive at Mustin's Gap, causing some breaks in the data series. During 1995 at the Eastern Reef Edge, nine dives (14 hours) were done in the early afternoon (1300 through 1430), from May 15 to May 27.

Daytime observations were 30 minutes long, taken every hour. Dusk observations started at 1900 and usually continued past the time of sunset, when spawning activities had completely ceased. Behavioral data were annotated on underwater paper sheets attached onto a clipboard. The total number of spawning rushes observed inside the sampling areas was annotated every minute, along with the spawning behavior employed in each rush. This procedure allowed the quantification of intense spawning bouts typical of groupspawning species (Colin \& Clavijo 1977, Colin \& Clavijo 1978, Robertson 1983). The 
total number of spawning fish present at the sampling was estimated at the beginning and end of each 30 minute spawning count. Only fishes exhibiting spawning related behaviors like courting, milling or bobbing were counted (Meyer 1977, Moyer \& Yogo 1982).

All pelagic spawning species were recorded ( 37 species), but in this study I will only use data from 11 of the most active spawning species: Parupeneus bifasciatus and Parupeneus multifasciatus (Mullidae); Chaetodon unimaculatus (Chaetodontidae); Cheilinus unifasciatus, Coris gaimard and Epibulus insidiator (Labridae); Chlorurus sordidus (Scaridae); Acanthurus nigroris, Ctenochaetus strigosus and Zebrasoma flavescens (Acanthuridae); and Ostracion meleagris (Ostracidae). Spawning occurred at various times during the day, with some species mostly spawning in groups and others in pairs (Table 1).

The presence or absence of piscivorous fish over the spawning grounds was recorded every minute, plus any predation events on adult spawners or on recently spawned eggs. The two main piscivorous species observed were Caranx melampygus (Carangidae) and Aphareus furca (Lutjanidae).

Current velocities and tidal heights were measured at the spawning sites with S-4 current meters (S4 InterOcean, San Diego), mounted on PVC tripods at a height of $1.5 \mathrm{~m}$ above the substrate. Their location was fixed inside both sampling areas. Current speed, direction and hydrostatic pressure were recorded every 15 minutes (average of 240 burst samples over a period of 2 minutes).

\section{Data analyses}

Raw spawning data collected every minute were transformed into number of spawns per 15-minute interval. This time period was long enough to detect short synchronized spawning bouts typical of some group-spawning species (Colin \& Clavijo 1977, Colin \& Clavijo 1978, Robertson 1983), and allowed spawning data to be 
compared with the water flow measurements. For group-spawning species, the spawning intensity (number of spawns per individual fish) was calculated by dividing the 15-minute spawning measurements by the number of fish present at the sampling site. For the analysis of lunar periodicity, all 15-minute samples from a single day were averaged.

The time of day when observations were made was standardized as the number of minutes from sunset for each individual day (negative values express time before sunset, positive ones indicate time after sunset has occurred). Measurements of piscivore presence (presence/absence during one minute periods) were expressed as the percent of time predators were present over the spawning sampling site per 15-minutes. Exact times for high and low tides at Johnston Atoll were obtained with the help of Worldtide software (Micronautics, Rockport), since tidal heights recorded with our current meters were nearly identical to those predicted by NOAA tables. Spawning times with respect to tides were expressed as number of minutes from the low tide. Negative values indicate that spawning occurred before low tide (flood tide), and positive values represent spawning observations taking place after low tide (ebb tide).

Current speed and direction data recorded by the current meters every 15 minutes were transformed into current velocities with positive values indicating outgoing flows with respect to the reef crest (from the lagoon into open waters) and negative values representing inflowing currents into the lagoon (Figures 2 and 3 ). For the analysis of lunar periodicity in spawning, an average current speed was calculated for each day by averaging all the 15minute values from 1300 to 1630 for midday spawners, and from 1900 to 2000 for dusk spawners. This transformation was done in order to choose representative values of current speeds occurring during the main diel spawning periods.

Observed frequency distributions of fish abundance and number of spawns were compared with expected distributions using Chi-square $\left(\chi^{2}\right)$ tests for goodness of fit. Classes of environmental variables were chosen such that expected frequencies were never 
less than two (Miller 1986), and significance of departure from independence in single cells was evaluated by comparing individual residuals with a Bonferroni familywise error rate of 0.05 (Sokal \& Rohlf 1995).

Multifactorial analyses were used to study the correlation of fish abundance, total number of spawns and spawning intensity (spawns per fish) with various independent environmental variables: time of day, tides, current velocity and presence of piscivores. The data set included afternoon observations from 1995, plus dusk observations from both 1994 and 1995. Two different statistical analyses were used to best fit the characteristics of each specific data set, due to the varying spawning rates recorded for different species.

Group-spawning species and dusk pair-spawning species had relatively high spawning rates, so a multiple regression model was used. Quadratic terms were included in the model for the independent variables of current velocity and tide, allowing the model to analyze for second order polynomic relations with the dependent variable. For each dependent variable an initial multiple regression model was calculated including all independent variables. Significant independent variables were then identified through a backwards elimination method ( $\mathrm{p}<0.05$ significance level).

Daytime pair spawners spawned infrequently, leading to many 15 -minute counts with no spawning observations or only one or two spawning observations. These data were transformed into binomial data sets. A logistic model based on a logistic transformation of binomial data was calculated for these data (Collett 1991). A backwards elimination method was used to simplify the model and identify the significant independent variables $(\mathrm{p}<0.05$ significance level).

Correlations among some independent variables precluded their joint inclusion into the multifactorial analyses. Abundance of $C$. melampygus and A. furca positively covaried significantly in dusk data sets $\left(R^{2}=0.552\right)$, so they were combined into one variable (presence of predators) by averaging the data from both species. Current speed and tides 
covaried during midday data sets at both Mustin's Gap and East Reef Edge. Their relation was well represented in most data sets by a third order polynomial regression. The solution to this problem was to design the multifactorial analysis so these two variables were not used simultaneously.

Dependent variable data transformations and selection of independent variables were as follows:

Fish Abundance. Data were only available for group spawners. No accurate abundance counts could be obtained for pair-spawning species due to cryptic behavior of certain females, high degree of mobility of pairs and lack of long pre-spawning courtships. In group spawners there was a high daily variability in fish abundance, which complicated direct comparisons between abundance values from different days. To solve this problem, abundance data from different observation periods were standardized by the maximum daily abundance value, creating a data set that varied between 0 and 1 . These data were normalized by arcsin transformation (Sokal \& Rohlf 1995) for the multiple regression analysis. Independent variables used in the multifactorial analysis of fish abundance were time of day, tides and current direction. All have been previously described as cues synchronizing specific Indo-Pacific reef fish migrations to spawning grounds: light intensity (Myrberg et al. 1989), tidal cycles (Robertson 1983, Colin \& Bell 1991) and reversals in current direction (Moyer 1989). Current speeds and predator abundance at the spawning sites cannot be detected by non-spawning fishes located far away from the spawning sites (unless they are tightly coupled with tides or time of day), and were not considered as potential causal factors for fish migration.

Number of spawns. For those species in which a regular tidal spawning periodicity was detected, only spawning data from the maximum spawning tidal period (flood tide or ebb tide, depending on the species) were used in the analysis. To avoid the influence of days when little spawning activity occurred, only those dates accounting for $85 \%$ of the 
total spawning output of non-tidal group-spawning species and dates when at least one spawn by non-tidal pair spawners was observed were used in the multifactorial analyses. To standardize spawning effort among days, all spawning values were divided by daily maximum spawning values and then arcsin transformed (Sokal \& Rohlf 1995). Independent variables used were time of day, current velocity, and abundance of $C$. melampygus and A. furca.

Spawning Intensity. Defined as the number of spawns per fish present, this variable was only available for group-spawning species, since accurate abundance estimates could not be obtained for pair-spawning species. All samples were used except days when no fish were present at the spawning grounds. Normalization of these data was done through a logarithmic transformation (Sokal \& Rohlf 1995). Independent variables used were time of day, current velocity and abundance of $C$. melampygus and $A$. furca. This analysis was performed to study behavioral choices in spawning times by the fish present at the spawning grounds. Potential causes leading to delays of spawning were perceived risk of reduced larval survivorship (affected by time of day and current velocity) and predation risks (affected by predator presence and time of day). Hydrostatic pressure hypothetically does not influence directly either the survivorship of adults or larvae, and therefore tides were not included in these analyses.

\section{GENERAL RESULTS}

\section{Water flow}

The main spawning site, Mustin's Gap, typically experienced tidally influenced semi-diurnal reversing flows (Figure 2). Currents were coupled with the tides, with outgoing flows (water flowing from the lagoon into the ocean) during flood tides and incoming flows into the lagoon during ebb tides. Outflowing currents were on average faster than inflowing ones (38.5 and $14.2 \mathrm{~cm} / \mathrm{s}$ respectively). 
This semi-diurnal circulation across the reef crest was disrupted on occasions, becoming a unidirectional flow with uniform current speeds in an outward direction (Figure 3A, B). These events occurred on days of high surf conditions (G. Sancho personal observation) and were tightly correlated with an increase in variability in the hydrostatic pressure profiles recorded by our current meters, probably due to large waves crossing over the moored current meter. In a 55-day current meter record (3 April - 27 May, 1995), 36 of the days (65.5\%) showed bi-directional currents coupled with tides and 19 days $(34.5 \%)$ displayed fully unidirectional flows.

At Eastern Reef Edge, the flows were not as tightly coupled with the tides as in Mustin's Gap (Figure 3C, D). Current velocities varied bearing no relation with the tides with respect to direction, but highest current speeds usually occurred shortly after low tide. This relation between tides and water flow was confirmed by the negative correlation found in 768 simultaneous measurements of tidal height and current speed (Spearman rank correlation $\left.r_{S}=-0.27 ; p<0.001\right)$. Average current speeds were similar for outflowing $(7.1 \mathrm{~cm} / \mathrm{s})$ and inflowing $(5.2 \mathrm{~cm} / \mathrm{s})$ currents at the East Reef Edge, and were much slower than at Mustin's Gap.

\section{Lunar spawning}

At Mustin's Gap, average current speeds for both midday (Figure 4) and dusk (Figures 5 and 6) periods did not follow a predictable lunar pattern. Daily spawning averages in general did not reflect the overall current intensity at the spawning site. When comparing the daily number of spawns with the average current velocity using 1995 data, I only found significant correlations in two of the eleven species: Cheilinus unifasciatus spawned more on days with weak currents (Spearman rank correlation $r_{S}=-0.47$ ), while for Parupeneus bifasciatus the daily average spawning was positively correlated with the average dusk current speed for a given day (Spearman rank correlation $r_{S}=0.69$ ). 
The two most active group-spawning species, Acanthurus nigroris and Chlorurus sordidus had non-overlapping spawning seasons during Spring of 1995 (Figure 4). A. nigroris only spawned during the first two thirds of the month of April while C. sordidus had only very limited afternoon spawning activity. During end of April and through May A. nigroris ceased spawning while $C$. sordidus greatly increased their spawning activities. The observed seasonal spawning pattern of $C$. sordidus could potentially be the consequence of the existence of a lunar spawning pattern with different spawning outputs during two consecutive lunar cycles and the short sampling period of this study. In subsequent analyses these two distinct spawning periods where taken into account, only using for A. nigroris and $C$. sordidus the data from their respective main spawning periods.

\section{Relation of fish abundance and spawning with tides}

All four group-spawning species had abundance distributions during tidal periods that were significantly different from those expected just from the sampling effort (Figure 7a). Acanthurus nigroris had reduced abundance values from two hours before until the hour after low tide. Chlorurus sordidus abundance was high from two hours before low tide until five hours after it. Ctenochaetus strigosus showed two minor peaks in abundance occurring during the middle of the flood and ebb tides. Zebrasoma flavescens showed a broad peak in abundance at low tide and during the beginning of the flood tide, with a narrow abundance peak at the time of high tide. The tidal distribution of spawns for each group-spawning species was similar to their abundance distribution, and were all significantly different from expected distributions based solely on sampling effort (Figure $7 b)$.

At the East Reef Edge, Chlorurus sordidus abundance gradually increased during the last hours of ebb tide, peaking one to three hours after the moment of low tide (Figure 
7a). Their spawning activity was almost exclusively concentrated during this two hour period (Figure $7 \mathrm{~b}$ ). Both abundance and spawning intensity varied over time and differed significantly from distributions based solely on sampling effort. These results from East Reef Edge are similar, but more concentrated, than the conspecific results from Mustin's Gap.

Distributions of spawns with respect to tidal times for pair-spawning species were significantly different from a tidally homogeneous distribution for three species (Chaetodon unimaculatus, Cheilinus unifasciatus and Ostracion meleagris ), and did not differ significantly for the other six species (Figure 8).

The differential allocation of spawns to either ebb or flood tides was established by comparing our observed spawning distributions with those expected based exclusively on the sampling effort $\left(\chi^{2}\right.$-test): A. nigroris $(\mathrm{p}<0.001), C$. sordidus $(\mathrm{p}<0.001), C$. strigosus $(\mathrm{p}<0.05)$, E. insidiator $(\mathrm{p}<0.05)$, C. unimaculatus $(\mathrm{p}<0.005)$ and P. bifasciatus $(\mathrm{p}<0.001)$ spawned significantly more often during flood tides and $O$. meleagris was the only species to preferentially use ebb tide for spawning $(\mathrm{p}<0.001)$. The other four species showed no difference in spawning between flood and ebb.

\section{Multifactorial analyses}

Abundance of group-spawning species at Mustin's Gap showed significant correlations with different environmental variables, which explained different proportions of the observed variability in fish abundance (Table 2). The correlations among fish abundance values and those environmental variables identified as significant by the multifactorial analyses are displayed graphically in Appendix 2. Abundance values of all four group-spawning species were significantly correlated with a specific time of the day, and abundance of three species peaked during flood tides. No incoming current flows were ever detected during the Acanthurus nigroris spawning season, so assessment of the 
influence of current direction on this species behavior was not possible. But of the other three species, two increased in abundance during outflowing currents and one increased during inflowing currents.

The multifactorial analyses of the total number of spawns observed in group spawners indicated a high interspecific variability of responses (Table 3). All four groupspawning species showed a significant correlation of the distribution of spawns with a particular time of the day. Spawns for two species (A. nigroris and C. strigosus) were significantly correlated only with time of day, and none of the other variables. Spawns from the other two species were negatively correlated with abundance of a single predatory species, and showed different relations with current velocity. The number of spawns by C. sordidus peaked during moderate outflowing currents (quadratic relation), while $Z$. flavescens showed an increase in spawning activity at high outflowing currents (linear relation).

Analysis of spawning intensity in A. nigroris showed a weak correlation with environmental variables, but an increase in spawning activities late in the afternoon and in the presence of C. melampygus were detected (Table 4). C. strigosus also had a positive correlation with predator presence, but decreased in spawning intensity as sunset approached. The other two species showed negative correlations with predators, an indication of spawning avoidance during moments of high predatory pressure. These two species also showed quadratic relations with current velocity, peaking during medium ( $C$. sordidus) and high (Z. flavescens) outflowing current speeds.

Analyses of pair-spawning dusk species at Mustin's Gap (Table 5) showed no significant correlations between the number of spawns and any of the environmental variables for two species (Chaetodon unimaculatus and Parupeneus bifasciatus). Spawning by the other two species were only correlated with time of day, Parupeneus 
multifasciatus decreasing its spawning activity towards sunset and $O$. meleagris increasing it.

The spawning of daytime pair-spawning labrids greatly varied with environmental conditions (Table 6). Cheilinus unifasciatus had negative correlations with the abundance of both predator species and showed increasing spawning as the day progressed. Spawns by Coris gaimard were positively correlated only with time of day, while the third daytime pair spawner, E. insidiator, showed no significant correlations with any of the environmental variables analyzed.

At the East Reef Edge spawning site, multifactorial analyses of $C$. sordidus showed no relation between the abundance of fishes and any of the environmental variables analyzed (Table 2). Both spawning and spawning intensity correlated in the same way with current velocity (Tables 3 and 4; Appendix I), with little spawning occurring at flows close to zero, and positive correlations as current speed increased (in both inflowing and outflowing conditions).

\section{Current reversal moments}

On a few occasions (3,12, 18 and 20 May 1995; 15 April 1994) a reversal in current direction occurred while spawning observations were being recorded, allowing the study of behavioral responses by spawning fishes to this change in water flow. Overall, C. sordidus showed a decrease in abundance with time during the afternoon and during moments of inflowing currents (Figure 9a). During the moments of current reversal, fish did not leave the spawning grounds while inflowing conditions persisted, but interrupted their courting behaviors and resumed feeding behaviors, grazing algae off the substrate (G. Sancho personal observation). Subsequently these fish were not considered in the spawning fish censuses, which counted only fishes showing spawning-related behaviors. Spawning counts clearly showed that $C$. sordidus strongly avoided inflowing conditions 
for spawning. Fish delayed their spawning until the moment when currents reversed and become outflowing, having a large spawning bout following the change in current direction (Figure 9b). On 18 May, 1995, fish spawned during the moments of weak outflowing currents $(3.9 \mathrm{~cm} / \mathrm{s})$, avoiding similarly weak inflowing currents $(3.4 \mathrm{~cm} / \mathrm{s})$. During three and a half hours on 15 April, 1994, a clear sequence of spawning for $C$. sordidus was observed (Figure 10a, b). Increasing fish abundance and spawning was detected during morning hours, but spawning fish were not present in the early afternoon during inflowing conditions. At 14:00 the currents reversed and became outflowing, followed by a very intense spawning bout and finally leading into rapidly decreasing spawning activities as the afternoon progressed.

The surgeonfish Z. flavescens showed an increase in presence and spawning as the afternoon progressed (Figure 11a, b). Sudden decreases in fish abundance at the spawning grounds during changing currents (as detected in C. sordidus) did not occur, but surgeonfish did not move into the spawning grounds until currents started flowing outwards.

At dusk, changes in current direction only occurred once (12 May 1995). C. strigosus abundance seemed unaffected by the change in current direction, and the number of spawns observed was comparable among inflowing, outflowing and transitional periods (Figure 12a, b). A decrease in abundance and spawning activity occurred late into the dusk period.

\section{Dispersal of propagules}

All three group-spawning species for which data were available (C. sordidus, $Z$. flavescens and C. strigosus ) spawned more often during outflowing conditions than expected $\left(\chi^{2}\right.$-test; $\left.\mathrm{p}<0.001\right)$. Acanthurus nigroris was not analyzed since no inflowing conditions were observed during its early spawning season. Of the seven pair-spawning 
species, C. unifasciatus preferred outflowing conditions for spawning $\left(\chi^{2}\right.$-test; $\mathrm{p}<0.05$ ), while $O$. meleagris spawned preferentially during inflowing conditions $\left(\chi^{2}\right.$-test; $\left.\mathrm{p}<0.001\right)$. C. sordidus at the Eastern Reef Edge spawning site also seemed to prefer inflowing conditions $\left(\chi^{2}\right.$-test; $\left.\mathrm{p}<0.001\right)$.

Spawning during fast current speeds is assumed to reduce the time that eggs are exposed to benthic predators. All four group-spawning species presented spawning distributions with respect to current speeds significantly different from expected distributions based solely on sampling effort (Figure 13), but only two species (A. nigroris and $C$. strigosus) showed preferences towards the fastest current speeds. Of the seven pair-spawning species, $O$. meleagris selected the fastest inflowing currents on those days when they spawned, which never had current speeds faster than $40 \mathrm{~cm} / \mathrm{s}$. Parupeneus bifasciatus seemed to increase their spawning with faster currents, but the significance of this result should be considered cautiously due to low sample size (Miller 1986). The rest of the species did not select any specific speed categories for spawning (Figure 13).

The potential influences by the different environmental variables analyzed in this study on the spawning by reef fishes vary among the different species studied (Table 7). This wide variety of results can be interpreted for each species according to hypotheses explaining the adaptive values of different diel spawning patterns.

\section{RESULTS IN RELATION TO HYPOTHESES}

\section{Use of currents for maximum dispersal of larvae}

This hypothesis predicts that spawning should occur at the time when a outflowing current begins. Two species (C. sordidus and A. nigroris) followed a uni-modal tidal spawning pattern (Figure 7), with high spawning values at low tide or shortly afterwards, when currents at Mustin's Gap began to outflow (Figure 2). Peak spawning times in these two were not reduced to a brief period after low tide as expected, but occupied most of the 
flood tide (Figure 7). The other nine species showed bi-modal or acyclic tidal spawning patterns. Interestingly, Z. flavescens had a significant increase in spawning at the exact time of low tide, but also showed an increase at the time of high tide. The study of specific dates when tidally influenced current reversals occurred while monitoring the spawning area showed that $C$. sordidus had spawning peaks immediately after the onset of outflowing currents (Figure 9), as expected by this hypothesis. But the observations of April 15 (Figure 10) showed how a significant part of the daily spawning output occurred many hours before inflowing currents started, a sub-optimal time according to the maximum dispersal hypothesis.

This hypothesis also predicts a variation of spawning patterns among sites with different tidal regimes. At Johnston Atoll only C. sordidus was observed spawning at the two different study sites. This species spawned after low tide at both locations (Figure 7), the time when fastest current speeds generally occurred at both locations, even though at the Eastern Reef Edge current direction was not tidally controlled (Figure 3).

\section{Use of currents to minimize benthic egg predation}

The following predictions were made based on the general hypothesis of Johannes (1978) on avoidance of benthic egg predation:

(1) Spawning during outflowing currents- Five species spawned preferentially during outflowing conditions, as indicated by $\chi^{2}$-tests comparing the distribution of spawns during inflowing and outflowing current directions. One species (O. meleagris) showed preferences for inflowing conditions (Table 7). Results from the multifactorial analyses showed reduced spawning intensity values for $C$. sordidus and $Z$. flavescens during inflowing currents. Data from the days with changes in current direction confirmed these last results for these two species, which mainly spawned during the moments of outflowing currents (Figures 12,13 and 14). C. strigosus spawned at the same rate in 
both inflowing and outflowing conditions on the only dusk period when a change on current direction was observed (Figure 12).

(2) Spawning during fastest currents- Five species preferentially spawned during the fast currents available to them, but only one of them selected the fastest available outflowing currents observed at Mustin's Gap $(60-80 \mathrm{~cm} / \mathrm{s})$, as shown by $\chi^{2}$-tests comparing number of spawns per 15 minutes with current speed categories (Figure 13, Table 7).

Multifactorial analyses only indicated a linear positive relation between number of spawns and current speed for Z. flavescens (Table 3). Looking at daily current averages during the diel spawning periods (afternoon or dusk) for all species, only spawning by Parupeneus bifasciatus correlated in a positive way with the current speed average values (Figures 5 and 6).

(3) Dusk spawners less likely to follow currents- Of the five dusk spawning species observed, only one (C. strigosus) spawned significantly more during outflowing currents than incoming, while three of the five daytime species analyzed preferentially spawned during outflowing conditions (Table 7). Both the multifactorial analyses of abundance (Table 2) and the opportunistic observation of May 12, 1995 (Figure 12) indicated, however, that current direction could be a factor of little importance for the spawning of $C$. strigosus. Two dusk spawning species showed a preference for spawning at high current speeds $(>40 \mathrm{~cm} / \mathrm{s})$, where as two daytime spawners showed a similar pattern according to the analysis of the 15-minute data (Table 7). The results from the multifactorial analyses of spawning showed that current speed failed to explain the variability in spawning for any of the dusk spawning species, but explained part of it in two daytime spawners. Using daily spawning averages, only spawning by $P$. bifasciatus (dusk spawner) correlated positively with current speed.

Use of tides as a synchronization cue by adults 
Abundance of group-spawning fishes at Mustin's Gap did not rapidly increase at the moment of low or high tide as expected under this hypothesis (Figure 7a), increases in abundance were gradual. For instance, $C$. sordidus abundance started increasing two hours before low tide at both observation sites, while spawning did not occur until after low tide. After a gradual increase, high levels of abundance of spawning fishes were maintained for relative long periods of time (3-6 hours). Multifactorial analyses indicate that tides are important variables explaining the abundance of three of the four groupspawning species, all of them showing peaks in abundance during flood tides (Table 7). The abundance of $C$. sordidus at the East Reef Edge could imply the use of tides as a synchronization cue since high abundance of fishes only occurs right after low tide (Figure 7a).

\section{Predation of spawners}

The multifactorial analysis of spawning intensities of group spawners showed two species (C. sordidus and Z. flavescens) with reduced spawning intensity values at moments of high predator abundance, and two species (A. nigroris and C. strigosus) with significant positive correlations with predator abundance (Table 4), indicating no reduction in spawning intensity due to predatory pressures. Considering the number of spawns of pair spawners, only one species ( $C$. unifasciatus) showed a significant negative correlation with predator presence (Table 6). Chlorurus sordidus and A. nigroris were the two species under the most intensive predatory pressures, and were the target for $94 \%$ of all the attacks observed on spawning adults (Chapter 3). Both species responded to predation pressures as expected. Chlorurus sordidus has a fusiform shape with no morphological defensive adaptations against predation, and showed reduced spawning intensities during moments of high predatory pressure. In contrast, $A$. nigroris is a deep bodied fish and possesses defensive caudal spines characteristic of surgeonfishes, and did not respond to predator 
abundance. But the observation of high attack and capture rates by piscivores feeding on A. nigroris (Chapter 3), indicate that this surgeonfish was vulnerable to piscivory, and therefore should behaviorally respond to predatory activities in the same way as $C$. sordidus. The reduction in spawning intensity of $Z$. flavescens at high abundance levels of C. melampygus was also unexpected, because of the low number of recorded attacks on $Z$. flavescens (Chapter 3) and the morphological defenses typical of surgeonfishes. The risk of predation (predatory abundance and number of attacks) at dusk was less that at daytime hours (Chapter 3), explaining the indifference of dusk spawning species to predatory abundance levels.

\section{DISCUSSION}

A first conclusion from this study is the great variability of spawning behaviors used by different species at the same spawning site. Not only did fish spawn at different times of the day, but had very different responses to other environmental cues as tides, currents and predators. This variety of spawning tactics is well known in coral reef fishes (Thresher 1984, Robertson 1991, Sadovy 1996) and observational studies have analyzed various species at a single spawning site (Thresher 1982, Robertson 1983, Colin \& Clavijo 1988, Colin \& Bell 1991). In this study no single explanatory variable was found to include all eleven species studied, as they seemed to utilize the highly variable environment of the spawning grounds in different ways to establish their spawning patterns. Since all fish spawned at same site, they were all potentially exposed to the same environmental conditions. The inter-specific differences found in spawning behaviors indicate that local environmental conditions are interpreted in different ways by reef fish species to determine their diel spawning patterns.

Water flow is an environmental factor considered in various hypotheses as crucial in determining spawning behavior, since it can affect propagule dispersal (Barlow 1981), 
their exposure to reef based predators (Johannes 1978) and egg fertilization (Petersen 1991, Petersen et al. 1992). Long-term current meter records at the main site (Mustin's Gap) revealed a flow system that is influenced by tides, but is also affected by the more unpredictable factor of wave action. Variability of water flow with respect to tides is important because tidal cues have been shown to synchronize ovarian development in some reef fishes (Hoffman \& Grau 1989) and have been proposed to act as local cues for spawning under certain water flow conditions considered selectively beneficial (Johannes 1978, Barlow 1981). Unpredictable flow conditions can be circumvented by postponing the release of gametes upon recognition of "inappropriate" water flows at the spawning site. Short-term postponement of egg release has been shown to occur on coral reef fishes when predation risks on adults are mimicked (Nemtzov 1994) or spawning is actively disturbed (Lobel \& Neudecker 1985). Observations of C. sordidus spawning on days with current reversals showed that reef fishes can delay their spawning due to inflowing water flow conditions. Fish aggregated at the spawning site and delayed spawning until currents reversed and became outflowing, interrupting their ongoing spawning if currents reversed again flowing into the lagoon. During this process $C$. sordidus displayed the ability of reef fishes to detect and react to changes in water velocity, responding to differences of 7.3 $\mathrm{cm} / \mathrm{s}$ between inflowing and outflowing currents.

The influence of the different environmental variables in determining the timing of spawning in coral reef fishes is discussed below:

\section{Time of day}

The existence of diel periodicities in spawning of coral reef fishes has been described in both tidal and non-tidally influenced locations (see review by Thresher 1994), with families of fishes spawning at approximately the same time of day across their geographical ranges (Robertson 1983, Gladstone \& Westoby 1988, Sadovy 1996). The 
eleven species from this study followed these previously described taxonomic patterns, spawning at similar times of the day than other family members in other locations. Time of day by itself seemed to be an important factor determining the timing of spawning in reef fishes at Johnston Atoll (eight of eleven species). Of the three species which the multifactorial analyses identified as not spawning at a certain of the time of day, two of them only spawned during a two hour period at dusk (1800 through 2000). These two species were not identified as influenced by the time of the day because of the short time interval of sampling (60 minutes) used at dusk, but should be considered as exclusive dusk spawners, and therefore influenced by the time of the day. In daytime species, which had long spawning periods, multifactorial analysis indicated the significant influence of a preferred time for spawning in five of six species. It is unknown why certain families have evolved strong preferences for spawning at specific times of the day. Hypotheses on various selective factors affecting larval and adult stages of fishes have been formulated to explain these differences (Robertson 1991), but there is a lack of empirical data supporting any specific hypothesis.

Predatory risks of recently spawned propagules by planktivorous fishes have been hypothesized to affect the timing of spawning of reef fishes (Johannes 1978), and should vary among different times of the day. Predation risks are expected to vary among spawning species according to their egg size among other factors, since larger eggs are easier targets for visual planktivores. Size of eggs varies consistently among families of pelagic spawning fishes (Thresher 1984, Duarte \& Alcaraz 1989), and families of reef fishes with large eggs are expected to spawn latest in the day, after most of the diurnal planktivorous fishes have stopped feeding due to low light levels (Hobson 1973, 1991). Trunkfishes (Ostracidae) have unusually large eggs (1.4 - $2 \mathrm{~mm}$ in diameter) when compared to most other families of pelagic spawning reef fishes (Thresher 1984), and predictably, trunkfishes are typically dusk spawning species (Moyer 1979, Lobel 1996). 
As expected, at Mustin's Gap the trunkfish $O$. meleagris displayed a tendency of spawning after sunset, much later than any of the other dusk spawning species analyzed in this study.

\section{Current direction}

One of the main hypotheses addressed by this study is the spawning of gametes exclusively during currents with an outflowing direction away from the natal reef, to reduce predation of propagules by benthic predators (Johannes 1978). This pattern has been described in Indo-Pacific reef channels for a variety of species (Robertson 1983, Moyer 1989, Colin \& Bell 1991), even though these studies did not measure water movements. As expected, more daytime spawning species in the present study preferentially selected outflowing conditions for spawning (four of six daytime species) than dusk spawning species (one of five dusk species) at Mustin's Gap. This higher selectivity of outflowing conditions by daytime spawners is likely due to their wider diel spawning windows, which allow them to wait for outgoing water flow conditions to occur at the spawning site. Rapidly decreasing light levels right before sunset limit the time available to dusk spawning species to wait for water flow conditions to change.

Spawning at times that insure maximum dispersal of propagules away from the spawning site (Barlow 1981) does not seem to occur over long time scales in a Caribbean site with weak wind driven currents (Appeldoorn et al. 1994, Hensley et al. 1994). In a tidally influenced current system the maximum dispersal is expected to occur right after the onset of an outflowing tidal current. No fish were observed to exclusively restrict their spawning to this time at Mustin's Gap. Species that had significant spawning bouts after a change in current direction also reproduced at other tidal moments with outflowing currents, indicating that (1) fish are not seeking maximum dispersal of their propagules, or that (2) the onset of outflowing flows does not insure maximum dispersal away from reefs (a possibility still untested). If this last case is true, then the degree of dispersal of 
propagules probably cannot be predicted by adults. This does not exclude the possibility that some species are attempting to insure maximal dispersal from reefs, but if adults cannot predict when maximal dispersal will occur, they are likely to just display a generalized response to large-scale physical characteristics (Warner 1997). At Mustin's Gap a general response of this kind could be to spawn during any time when outgoing flow conditions occur. Measurements of benthic predation levels of propagules and dispersal distances from the spawning site are needed to decide which of the two hypothesized selective forces causes certain species to spawn during outgoing flows: risk of benthic predation or maximum dispersal of propagules.

\section{Current speed}

A related larval biology hypothesis predicts coral reef fishes to select fast current velocities for spawning, to reduce the time spent by propagules over the reef environment (Johannes 1978). Studies relating spawning with current speed (Hunt von Herbing \& Hunte 1991, Appeldoorn et al. 1994, Hensley et al. 1994, Colin 1995) have been done over long time scales and in the Caribbean, under slow current speed conditions (mostly 0 to $10 \mathrm{~cm} / \mathrm{s}$ ) typical of locations with small tidal amplitudes. At Indo-Pacific spawning sites located on reef channels, currents have only been subjectively estimated in spawning studies (Robertson 1983, Moyer 1989, Colin \& Bell 1991) . Currents measured at Mustin's Gap are of same magnitude as those from the Deep Entrance at Enewetak Atoll (Atkinson et al. 1981), a channel where large multispecific spawning aggregations have been described (Thresher \& Brothers 1985, Bell \& Colin 1986, Colin \& Bell 1991).

The present study measured current velocity during short time intervals, behavioral responses of spawning fishes to quick changes in local current speed conditions could be detected. At Mustin's Gap only one species (A. nigroris), of the eleven species monitored, was found allocating significant part of its total spawns in the fastest outflowing current 
speed category observed at the spawning site $(60-80 \mathrm{~cm} / \mathrm{s})$, and only for one species $(Z$. flavescens) were current speed and spawning effort significantly correlated in a positive linear way, as expected under the above hypothesis. Potential reasons for most species not selecting the fastest current speeds for spawning are (1) low importance of current speed as a selective force determining spawning, (2) unpredictability of the times when the fastest currents occur, (3) reduced fertilization rates at very high speeds (Petersen et al. 1992) and (4) existence of a minimum current speed threshold past which no further benefit in avoidance of planktivorous predation is achieved. More detailed research is needed to resolve among these possibilities, since some of the spawning patterns described in this study indicate potentially complex interactions of spawning with current speed. The only two species with significant correlations between spawning intensity (spawns / fish abundance) and current velocity in group-spawning species at Mustin's Gap showed depressions in spawning at both slow and fast flows, with maximum values at intermediate speeds (resulting in parabolic curve fits in the multifactorial analyses). These relations could be a combination of avoidance of slow flows due to high predation risks of propagules, and avoidance of high flows due to low fertilization rates. Chlorurus sordidus spawning intensity data from the second spawning site (East Reef Edge), where current speeds were much slower, showed increases in spawning with moderate increasing current speeds. This pattern is similar to the correlation of $C$. sordidus spawning intensity and current speed at moderate values at Mustin's Gap, indicating that $C$. sordidus at two different locations increased their spawning rates with increasing current speeds in the 0 to $20 \mathrm{~cm} / \mathrm{s}$ range.

Tides 
Reef fishes have been proposed to use tides as cues to synchronize spawning (Colin \& Clavijo 1988). This hypothesis implies that tidal flows are not important in the selection of spawning times, but that hydrostatic pressure is a useful cue for migration to the spawning grounds, reducing the time spent by fish in spawning activities and allowing more time for other activities such as feeding. Indo-Pacific reef fishes are capable of synchronizing their ovarian cycles with local tidal cycles (Hoffman \& Grau 1989). But Indo-Pacific reef fishes described as following tidal spawning cycles preferentially spawn at the tidal stage that is most likely to produce a transport of propagules away from the reef system (Randall 1961, Robertson \& Hoffman 1977, Johannes 1978, Lobel 1978, Thresher 1979, Kuwamura 1981, Tribble 1982, Warner 1982, Robertson 1983, Ross 1983, Bell \& Colin 1986, Moyer 1989, Colin \& Bell 1991), either during flood or ebb tides. This indicates than even though tides can be used as a synchronizing cue for spawning, larval transport is a crucial factor determining spawning periodicity in locations with significant tidal amplitudes. At Mustin's Gap, seven out of eleven species spawned more intensively during flood tides, which is the period when the currents most likely flow away from the reef at this location, thus supporting observations from previous studies at locations with significant tidal currents. Of the other four species, one spawned mostly during ebb tides and three species showed no preference for either tide cycle.

At Mustin's Gap, group-spawning species showing tidal influences in spawning were present in high abundance at the spawning grounds for extended periods of time, which does not indicate a reduction of time allocated to spawning activities as expected by the above hypothesis. The abundance estimates of all group spawning species were also significantly correlated with a specific time of day, a cyclic variable which can also be used to synchronize ovarian cycles in reef fishes (Fischer \& Hardison 1987).

At the East Reef Edge spawning site $C$. sordidus spawned during a short period after low tide, even though there appears to be no clear advantage to spawning at this time 
for larval transport due to unpredictable current direction. But the East Reef Edge spawning site was located in the migration route to a much larger aggregation site located farther East along the submerged reef edge of the Atoll (G. Sancho personal observation). The tidal periodicity in spawning activities measured at the East Reef Edge site probably are a secondary result from the periodicity existent at the nearby larger spawning site, where strong tidally influenced currents are expected to occur because of the location at the reef crest of this spawning site (no current meter deployments were possible at this site due to very strong surf). Also current speeds at the East Reef Edge were fastest after low tide, and within the range of speed values apparently selected by $C$. sordidus, so the observed spawning pattern could actually have a potential effect on larval survivorship by reducing time of exposure to benthic predators (Johannes 1978).

Populations of $C$. sordidus spawn during flood tides at Johnston Atoll and during ebb tides in other locations (Moyer 1989, Colin \& Bell 1991), depending on which tidal cycle outflowing currents occur. This indicates that a specific tidal phase is not used as a fixed environmental cue across the geographic range of this species, but that fish are responding to directional water flows.

\section{Predation}

Predation risks on adult spawning fish have been proposed in numerous occasions as a potential factor controlling the timing of spawning of coral reef fishes, but there is a lack of information on diel activities patterns at spawning grounds of piscivores and on specific interactions of these predators with their prey (Robertson 1991). Information on the specific behavior of predators at spawning grounds resulting from this study is presented elsewhere (Chapters 3 and 4). Results regarding the relation of spawning intensity with abundance of predators illustrate the effects of predation in determining spawning behavior in certain species. Parrotfishes such as C. sordidus were expected to 
be most affected by predatory risks, since they were present in high abundance and lack anti-predatory morphological adaptations (Godin 1997, Smith 1997), and they showed reduced spawning intensities when predators were abundant. But other predator-prey relations observed were not expected. The most abundant surgeonfish, A. nigroris, seemed unaffected by predator activities, as originally expected according to the morphological characteristics of this species. But the observation of high predatory rates on this species, and capture rates comparable to those of parrotfishes (Chapter 3), indicate that piscivores overcame the morphological defenses of A. nigroris, and therefore predator activity should have caused reduced spawning intensity in this surgeonfish. Also the observed reductions in spawning intensity of two species of large size and morphological defenses (Z. flavescens and C. unifasciatus) during moments of high abundance of piscivores were unexpected.

The overall risk of predation was much lower at dusk that during daytime hours (Chapter 3), explaining the indifference of all six dusk spawning species to the abundance levels of piscivores occurring at this time.

The most vulnerable moment in a spawning sequence is during the spawning rush (Moyer 1987, Chapter 3). Various changes in spawning behavior of prey could explain the observations in certain species of reduced spawning intensities during moments of high predatory risks: (1) elimination of the spawning rush, releasing eggs among the coral heads (Lobel \& Neudecker 1985), (2) delay of spawning until predator abundance diminishes (Nemtzov 1994), (3) migration and spawning at another location and (4) interruption of spawning and re-absorption of gametes. Re-absorption of eggs has not been observed in coral reef pelagic spawners, and it is considered an unlikely explanation since most coral reef fishes are batch spawners (Sadovy 1996) and can have egg maturation cycles as short as 24 hours (Hoffman \& Grau 1989). No significant energetical benefit is expected form egg re-absorption in coral reef fishes. The other explanations which involve release of 
eggs are more plausible, but more specific studies on predator-prey relationships at spawning grounds are necessary to resolve among these possibilities.

The continuous water flow measurements and the evaluation of predatory activities at the spawning grounds presented in this study allowed me to address the importance of these selective factors in influencing the spawning behavior of reef fishes. More studies quantifying both spawning output and variability of environmental cues in other locations are needed to analyze the geographic variability in spawning patterns and the specific plasticity of decision mechanisms leading to the potential establishment of locally adapted spawning patterns.

\section{SUMMARY}

This study showed that diel timing patterns of spawning in coral reef fishes were very diverse and seemed influenced by a variety of environmental factors. Correlations between spawning and outgoing flows indicated that dispersal of propagules away from the reef environment may be an important selective force for daytime spawning species, which on occasions showed the ability to postpone spawning until flow direction was appropriate. Spawning at high current speeds was a rare pattern among the species studied, which were exposed to a relatively high range of current speeds. The presence of piscivorous fishes wa negatively correlated with the spawning intensity of a few species, while the majority of species showed no correlation. Tides did not seem to be used as synchronizing cues for spawning by fish migrating to the spawning sites. Most species analyzed had a peak maximum spawning activity, with daytime spawners displaying a large variability of times for spawning and dusk spawners more restricted spawning times.

Results indicating the importance of outflowing currents as an environmental cue for various species support the validity of either the hypothesis proposing the dispersal of 
propagules away from reefs (Barlow 1981), or the hypothesis proposing reduction of reef based predation of propagules (Johannes 1978) as two selective mechanisms controlling the timing of reproduction. The avoidance predation risks by adults (Robertson 1991) can also influence the spawning patterns of certain species.

Warner $(1991,1997)$ hypothesized about the mechanisms employed by reef fishes to develop local adaptations in their adult environment, since they have a dispersive larval stage. The mechanisms involve (1) finely tuned responses by adult fishes to detectable local environmental cues, and (2) fixed responses across the range of a species when certain environmental factors cannot be detected by the adults (Warner 1997). The present study suggests that current direction and predatory risks are environmental cues that can be detected by adult fishes and elicit reproductive responses in very short time scales. In contrast, time of day seems to elicit a fixed reproductive responses among fish of the same family across wide distribution areas. Daytime spawners tend to display short term spawning responses to local changes in the environment, while dusk spawners show few locally adapted reproductive responses. Dusk spawners potentially benefit from reduced predatory risks occurring at dusk. The existence of species spawning during different tidal cycles at different locations indicates that tides are not used as fixed environmental cues for spawning, but that fishes are likely responding to associated directional water flows. The importance of current speed as an environmental variable influencing spawning varied among species, some avoiding to spawn at very low current speeds. 


\section{BIBLIOGRAPHY}

Appeldoorn, R. S., Hensley, D. A., Shapiro, D. Y., Kioroglou, S., Sanderson, B. G. (1994). Egg dispersal in a Caribbean coral reef fish, Thalassoma bifasciatum. II. Dispersal off the reef platform. Bull. Mar. Sci. 54: 271-280

Atkinson, M., Smith, S. V., Stroup, E. D. (1981). Circulation in Enewetak Atoll lagoon. Limnol. Oceanogr. 26: 1074-1083

Balon, E. K. (1981). Additions and amendments to the classification of reproductive styles in fishes. Env. Biol. Fish. 6: 377-389

Barlow, G. W. (1981). Patterns of parental investment, dispersal and size among coralreef fishes. Env. Biol. Fish. 6: 65-85

Bell, L. J., Colin, P. L. (1986). Mass spawning of Caesio teres (Pisces:Caesionidae) at Enewetak Atoll, Marshall Islands. Env. Biol. Fish. 15: 69-74

Clavijo, I. E. (1983). Pair spawning and formation of a lek-like mating system in the parrotfish Scarus vetula. Copeia. 1983: 253-256

Colin, P. L. (1995). Surface currents in Exuma sound, Bahamas and adjacent areas with reference to potential larval transport. Bull. Mar. Sci. 56: 48-57

Colin, P. L., Clavijo, I. E. (1978). Mass spawning by the spotted goatfish, Pseudupeneus maculatus (Bloch) (Pisces: Mullidae). Bull. Mar. Sci. 28: 780-782

Colin, P. L., Clavijo, I. (1985). Spawning of western atlantic surgeonfishes. In: Swanson, W. (ed.) National Geographic Society Research Reports 1977, p. 243-250

Colin, P. L., Clavijo, I. E. (1988). Spawning activity of fishes producing pelagic eggs on a shelf edge coral reef, Southwestern Puerto Rico. Bull. Mar. Sci. 42: 249-279

Colin, P. L., Bell, L. J. (1991). Aspects of spawning of labrid and scarid fishes (Pisces: Labroidei) at Enewetak Atoll, Marshall Islands with notes on other families. Env. Biol. Fish. 31: 229-260

Collett, B. (1991). Modelling binary data. Chapman \& Hall, London

Duarte, C. M., Alcaraz, M. (1989). To produce many small or few large eggs: a sizeindependent reproductive tactic of fish. Oecologia. 80: 401-404

Fischer, E. A., Hardison, P. D. (1987). The timming of spawning and egg production as constraints on male mating suscess ina simultaneously hermaphroditic fish. Env. Biol. Fish. 20: $301-310$

Gladstone, W., Westoby, M. (1988). Growth and reproduction in Canthigaster valentini (Pisces: Tetraodontidae): a comparison of a toxic reef fish with other reef fishes. Env. Biol. Fish. 21: 207-221 
Godin, J.-G. J. (1997). Evading predators. In: Godin, J.-G. J. (ed.) Behavioral ecology of teleost fishes. Oxford University Press, Oxford, p. 191-236

Hensley, D. A., Appeldoorn, R. S., Shapiro, D. Y., Ray, M., Turingan, R. G. (1994). Egg dispersal in a Caribbean coral reef fish, Thalassoma bifasciatum. I. Dispersal over the reef platform. Bull. Mar. Sci. 54: 256-270

Hobson, E. S. (1973). Activity of Hawaiian reef fishes during the evening and morning transitions between daylight and darkness. Fish. Bull. 70:715-740

Hobson, E. S. (1991). Trophic relationships of fishes specialized to feed on zooplankters above coral reefs. In: Sale, P. F. (ed.) The ecology of fishes on coral reefs. Academic Press, San Diego, p. 69-95

Hoffman, K. S., Grau, E. G. (1989). Daytime changes in oocyte development with relation to the tide for the Hawaiian saddleback wrasse, Thalassoma duperrey. J. Fish. Biol. 34: 529-546

Hunt von Herbing, I., Hunte, W. (1991). Spawning and recruitment of the bluehead wrasse Thalassoma bifasciatum in Barbados, West Indies. Mar. Ecol. Prog. Ser. 72: 49-58

Johannes, R. E. (1978). Reproductive strategies of coastal marine fishes in the tropics. Env. Biol. Fish. 3: 65-84

Kuwamura, T. (1981). Diurnal periodicity of spawning activity in free-spawning labrid fishes. Japan. J. Ichthyol. 28: 343-348

Lobel, P. S. (1978). Diel, lunar, and seasonal periodicity in the reproductive behavior of the pomacanthid fish, Centropyge potteri, and some other reef fishes in Hawaii. Pacific Science. 32: 193-207

Lobel, P. S. (1996). Spawning sound of the trunkfish, Ostracion meleagris (Ostraciidae). Biol. Bull. 191: 308-309

Lobel, P. S., Neudecker, S. (1985). Diurnal periodicity of spawning activity by the hamlet fish, Hypoplectrus guttavarius (Serranidae). In: Reaka, M. L. (ed.) The ecology of coral reefs. vol. 3. NOAA Undersea Research Program, Rockville, MD, p. $71-86$

Meyer, K. A. (1977). Reproductive behavior and patterns of sexuality in the Japanese labrid fish Thalassoma cupido. Japan. J. Ichthyol. 24: 101-112

Miller, R. G. (1986). Beyond ANOVA, basics of applied statistics. John Wiley \& Sons, New York

Morgan, S. G. (1996). Plasticity in reproductive timing by crabs in adjacent tidal regimes. Mar. Ecol. Prog. Ser. 139: 105-118

Morgan, S. G., Christy, J. H. (1994). Plasticity, constraint, and optimality in reproductive timing. Ecology. 75: 2185-2203 
Moyer, J. T. (1979). Mating strategies and reproductive behavior of Ostraciid fishes at Miyake-jima, Japan. Japan. J. Ichthyol. 26: 148-160

Moyer, J. T. (1987). Quantitative observations of predation during spawning rushes of the labrid fish Thalassoma cupido at Miyake-jima, Japan. Japan. J. Ichthyol. 34: 76-81

Moyer, J. T. (1989). Reef channels as spawning sites for fishes on the Shiraho coral reef, Ishigaki Island, Japan. Japan. J. Ichthyol. 36: 371-375

Moyer, J. T., Yogo, Y. (1982). The lek-like mating system of Halichoeres melanochir (Pisces: Labridae) at Miyake-jima, Japan. Z. Tierpsychol. 60: 209-226

Myrberg, A. A., Montgomery, W. L., Fishelson, L. (1989). The reproductive behavior of Acanthurus nigrofuscus (Forskal) and other surgeonfishes (Fam. Acanthuridae) off Eilat, Israel (Gulf of Aqaba, Red Sea). Ethology. 79: 31-61

Nemtzov, S. C. (1994). Intraspecific variation in sand-diving and predator avoidance behavior of green razorfish, Xyrichtys splendens (Pisces: Labridae): effect on courtship and mating suscess. Env. Biol. Fish. 41: 403-414

Petersen, C. W. (1991). Variation in fertilization rate in the tropical reef fish: Halichoeres bivittatus: correlates and implications. Biol. Bull. 181: 232-237

Petersen, C. W., Warner, R. R., Cohen, S., Hess, H. C., Sewell, A. T. (1992). Variable pelagic fertilization suscess: implications for mate choice and spatial patterns of mating. Ecology. 73: 391-401

Randall, J. E. (1961). Observations on the spawning of surgeonfishes (Acanthuridae) in the Society Islands. Copeia. 2: 237-288

Robertson, D. R. (1982). Gonochorism, protogynous sex-change and spawning in three Sparisomatinine parrotfishes from the Western Indian Ocean. Bull. Mar. Sci. 32: 868879

Robertson, D. R. (1983). On the spawning behavior and spawning cycles of eight surgeonfishes (Acanthuridae) from the Indo-Pacific. Env. Biol. Fish. 9: 193-223

Robertson, D. R. (1991). The role of adult biology in the timing of spawning of tropical reef fish. In: Sale, P. F. (ed.) The ecology of fishes on coral reefs. Academic Press, San Diego, p. 356-386

Robertson, D. R., Hoffman, S. G. (1977). The roles of female mate choice and predation in mating systems of some tropical labroid fishes. Z. Tierpsychol. 45: 298320

Robertson, D. R., Warner, R. R. (1978). Sexual patterns in the labroid fishes of the Western caribbean. II: The parrotfishes (Scaridae). Smithson. Contrib. Zool. 255: 126 
Robertson, D. R., Petersen, C. W., Brawn, J. D. (1990). Lunar reproductive cycles of benthic-brooding reef fishes: reflections of larval biology or adult biology? Ecol. Monogr. 60: 311-329

Ross, R. M. (1983). Annual, semilunar, and diel reproductive rhythms in the hawaiian labrid Thalassoma duperrey. Mar. Biol. 72: 311-318

Sadovy, Y. J. (1996). Reproduction of reef fishery species. In: Polunin, N. V. C., Roberts, C. M. (ed.) Reef Fisheries. vol. 20. Chapman \& Hall, London, p. 15-59

Scott, D. B. C. (1979). Environmental timing and the control of reproduction in teleost fish. Symp. Zool. Soc. Lond. 44: 105-132

Shapiro, D. Y., Hensley, D. A., Appledoorn, R. S. (1988). Pelagic spawning and egg transport in coral-reef fishes: a skeptical overview. Env. Biol. Fish. 22: 3-14

Shibuno, T., Gushima, K., Kakuda, S. (1993). Female spawning migrations of the protogynous wrasse, Halichoeres marginatus. Japan. J. Ichthyol. 39: 357-362

Smith, R. J. F. (1997). Avoiding and deterring predators. In: Godin, J.-G. J. (ed.) Behavioral ecology of teleost fishes. Oxford University Press, Oxford, p. 163-189

Sokal, R. R., Rohlf, F. J. (1995). Biometry. W.H. Freeman and Company, New York

Thresher, R. E. (1979). Social behavior and ecology of two sympatric wrasses (Labridae: Halichoeres spp.) off the coast of Florida. Mar. Biol. 53: 161-172

Thresher, R. E. (1982). Courtship and spawning in the emperor angelfish Pomacanthus imperator, with comments on reproduction by other pomacanthid fishes. Mar. Biol. 70: $149-156$

Thresher, R. E. (1984). Reproduction in reef fishes. T.F.H. Publications. Neptune City, New Jersey

Thresher, R. E., Brothers, E. B. (1985). Reproductive ecology and biogeography of Indo-West Pacific angelfishes (pisces: Pomacanthidae). Evolution. 39: 878-887

Tribble, G. W. (1982). Social organization, patterns of sexuality, and behavior of the wrasse Coris dorsomaculata at Miyake-jima, Japan. Env. Biol. Fish. 7: 29-38

Warner, R. R. (1982). Mating systems, sex change and sexual demography in the rainbow wrasse, Thalassoma lucasanum. Copeia. 1982: 653-661

Warner, R. R. (1991). The use of phenotypic plasticity in coral reef fishes as tests of theory in evolutionary ecology. In: Sale, P. F. (ed.) The ecology of fishes on coral reefs. Academic Press, San Diego, p. 387-398

Warner, R. R. (1997). Evolutionary ecology: how to reconcile pelagic dispersal with local adaptation. Coral Reefs. 16 Suppl.: S115-S120 
Warner, R. R., Robertson, D. R. (1978). Sexual patterns in the labroid fishes of the Western Caribbean. I: The wrasses (Labridae). Smithson. Contrib. Zool. 254: 1-27 
Table 1. Spawning behavior of eleven reef fishes at the spawning aggregations of Johnston Atoll.

No. Spawns: Total number of spawns observed during each observation year. Spawning behavior: $G=$ group spawning, $P=$ pair spawning, $\mathrm{G}+\mathrm{P}=$ group and pair spawning, $\mathrm{G}>\mathrm{p}=$ mostly group spawning with some pair spawning. Mating system: MON = monogamy, $\mathrm{MT}=$ male territory, $\mathrm{PRO}=$ promiscuity, $\mathrm{HAR}=$ Haremic. Predation on Adults: attacks on spawners by Caranx melampygus or Aphareus furca. Predation on Eggs: attacks on eggs by Melichthys niger or M. vidua. Time spawning: 1 hour period where spawning median value is located. Sunset ocurred between $1932-1946 \mathrm{~h}$.

\begin{tabular}{|c|c|c|c|c|c|c|c|c|}
\hline \multirow[t]{2}{*}{ Family } & \multirow[t]{2}{*}{ Species } & \multicolumn{2}{|c|}{ Number of spawns: } & \multirow{2}{*}{$\begin{array}{l}\text { Spawning } \\
\text { behavior }\end{array}$} & \multirow[t]{2}{*}{ Mating system } & \multicolumn{2}{|c|}{ Predation on: } & \multirow{2}{*}{$\begin{array}{c}\text { Time spawning } \\
\text { (median) }\end{array}$} \\
\hline & & 1994 & 1995 & & & Adults & Eggs & \\
\hline $\begin{array}{l}\text { Mullidae } \\
\text { (goatfish) }\end{array}$ & $\begin{array}{l}\text { Parupeneus bifasciatus } \\
\text { Parupeneus multifasciatus }\end{array}$ & $\begin{array}{l}15 \\
36\end{array}$ & $\begin{array}{l}44 \\
50\end{array}$ & $\begin{array}{l}\mathrm{P} \\
\mathrm{P}\end{array}$ & $\begin{array}{l}\text { MT } \\
\text { MT }\end{array}$ & $\begin{array}{l}\text { No } \\
\text { No }\end{array}$ & $\begin{array}{l}\text { No } \\
\text { Yes }\end{array}$ & $\begin{array}{l}1900-2000 \\
1900-2000\end{array}$ \\
\hline $\begin{array}{l}\text { Chaetodontidae } \\
\text { (butterflyfish) }\end{array}$ & Chaetodon unimaculatus & 3 & 16 & $\mathrm{P}$ & MON & No & No & $1900-2000$ \\
\hline $\begin{array}{l}\text { Labridae } \\
\text { (wrasses) }\end{array}$ & $\begin{array}{l}\text { Cheilinus unifasciatus } \\
\text { Coris gaimard } \\
\text { Epibulus insidiator }\end{array}$ & $\begin{array}{l}24 \\
39 \\
41\end{array}$ & $\begin{array}{l}69 \\
66 \\
21\end{array}$ & $\begin{array}{l}P \\
P \\
P\end{array}$ & $\begin{array}{l}\text { MT } \\
\text { MT } \\
\text { MT }\end{array}$ & $\begin{array}{l}\text { No } \\
\text { No } \\
\text { No }\end{array}$ & $\begin{array}{l}\text { No } \\
\text { No } \\
\text { No }\end{array}$ & $\begin{array}{l}1700-1800 \\
1600-1700 \\
1400-1500\end{array}$ \\
\hline $\begin{array}{l}\text { Scaridae } \\
\text { (parrotfish) }\end{array}$ & Chlorurus sordidus & 1433 & 2654 & $G>p$ & PRO, MT & Yes & Yes & $1400-1500$ \\
\hline $\begin{array}{l}\text { Acanthuridae } \\
\text { (surgeonfish) }\end{array}$ & $\begin{array}{l}\text { Acanthurus nigroris } \\
\text { Ctenochaetus strigosus } \\
\text { Zebrasoma flavescens }\end{array}$ & $\begin{array}{l}1520 \\
339 \\
504\end{array}$ & $\begin{array}{l}1981 \\
531 \\
479\end{array}$ & $\begin{array}{c}G \\
G+P \\
G>p\end{array}$ & $\begin{array}{l}\text { PRO } \\
\text { PRO } \\
\text { PRO }\end{array}$ & $\begin{array}{l}\text { Yes } \\
\text { Yes } \\
\text { Yes }\end{array}$ & $\begin{array}{l}\text { Yes } \\
\text { No } \\
\text { No }\end{array}$ & $\begin{array}{l}1600-1700 \\
1800-1900 \\
1700-1600\end{array}$ \\
\hline $\begin{array}{c}\text { Ostracidae } \\
\text { (trunkfish) }\end{array}$ & Ostracion meleagris & 85 & 13 & $\mathrm{P}$ & HAR? & No & Yes & $1900-2000$ \\
\hline
\end{tabular}


Table 2. Multiple regression analyses of the abundance of group-spawning fish species. Normalized abundance data are arcsin transformed. Columns contain the number of 15 minute samples used in each model $(\mathbf{N})$, the coefficient of multiple determination for each model (R-square) and its correspondent p-value, the significant independent model estimators (significant variables), the coefficients of each individual model estimator and the p-value of each of these estimators. Independent variables are time of day, tide, tide $^{2}$ and current direction. Positive coefficients of current direction represent outflowing currents. See methods section for more details.

\begin{tabular}{|c|c|c|c|c|c|c|}
\hline Species & $\mathrm{N}$ & $R^{2}$ & $\begin{array}{c}\text { Regression } \\
\text { p-value }\end{array}$ & $\begin{array}{l}\text { Significant } \\
\text { variables }\end{array}$ & Coeff. & $p$-value \\
\hline \multicolumn{7}{|l|}{ Mustin's Gap } \\
\hline \multirow[t]{3}{*}{ A. nigroris } & 68 & 0.481 & $<0.0001$ & Time of day & 0.204 & $<0.0001$ \\
\hline & & & & Tide & 0.063 & 0.0002 \\
\hline & & & & Tide $^{2}$ & $2.29 E-04$ & 0.0037 \\
\hline \multirow[t]{4}{*}{ C. sordidus } & 86 & 0.431 & $<0.0001$ & Current direction & 15.999 & 0.0001 \\
\hline & & & & Time of day & -2.400 & $<0.0001$ \\
\hline & & & & Tide & 0.041 & 0.0188 \\
\hline & & & & Tide $^{2}$ & $-2.14 \mathrm{E}-04$ & 0.005 \\
\hline \multirow[t]{4}{*}{ Z. flavescens } & 118 & 0.429 & $<0.0001$ & Current direction & 0.388 & $<0.0001$ \\
\hline & & & & Time of day & 0.233 & $<0.0001$ \\
\hline & & & & Tide & 0.003 & NS \\
\hline & & & & Tide $^{2}$ & $-2.89 E-04$ & $<0.0001$ \\
\hline \multirow[t]{2}{*}{ C. strigosus } & 28 & 0.737 & $<0.0001$ & Current direction & -11.934 & 0.0181 \\
\hline & & & & Time of day & -1.520 & $<0.0001$ \\
\hline \multicolumn{7}{|c|}{ Eastern Reef Edge } \\
\hline C. sordidus & 32 & - & - & (none) & & NS \\
\hline
\end{tabular}


Table 3. Multiple regression analyses of the number of spawns of group-spawning species. Normalized spawning data are arcsin transformed. Independent variables are time of day, current velocity, current velocity ${ }^{2}$ and abundance of piscivores (C. melampygus and A. furca). Details as in legend of Table 2.

\begin{tabular}{|c|c|c|c|c|c|c|}
\hline Species & $N$ & $R^{2}$ & $\begin{array}{c}\text { Regression } \\
\text { p-value }\end{array}$ & $\begin{array}{l}\text { Significant } \\
\text { variables }\end{array}$ & Coeff. & $p$-value \\
\hline \multicolumn{7}{|l|}{ Mustin's Gap } \\
\hline A. nigroris & 43 & 0.164 & 0.007 & Time of day & 0.179 & 0.007 \\
\hline \multirow[t]{4}{*}{ C. sordidus } & 61 & 0.497 & $<0.0001$ & A. furca & -0.316 & 0.0084 \\
\hline & & & & Current velocity & 1.435 & $<0.0001$ \\
\hline & & & & Current velocity 2 & -0.027 & $<0.0001$ \\
\hline & & & & Time of day & -0.232 & $<0.0001$ \\
\hline \multirow[t]{3}{*}{ Z. flavescens } & 74 & 0.455 & $<0.0001$ & C. melampygus & -0.390 & $<0.0001$ \\
\hline & & & & Current velocity & 0.657 & 0.001 \\
\hline & & & & Time of day & 0.099 & 0.0307 \\
\hline C. strigosus & 20 & 0.717 & $<0.0001$ & Time of day & -1.841 & $<0.0001$ \\
\hline \multicolumn{7}{|c|}{ Eastern Reef Edge } \\
\hline \multirow[t]{2}{*}{ C. sordidus } & 32 & 0.21 & 0.0327 & Current velocity & -0.143 & NS \\
\hline & & & & Current velocity 2 & 0.311 & 0.0098 \\
\hline
\end{tabular}


Table 4. Multiple regression analyses of the spawning intensity rates (number of spawns per fish present) of group-spawning species. Normalized spawning intensity data are log transformed. Independent variables are time of day, current velocity, current velocity ${ }^{2}$ and abundance of piscivores (C. melampygus and A. furca). Details as in legend of Table 2.

\begin{tabular}{|c|c|c|c|c|c|c|}
\hline Species & $\mathrm{N}$ & $R^{2}$ & $\begin{array}{l}\text { Regression } \\
\text { p-value }\end{array}$ & $\begin{array}{l}\text { Significant } \\
\text { variables }\end{array}$ & Coeff. & $\mathrm{p}$-value \\
\hline \multicolumn{7}{|l|}{ Mustin's Gap } \\
\hline \multirow[t]{2}{*}{ A. nigroris } & 63 & 0.152 & 0.0026 & C. melampygus & 0.003 & 0.0167 \\
\hline & & & & Time of day & 0.002 & 0.0048 \\
\hline \multirow[t]{4}{*}{ C. sordidus } & 78 & 0.442 & $<0.0001$ & A. furca & -0.005 & 0.001 \\
\hline & & & & C. melampygus & -0.003 & 0.0037 \\
\hline & & & & Current velocity & 0.032 & $<0.0001$ \\
\hline & & & & Current velocity ${ }^{2}$ & $-5.24 \mathrm{E}-04$ & $<0.0001$ \\
\hline \multirow[t]{4}{*}{ 2. flavescens } & 118 & 0.4 & $<0.0001$ & C. melampy'gus & -0.004 & $<0.0001$ \\
\hline & & & & Current velocity & 0.018 & 0.0002 \\
\hline & & & & Current velocity ${ }^{2}$ & $-1.59 \mathrm{E}-04$ & 0.0212 \\
\hline & & & & Time of day & 0.002 & 0.0013 \\
\hline \multirow[t]{2}{*}{ C. strigosus } & 37 & 0.353 & 0.0006 & Predators & 0.014 & 0.0003 \\
\hline & & & & Time of day & -0.011 & 0.0477 \\
\hline \multicolumn{7}{|l|}{ East Reef Edge } \\
\hline \multirow[t]{2}{*}{ C. sordidus } & 29 & 0.289 & 0.0119 & Current velocity & -0.012 & 0.5102 \\
\hline & & & & Current velocity ${ }^{2}$ & 0.008 & 0.0033 \\
\hline
\end{tabular}


Table 5. Multiple regression analyses of the number of spawns of dusk pair-spawning species. Normalized spawning data are arcsin transformed. Independent variables are time of day, current velocity, current velocity ${ }^{2}$ and abundance of piscivores (average of $C$. melampygus and A. furca). Details as in legend of Table 2.

\begin{tabular}{lccclcc}
\hline Species & $\mathrm{N}$ & $\mathrm{R}^{2}$ & $\begin{array}{c}\text { Regression } \\
\mathrm{p} \text {-value }\end{array}$ & $\begin{array}{l}\text { Significant } \\
\text { variables }\end{array}$ & Coeff. & P-value \\
\hline C. unimaculatus & 36 & - & - & (none) & $\mathrm{NS}$ \\
$\begin{array}{l}\text { O. meleagris } \\
\text { P. bifasciatus }\end{array}$ & 51 & 0.498 & $<0.0001$ & Time of day & 1.827 & $<0.0001$ \\
P. multifasciatus & 54 & - & - & (none) & & $\mathrm{NS}$ \\
\hline
\end{tabular}


Table 6. Multiple logistic model of the number of spawns of daytime pair-spawning species. Columns contain the number of 15 minute samples used in each model $(\mathbf{N})$, the value of the model loss function, the significant independent model estimators (significant variables), the coefficients of each individual model estimator and their 95\% confidence interval limits. Independent variables are time of day, current velocity, current velocity ${ }^{2}$ and abundance of piscivores (C. melampygus and $A$. furca). See methods section for more details.

\begin{tabular}{|c|c|c|c|c|c|c|}
\hline \multirow[t]{2}{*}{ Species } & \multirow[t]{2}{*}{$\bar{N}$} & \multirow{2}{*}{$\begin{array}{c}\text { Loss } \\
\text { Function }\end{array}$} & \multirow{2}{*}{$\begin{array}{l}\text { Significant } \\
\text { variables }\end{array}$} & \multirow[t]{2}{*}{ Coeff. } & \multicolumn{2}{|l|}{$95 \% \mathrm{Cl}$} \\
\hline & & & & & Lower & Upper \\
\hline \multirow[t]{3}{*}{ C. unifasciatus } & 108 & 25.126 & A. furca & -0.038 & -0.064 & 0.077 \\
\hline & & & C. melampygus & -0.03 & -0.052 & -0.007 \\
\hline & & & Time of day & 0.05 & 0.023 & -0.012 \\
\hline C. gaimard & 117 & 74.322 & Time of day & 2.885 & -0.003 & 0.015 \\
\hline E. insidiator & 42 & - & (none) & & & \\
\hline
\end{tabular}


Table 7. Compilation of results from different analyses comparing the number of spawns with different variables. Tide Analyses: results from G-test analyses of tidal spawning periodicity indicating deviations from random; tidal times are divided into ebb/flood (significant deviations indicated as flood or ebb) and 1-2 hour categories (significant deviations indicated by asterisks). Multifactorial Analyses: results from multifactorial analyses comparing number of spawns with time of day, current speed and predator abundance; significant positive $(+)$, negative $(-)$ or quadratic $( \pm$ ) relations between dependent and independent variables are indicated. Positive and negative relations with time of day indicate increasing and decreasing spawning activity during observtion times. Dispersal Analyses: results from G-test analyses of spawning with respect to currents, indicating deviations from random; currents are divided into current direction (significant deviations indicated as Out or In) and current speed (significant deviations indicated by asterisks).

\begin{tabular}{|c|c|c|c|c|c|c|c|}
\hline \multirow[t]{2}{*}{ Species } & \multicolumn{2}{|c|}{ Tide Analyses } & \multicolumn{3}{|c|}{ Mlultifactorial Analyses } & \multicolumn{2}{|c|}{ Dispersal Analyses } \\
\hline & Ebb/Flood & Categories & $\begin{array}{c}\text { Time of } \\
\text { Day }\end{array}$ & $\begin{array}{r}\text { Current } \\
\text { Speed }\end{array}$ & $\begin{array}{c}\text { Predator } \\
\text { Abundance }\end{array}$ & Direction & Speed \\
\hline Parupeneus bifasciatus & Flood & & & & & & * \\
\hline Parupeneus multifasciatus & & & - & & & & \\
\hline Chaetodon unimaculatus & Flood & * & & & & & \\
\hline Cheilinus unifasciatus & & * & + & & - & Out & \\
\hline Coris gaimard & & & + & & & & \\
\hline Epibulus insidiator & Flood & & & & & & \\
\hline Chlorurus sordidus & Flood & * & - &,+ \pm & - & Out & $\star$ \\
\hline C. sordidus (East Reef Edge) & Flood & * & & - & & & \\
\hline Acanthurus nigroris & Flood & * & + & & & (no data) & * \\
\hline Ctenochaetus strigosus & Flood & * & - & & & Out & * \\
\hline Zebrasoma flavescens & & * & + & + & - & Out & * \\
\hline Ostracion meleagris & Ebb & * & + & & & $\ln$ & * \\
\hline
\end{tabular}


Figure 1. Map of Johnston Atoll with the locations the two spawning aggregations sites used in this study: Mustin's Gap and Eastern Reef Edge. 


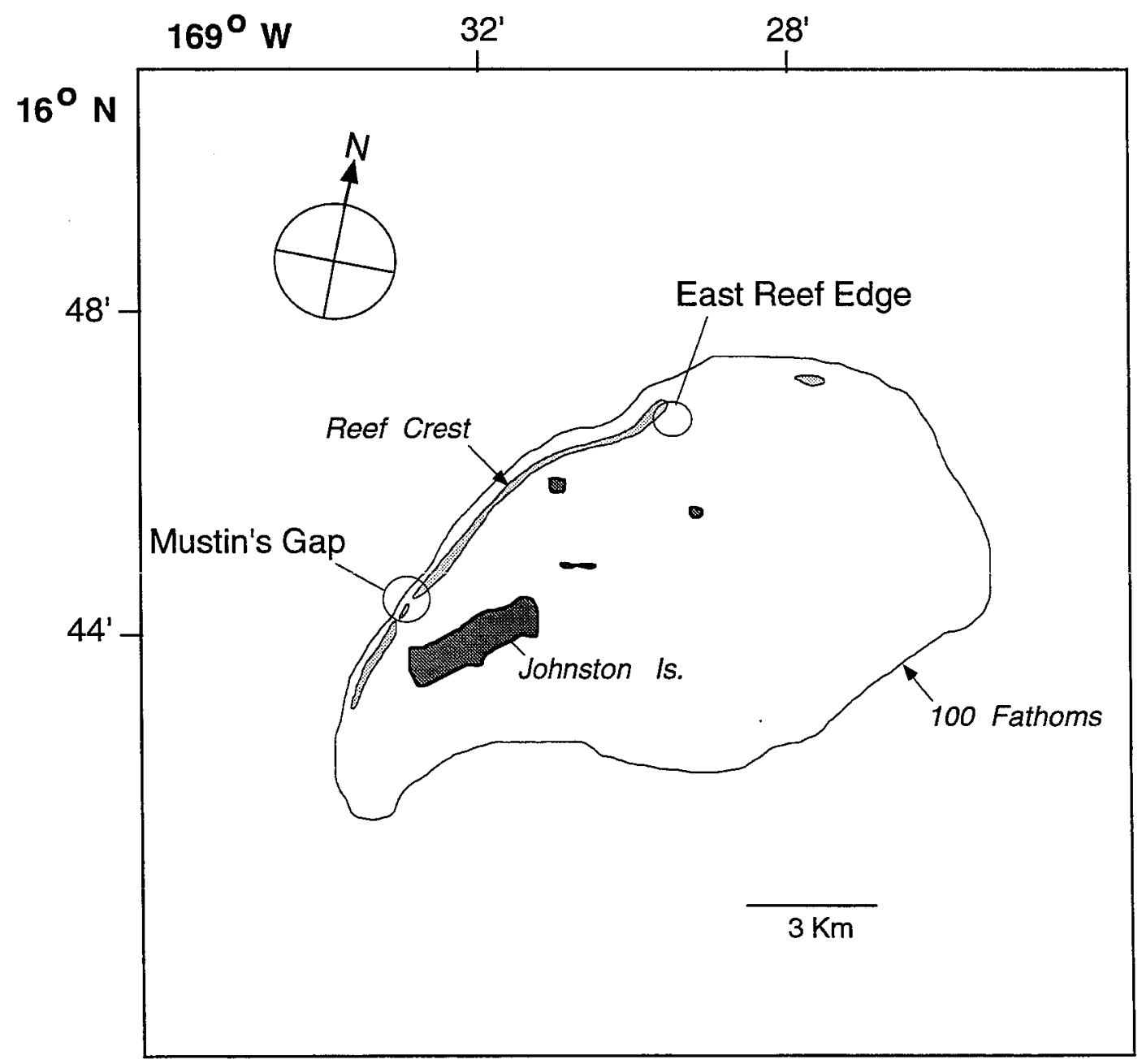


Figure 2. Current velocities and tidal heights at Mustin's Gap during May 2, 1995, representing a tidally influenced day. Dashed lines indicate the moments of high and low tides. Positive current velocity values represent outflowing directions, and negative represent inflowing ones (oriented perpendicularly relative to the reef crest). 

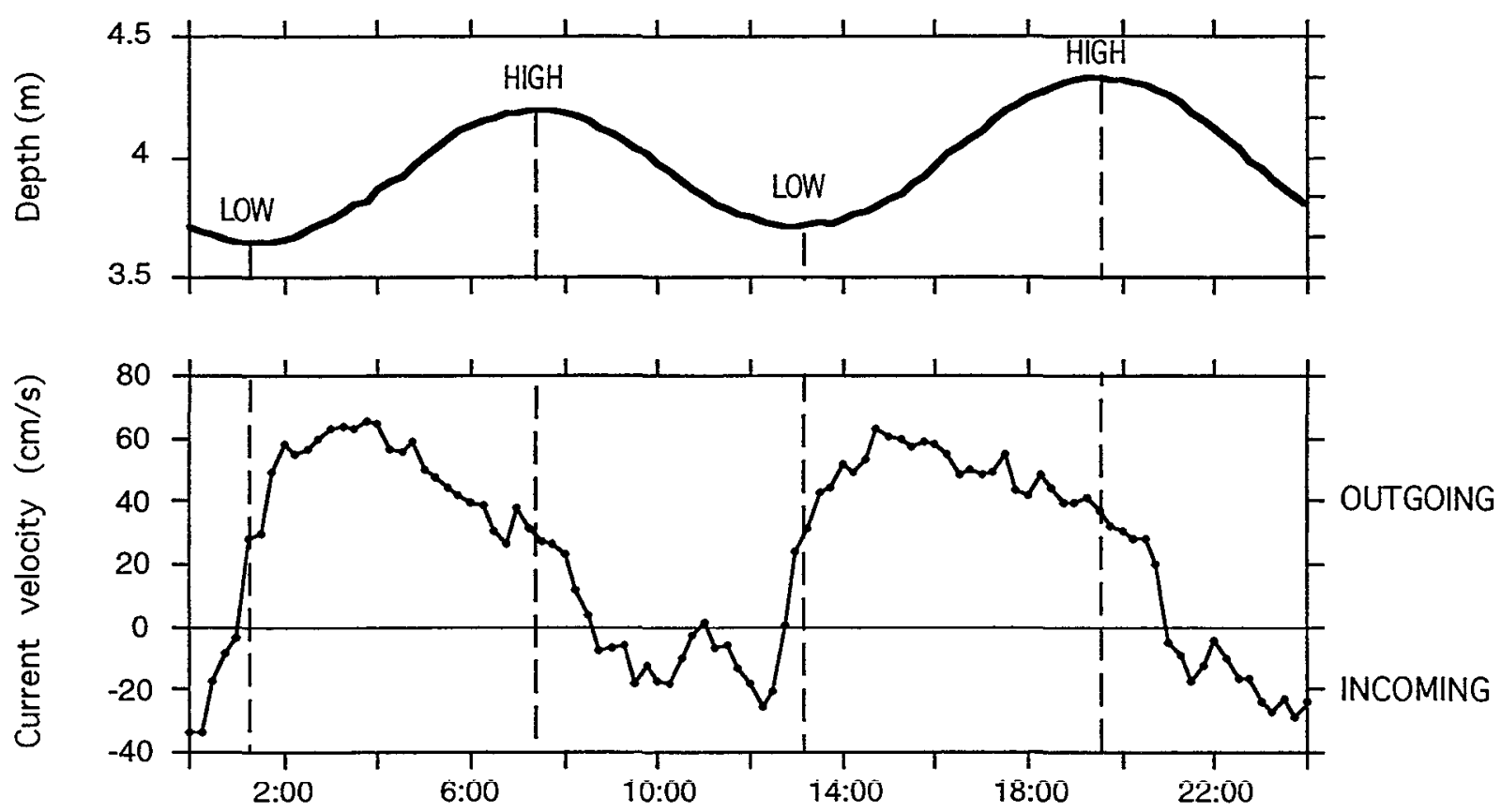
Figure 3. A. Depth profile and $\mathbf{B}$. Current velocities representing a transition from tidally influenced currents to wave influenced currents recorded at Mustin's Gap between May 38, 1995; C. Depth profile and D. Current velocities recorded at Eastern Reef Edge between May 15-20, 1995. 

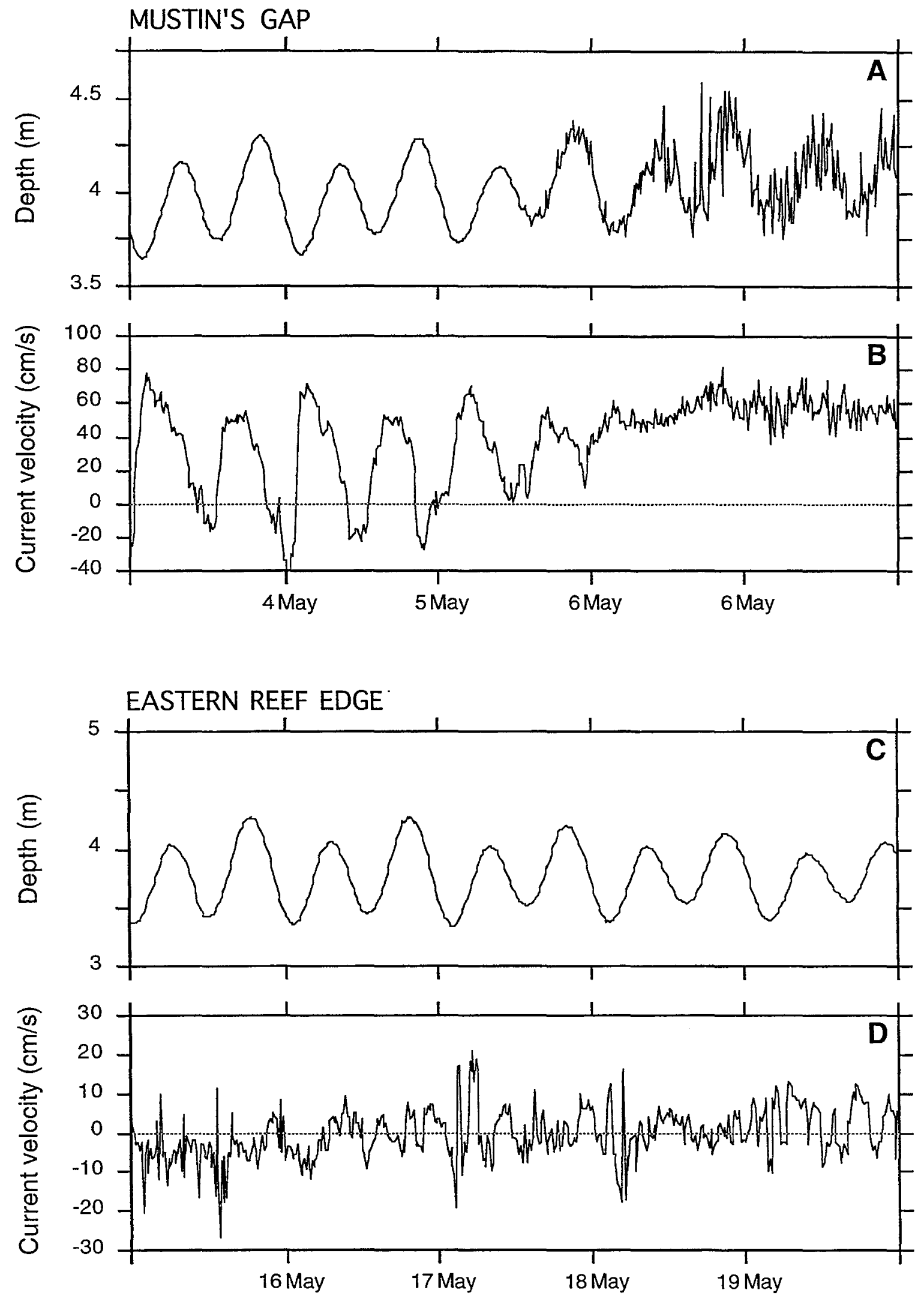
Figure 4. Daily afternoon (1300 - 1630) averages of (A) current speed and (B) spawning at Mustin's Gap from April 2 to May 20, 1995. In graph $\mathbf{A}$ gray bars represent the current speed on the days when daytime spawning observations were done and white bars represent days when no spawning observations were done. The $\mathrm{x}$-axis represents the different moon phases: black circles indicate new moon, white circles indicate full moon. 
1995 - Daytime

A) Currents

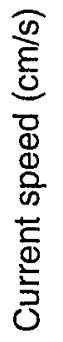

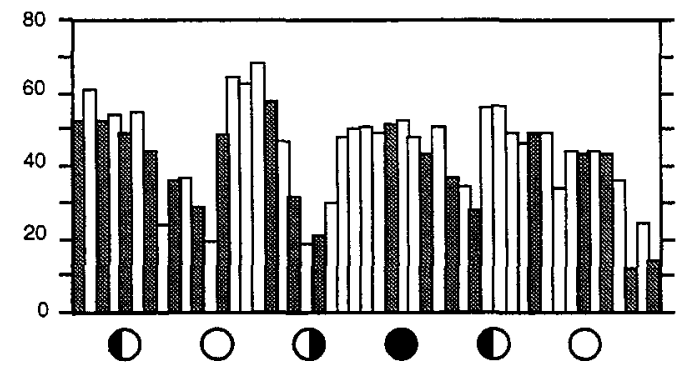

B) Spawning
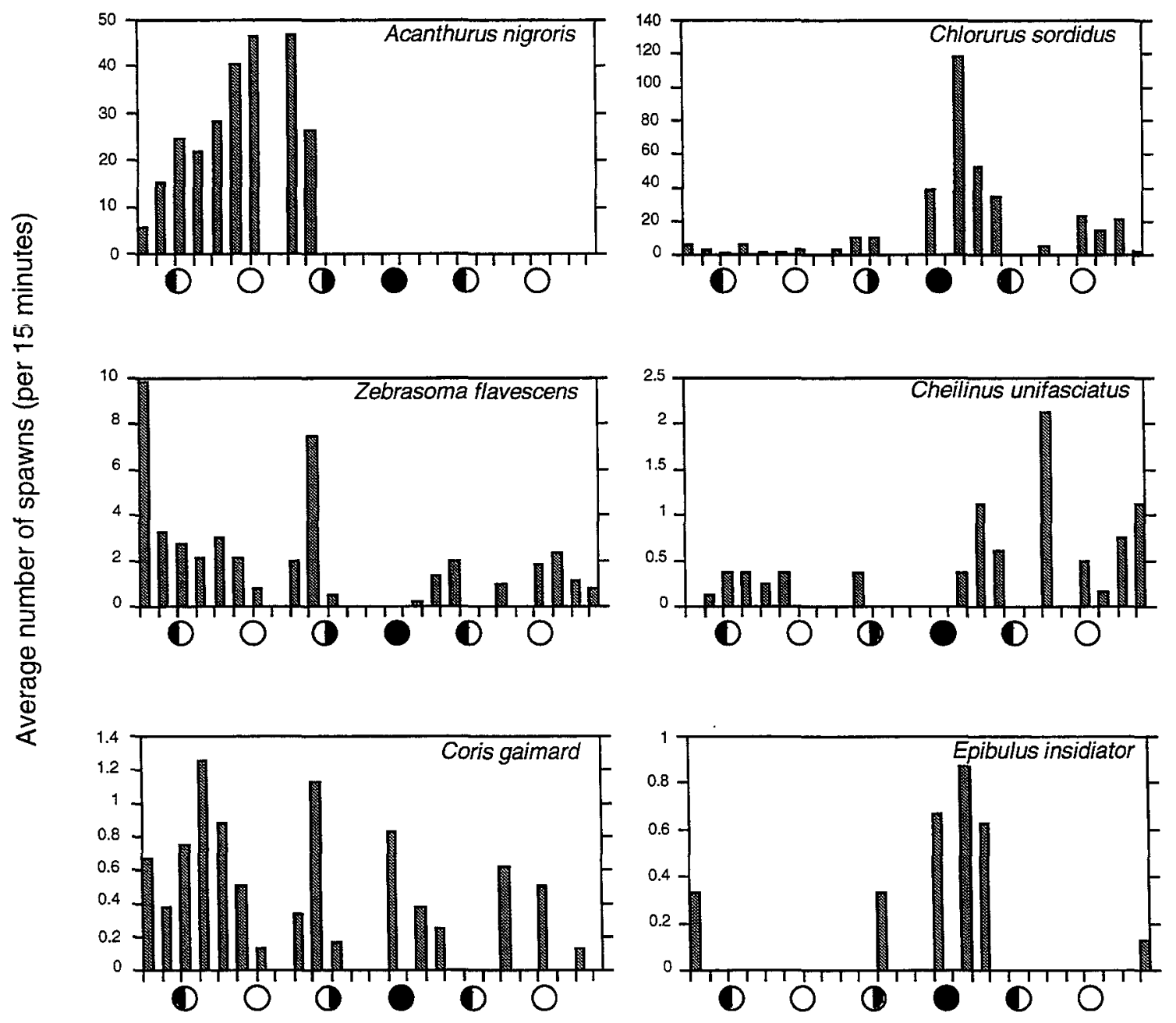
Figure 5. Daily dusk (1900 - 2000) averages of (A) current speed and (B) spawning at Mustin's Gap from April 11 to May 25, 1994. In graph A gray bars represent the current speed on the days when daytime spawning observations were done and white bars represent days when no spawning observations were done. Cross-marks represent days when data were not recorded. The $\mathrm{x}$-axis represents the different moon phases: black circles indicate new moon, white circles indicate full moon. 
1994 - Dusk

A) Currents

\begin{tabular}{l}
$\frac{\pi}{0}$ \\
$\frac{5}{0}$ \\
\hline 0 \\
0 \\
0 \\
0 \\
0 \\
\\
0 \\
0 \\
$\frac{0}{3}$ \\
0
\end{tabular}

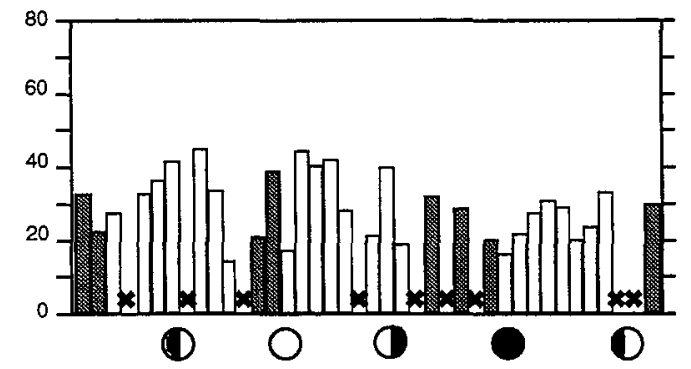

B) Spawning

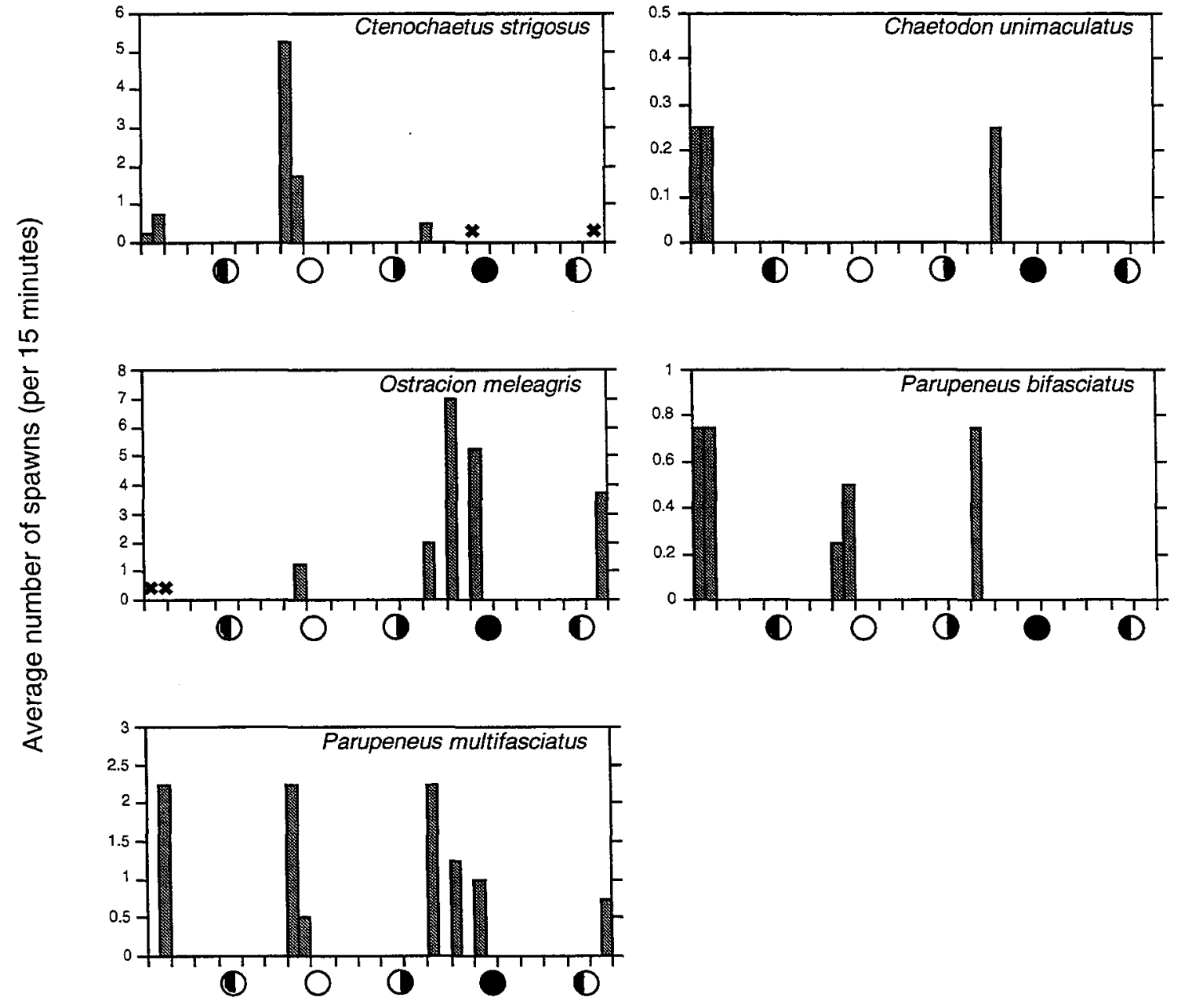


Figure 6. Daily dusk (1900 - 2000) averages of (A) current speed and (B) spawning at Mustin's Gap from April 3 to May 23, 1995. In graph A gray bars represent the current speed on the days when daytime spawning observations were done and white bars represent days when no spawning observations were done. The $\mathrm{x}$-axis represents the different moon phases: black circles indicate new moon, white circles indicate full moon. 
1995 - Dusk

A) Currents

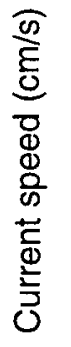

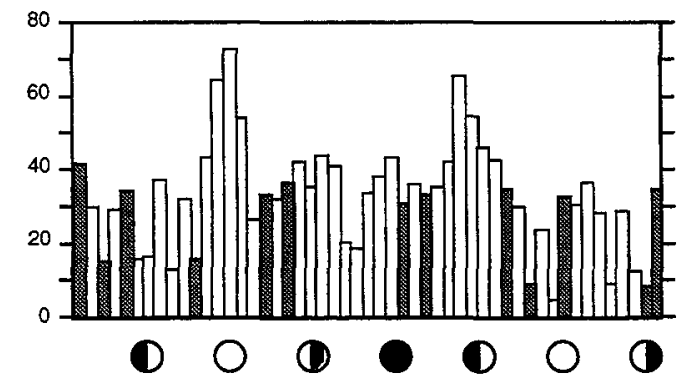

B) Spawning
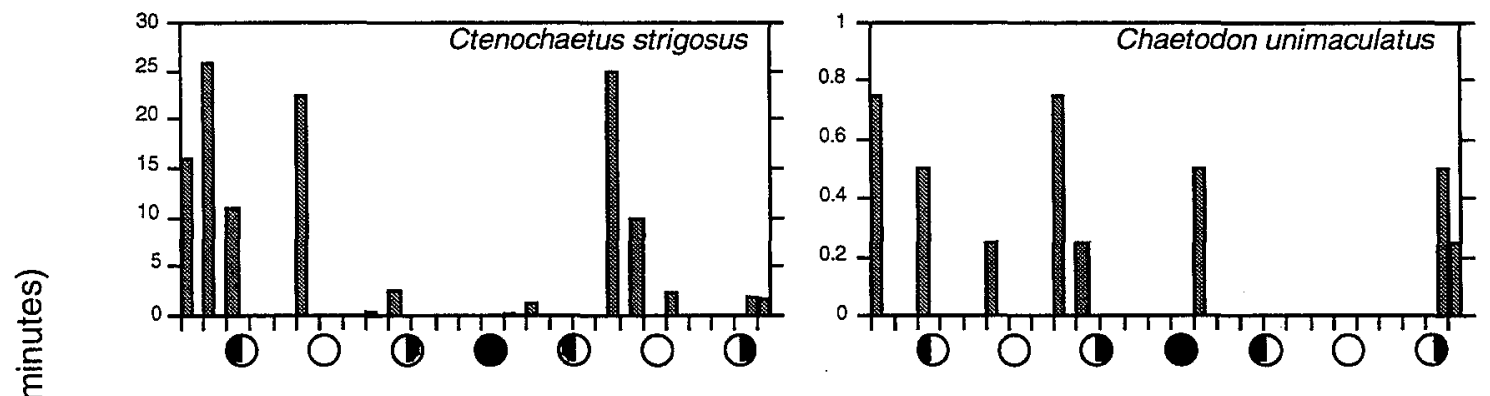

a
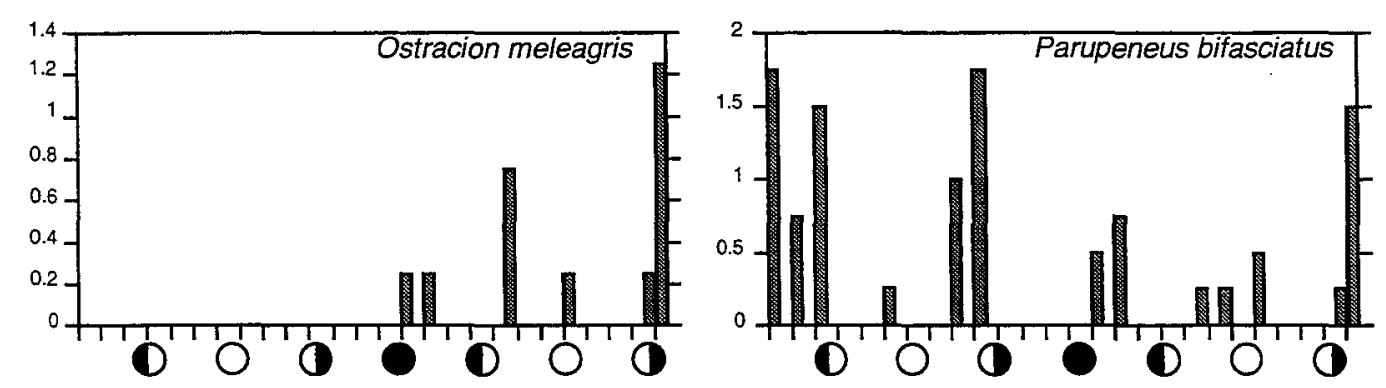

迩

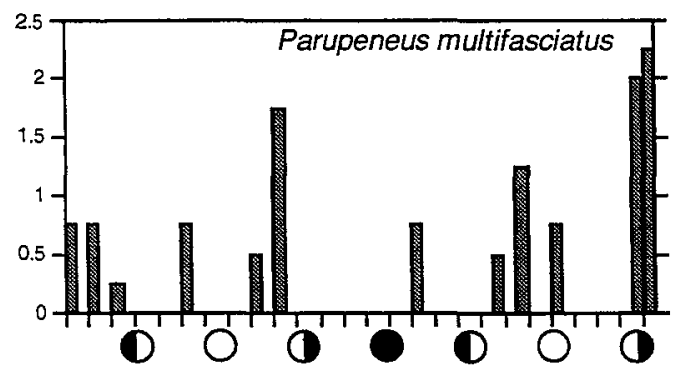


Figure 7. Fish abundance (A) and spawns (B) of group-spawning species at different tidal times. Abundance and spawning values are averages of 15 -minute observations $( \pm$ $\mathrm{SE}$ ) pooled from a total of 140 measurements. Tidal categories express hours from low tide. Negative tidal category values indicate number of hours before low tide (ebb tides) and positive values indicate hours after low (flood tides). Top eight graphs correspond to Mustin's Gap, bottom two to East Reef Edge. Observed values are compared with a distribution based only on the sampling effort at different tidal times through a $\chi^{2}$-test, $\mathrm{p}$ values are shown when significant. Asterisks indicate significance of $\chi^{2}$ residuals with a Bonferroni familywise error of 0.05 . 
A)
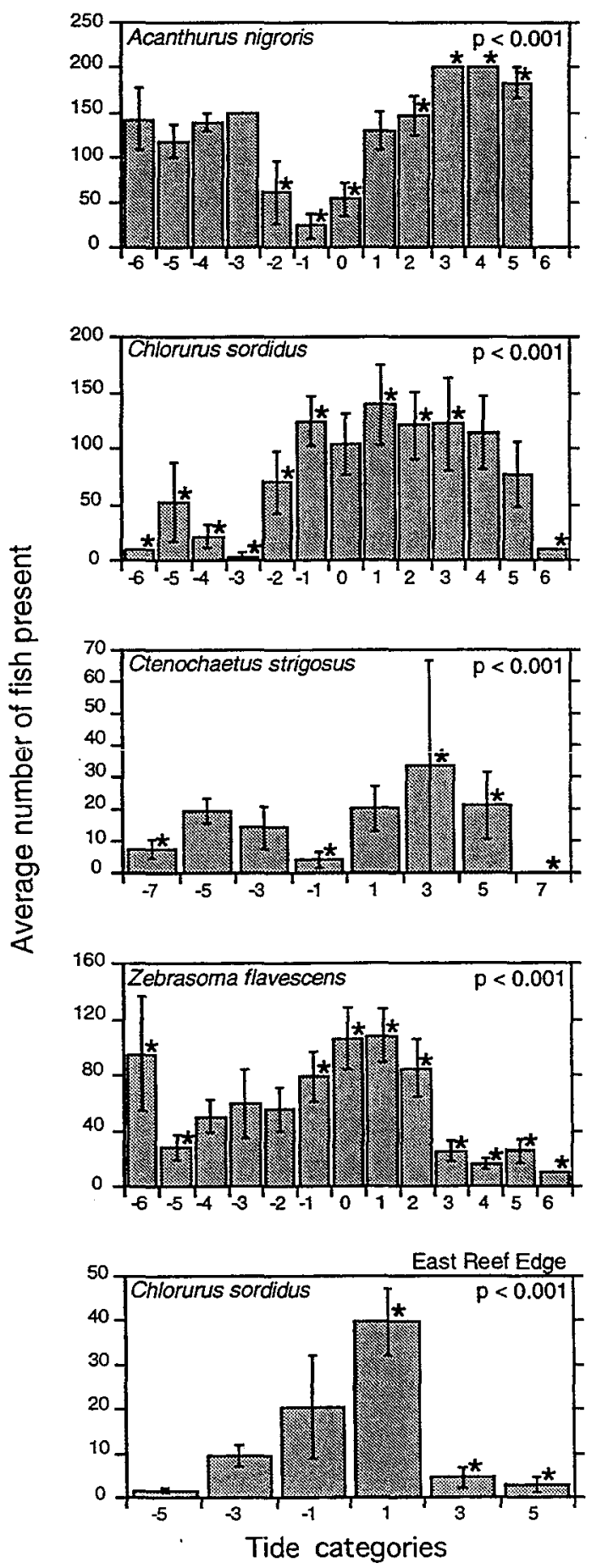

B)
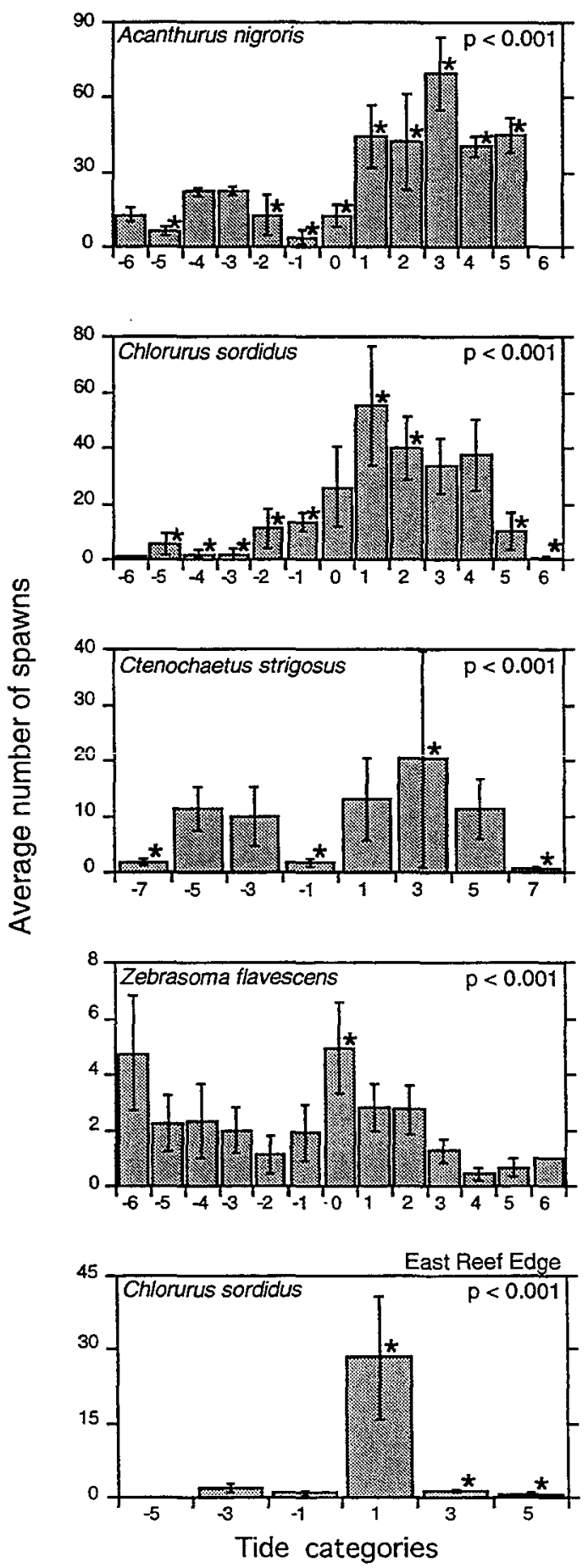
Figure 8. Spawns of pair-spawning species at different tidal times. Spawning values are averages of 15-minute observations $( \pm S E$ ) pooled from a total of 140 measurements for afternoon spawners, and 72 measurements for dusk spawners. Other details as in legend of figure 7, all graphs are from Mustin's Gap. Asterisks indicate significance of $\chi^{2}$ residuals with a Bonferroni familywise error of 0.05 . 

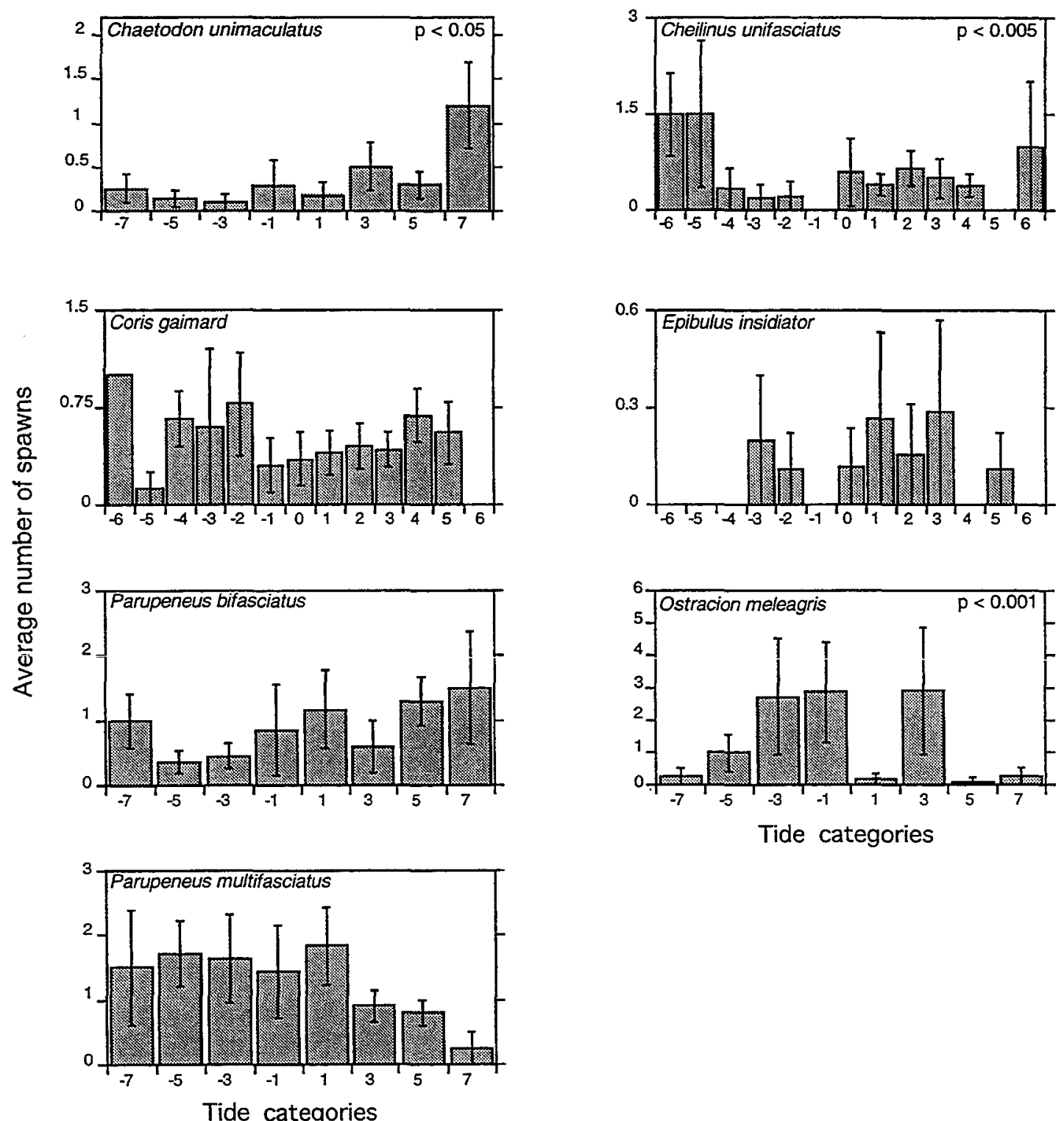
Figure 9. Abundance (A) and spawning sequences (B) of Chlorurus sordidus at Mustin's Gap during days when current reversals occurred in 1995. Gray bars indicate number of fish present at spawning grounds or the number of spawns observed in 15 minute counts. The black solid lines indicate the current velocities $(\mathrm{cm} / \mathrm{s})$ recorded with the current meter (positive=outflowing, negative=inflowing). Horizontal dotted lines represent the change of current direction. The arrows on top of graphs indicate the exact time of low tide. 
A)
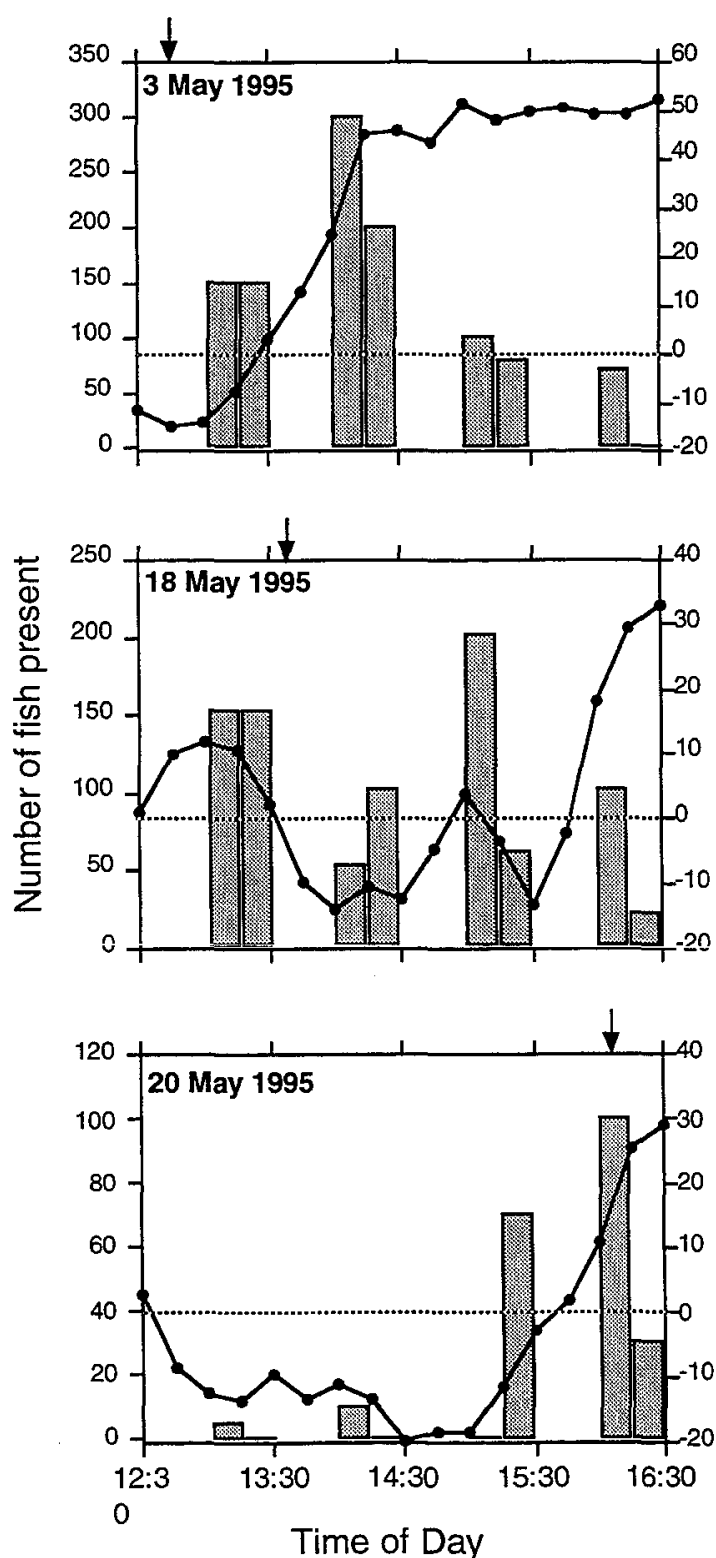

B)
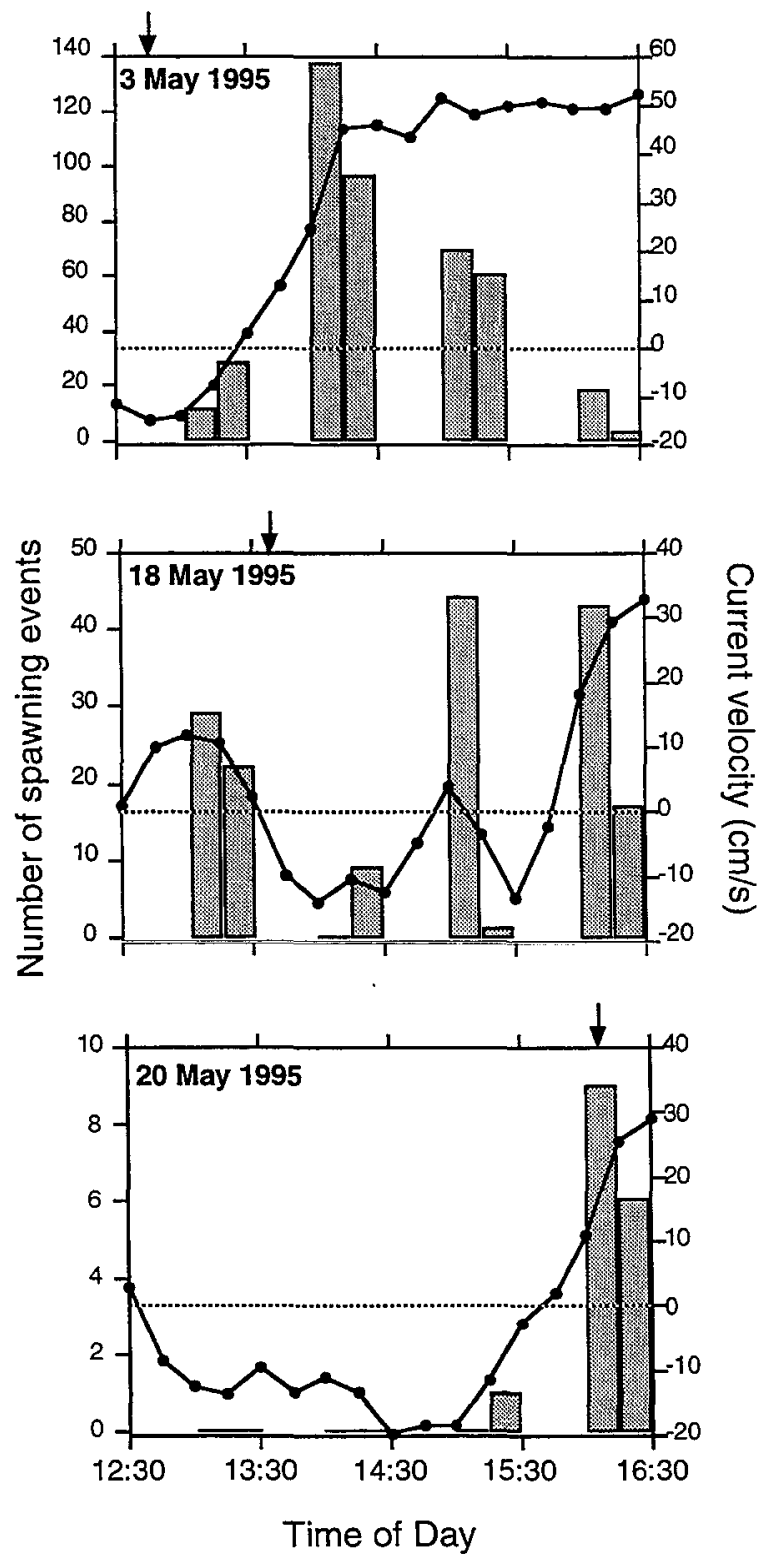
Figure 10. Abundance (A) and spawning sequences (B) of Chlorurus sordidus at Mustin's Gap during April 15, 1994. The arrows on top of graphs indicate the exact time of high and low tides. Details as in legend of Figure 9. 
A)
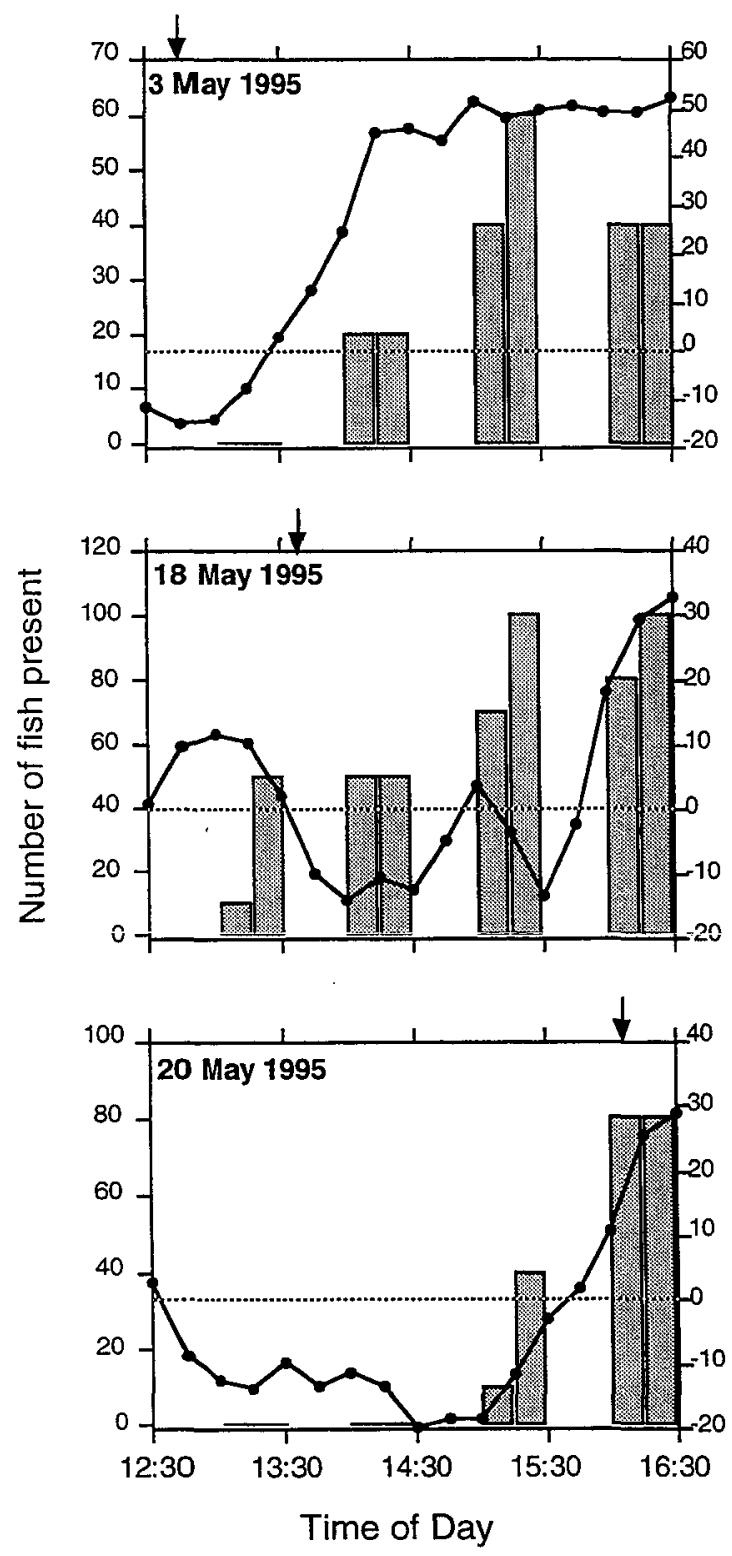

B)
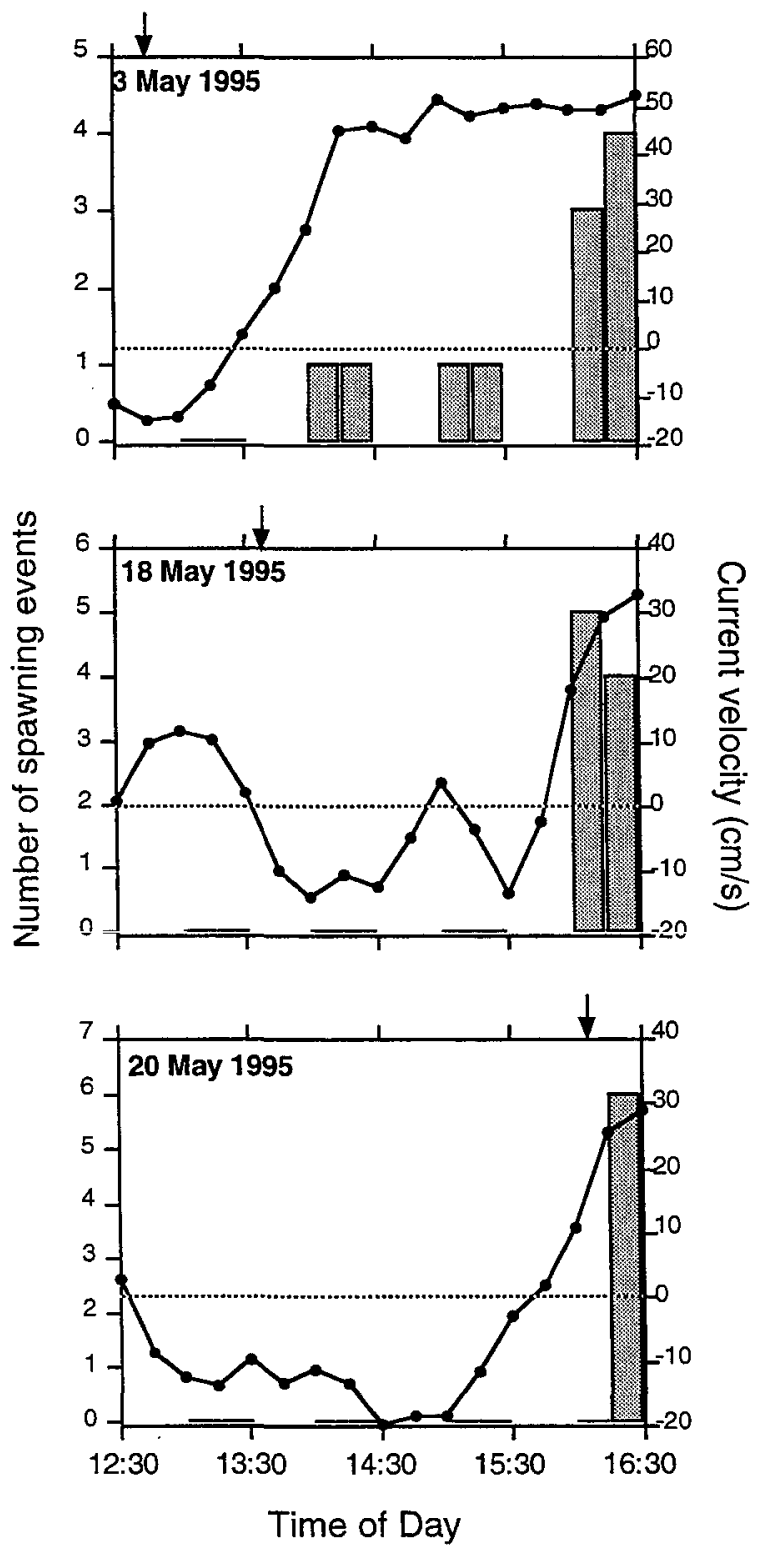
Figure 11. Abundance (A) and spawning (B) sequences of Zebrasoma flavescens at Mustin's Gap during days when current reversals occurred in 1995. Details as in legend of Figure 9. 
A)

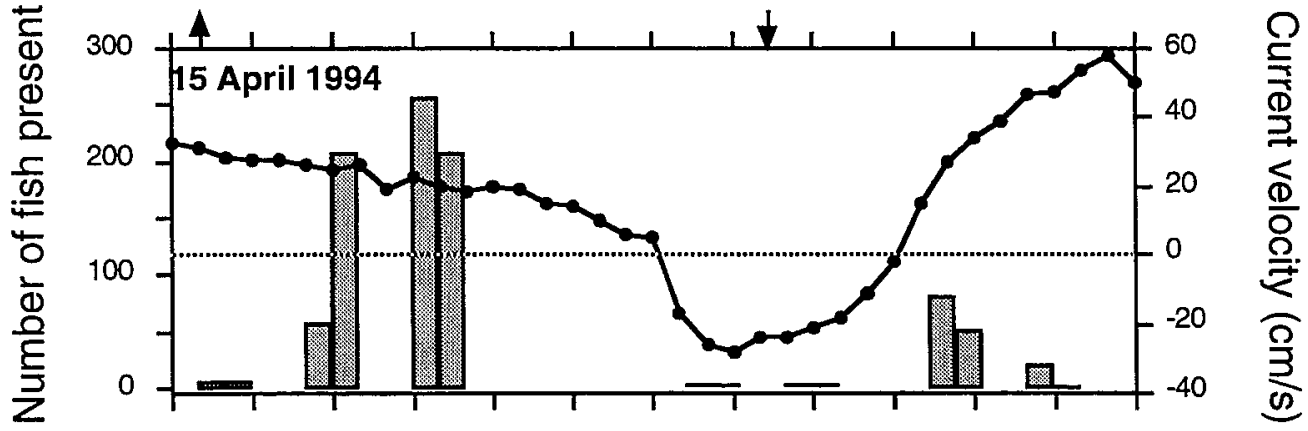

B)

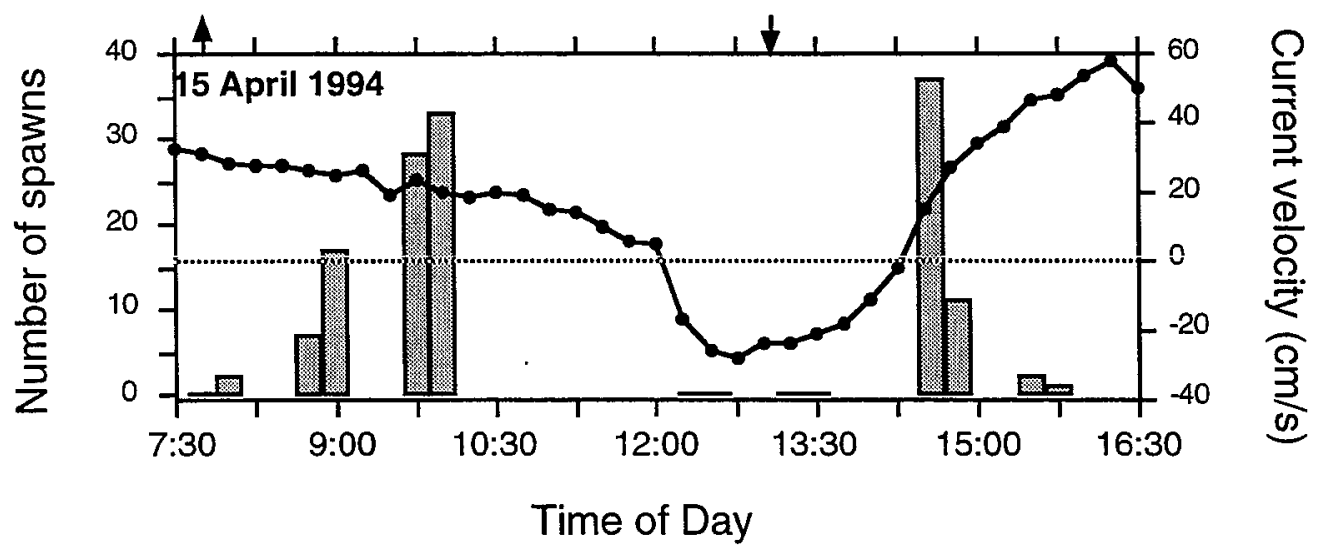


Figure 12. Abundance (A) and spawning sequences (B) of Ctenochaetus strigosus at Mustin's Gap during May 12, 1995. Details as in legend of Figure 9. 


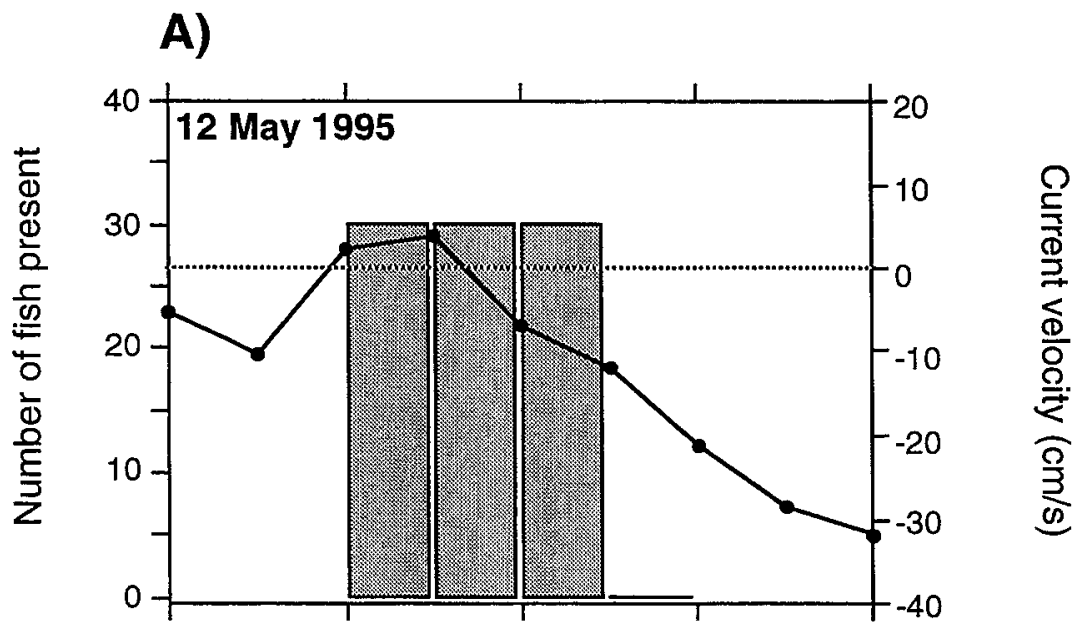

B)

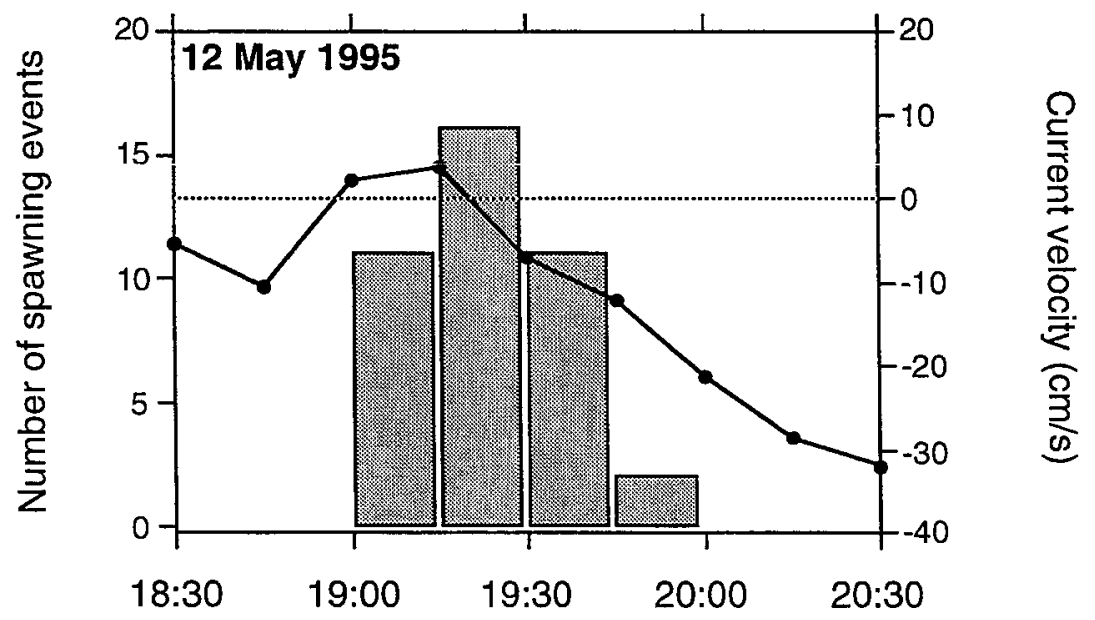


Figure 13. Spawns at different current speed categories. Spawning values are averages of 15-minute observations $( \pm S E$ ). Data used in this analysis is from days when spawning occurred, and in the case of species that selected certain flow directions for spawning, only current speed data from flows in the preferred direction were considered. Observed values are compared with a distribution based only on the sampling effort at different tidal times through a $\chi^{2}$-test; $p$-values are shown when significant. Asterisks indicate significance of $\chi^{2}$ residuals with a Bonferroni familywise error of 0.05 . 

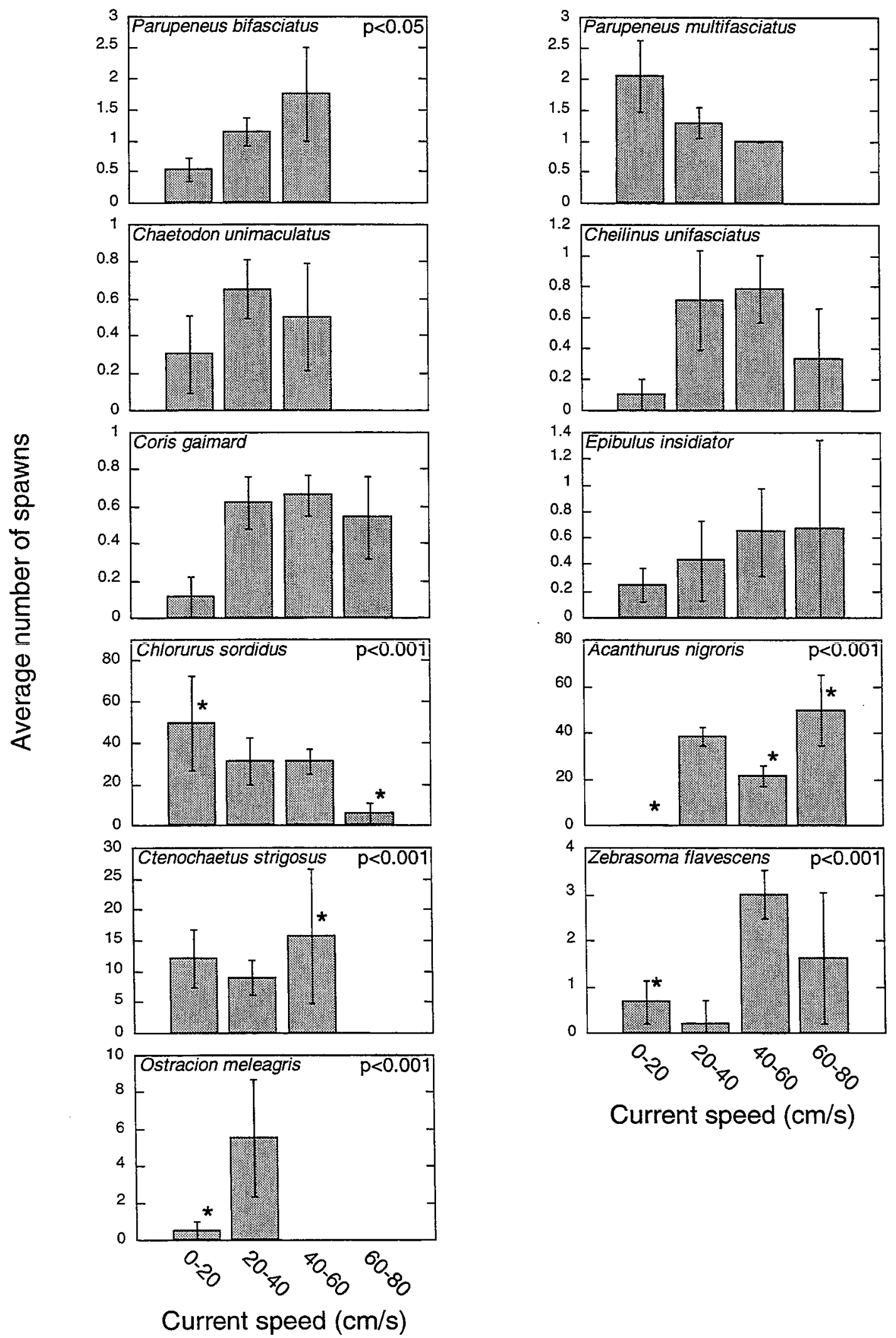

Current speed $(\mathrm{cm} / \mathrm{s})$ 


\section{CHAPTER 3}

\section{Predator-prey relations at a spawning aggregation site of coral reef fishes}




\section{ABSTRACT}

Predation is a selective force hypothesized to influence the spawning behavior of coral reef fishes. This study describes and quantifies the predatory activities of two piscivorous and three planktivorous species at a coral reef fish spawning aggregation site in Johnston Atoll (Central Pacific). To characterize predator-prey relations, the spawning behavior of prey species was quantified simultaneously with measurements of predatory activity, current speed and substrate topography.

Diel activity patterns and predator-prey relations varied among the predatory species analyzed. The activity patterns of piscivores, measured both as abundance and attack rates, were high during the daytime, decreased during the late afternoon hours and reached a minimum at dusk. The abundance of piscivores was significantly correlated with the abundance of prey for only one (Caranx melampygus) of the two piscivorous species, while the other species (Aphareus furca) did not respond to prey abundance. The selection of certain prey species by piscivores was consistent with two different hypotheses: the satiation of predators and the differences in spawning behaviors among prey species. Two of the three planktivorous species fed most actively at dusk, and selected as prey those species of reef fishes that produced eggs of large size. The third planktivorous species fed at all times of the day.

Spawning prey fishes were more abundant over substrates with complex topography where refuges from piscivores were abundant than over smooth substrates. Overall attack rates by piscivores on adult spawning fishes were higher than by planktivores feeding on recently released eggs. The diel spawning patterns displayed by reef fishes at the study site seem to be influenced by the diel activity and prey selection patterns of piscivores previously described. The highest diversity of prey species occurred 
at dusk, when piscivores were least abundant and overall abundance of prey fishes was lowest. 


\section{INTRODUCTION}

Predation is an important force in the evolution of fishes and in the regulation of fish populations in coral reef ecosystems (Hixon 1991). Predation affects fishes at different life history stages such as eggs and larvae (via planktivory) as well as juveniles and adults (via piscivory).

Predation of juvenile fishes in particular has been hypothesized to be a major factor controlling post-settlement processes that eventually determine the numbers of adult fishes on coral reefs (Hixon 1991, Jones 1991, Hixon \& Carr 1997). The effects of piscivores on adult fish populations can be direct, through the consumption of large numbers of adult fishes (Sweatman 1984, Sudekum et al. 1991, Kingsford 1992), or indirect, through influencing various behaviors of the prey species that affect their susceptibility to attacks, such as choice of habitat (Jones 1988, Connell \& Jones 1991) and feeding behavior (Sackley \& Kaufman 1996). Piscivory is also an important force in the evolution of fishes by selecting and promoting the evolution of defensive adaptations such as rigid spines, toxins and armors (Godin 1997, Smith 1997).

The effects of planktivores on fish populations can be direct, through the consumption of propagules (Hobson 1991), or indirect, by influencing the reproductive behavior of reef fishes (Johannes 1978).

Piscivory can be intense on adult reef fishes while they are spawning (Moyer 1987). The same traits that enhance mating success in fishes can also increase their susceptibility to piscivory (Lima \& Dill 1990), even though some relations between mating tactics of coral reef fishes and piscivory observed in the field contradict theoretical predictions on prey susceptibility (Clifton \& Robertson 1993). Predation of reef fish eggs in coral reefs can also be very intense during spawning (Moyer 1987, Robertson 1983). Different mating strategies (pair and group spawning) employed by pelagic-spawning reef 
fishes have been observed to receive different predation pressures by planktivores (Robertson 1983), but the cause for these differences between pair and group spawns remains unresolved (Shapiro et al. 1988). Information is needed to elucidate which moments of the spawning sequences of reef fishes are selected by attacking piscivores and planktivores.

Many hypotheses formulated to explain the reproductive behavior of reef fishes are based on risks from piscivorous or planktivorous predation, including explanations for the timing, location and behavior of reproduction in pelagic spawning fishes (Shapiro et al. 1988, Robertson 1991). Johannes (1978) hypothesized that the choice of spawning times and locations by coral reef fishes functions to minimize reef-based predation of their eggs by planktivorous fishes and invertebrates. In a similar way, various reef fish behaviors, including the choice of timing and location of spawning activities (Johannes 1978), have been hypothesized to be risk-minimizing responses to diel feeding patterns of piscivores (Hobson 1973).

Predation-related hypotheses explaining the timing of reproduction of reef fishes predict spawning to be restricted to (1) periods when predators are inactive, (2) periods when predators, although active, are satiated from previous feeding, or (3) periods when the ability of predators to detect or capture prey is somehow impaired. But too little information exists on the diel feeding patterns of reef predators and their relation with spawning prey to test these hypotheses (Robertson 1991).

Early observations of predation on schooling fishes from the Gulf of California, where a crepuscular peak in piscivorous activities occurs (Hobson 1968), led to the hypothesis that a similar crepuscular peak in piscivorous activity occurred in coral reef environments (Hobson 1973). This idea was substantiated in coral reefs by the observation of a midwater predator swimming close to the reef at twilight (Collette \& Talbot 1972) and the crepuscular peaks of activity of piscivores feeding on schooling prey with predictable 
twilight migrations over non-reef areas (Major 1977, Ogden \& Ehrlich 1977). But more recent studies quantifying diel activity rates of piscivores feeding on non-schooling reef fishes showed coral reef piscivores active during the daytime period, sometimes with reduced activity patterns during crepuscular hours (Sweatman 1984, Shpigel \& Fishelson 1989, Clifton \& Robertson 1993). Diel activity patterns of planktivorous fishes, including species that incidentally catch fish eggs, have been described in coral reefs (Hobson \& Chess 1978, Hobson 1991). But these descriptions of feeding activities do not include planktivores specialized in feeding on recently released eggs at spawning sites. An objective of the present study is to analyze in detail the diel activity patterns of piscivores and planktivores at reef fish spawning sites.

Flexible responses to different predatory risks are expected to occur in marine organisms with dispersive planktonic phases (Morgan \& Christy 1994, Warner 1991, 1997). But these same marine organisms have also been hypothesized to display fixed responses across entire geographical ranges (Warner 1997). Theoretical studies of predator-prey relations predict that activity patterns of predators should follow those of their prey (Werner 1992, Hugie \& Dill 1994). Some field studies of predatory behavior in coral reefs have found evidence for this correlation in predator-prey activity patterns for some species (Shpigel \& Fishelson 1989, Kingsford 1992, Clifton \& Robertson 1993), while other studies have shown predator activity patterns which are independent of prey activities (Sweatman 1984, Shpigel \& Fishelson 1989). At spawning aggregations of reef fishes where many different species concentrate to spawn at different times of the day, the existence of specific predator-prey interactions can result in unique activity patterns of both predators and prey.

Hypotheses regarding the effect of predation on the choice of spawning sites by reef fishes predict that they will (1) spawn from locations with abundant refuges from piscivores (Hugie \& Dill 1994), or (2) from locations with fast outflowing current speeds 
that will reduce the exposure of eggs to benthic predators at the spawning site (Johannes 1978). Small coral reef fishes typically use holes and crevices in the substrate as refuges when attacked by piscivores (Hixon 1991, Hixon \& Carr 1997). Many studies describe reef fishes spawning over specific substrate formations (see Shapiro et al. 1988), but no measurements of the availability of refuges at spawning locations exist. An objective of this study is to estimate the availability of refuges in both spawning and non-spawning sites. On many occasions reef fishes migrate to spawning aggregation sites which have strong currents (Robertson 1983, Thresher \& Brothers 1985, Moyer 1989, Bell \& Colin 1986, Colin \& Bell 1991), but within these aggregation sites current speeds have rarely been compared between discrete spawning and non-spawning areas (Appeldoorn et al. 1994).

The present study describes the behavior of two piscivorous and three planktivorous predators at a spawning aggregation site of reef fishes. I attempted to evaluate the effect of predators on the reproductive behavior of prey fishes by comparing the activities of predator and prey species present at a spawning aggregation site. The activity of pelagic spawning reef fishes in the area was monitored simultaneously with predator observations.

For this study, the hypotheses regarding predator-prey relationships among piscivores, planktivores and spawning fishes (Hobson 1968, Johannes 1978, Shapiro et al. 1988, Robertson 1991) are transformed into conceptual models (Figure 1) with alternative predictions that can be tested using simultaneous observations of predator and prey species at a single study site. The predictions for the relative timing of predator and prey activities are:

1. Predation occurs predictably on a daily schedule, independently of prey activity. This hypothesis implies that the diel feeding cycles of predators show no response to changes in prey behavior or capture success. Predators with this fixed response are 
expected to feed on many different organisms and not show strong preferences towards any specific prey species (Shpigel \& Fishelson 1989). If predation influences the timing of spawning of prey fish as hypothesized by Johannes (1978), prey are expected to spawn during moments of low predatory activities.

2. Predation is reduced at the end of the day as predators become satiated from previous feeding activities. As predators fill up their stomachs with prey, they are expected to become less responsive to prey activities (Curio 1976). Long periods of successful feeding should be followed by times of low predatory activities, allowing prey fish to spawn at this time with less predation risks (Robertson 1991). In daytime-active predators, satiation is expected to occur late in the afternoon or at dusk. Prey species that spawn at dusk would be exposed to reduced predation only if other prey fishes have been previously active during the daytime, causing satiation of the predators.

3. Predators change their activities in response to prey behavior. Various spawning-related behaviors affect variability in the vulnerability of prey to predators (Lima \& Dill 1990). Differences in prey vulnerability would consequently affect the feeding behavior of predators, so predatory attacks should be concentrated when prey do their most vulnerable behaviors. To test this hypothesis it is necessary to first address the question of which reproductive behaviors (if any) lead to an increase in prey vulnerability. Under this hypothesis, moments of high predatory activity are expected to occur when prey fishes perform vulnerable behaviors, whenever they might occur.

Whereas the models above focus on the temporal patterns in predator activity, complementary models can be cosntructed to address prey selectivity by predators. Factors such as species-specific differences in behavior, morphology or timing of spawning of prey species can affect predator preferences (Lima \& Dill 1990, Godin 1997, Smith 1997). The three previous models can be transformed to state that: predators will not select any specific prey species (Hypothesis 1); will select early-spawning species versus those 
spawning late in the day (Hypothesis 2); or will predominantly attack those species displaying the most vulnerable behaviors (Hypothesis 3). A fourth alternative hypothesis explaining prey selectivity by predators is:

4. Predation is influenced by prey morphology. Predation risks should vary with body morphology of prey. Piscivores should select species lacking morphological adaptations that make ingestion difficult, such as deep bodies, defensive spines or toxic substances (Godin 1997). Planktivores feeding on recently spawned eggs should select prey species in an analogous manner, selecting species with large visible eggs over those with small inconspicuous ones.

An expectation of this predator-selectivity hypothesis is that predators with flexible diel activity patterns (Hypothesis 3 ) should be independent of the activity patterns of species with significant anti-predatory adaptations, but be influenced by the activity patterns of those species without adaptations (Figure 1).

Predatory risks are expected to influence certain behaviors in prey fishes (Lima \& Dill 1990). One of the behaviors of prey at spawning grounds that can be affected by predation is the choice of spawning location:

5. Risk of predation determines the choice of spawning location by prey. Due to risks of predation by piscivores, fish should spawn at locations with abundant refuges (Hugie \& Dill 1994), where prey can seek protection when attacked. Due to risks of predation by planktivores, fish should spawn at locations with the fastest current speeds available, to minimize the time eggs are exposed to benthic planktivores on the reefs (Johannes 1978). These are two different responses by prey fishes to predatory pressures, and the adoption of one or the other strategy will indicate the relative importance of piscivory and planktivory in controlling the choice of spawning site by reef fishes. 


\section{Background on predatory species}

Two piscivorous species that were routinely observed attacking reef fishes at spawning aggregation sites at Johnston Atoll, Caranx melampygus (Carangidae) and Aphareus furca (Lutjanidae), were monitored for this study. Caranx melampygus is generally found in clear lagoons and seaward reefs across the tropical and sub-tropical areas of the Indo-Pacific (Myers 1991). The diet of C. melampygus consists mostly of shallow water reef fishes (Potts 1981, Sudekum et al. 1991) and this piscivore typically shows active roaming predatory behaviors over shallow reefs during daytime hours (Potts 1980, Holland et al. 1996). Aphareus furca is found in the same habitats across the tropical Indo-Pacific region (Myers 1991). Little information is available on the diet and predatory behaviors of this lutjanid, but casual observations by various researchers and during this study indicate that reef fish are an important component of their diet and they seem to be less mobile over the reefs than C. melampygus (Randall 1955, Hobson 1974, Potts 1981, G. Sancho personal observation). Other large transient piscivorous species that were sighted during this study, but not observed attacking reef fishes, included Triaenodon obesus (Hemigaleidae), Carcharhinus amblyrhynchos (Carcharhinidae), Caranx ignobilis, Caranx lugubris, Caranx sexfasciatus, Scomberoides lysan (Carangidae) and Sphyraena barracuda (Sphyraenidae).

Three species of planktivores were monitored in this study. Two mobile planktivorous species were observed following spawning fishes during their ascent and feeding on clouds of gametes: Melichthys niger and Melichthys vidua (Balistidae). These triggerfishes seem to feed only occasionally on pelagic eggs, since $70 \%$ of their diet consists of algae (Randall \& Klausewitz 1973). The third planktivorous species monitored was Dascyllus albisella (Pomacentridae), a small damselfish that feeds by picking individual plankters out of the water column. Pomacentrids are known to feed on drifting 
fish eggs (Hobson \& Chess 1978), and gut content analyses of $D$. albisella indicate that they are occasional consumers of planktonic fish eggs (Mann \& Sancho in prep.).

\section{METHODS}

Data collection for this study took place during April- May of 1994 and 1995 at Johnston Atoll (Central Pacific), in a reef channel which was used as a resident spawning aggregation site (Domeier \& Colin 1997) by various species of pelagic spawning reef fishes. This channel (Mustin's Gap) crosses the NW reef crest of the Atoll (Figure 2), and is $70 \mathrm{~m}$ long and $28 \mathrm{~m}$ wide, with an average depth of $4.5 \mathrm{~m}$. Substrate composition consists of a mix of live tabular coral formations dispersed among dead coral boulders and fine rubble. Currents at Mustin's Gap were bi-directional, influenced by both tides and waves (Chapter 2).

\section{Behavior of piscivores and prey}

Observations of the behavior of piscivores and prey were done by a single observer (G. Sancho) while diving with SCUBA. Behavioral sampling was limited to a rectangular sampling area of $170 \mathrm{~m}^{2}$, used for all observations of piscivorous predators and for the quantification of spawning by various reef species (Figure 2). The diver made observations from a fixed position located $5 \mathrm{~m}$ away from the sampling area, annotating every minute the presence of any piscivores above the sampling area during one-minute periods (score $=1$ ), or their absence (score $=0$ ). This one-zero scoring (Altmann 1974) was done continuously for two consecutive 15-minute periods. Abundance of piscivores was expressed as the percentage of one-minute sampling intervals when predators were present above the sampling area, out of a 15 -minute period. Attacks by piscivores on reef fishes inside the sampling area were recorded, as well as the specific motor pattern displayed by the intended prey fish at the moment of the attack. Two spawning-related 
motor patterns were identified in these observations. "Bobbing" consisted of courtshiprelated behaviors by pre-spawning fishes and involved fish interacting while swimming above the substrate ( 0.1 to $2 \mathrm{~m}$ approximately). This motor pattern combined what other authors described for Thalassoma cupido as "bobbing" and "milling" behaviors (Meyer 1977, Moyer 1987). "Rushing" occurred when two fishes (pair-spawning) or more (group-spawning) rapidly dashed upwards through the water column to release gametes at the apex of the rush ( 0.5 to $4.5 \mathrm{~m}$ above the bottom), after which the fish would quickly return to the substrate. Successful attacks or kills were recorded when ingestion of the prey by a piscivore was observed, or when after an attack the prey was observed inside the oral cavity of the piscivore.

In the spring of 1994, a total of 31 hours of behavioral observations of predators were done between dawn and dusk $(0700-2000 \mathrm{~h})$, while in the spring of $1995 \mathrm{a}$ total of 46.5 hours of observations were concentrated in the early afternoon $(1300-1630 \mathrm{~h})$ and dusk (1900 - 20:00 h) periods. Spawning and abundance data of prey species were simultaneously recorded during these observations periods (Chapter 2). Spawning sequences of various species were video-recorded in May of 1994.

Duration of spawning rushes was measured from the video-recordings by counting the total number of frames per rushing event. The time spent rushing by each species at the spawning grounds was estimated by multiplying the average spawning rush duration by the total number of spawns observed for each species in a given time. For this calculation, only data from times when spawning fish were present and actively spawning were used (Chapter 2).

\section{Behavior of planktivores}

During the observations of piscivorous fishes described above, all cases of predation by mobile planktivores (Melichthys niger and $M$. vidua) on recently released 
propagules observed were recorded. Data on egg sizes of different species spawning at Mustin's Gap were obtained from published values of the individual species if possible, or otherwise from a member of the same genus or family (Randall 1961, Thresher 1984, Leis \& Moyer 1985, Colin \& Clavijo 1988) .

The feeding behavior of Dascyllus albisella was studied differently at Mustin's Gap, since they do not swim with rushing fishes to feed on concentrated clouds of gametes but pick individual drifting eggs from the water column. Due to their site attachment behavior, individual $D$. albisella occupying specific territories were identified on different dates and their feeding behavior observed under various environmental conditions. Six different individuals were continuously monitored for two minutes at a time, recording any changes in their behavior (feeding, courting or resting) and their approximate position in the water column ( $\mathrm{cm}$ above substrate). Two-minute observation series were always made consecutively on all six individuals in approximately 15 to 20 minutes. From 20 April to 20 May of 1995, a total of 27 series of observations of damselfish feeding behavior were made, at times ranging between $1300-2000 \mathrm{~h}$.

\section{Topographical and current speed measurements}

To study the potential effects of predation in the choice of prey spawning grounds, I measured the topographical complexity of the substrate, water velocity above the substrate and abundance of spawning reef fishes at the reef channel. A large section $\left(1820 \mathrm{~m}^{2}\right)$ of the Mustin's Gap reef channel was delimited and divided into 10 defined sampling areas (Figure 2). The bottom topography was quantified using a modification of the ratio of linear versus contoured distance technique (Risk 1972, Luckhurst \& Luckhurst 1978, Leum \& Choat 1980, Connell \& Jones 1991). This method was chosen because it is highly sensitive to detecting bottom structures with deep crevices and holes (McCormick 1994), which are used as refuges by prey fish (Hixon \& Beets 1989, Hixon 1993). A total 
of five quadrates $\left(1 \mathrm{~m}^{2}\right)$ were randomly positioned in each of the 10 sampling areas. The contoured distance was measured with a fine-link chain applied over the substrate along the two middle axes $(1 \mathrm{~m})$ of all fifty quadrates. A topographic index (TI), referred elsewhere as substrate rugosity index, was calculated as the ratio of linear distances $(1 \mathrm{~m})$ to contoured distances. Flat surfaces have values of 1 , while more complex surfaces will have values closer to 0 .

Two current meters (S4 InterOcean, San Diego) were mounted simultaneously on PVC tripods at two contiguous sampling areas with different topographic complexity values (Figure 1, Table 4). The first current meter was mounted $1.5 \mathrm{~m}$ above a complex substrate area composed of broken coral heads, while the second one was located $1.7 \mathrm{~m}$ above a smooth substrate composed of coral rubble. They recorded current velocity every second. Simultaneous data used for comparative analyses were recorded on May 21 (1005 - 1105 h) and May 25 (1345 - 1459 h) of 1994, for which consecutive one-second recordings of current speed were combined into 1 minute averages.

Fish censuses at Mustin's Gap were performed on 14 occasions during May 1995 by swimming down the reef channel and estimating the number of fishes above each of the ten sampling areas. Sampling was done in the afternoon $(1300-1600 \mathrm{~h})$ and only fish showing courting and spawning behaviors were censused.

\section{Data analyses}

All statistical procedures were done according to Sokal \& Rohlf (1995). Observed diel distributions of predatory activities were compared with expected distributions, based solely on the relative sampling effort, by using G-tests for goodness of fit, modified with a William's correction. To detect differences between daytime and dusk predatory activity rates, Mann-Whitney $U$ tests were used. The statistical independence of pairs of variables was analyzed using two way G-tests for independence at a 95\% significance level. The 
distribution of successful piscivorous attacks at different time periods and among different prey species was analyzed by a Fisher's exact probability test. Simultaneous current speed recordings were compared through a paired t-test analyses for equal variances. Significant correlations among variables were established through Spearman rank correlation tests.

\section{RESULTS}

Piscivores

A total of 254 attacks by piscivores were observed on 5 different prey species: Chlorurus sordidus, Scarus psittacus (Scaridae), Acanthurus nigroris, Ctenochaetus strigosus and Zebrasoma flavescens (Acanthuridae). All five species can be classified as predominantly group spawners at Mustin's Gap, and all observed attacks occurred during spawning related behaviors (bobbing or rushing) of the prey, with no attacks observed on feeding or migrating fishes. The two piscivorous species, Caranx melampygus and Aphareus furca, had similar attack rates during 1994 and 1995 (Table 1). The proportion of attacks by C. melampygus and A. furca (50 versus 32 attacks in 1994; 123 versus 49 in 1995) did not vary significantly between the two sampling years (G-test of independence, $\mathrm{p}>0.05)$.

Ten of these piscivorous attacks resulted in the successful capture and ingestion of prey (Table 1). The total success rate of attacks, defined as proportion of attacks leading to prey capture, was $3.9 \%$. The success rates for C. melampygus ( $4.0 \%$ ) and $A$. furca (3.7 $\%)$ were not significantly different (G-test of independence, $p>0.05$ ).

Diel abundance and attack distributions were significantly different from expected distributions based solely on the sampling effort at each time category for both $C$. melampygus and A. furca, and for both years of sampling (G-test; $\mathrm{p}<0.001$ ). The abundance of $C$. melampygus at the spawning grounds during 1994 increased along the day, reaching a maximum during the early afternoon $(1300-1500 \mathrm{~h})$, then decreased in the 
later afternoon, reaching a minimum at dusk (Figure 3). Abundance of $A$. furca was constant along all daytime periods, abruptly decreasing at dusk (Figure 3). In 1995, the abundance values of $C$. melampygus and $A$. furca were significantly higher during the afternoon than at dusk (Mann-Whitney $U$ test; $p<0.001$ for both species; Figure 4).

The timing of attacks on reef fishes was similar to the abundance distributions of the attacking piscivores. In 1994, C. melampygus attacked spawning fishes during the morning and the early part of the afternoon, with most of predatory activity occurring at the time period when they were most abundant $(1300-1500 \mathrm{~h})$. Aphareus furca had its highest attack rates in the early morning $(0700-0900 \mathrm{~h})$ and in the afternoon (1500 - 1700 h). During 1994 no attacks were observed for either species after $1700 \mathrm{~h}$ (Figure 3). In 1995, A. furca was only observed attacking during the afternoon, with no attacks at dusk, while C. melampygus was observed attacking spawning fish at dusk. Both species had significant lower attack rates at dusk than during the daytime period (Mann-Whitney U test; $\mathrm{p}<0.004$ for C. melampygus and $\mathrm{p}<0.02$ for $A$. furca; Figure 4).

All successful attacks (kills) occurred during the daytime period (between 1107 and $1529 \mathrm{~h}$ ), except for one attack by Caranx melampygus directed on three rushing Ctenochaetus strigosus which occurred at $1934 \mathrm{~h}$ and resulted in the capture of one spawning individual. But this difference in the number of successful attacks by piscivores at daytime and dusk was not statistically significant (Fisher's exact probability test; $p>0.05$ ) when compared with the number of observational samples recorded during each diel period.

To evaluate which prey were most vulnerable to attacks, I measured the duration of the spawning rush for different species, which varied between 0.8 and 2 seconds in duration (Table 2). Combining these data with the number of spawns observed in the observation area, the proportion of time spent rushing by each species while aggregated at the spawning site was calculated (Table 2). The proportion of time spent by different prey 
species rushing to release gametes in the water column varied between $7.9 \%$ and $0.8 \%$ of the total time present at the spawning sites.

Of all the attack sequences observed in their entirety, 210 attacks ( $84.7 \%$ ) occurred on prey while they were ascending into the water column in a spawning rush, while only $38(15.3 \%)$ occurred on fish that were involved in pre-spawning related behaviors (bobbing and milling). Comparing the proportion of attacks by piscivores during spawning rushes with the actual time spent by each species rushing (Table 2), a significant difference between the two distributions (G-test; $\mathrm{p}<0.001$ ) indicated that predators preferentially attacked their prey while they rushed above the substrate, and they avoided attacking fishes located near the substrate. This selection for attacks on rushing fish is still significant even if it is considered that spawning fish could spend up to $50 \%$ of their time rushing to release eggs (G-test; $\mathrm{p}<0.001)$.

Most of the attacks ( $93.9 \%$ ) by piscivores were directed towards two species: Chlorurus sordidus and Acanthurus nigroris, the two most active spawning species at Mustin's Gap (Table 3), accounting for $80.2 \%$ of the total number of spawns by group spawning species at Mustin's Gap. Comparing the number of attacks observed with the number of spawns by each prey species, both C. melampygus and A. furca were found to select $C$. sordidus and $A$. nigroris as prey items with respect to the other group-spawning species (G-test of independence, $\mathrm{p}<0.001$ ).

Considering the total number of spawns observed, I calculated the proportion of spawning rushes that were attacked by piscivores for each individual prey species (Table 3). Chlorurus sordidus (3.0\%), Acanthurus nigroris (2.4\%) and Scarus psittacus (5.3\%) suffered significantly more attacks per spawning rush (G-test of independence, $p<0.001)$ than Ctenochaetus strigosus ( $0.6 \%)$ and Zebrasoma flavescens $(0.3 \%)$.

One attack was observed on a pair spawning event and one attack on a group of three spawning individuals, but all other piscivorous attacks occurred on groups of four or 
more spawning fishes. Comparing this distribution of attacks with the number of spawns involving two and three spawners (494) versus those with more than four individuals (8501), piscivores were found to preferentially attack their prey when they were spawning in groups, rather than in pairs or trios (G-test of independence, $\mathrm{p}<0.001$ ).

Considering only the attacks for which the identity of the intended prey was clearly identified by the observer (248 attacks), the total attack success by piscivores was $4.0 \%$ (Table 3). The differences in attack successes of piscivores on different prey species were not statistically significant (Fisher's exact probability test; $p>0.05$ ), even though they varied between $17 \%$ (C. strigosus) and $0 \%$ (S. psittacus and Z. flavescens). The probability of a successful attack occurring during a spawning rush for all group-spawning species was estimated to be $0.1 \%$.

\section{Planktivores}

Melichthys niger formed aggregations of variable size (from 2 to 15 individuals)

and spent most of their time close the surface among breaking waves as described by Lubbock (1980), while $M$. vidua were usually observed in pairs or as single fish close to the substrate. The attack behaviors of the two planktivorous species on planktonic gametes were almost identical: planktivores would quickly approach groups and pairs of spawning fishes during their spawning ascent and proceed to bite in the center of the released cloud of gametes as it drifted down current.

Attacks were observed at all times of the day, from 0922 - $1941 \mathrm{~h}$, but a higher proportion of attacks occurred during the dusk period than during daytime hours (G-test, $\mathrm{p}<0.005$; Figure 5). A total of 48 attacks on eggs by $M$. niger (25 attacks) and $M$. vidua (23 attacks) were observed at Mustin's Gap over the two sampling years, on both groupspawning (25 attacks) and pair-spawning events (23 attacks). The comparison of the proportion of attacks with the total number of group (7521) and pair (300) spawns 
recorded at Mustin's Gap by the six species attacked by triggerfishes, revealed that triggerfishes selected pair-spawning events over group-spawns (G-test of independence, $\mathrm{p}<0.001)$.

The selection of prey was further explored by studying the proportion of spawns of each individual species whose gametes were eaten by mobile planktivores. Triggerfishes preyed on high proportions of spawns of those species which had larger egg sizes (Figure 6), independently of their abundance at the spawning grounds. Families with large eggs observed spawning at Mustin's Gap (Bothidae, Ostracidae and Aulostomidae) are mostly composed of pair spawning species (Sancho in prep.). Families with low proportions of spawning rushes subjected to planktivorous attacks all had small eggs, and contained pairspawning (Mullidae) and group-spawning (Scaridae and Acanthuridae) species. Two other families (Labridae and Chaetodontidae) with species which were often observed spawning in pairs at Mustin's Gap have small egg volumes (range of $1.20-1.32 \mathrm{~mm}^{3}$; Thresher 1984, Colin \& Bell 1991), and were not attacked by planktivorous triggerfishes.

The planktivorous damselfish $D$. albisella spent $99.1 \%$ of its time feeding in the water column, and no significant differences in the average time spent feeding were found between afternoon and dusk periods (Table 4). Damselfishes fed almost continuously during the day and no indications of satiation were observed.

The average feeding height above the substrate of all six monitored damselfishes pooled together was $0.7 \mathrm{~m}$. For each individual fish the feeding height at dusk was lower than at daytime, but this difference was statistically significant only for one of the six fishes (Mann-Whitney $\mathrm{U}$ test; $\mathrm{p}<0.05$ ). Pooling all six fish together, a significantly smaller average feeding height occurs at dusk than during afternoon hours (Table 4), with an average difference of $25 \mathrm{~cm}$. The average current speeds between daytime and dusk sampling periods were not significantly different (Table 4). 
Current speed was correlated with the feeding height of $D$. albisella, with fish feeding closer to the substrate at higher current speeds (Figure 7). At daytime the average difference in feeding heights during slow $(0$ to $20 \mathrm{~cm} / \mathrm{s})$ and fast $(>40 \mathrm{~cm} / \mathrm{s})$ current speeds was $63 \mathrm{~cm}$ (Mann-Whitney U test; $\mathrm{p}<0.001$ ).

\section{Diel spawning patterns}

A total of 3754 spawns by a total of 20 species were observed in 1994 during monitoring of predatory activities at the spawning grounds. The diel distributions of spawning fish abundance and spawning activity (Figure 8) were significantly different (Gtest; $\mathrm{p}<0.001$ ) than those expected from considering only sampling effort. Highest abundance and spawning rate values occurred during the afternoon hours (1300 - 1900), with the lowest values recorded at dusk. The diel distribution pattern of the two most abundant species spawning at Mustin's Gap (C. sordidus and A. nigroris) had shorter periods of peak abundance and activities $(1300-1700 \mathrm{~h})$ and a more drastic decrease in activities in the late afternoon period $(1700-1900 \mathrm{~h})$ than the total prey abundance distribution (Figure 8). Neither of these two species was observed spawning at dusk.

The number of different species observed spawning over discrete time intervals increased as the day progressed (Figure 8). Only three species spawned in the morning hours, while a maximum of 16 species were observed spawning at dusk.

\section{Spawning grounds}

The abundance of group-spawning fishes was significantly correlated (Spearman rank correlation $\mathrm{r}=-0.71 ; \mathrm{p}<0.05)$ with the Topographical Index (TI) measurements at Mustin's Gap (Figure 9). Fish avoided spawning above the areas with the lowest topographical complexity values, and were more abundant in areas with abundant crevices and holes (low TI values). This relation was also significant when considering individually 
the abundance of the two most abundant group-spawning species during May of 1995: Chlorurus sordidus and Zebrasoma flavescens (Spearman rank correlation $\mathrm{r}=-0.68$ and $\mathrm{r}$ $=-0.79$ respectively; $\mathrm{p}<0.05)$.

Mean current velocities measured simultaneously at two adjacent sampling areas with different substrate morphologies (site $1: \mathrm{TI}=0.48$; site 2 : $\mathrm{TI}=0.74$ ), were significantly different on each of two independent sampling days (Table 5). The location with lower topographical complexity (site 1$)$ had slightly faster currents $(6 \mathrm{~cm} / \mathrm{s}$ average difference) than the more complex area (site 2), while density of spawning fishes was much lower at site 1 than at site 2 ( 0.06 and 0.77 fish per $\mathrm{m}^{2}$ respectively).

\section{DISCUSSION}

\section{Piscivores}

An initial objective of this study was to describe the diel activity patterns displayed by predators at spawning aggregation sites of coral reef fishes. Predatory activities by Caranx melampygus and Aphareus furca were high during the day, decreased during the late afternoon and were significantly lower at dusk. These results do not rule out the possibility of piscivores feeding actively at dusk somewhere else in the reef system, but clearly predatory pressure decreased at the spawning grounds in the later part of the day. These data are consistent with the diurnal activity patterns shown by other piscivores that feed on diurnal coral reef fishes (Sweatman 1984, Shpigel \& Fishelson 1989, Clifton \& Robertson 1993). Specifically, C. melampygus showed high daytime predatory activities at Aldabra Atoll (Potts 1980, 1981) and a diet mainly composed of diurnal reef fishes in the Hawaiian Islands (Sudekum et al. 1991). Sonic tracking studies in Hawaii showed how C. melampygus actively patrol an extensive territory during the daytime, while at nighttime they display 50\% lower activity rates than at daytime, and are restricted to a distinct smaller territory (Holland et al. 1996). The results from the present study are inconsistent with 
studies arguing for increased piscivore activities during crepuscular hours in coral reefs (Collette \& Talbot 1972, Hobson 1973), an idea derived from observations of predators feeding in temperate waters (Hobson 1968) and supported by studies of piscivores feeding on schooling prey speciẹs over non-reef areas (Major 1977, Ogden \& Ehrlich 1977).

The first hypothesis regarding diel activity patterns of piscivores states that predation occurs predictably on a daily schedule and is independent of prey activity (Hypothesis 1). The general patterns of abundance of piscivores and prey were similar, with higher abundance values during the daytime than at dusk. To further investigate the relation between predator and prey abundance, I compared the abundance of the two most abundant prey species selected by piscivores ( $C$. sordidus and A. nigroris) with the specific values of predator abundance through a linear regression analyses during a short time scale (15 minutes), using 123 paired measurements collected in 1994.

For C. melampygus the joint abundance of the two prey species explained an important portion $\left(\mathrm{R}^{2}=0.52\right.$, linear regression) of the variance in abundance of this predator at the spawning grounds (Figure 10). This result indicates that the abundance of this piscivore is most likely dependent on the abundance of its prey. The reef channel of Mustin's Gap is likely to be part of a larger daytime hunting territory for various $C$. melampygus individuals, which patrol through it in search of food (Potts 1980). When large groups of suitable prey species aggregate to spawn (Chapter 2), patrolling $C$. melampygus will likely locate them and stop patrolling to concentrate their hunting activities in the channel to exploit this food resource. This flexible activity pattern regulated through the abundance of prey could also explain the low abundance of $C$. melampygus at dusk, since this is the time of day when overall prey abundance is lowest. This prey-dependent change in predator abundance has been observed in other transient carangids feeding on juvenile reef fishes (Hixon \& Carr 1997). 
Prey abundance was not significantly correlated with the pattern of abundance of $A$. furca $\left(\mathrm{R}^{2}=0.004\right.$, linear regression) when measured in 15-minute intervals (Figure 10), indicating that $A$. furca has a daytime activity pattern that is not closely controlled by short term variations in prey abundance at the study site. Generalist piscivores which do not select for any specific reef fishes have been shown to have regular diel activity patterns (Sweatman 1984, Shpigel \& Fishelson 1989). Fish and crustaceans have been found in stomach contents of $A$. furca (Randall 1955, Hobson 1974), but it is presently unknown which is the relative importance of reef fishes in the overall diet of this predator. The limited information describing $A$. furca as a territorial predator with low mobility (Randall 1955, Hobson 1974, Potts 1981, G. Sancho personal observation) supports the supposition that they adapt a diel activity pattern independent of prey activity. It is likely that $A$. furca individuals were present at the spawning grounds at all times, but visual censuses only counted those individuals swimming above the substrate, during feeding and non-feeding periods, and ignored those hiding among coral formations.

Successful feeding by these diurnal piscivores can potentially lead to their satiation, which would result in a decrease in their feeding activity toward the end of the day (Hypothesis 2). Low predation activity levels (measured as abundance and attack rates) found during the late afternoon and dusk periods may indicate the occurrence of satiation of piscivores at Mustin's Gap. The number of prey items ingested per day by reef piscivores probably varies with the predator-prey size relation, but ingestion rates of one or two prey fish per day are common values for coral reef piscivores (Sweatman 1984, Kingsford 1992). With a measured capture rate of 3.9\%, piscivores at Mustin's Gap would need to perform approximately 25 to 50 attacks to reach their estimated daily ration, a figure comparable to attack rates by diurnal ambushing lizardfishes, which on average attempt 27 attacks on small reef fishes every day (Sweatman 1984). 
Piscivorous activities can be directly related to specific behaviors of their prey (Hypothesis 3), since different spawning related behaviors of potential prey affect their vulnerability to predation (Lima \& Dill 1990, Clifton \& Robertson 1993). Piscivores preferred to attack reef fishes when these rushed up into the water column to release gametes, which constitutes an example of predator-prey dependence. Piscivores attack prey while they temporarily become vulnerable by abandoning the reef substrate, where refuges from predation exist (Major 1978, Hixon 1991, Hixon \& Carr 1997). At Mustin's Gap successful attacks by piscivores only occurred on individuals engaged in spawning rushes. In a similar study, Moyer (1987) described the same selection by piscivores of attacking during the rushing movements of their prey, but successful attacks were only observed on reef fishes that were bobbing close to the substrate. The difference in results is probably due to differences in predatory behaviors. Both C. melampygus and A. furca are large mobile predators, and mostly performed midwater, high-speed swimming attacks. All piscivores from Moyer's study were small cryptic resident predators with ambushing attack behaviors, some with striking areas limited to a distance of only 6-7 cm from the substrate. The specific hunting behavior of different piscivores is likely to determine which behavioral motor pattern of spawning prey is most susceptible to predation.

The abundance of Caranx melampygus was positively correlated with the abundance of Chlorurus sordidus and A. nigroris (Figure 10). The abundance of groupspawning fishes at Mustin's can be considered a spawning related behavior, since they migrate to this location to spawn (Chapter 2). Therefore, C. melampygus seemed to modify its hunting behavior in response to changes in behavior of its prey (Hypothesis 3). The abundance of $A$. furca was independent of changes in prey abundance at the spawning grounds, indicating that the presence of this predator was not affected by spawning activities of reef fishes (see previous discussion). 
Piscivores selected prey spawning in groups versus those spawning in pairs, indicating that mating behavior can affect predation patterns. Stomach content analyses of Caranx bartholomaei revealed that male parrotfishes that typically spawn in groups were predated more often than males spawning in pairs (Clifton \& Robertson 1993). Both results indicate that group-spawning is a riskier mating tactic than pair-spawning. These differential predation risks could explain why pair-spawning tactics are common among certain reef species, even though group-spawns provide significantly higher fertilization rates of eggs than pair-spawns (Marconato et al. 1997).

Piscivores showed a certain specificity when attacking group-spawning species: $C$. sordidus, S. psittacus and A. nigroris were selected as prey over C. strigosus and $Z$. flavescens (Table 3). This selectivity pattern can be explained according to interspecific differences in timing of spawning and spawning behavior of the prey.

Predator satiation (Hypothesis 2) can explain the differences in attack rates suffered by group-spawning prey species. The prey species that received high attack rates by piscivores spawned during the morning and early afternoon hours, while the two species that suffered low attack rates spawned late in the afternoon and at dusk (Chapter 2), when piscivores were potentially satiated.

Because of the behavioral selectivity shown by piscivores at Mustin's Gap for attacking spawning fishes in the water column, the total time spent by each individual prey species rushing up in the water column to spawn (Table 2) can be considered an estimate of prey availability to piscivores (Hypothesis 3). Of the four prey species for which the proportion of time spent in the water column was calculated, attacking piscivores selected the two species which spent most time rushing up in the water column.

Certain anti-predatory morphological adaptations are expected to reduce the risk of predation for certain species (Godin 1997). Patterns of predatory activity were predicted to depend on the behavior of vulnerable species (Hypothesis 4). But the observed patterns of 
prey selectivity by piscivores indicated that prey morphological characteristics were of low importance to piscivores. The morphological characteristics of surgeonfishes did not protect them from piscivorous activity as expected: $A$. nigroris suffered high attack and capture rates by piscivores, plus a capture event of a $C$. strigosus individual by $C$. melampygus was observed. Selectivity of different group-spawning species by piscivores did not seem controlled by prey morphology at Mustin's Gap.

\section{Planktivores}

Mobile planktivorous triggerfishes (Melichthys niger and $M$. vidua) were active at all times of day, and showed a higher proportion of attacks at dusk. These triggerfishes seem to feed only occasionally on pelagic eggs, since $70 \%$ of their diet consists of algae (Randall \& Klausewitz 1973). At Mustin's Gap both species were observed feeding on recently spawned eggs, but often they would feed in midwater on drifting clumps of algae, and on occasion they were observed biting algae directly on the coral substrate. The relative importance of fish eggs in the diet of triggerfishes at spawning aggregation areas is unknown, but satiation (Hypothesis 2) did not seem to occur in these predators.

Planktivores have been hypothesized to feed less actively and to be less effective in locating eggs at dusk (Johannes 1978, Lobel 1978, Robertson 1983, Colin \& Clavijo 1988), but this does not seem to be the case with planktivorous triggerfishes at Mustin's Gap.

Triggerfishes directed their feeding efforts towards those fish species with large egg sizes. This selection of prey explains the diel activity pattern of these planktivores, since species with large eggs predominantly spawned at dusk in Mustin's Gap (Sancho pers. obs.), when triggerfishes were most active. These results indicate that triggerfishes displayed an activity pattern that matched the activity of prey species with a certain morphological characteristic that made them more vulnerable and attractive to these planktivores (Hypothesis 4). Large eggs are probably easier to locate and ingest by these 
planktivores, since their mouths are not protrusible and their teeth are designed to bite hard surfaces. Their feeding behavior corroborates this idea, since they only prey upon clouds of recently spawned eggs while they are still in high concentrations. The selection of prey species was independent of prey abundance, which implies that triggerfishes can recognize the identity of fishes when rushing.

Mobile planktivores attacking gametes from two surgeonfish species at Palau showed intraspecific preferences for gametes originated from group-spawning rushes over those produced in pair-spawning rushes (Robertson 1983). At Mustin's Gap not enough information was available to compare group and pair spawning predation rates within a single species (intraspecific comparison), but considering all spawning species together (interspecific comparison), planktivorous triggerfishes selected pair-spawns to prey upon, which would indicate a preference based on the behavior of their prey (Hypothesis 3). But this difference is likely due to the preference of triggerfishes for species with large egg sizes, which predominantly spawned in pairs at Mustin's Gap (Sancho in prep.). Other spawning sites where mobile planktivores are abundant (Colin 1978, Robertson 1983, Moyer 1987) have planktivorous species which are more adapted to the ingestion of individual planktonic particles from the water column than triggerfishes (Hobson 1991), and will readily prey upon gametes from species with small egg sizes (Colin 1978, Robertson 1983, Moyer 1987). Preference by planktivores for pair-spawning species was likely caused by differences in egg characteristics (this study), while preference by planktivores for group-spawning behaviors within a single spawning species was likely caused by the simpler visual localization of gametes released in group-spawns versus pairspawns (Robertson 1983). The selection of certain prey species over others is expected to vary among different spawning locations according to the composition of the planktivorous fish community and their dietary preferences. 
Dascyllus albisella is a planktivorous damselfish that feeds on individual zooplankters as they drift over the reef. These planktivores were observed feeding continuously in the water column every day until late at dusk. Dascyllus albisella seemed to have a predictable feeding schedule that was independent of prey activities (Hypothesis 1). These planktivores did not show any signs of feeding satiation as the day progressed. Feeding height of planktivorous damselfishes is hypothesized to be controlled by piscivorous predation risks (Sackley \& Kaufman 1996) and current strength (Hobson \& Chess 1978). The average feeding height of damselfishes measured at Mustin's Gap decreased at dusk, potentially due to reduced detection abilities of piscivores in twilight conditions (Pitcher \& Turner 1986). But this decrease in feeding height with decreasing light levels was smaller that the decrease caused by fast current velocities. It is still uncertain how important benthic planktivores are in determining the survivorship of propagules, or whether a reduction in feeding height of planktivores would have any effect. But with regard to planktivorous damselfishes, predation risks for drifting eggs were potentially lower during high current speeds than at crepuscular light levels.

\section{Choice of spawning location by reef fishes}

The choice of spawning locations within a spawning aggregation site by groupspawning reef fishes is hypothesized to (1) reduce reef-based predation of eggs (Johannes 1978) or to (2) reduce predation risks on adult spawners (Hugie \& Dill 1994). The spatial abundance pattern of group-spawning fishes along the channel of Mustin's Gap was correlated with the topographical complexity of the underlying substrate at small scales (1020 meters). The significant positive result suggests the importance of refuge availability in determining the spawning location of reef fishes, since fish attacked by transient piscivores escape by swimming into crevices and holes among the corals (Hixon 1991, Hixon \& Carr 1997). Topographic complexity and availability of holes have been also shown to 
positively correlate with survivorship of juvenile and adult fishes in non-spawning situations (Luckhurst \& Luckhurst 1978, Roberts \& Ormond 1987, Hixon \& Beets 1989, Connell \& Jones 1991, Buchheim \& Hixon 1992, Hixon 1993, Tupper \& Boutilier 1997).

Locations with fast current speeds are expected to minimize the exposure of eggs to reef based predators (Johannes 1978). Current speed data from two adjacent locations with different topography showed that the site with low topographical complexity and fastest current speeds was not used by spawning fishes. Topography, and not current velocity, appeared to influence the choice of spawning sites at Mustin's Gap.

\section{Effects of predation on reef fish populations}

Predation pressures at spawning aggregation sites seem to vary greatly among different geographical locations (for review see Shapiro et al 1988, Robertson 1991). In the present study piscivores attacked $2.3 \%$ of all spawning rushes, and mobile planktivores attacked the eggs from $0.6 \%$ of all spawning rushes. But these general predatory pressures should be considered cautiously, since they could greatly increase for specific spawning species that are selected as prey by predators (see previous discussion). Overall, spawning can be considered a dangerous activity if compared with other nonreproductive behaviors (foraging, migration), since predatory attacks on adult fishes were always directed towards fishes displaying spawning-related behaviors.

In the case of piscivores feeding on spawning fishes, the overall attack success rate measured in this study was $3.9 \%$. The estimated mortality risk per individual spawning rush for group-spawning fishes at Mustin's Gap was $0.1 \%$. By estimating the number of spawning rushes that an individual fish makes in a spawning season, the yearly mortality rates of individual adult fishes due to piscivory at spawning aggregations sites can be calculated. Considering that about 15 fishes are typically involved in a group spawning rush (G. Sancho personal observation), a four to six month spawning season typical of 
many Hawaiian fishes (Lobel 1989, Sadovy 1996, Appendix 2) and a maximum spawning rate for female fish of one spawning rush per day (Hoffman \& Grau 1989), the chances of an individual female of being killed while performing a spawning rush during a whole spawning season are low $(1.2-0.8 \%)$. But the estimated annual spawning mortality rates for group-spawning males that can spawn between 20 and 50 times per day are very high $(15-60 \%)$. These calculations indicate that predation of adult male fishes by large piscivores at spawning aggregation sites could be of crucial importance for population regulation of group-spawning species at Mustin's Gap. Prey selectivity by carangids feeding on parrotfishes in Panama confirm the higher risks of male versus female fishes during spawning activities, specifically of males participating in group spawns (Clifton \& Robertson 1993)

\section{Effects of predation on timing of spawning of reef fishes}

An important question regarding the timing of spawning of reef fishes is whether they spawn at times when predation risks are reduced (Johannes 1978, Robertson 1991). The degree of prey selectivity by predators can be important, since species that are highly selected by flexible predators are unlikely to be able to reduce predatory risks by modifying their timing of spawning. Also, species with low vulnerability to predation should not be influenced by predatory risks and should spawn independently of predatory activities (Gladstone \& Westoby 1988).

Dusk was the time when predator abundance and activity levels of piscivores were lowest. Dusk was also the period of the day with lowest overall abundance of spawning fishes and lowest spawning intensities, which could potentially be an explanation for the reduced activity by piscivores during the dusk period at the spawning grounds. At Mustin's Gap, the largest diversity of spawning fishes occurred at dusk, a characteristic of other multispecific spawning sites (Johannes 1978, Lobel 1978, Thresher 1984). 
These observations support the hypothesis that piscivores principally feed during the daytime on vulnerable group-spawning species, and then due to either satiation, decreasing prey abundance or changes in prey composition, piscivores reduce their feeding activity during the late afternoon. Dusk could be used as the time for spawning by many species which exist in low abundance, which would benefit from the reduced piscivorous activity levels at the spawning grounds during this time period. This potentially constitutes an example of how the abundance of certain species can affect the mortality rates of other species (Kingsford 1992).

Planktivores showed different activity patterns than piscivores. Because of the high selectivity shown by triggerfishes for certain prey species, the feeding activity of these planktivores affected a small number of the spawning species. Spawning reef fishes with small eggs seem to potentially benefit from reduced predatory rates of their gametes during the daytime and dusk periods, since triggerfishes selectively attacked species with large eggs. Planktivores which feed indiscriminately at all times of the day such as D. albisella are unlikely to affect the timing of spawning of reef fishes.

Comparative studies at different locations are needed to further resolve the generality of the predator-prey relationships occurring at the spawning aggregation site described in this study. Changes in predatory pressures are expected to have behavioral and population effects on coral reef fish communities. Due to increasing fishing pressures in the coral reef environments the populations of predators are declining, in particular of large-sized piscivores (Roberts 1997). Predator-prey interactions in environments with abundant predatory populations, such as marine reserves and remote reefs, should be compared with those from locations impacted by fishing activities.

\section{SUMMARY}


This study describes different predator-prey relations occurring at a spawning aggregation site. The large transient piscivore Caranx melampygus displayed a flexible daytime predatory activity pattern which was correlated with the abundance of selected prey species. The other main piscivore, Aphareus furca, had a daytime feeding activity pattern which was independent of prey abundance. Potential explanations for the low abundance of piscivores during the dusk period include satiation of piscivores, changes in prey abundance and interspecific differences of prey spawning behaviors. Piscivores showed preferences toward certain prey species, but it is unclear if this selectivity was caused by satiation processes or prey behavioral characteristics. Mobile planktivorous species (Melichthys niger and $M$. vidua) selected prey species that released large eggs. These planktivores displayed a flexible diel feeding pattern with peak activity rates occurring at dusk, the time when species with large eggs spawned. In contrast, the planktivorous damselfish Dascyllus albisella fed continuously during the daytime and dusk periods, independently of the spawning activities occurring at the observation site. Overall, predation rates by piscivores on adult prey were higher than those by planktivore feeding on recently released eggs. Piscivory was inferred to be an important selective force affecting certain spawning behaviors of prey species, and to potentially have an impact on populations of group-spawning prey species. 


\section{BIBLIOGRAPHY}

Altmann, J. (1974). Observational study of behavior: sampling methods. Behavior. 49: 227-267

Appeldoorn, R. S., Hensley, D. A., Shapiro, D. Y., Kioroglou, S., Sanderson, B. G. (1994). Egg dispersal in a Caribbean coral reef fish, Thalassoma bifasciatum. II. Dispersal off the reef platform. Bull. Mar. Sci. 54: 271-280

Bell, L. J., Colin, P. L. (1986). Mass spawning of Caesio teres (Pisces:Caesionidae) at Enewetak Atoll, Marshall Islands. Env. Biol. Fish. 15: 69-74

Buchheim, J. R., Hixon, M. A. (1992). Competition for shelter holes in the coral reef fish Acanthemblemaria spinosa Metzelaar. J. Exp. Mar. Biol. Ecol. 164: 45-54

Clifton, K. E., Robertson, D. R. (1993). Risks of alternative mating strategies. Nature. 366: 520

Colin, P. L. (1978). Daily and summer-winter variation in mass sapwning of the striped parrotfish, Scarus croicensis. Fish. Bull. 76: 117-124

Colin, P. L., Bell, L. J. (1991). Aspects of spawning of labrid and scarid fishes (Pisces: Labroidei) at Enewetak Atoll, Marshall Islands with notes on other families. Env. Biol. Fish. 31: 229-260

Colin, P. L., Clavijo, I. E. (1988). Spawning activity of fishes producing pelagic eggs on a shelf edge coral reef, Southwestern Puerto Rico. Bull. Mar. Sci. 42: 249-279

Collette, B. B., Talbot, F. H. (1972). Activity patterns of coral reef fishes with emphasis on nocturnal-diurnal changeover. Bulletin of the Natural History Museum of Los Angeles County. 14: 99-124

Connell, S. D., Jones, G. P. (1991). The influence of habitat complexity on postrecruitment processes in a temperate reef fish population. J. Exp. Mar. Biol. Ecol. 151: $271-294$

Curio, E. (1976). The ethology of predation. Springer-Verlag, Berlin

Domeier, M. L., Colin, P. L. (1997). Tropical reef fish spawning aggregations: defined and reviewed. Bull. Mar. Sci. 60: 698-726

Gladstone, W., Westoby, M. (1988). Growth and reproduction in Canthigaster valentini (Pisces: Tetraodontidae): a comparison of a toxic reef fish with other reef fishes. Env. Biol. Fish. 21: 207-221

Godin, J.-G. J. (1997). Evading predators. In: Godin, J.-G. J. (ed.) Behavioral ecology of teleost fishes. Oxford University Press, Oxford, p. 191-236 
Hixon, M. A. (1991). Predation as a process structuring coral reef communities. In: Sale, P. F. (ed.) The ecology of fishes on coral reefs. Academic Press, San Diego, p. 475-508

Hixon, M. A. (1993). Predation, prey refuges, and the structure of coral-reef fish assemblages. Ecol. Monogr. 63: 77-101

Hixon, M. A., Beets, J. P. (1989). Shelter characteristics and caribbean fish assemblages: experiments with artificial reefs. Bull. Mar. Sci. 44: 666-680

Hixon, M. A., Carr, M. H. (1997). Synergistic predation, density dependence, and population regulation in marine fish. Science. 277: 946-949

Hixon, M. A., Menge, B. A. (1991). Species diversity, prey refuges modify the interactive effects of predation and competition. J. Theor. Biol. 39: 178-200

Hobson, E. S. (1968). Predatory behavior of some shore fishes in the Gulf of California. Research Report - U.S. Fish and Wildlife Service. 73: 1-92

Hobson, E. S. (1973). Activity of Hawaiian reef fishes during the evening and morning transitions between daylight and darkness. Fish. Bull. 70: 715-740

Hobson, E. S. (1974). Feeding relationships of teleostan fishes on coral reefs in Kona Hawaii. Fish. Bull. 72: 915-1031

Hobson, E. S. (1991). Trophic relationships of fishes specialized to feed on zooplankters above coral reefs. In: Sale, P. F.(ed.) The ecology of fishes on coral reefs. Academic Press, San Diego, p. 69-95

Hobson, E. S., Chess, J. R. (1978). Trophic relationships among fishes and plankton in the lagoon at Enewetak Atoll, Marshall Islands. Fish. Bull. 76: 133-153

Hoffman, K. S., Grau, E. G. (1989). Daytime changes in oocyte development with relation to the tide for the Hawaiian saddleback wrasse, Thalassoma duperrey. J. Fish. Biol. 34: 529-546

Holland, K. N., Lowe, C. G., Wetherbee, B. M. (1996). Movements and dispersal patterns of blue trevally (Caranx melampygus) in a fisheries conservation zone. Fisheries Research. 25: 279-292

Hugie, D. M., Dill, L. M. (1994). Fish and game: a game theoretic approach to habitat selection by predators and prey. J. Fish Biol. 45 (Suppl. A): 151-169

Johannes, R. E. (1978). Reproductive strategies of coastal marine fishes in the tropics. Env. Biol. Fish. 3: 65-84

Jones, G. P. (1988). Experimental evaluation of the effects of habitat structure and competitive interactions on the juveniles of two coral reef fishes. J. Exp. Mar. Biol. Ecol. 123: 115-126 
Jones, G. P. (1991). Postrecruitment proceses in the ecology of coral reef fish populations: a multifactorial perspective. In: Sale, P. F. (ed.) The ecology of fishes on croal reefs. Academic Press, San Diego, p.

Jutare, T. V. (1962). Studies on the biology of Bothus ocellatus with a description of a related new species. M.S. Thesis, University of Miami.

Kingsford, M. J. (1992). Spatial and temporal variation in predation on reef fishes by coral trout (Plectropomus leopardus, Serranidae). Coral Reefs. 11: 193-198

Leis, J. M., Rennis, D. S. (1983). The larvae of Indo-Pacific coral reef fishes. New South Wales University Press and University of Hawaii Press

Leis, J. M., Moyer, J. T. (1985). Development of eggs. larvae and pelagic juveniles of three Indo-Pacific Ostraciid fishes (Tetraodontiformes): Ostracion meleagris, Lactoria fornasini and L. diaphana. Japan. J. Ichthyol. 32: 189-202

Leis, J. M., Trnski, T. (1989). The larvae of Indo-Pacific shorefishes. University of Hawaii Press.

Leum, L. L., Choat, J. H. (1980). Density and distribution patterns of the temperate marine fish Cheilodactylus spectabilis (Ceilodactylidae) in a reef environment. Mar. Biol. 57: 327-337

Lima, S. L., Dill, L. M. (1990). Behavioral decisions made under the risk of predation: a review and prospectus. Can. J. Zool. 68: 619-639

Lobel, P. S. (1978). Diel, lunar, and seasonal periodicity in the reproductive behavior of the pomacanthid fish, Centropyge potteri, and some other reef fishes in Hawaii. Pacific Science. 32: 193-207

Lobel, P. S. (1989). Ocean Variability and the Spawning Season of Hawaiian Reef Fishes. Env. Biol. Fish. 24: 161-171

Lubbock, R. (1980). The shore fishes from Ascension Island. J. Fish Biol. 17: 283-303

Luckhurst, B. E., Luckhurst, K. (1978). Analysis of the influence of substrate variables of coral reef fish communities. Mar. Biol. 49: 317-323

Major, P. F. (1978). Predator-prey interactions in two schooling fishes, Caranx ignobilis and Stolephorus purpureus. Animal Behaviour. 26: 760-777

Major, P. F. (1977). Predatory-prey interaction in schooling fishes during periods of twilight: a study of the silverside Pranesus insularum in Hawaii. Fish. Bull. 75: 415426

Marconato, A., Shapiro, D. Y., Petersen, C. W., Warner, R. R., Yoshikawa, T. (1997). Methodological analysis of fertilization rate in the bluehead wrasse Thalassoma

bifasciatum: pair versus group spawns. Mar. Ecol. Prog. Ser. 161: 61-70 
Martin, D. F., Drewry, G. E. (1978). Development of fishes of the Mid-Atlantic Bight; an atlas of egg. larval and juvenile stages. Volume VI - Stromateidae through Ogcocephalidae. Biological Services Program, U.S. Fish and Wildlife Service.

McCormick, M. I. (1994). Comparison of field methods for measuring surface topography and their associations with a tropical reef assemblage. Mar. Ecol. Prog. Ser. 112: 87-97

Meyer, K. A. (1977). Reproductive behavior and patterns of sexuality in the Japanese labrid fish Thalassoma cupido. Japan. J. Ichthyol. 24: 101-112

Morgan, S. G., Christy, J. H. (1994). Plasticity, constraint, and optimality in reproductive timing. Ecology. 75: 2185-2203

Moyer, J. T. (1987). Quantitative observations of predation during spawning rushes of the labrid fish Thalassoma cupido at Miyake-jima, Japan. Japan. J. Ichthyol. 34: 7681

Moyer, J. T. (1989). Reef channels as spawning sites for fishes on the Shiraho coral reef, Ishigaki Island, Japan. Japan. J. Ichthyol. 36: 371-375

Myers, R. F. (1991). Micronesian reef fishes: a practical guide to the identifiction of the inshore marine fishes of the tropical Central and Western Pacific. Coral Graphics, Guam

Ogden, J. C., Ehrlich, P. R. (1977). The behavior of heterotypic resting schools of juvenile grunts (Pomadasyidae). Mar. Biol. 42: 273-280

Pitcher, T. J., Turner, J. R. (1986). Danger at dawn: experiemntal support for the twighlight hypothesis in shoaling minnows. J. Fish Biol. 29: 59-70

Potts, G. W. (1980). The predatory behavior of Caranx melampygus (Pisces) in the channel environment of Aldabra Atoll (Indian Ocean). J. Zool., Lond. 192: 323-350

Potts, G. W. (1981). Behavioral interactions between Carangidae (Pisces) and their prey on the fore-reef slope of Aldabra, with notes on other predators. J. Zool., Lond. 195: $385-404$

Randall, J. E. (1955). Fishes of the Gilbert Islands. Atoll Res. Bull. 47: 1-243

Randall, J. E. (1961). Observations on the spawning of surgeonfishes (Acanthuridae) in the Society Islands. Copeia. 2: 237-288

Randall, J. E., Klausewitz, W. (1973). A review of the trigger-fish genus melichthys, with description of a new species from the Indian Ocean. Senckenberg. Biol. 54: 5769

Risk, M. J. (1972). Fish diversity on a coral reef in the Virgin Islands. Atoll Res. Bull. 193: $1-6$ 
Roberts, C. M. (1997). Ecological advice for the global fisheries crisis. TREE. 12: 3538

Roberts, C. M., Ormond, R. F. G. (1987). Habitat complexity and coral reef fish diversity and abundance on Red Sea fringing reefs. Mar. Ecol. Prog. Ser. 41: 1-8

Robertson, D. R. (1983). On the spawning behavior and spawning cycles of eight surgeonfishes (Acanthuridae) from the Indo-Pacific. Env. Biol. Fish. 9: 193-223

Robertson, D. R. (1991). The role of adult biology in the timing of spawning of tropical reef fish. In: Sale, P. F. (ed.) The ecology of fishes on coral reefs. Academic Press, San Diego, p. 356-386

Sackley, P. G., Kaufman, L. S. (1996). Effect of predation on foraging height in a planktivorous coral reef fish, Chromis nitida. Copeia. 1996: 726-729

Sadovy, Y. J. (1996). Reproduction of reef fishery species. In: Polunin, N. V. C., Roberts, C. M. (ed.) Reef Fisheries. vol. 20. Chapman \& Hall, London, p. 15-59

Shapiro, D. Y., Hensley, D. A., Appledoorn, R. S. (1988). Pelagic spawning and egg transport in coral-reef fishes: a skeptical overview. Env. Biol. Fish. 22: 3-14

Shpigel, M., Fishelson, L. (1989). Food habits and prey selection of three species of groupers from the genus Cephalopholis (Serranidae: Teleostei). Env. Biol. Fish. 24: $67-73$

Smith, R. J. F. (1997). Avoiding and deterring predators. In: Godin, J.-G. J. (ed.) Behavioral ecology of teleost fishes. Oxford University Press, Oxford, p. 163-189

Sokal, R. R., Rohlf, F. J. (1995). Biometry. W.H. Freeman and Company, New York

Sudekum, A. E., Parrish, J. D., Radtke, R. L., Ralston, S. (1991). Life history and ecology of large jacks in undisturbed, shallow, oceanic communities. Fish. Bull. 89: 493-513

Suzuki, K., Tanaka, Y., Hioki, S., Shiobara, Y. (1980). Studies on reproduction and larval rearing of coastal marine fishes. In: Yamamoto, G. (ed.) Research in largescale culture of marine fisheries resources. Institute of Oceanic Research and Development Tokai University Shimizu.

Sweatman, H. P. A. (1984). A field study of the predatory behavior and feeding rate of a piscivorous coral reef fish, the lizardfish Synodus englemani. Copeia. 1984: 187-194

Thresher, R. E. (1984). Reproduction in reef fishes. T.F.H. Publications,

Thresher, R. E., Brothers, E. B. (1985). Reproductive ecology and biogeography of Indo-West Pacific angelfishes (pisces: Pomacanthidae). Evolution. 39: 878-887

Tupper, M., Boutilier, R. G. (1997). Effect of habitat on settlement, growth, predation risk and survival of a temperate reef fish. Mar. Ecol. Prog. Ser. 151: 225-236 
Watson, W., Leis, J. M. (1974). Ichthyoplankton of Kaneohe Bay, Hawaii: a one year study of the fish eggs and larvae. University of Hawaii Sea Grant Program Honolulu Technical Report UNIHI-SEAGRANT-TR-75-01.

Warner, R. R. (1991). The use of phenotypic plasticity in coral reef fishes as tests of theory in evolutionary ecology. In: Sale, P. F. (ed.) The ecology of fishes on coral reefs. Academic Press, San Diego, p. 387-398

Warner, R. R. (1997). Evolutionary ecology: how to reconcile pelagic dispersal with local adaptation. Coral Reefs. 16 Suppl.: S115-S120

Werner, E. E. (1992). Individual behavior and higher-order species interactions. Am. Nat. 140: 25-32 
Table 1. Attacks by Caranx melampygus and Aphareus furca on different prey species.

Numbers in parenthesis represent successful attacks (kills). The motor pattern of prey fish was categorized as bobbing or rushing when an attack was observed. The

indiscriminate category represents attacks that occurred when (1) the specific spawning behavior of the prey was not observed, or (2) the attack was directed to a mixed species aggregation.

\begin{tabular}{|c|c|c|c|c|c|}
\hline Year & Prey species & Motor pattern & $\begin{array}{l}\text { C. melampygus } \\
\text { attacks }\end{array}$ & $\begin{array}{l}\text { A. Furca } \\
\text { attacks }\end{array}$ & $\begin{array}{l}\text { Total } \\
\text { attacks }\end{array}$ \\
\hline \multicolumn{6}{|l|}{1994} \\
\hline & \multirow{2}{*}{ C. sordidus } & Rushing & $26(1)$ & $16(2)$ & 45 \\
\hline & & Bobbing & 8 & 1 & 9 \\
\hline & \multirow[t]{2}{*}{ A. nigroris } & Rushing & $7(2)$ & 4 & 13 \\
\hline & & Bobbing & 2 & 2 & 4 \\
\hline & \multirow[t]{2}{*}{ Z. flavescens } & Rushing & 2 & 0 & 2 \\
\hline & & Bobbing & 1 & 0 & 1 \\
\hline & \multirow[t]{2}{*}{ S. psittacus } & Rushing & 0 & 4 & 4 \\
\hline & & Bobbing & 0 & 0 & 0 \\
\hline & \multicolumn{2}{|l|}{ Indiscriminate } & 1 & 3 & 4 \\
\hline \multicolumn{6}{|l|}{1995} \\
\hline & \multirow[t]{2}{*}{ C. sordidus } & Rushing & $56(3)$ & 10 & 69 \\
\hline & & Bobbing & 10 & 2 & 12 \\
\hline & \multirow[t]{2}{*}{ A. nigroris } & Rushing & 37 & 34 & 71 \\
\hline & & Bobbing & 8 & 2 & 10 \\
\hline & \multirow[t]{2}{*}{ Z. flavescens } & Rushing & 1 & 0 & 1 \\
\hline & & Bobbing & 1 & 0 & 1 \\
\hline & \multirow[t]{2}{*}{ C. strigosus } & Rushing & $4(1)$ & 0 & 5 \\
\hline & & Bobbing & 1 & 0 & 1 \\
\hline & \multicolumn{2}{|l|}{ Indiscriminate } & 1 & $0(1)$ & 2 \\
\hline \multirow{3}{*}{\multicolumn{2}{|c|}{ TOTAL }} & Rushing & 140 & 70 & 210 \\
\hline & & Bobbing & 31 & 7 & 38 \\
\hline & & All & 173 & 81 & 254 \\
\hline
\end{tabular}


Table 2. Results for four prey fish species on the duration of individual spawning rushes, the proportion of time spent rushing up into the water column and the proportion of attacks by piscivores directed towards rushing fishes. The selection by attacking piscivores of spawning rushes as the moment to attack their prey was established by comparing the proportion of time spent rushing with the proportion of attacks directed on rushing fishes.

\begin{tabular}{lllll}
\hline Prey species & $\begin{array}{l}\text { Duration of } \\
\text { spawning rush } \\
\text { (seconds) }\end{array}$ & $\begin{array}{l}\text { Proportion of } \\
\text { time spent } \\
\text { rushing }\end{array}$ & $\begin{array}{l}\text { Proportion of } \\
\text { attacks on } \\
\text { rushing fish }\end{array}$ & $\begin{array}{l}\text { Selection of } \\
\text { spawning rushes } \\
\text { by piscivores } *\end{array}$ \\
\hline C. sordidus & 1.9 & $7.9 \%$ & $84.4 \%$ & Yes \\
A. nigroris & 1.1 & $4.9 \%$ & $85.7 \%$ & Yes \\
C. strigosus & 0.9 & $2.1 \%$ & $83.3 \%$ & Yes \\
Z. flavescens & 2.0 & $0.8 \%$ & $60.0 \%$ & Yes \\
\hline
\end{tabular}

(*) G-test for goodness of fit; $p<0.001$ 
Table 3. Attacks by piscivorous predators and spawning activities of their prey. Predation data from Caranx melampygus and Aphareus furca, as well as from both 1994 and 1995 sampling seasons were combined. The proportion of spawns attacked, attack success rates and mortality risks per individual spawning rush were calculated using data on attacks and kills by predators, and data on prey spawning..

\begin{tabular}{|c|c|c|c|c|c|c|c|}
\hline Prey species & $\begin{array}{l}\text { Total no. } \\
\text { attacks }\end{array}$ & $\begin{array}{l}\text { No. attacks on } \\
\text { rushing fish }\end{array}$ & No. spawns & $\begin{array}{l}\text { Proportion of } \\
\text { spawns attacked }\end{array}$ & No. kills & $\begin{array}{l}\text { Total attack } \\
\text { success rate }\end{array}$ & $\begin{array}{l}\text { Mortality risk per } \\
\text { spawning rush }\end{array}$ \\
\hline C. sordidus & 135 & 114 & 3749 & $3.0 \%$ & 7 & $5.2 \%$ & $0.2 \%$ \\
\hline S. psittacus & 4 & 4 & 76 & $5.3 \%$ & 0 & $0.0 \%$ & $0 \%$ \\
\hline A. nigroris & 98 & 84 & 3461 & $2.4 \%$ & 2 & $2.0 \%$ & $0.1 \%$ \\
\hline C. strigosus & 6 & 5 & 770 & $0.6 \%$ & 1 & $16.7 \%$ & $0.1 \%$ \\
\hline$Z$. flavescens & 5 & 3 & 939 & $0.3 \%$ & 0 & $0.0 \%$ & $0 \%$ \\
\hline Total & 248 & 210 & 8995 & $2.3 \%$ & 10 & $4.0 \%$ & $0.1 \%$ \\
\hline
\end{tabular}


Table 4. Average feeding intensity and feeding height of $D$. albisella during afternoon and dusk periods, and diel distribution of current speeds. Behavioral feeding variables are averages from 6 individual fishes. N: number of observations (each observation included all six individual planktivores); Max-Min: extreme values from individual fishes. Mann-Whitney U tests compare afternoon and dusk values for percentage of time spent feeding, feeding height above the bottom and current speeds.

\begin{tabular}{|c|c|c|c|c|c|c|c|c|c|c|}
\hline & $\mathrm{N}$ & $\begin{array}{l}\text { Average } \\
\text { percentage } \\
\text { of time } \\
\text { feeding } \\
\end{array}$ & Max-Min & $\begin{array}{l}\text { UMann- } \\
\text { Whitney } \\
\text { (p-value) }\end{array}$ & $\begin{array}{l}\text { Average } \\
\text { feeding } \\
\text { height }(\mathrm{m})\end{array}$ & Max- Min & $\begin{array}{l}\text { U Mann- } \\
\text { Whitney } \\
\text { (p-value) }\end{array}$ & $\begin{array}{l}\text { Current } \\
\text { speed } \\
\text { (cm/s) }\end{array}$ & Max-Min & $\begin{array}{l}\text { UMann- } \\
\text { Whitney } \\
\text { (p-value) }\end{array}$ \\
\hline Afternoon & 19 & $98.8 \%$ & $100-36.7 \%$ & $\begin{array}{l}2574.5 \\
\text { NS }\end{array}$ & 0.78 & $2.16-0.25$ & $\begin{array}{l}1963.5 \\
(p<0.009)\end{array}$ & 30.9 & $58.6-3.5$ & $\begin{array}{l}65 \\
\text { NS }\end{array}$ \\
\hline Dusk & 8 & $99.8 \%$ & $100-91.7 \%$ & & 0.53 & $1.19-0.25$ & & 27.9 & $45.0-2.3$ & \\
\hline Total & 27 & $99.1 \%$ & & & 0.70 & & & 30.0 & & \\
\hline
\end{tabular}


Table 5. Comparison of current speeds from two adjacent sampling sites (1 and 2). TI: topographical index calculated as the ratio of linear to contoured length (see methods section); N: number of 1 minute samples used in analysis; average speed: total current speed average $(\mathrm{cm} / \mathrm{s})$; speed max-min: maximum and minimum current speed values; $\mathbf{t}$ values: $t$-statistic from a paired comparison between simultaneous currents at both sites.

\begin{tabular}{lllllllll}
\hline Site & Substrate & T.l. & $\begin{array}{l}\text { Fish } \\
\text { density }\end{array}$ & Date & $\mathrm{N}$ & $\begin{array}{l}\text { Average } \\
\text { speed }\end{array}$ & $\begin{array}{l}\text { Speed } \\
\text { Min -Max }\end{array}$ & $\begin{array}{l}\text { t-value } \\
\text { (p-value) }\end{array}$ \\
\hline 1 & $\begin{array}{l}\text { broken } \\
\text { coral heads }\end{array}$ & 0.48 & 0.77 & May 21 & 60 & 41.4 & $32.0-50.1$ & $\begin{array}{l}5.9 \\
(<0.001)\end{array}$ \\
2 & coral rubble & 0.74 & 0.06 & May 21 & 60 & 43.8 & $36.7-52.1$ & \\
1 & & & & May 25 & 75 & 40.8 & $32.9-49.1$ & $\begin{array}{l}19.6 \\
(<0.001)\end{array}$ \\
2 & & & & May 25 & 75 & 50.3 & $35.5-59.5$ & \\
\hline
\end{tabular}


Figure 1. Hypotheses regarding the diel activity of predators in relation to their prey. 1. Predation is independent of prey activity. 2. Predation is reduced after satiation from previous feeding. 3. Predation is dependent on prey behavior or activity. 4. Predation is dependent only on the activity of vulnerable prey species, and independent of prey with anti-predatory adaptations. 


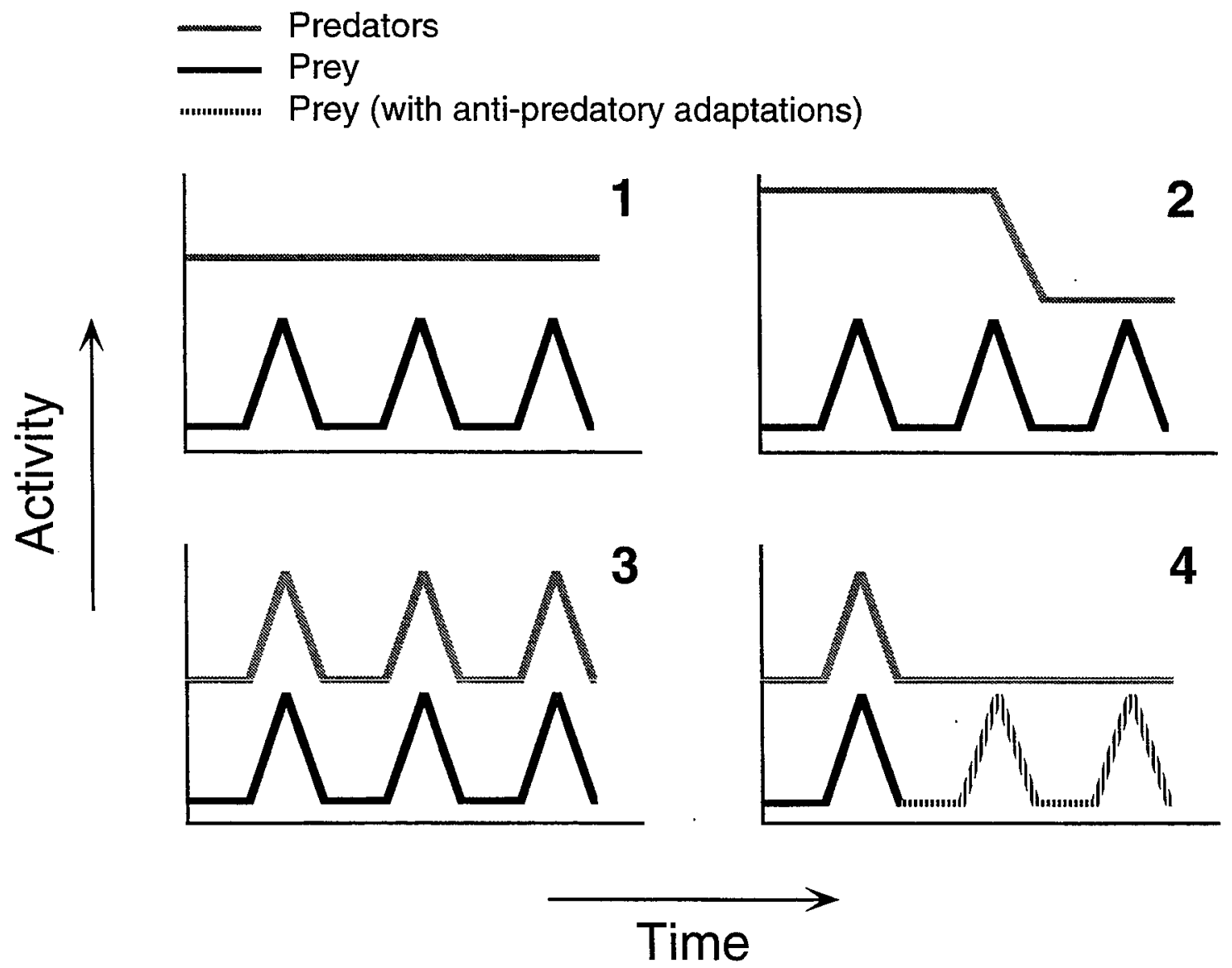


Figure 2. A. Map of Johnston Atoll showing the location of the spawning aggregation site, Mustin's Gap. B. Schematic representation of Mustin's Gap showing the position and size of the 10 sampling areas used in topographical and fish census measurements. The dominant substrate elements in each area are Acropora spp. (a), broken coral heads (c) and fine coral rubble (r). Cross-marks indicate the position of current meters. The darker area shows where behavioral observations of piscivores and spawning fish were made. 


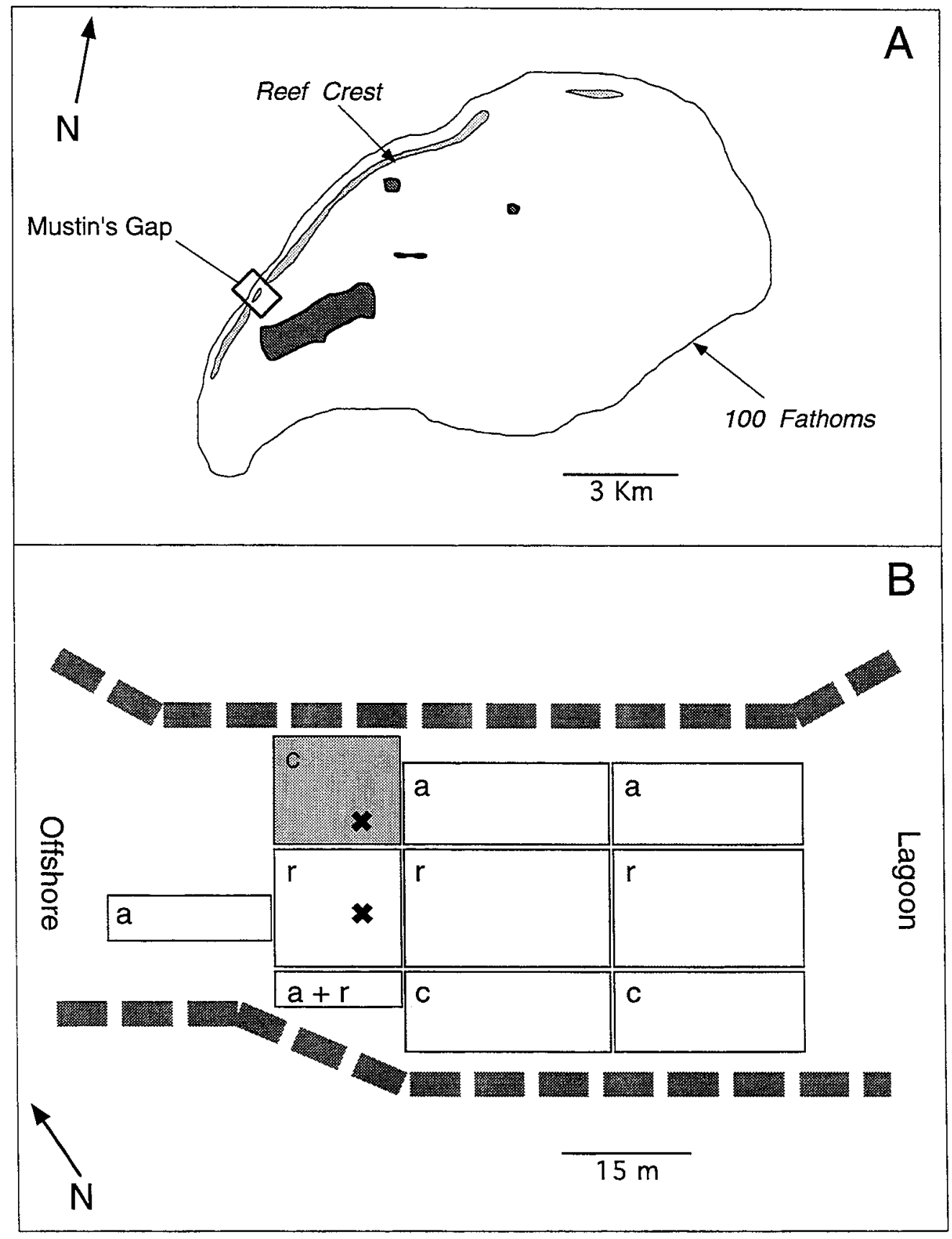


Figure 3. Timing of Caranx melampygus and Aphareus furca presence (A) and attacks (B) during 1994. Data are averages from 15-minute observations $( \pm S E)$. 
A)

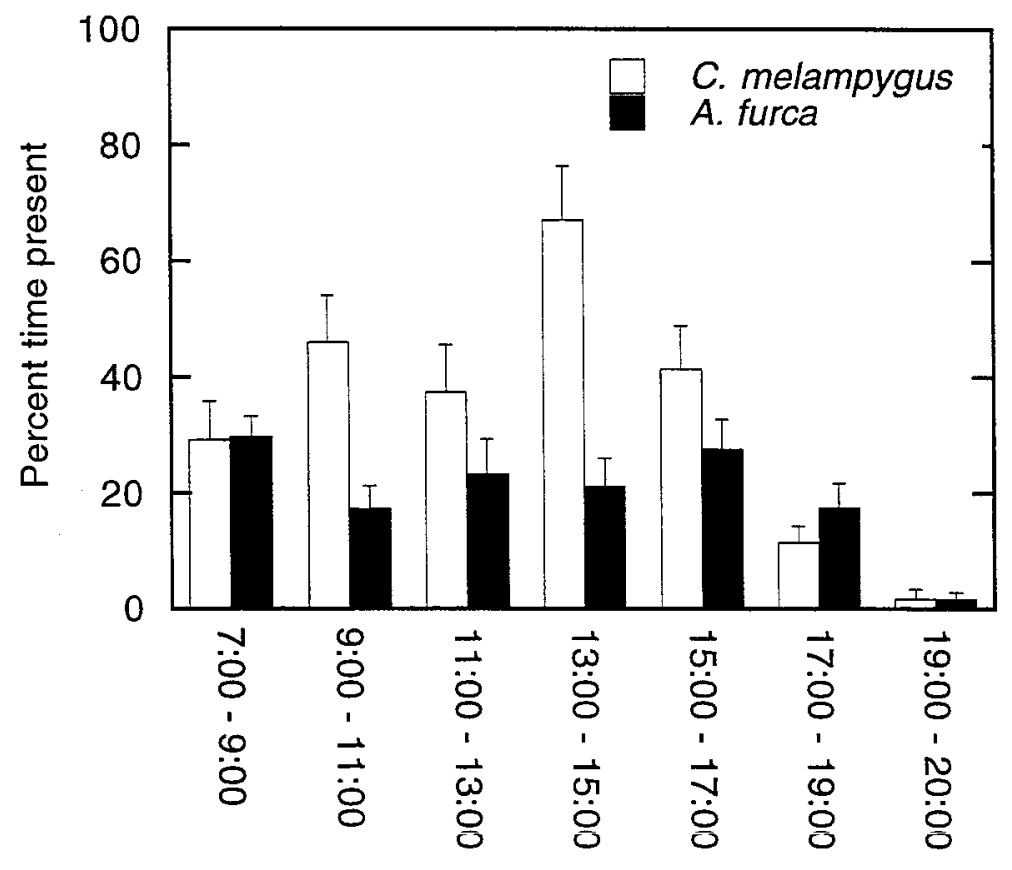

B)

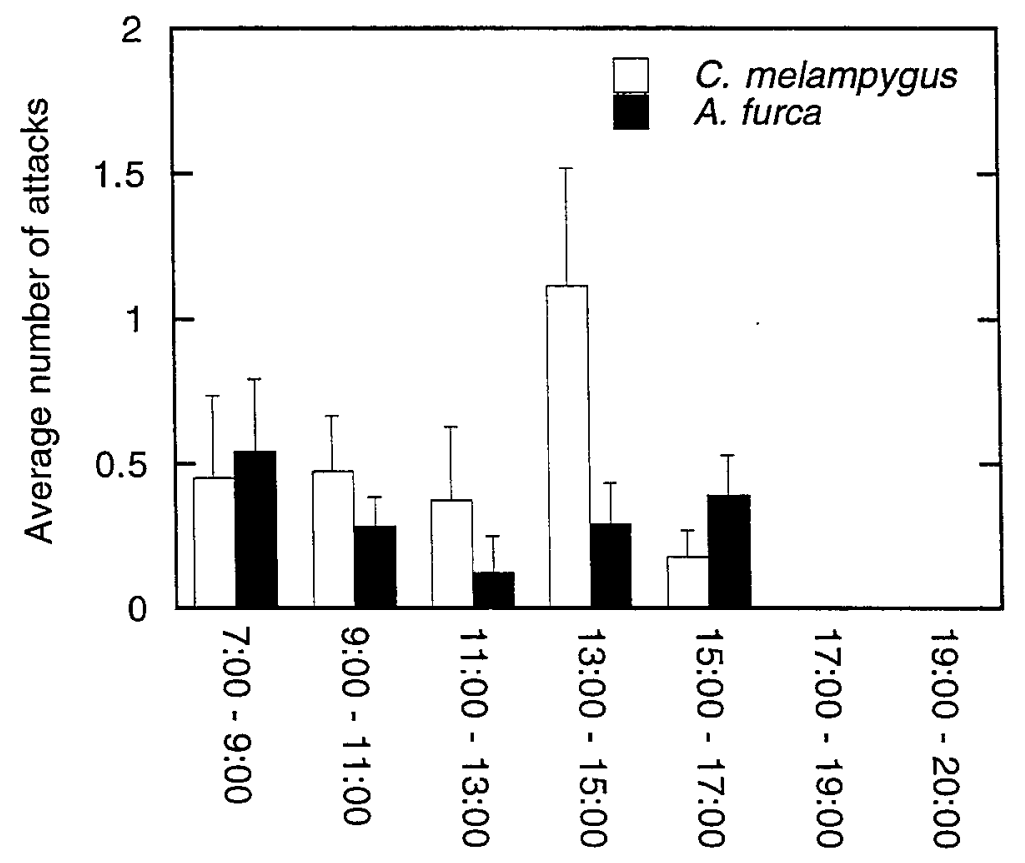


Figure 4. Caranx melampygus and Aphareus furca presence (A) and attacks (B) during daytime (1300-1630) and dusk (1900-2000) periods of 1995. Data are averages per 15minute observations ( $\pm \mathrm{SE})$. 


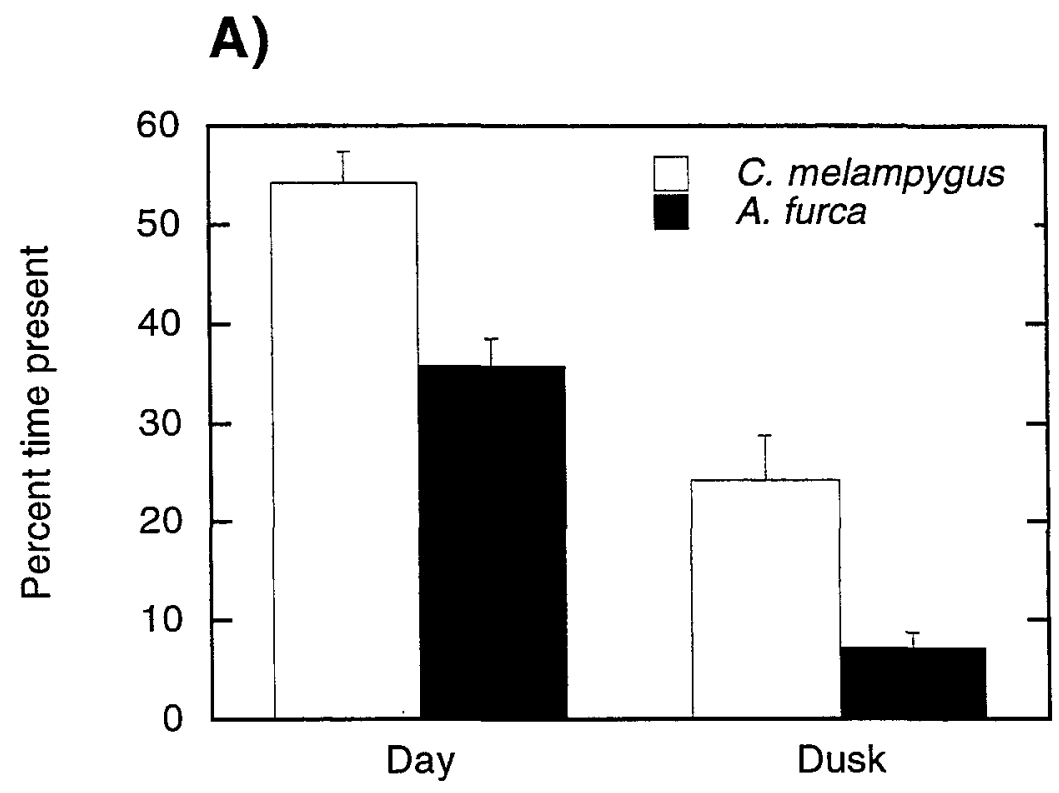

B)

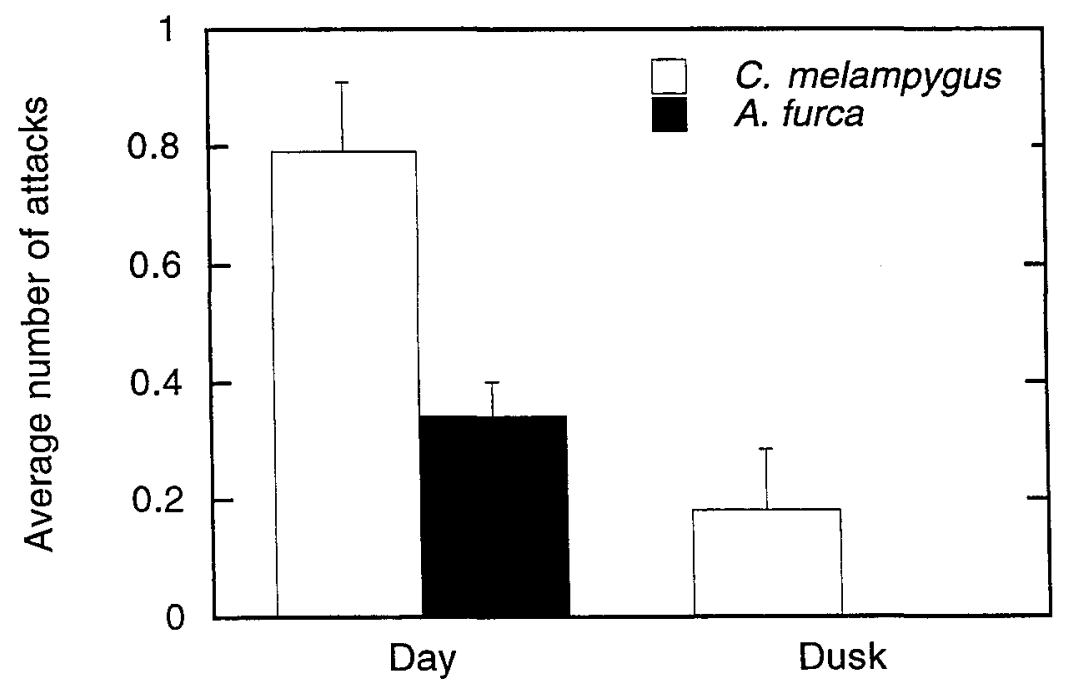


Figure 5. Number of Melichthys spp. attacks on recently spawned gametes during daytime (1300-1630) and dusk (1900-2000) periods (1994 and 1995). Data are averages per 15minute observations $( \pm \mathrm{SE})$. 


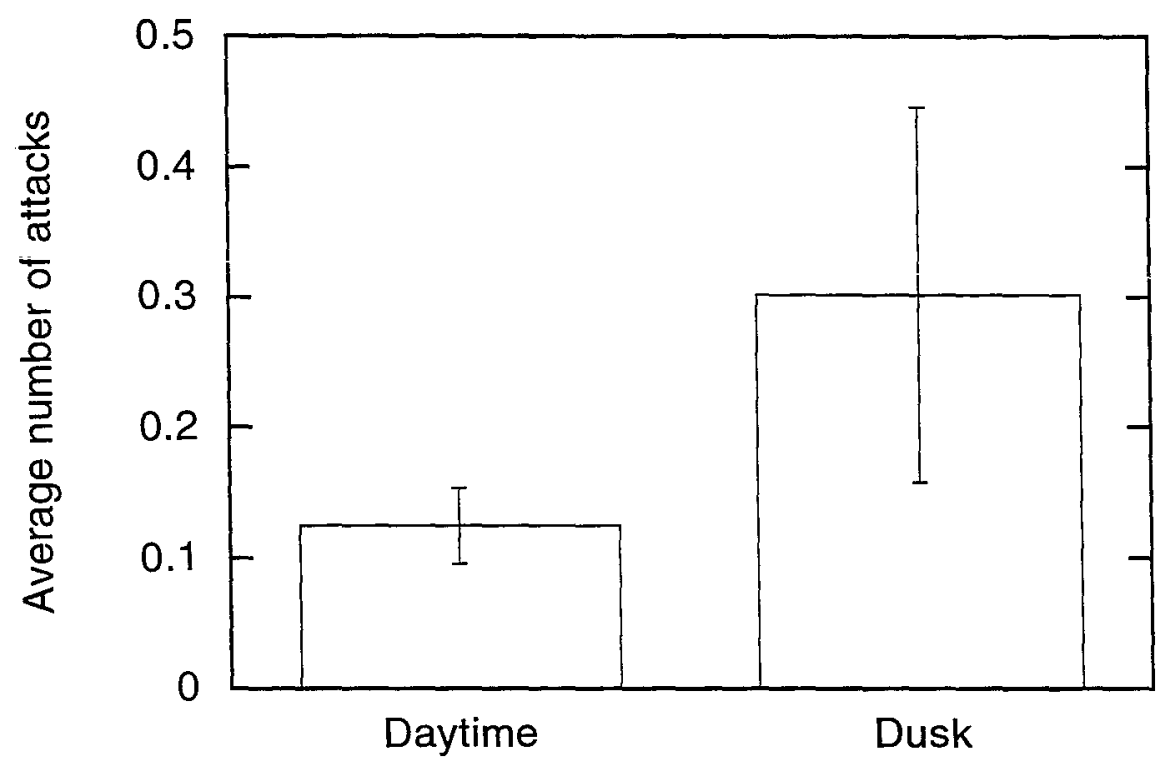


Figure 6. Relation between the percentage of spawns attacked by mobile triggerfishes (Melichthys niger and Melichthys vidua) and the egg volume of different spawning species. Egg volumes correspond to the species of Aulostomus chinensis (Watson \& Leis 1974, as cited in Leis \& Trnski 1989),Chlorurus sordidus (Colin and Bell 1991) and Ostracion meleagris (Leis \& Moyer 1985); and to species from the same genus of Parupeneus multifasciatus (Parupeneus sp.; Suzuki et al. 1980, as cited in Leis \& Rennis 1983), Acanthurus nigroris (A. triostegus; Randall 1961) and Bothus mancus (B. robinsi; Jutare 1962, as cited in Martin \& Drewry 1978). 


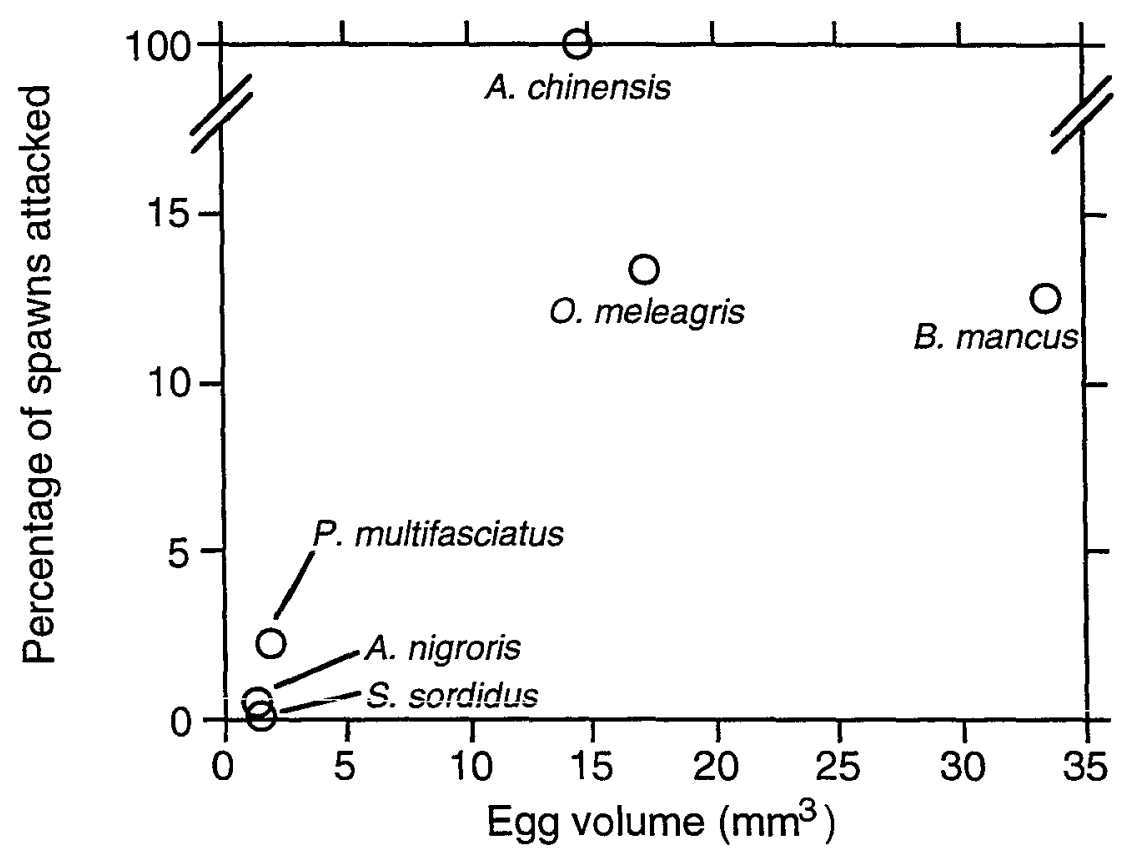


Figure 7. Feeding heights of six individual Dascyllus albisella versus current speed. Data are averages per 2-minute observations. Lines are linear regressions corresponding to data from each individual fish. 

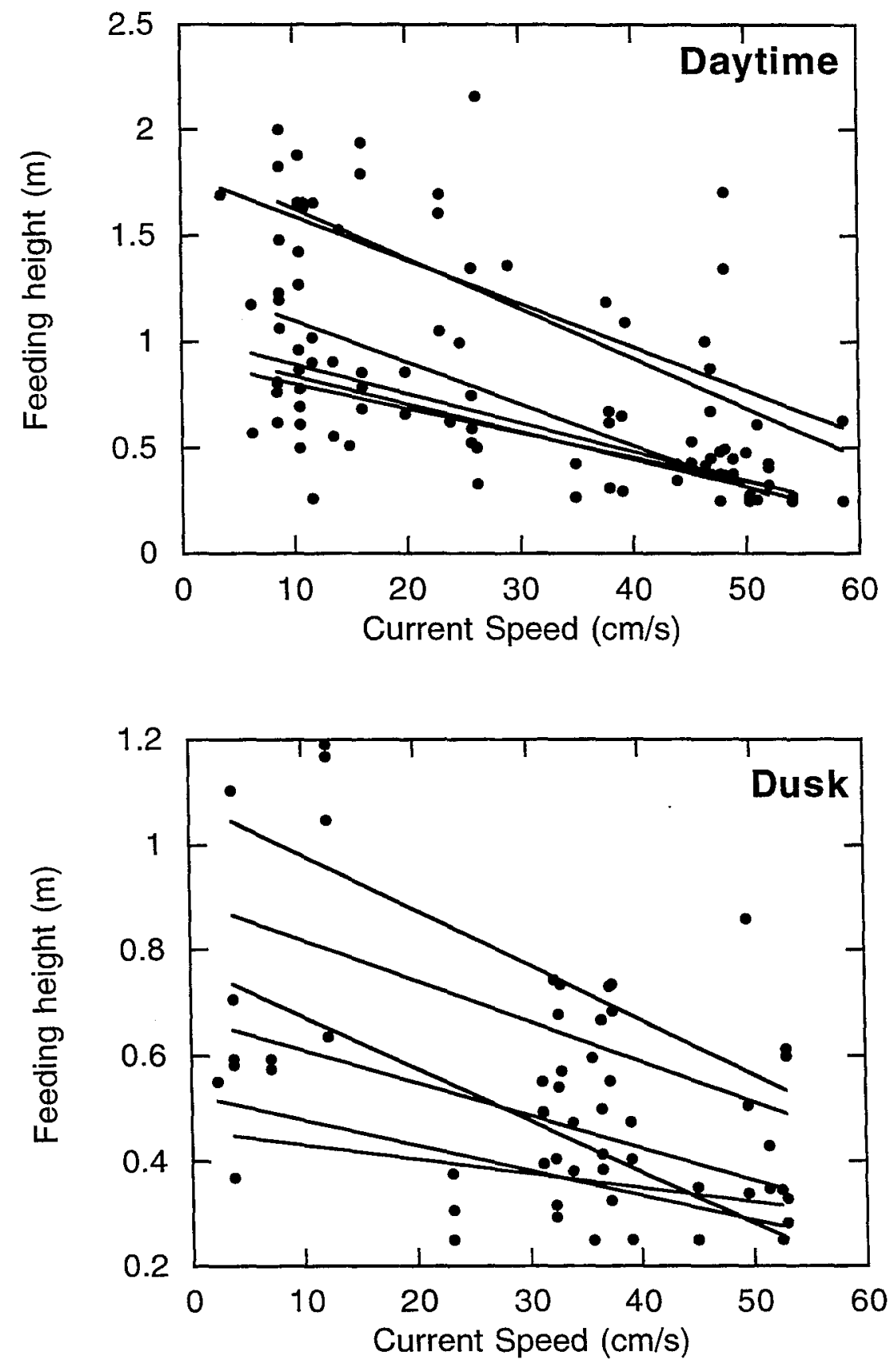
Figure 8. Diel distribution of abundance of spawning fish (A), spawning rate $(\mathbf{B})$ and number of species (C) at Mustin's Gap during 1994. Data are from 15-minute observation periods ( $n=123)$. Abundance of fish values are averages and include all species observed spawning $(n=24)$. Spawning rate is expressed as the average number of spawns (number of spawns observed $=3754$ ) per minute of observation. Black bars represent abundance and spawning rate of only Chlorurus sordidus and Acanthurus nigroris, while white bars represent values from the other species. Gray bars represent number of species. 

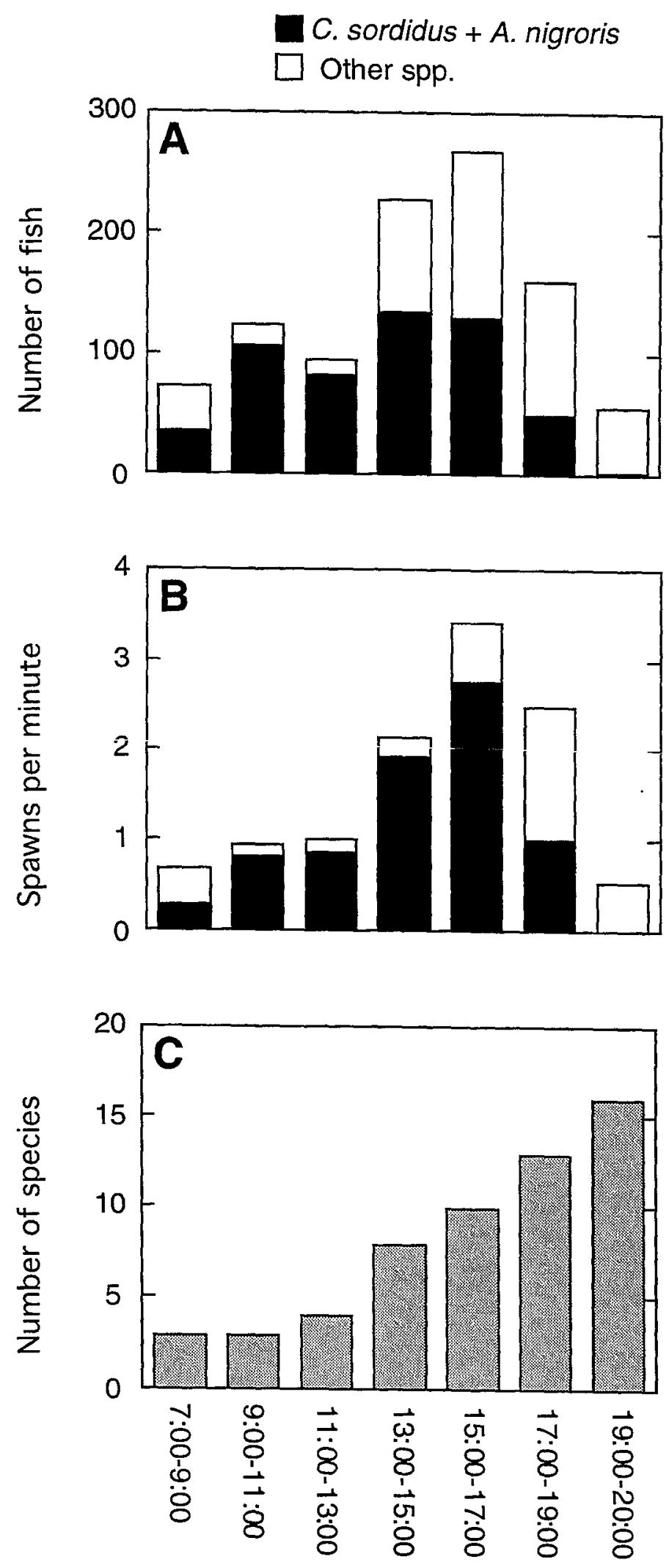
Figure 9. Relation of density of spawning fishes (number of fish per $\mathrm{m}^{2}$ ) with substrate topographical index (ratio of contoured length to linear length). Fish density values (sum of Chlorurus sordidus, Acanthurus nigroris and Zebrasoma flavescens) are averages from 14 censuses ( $\pm \mathrm{SE}$ ); individual topographical indices values are averages from 2 diagonals from 5 quadrates $( \pm S E)$. 


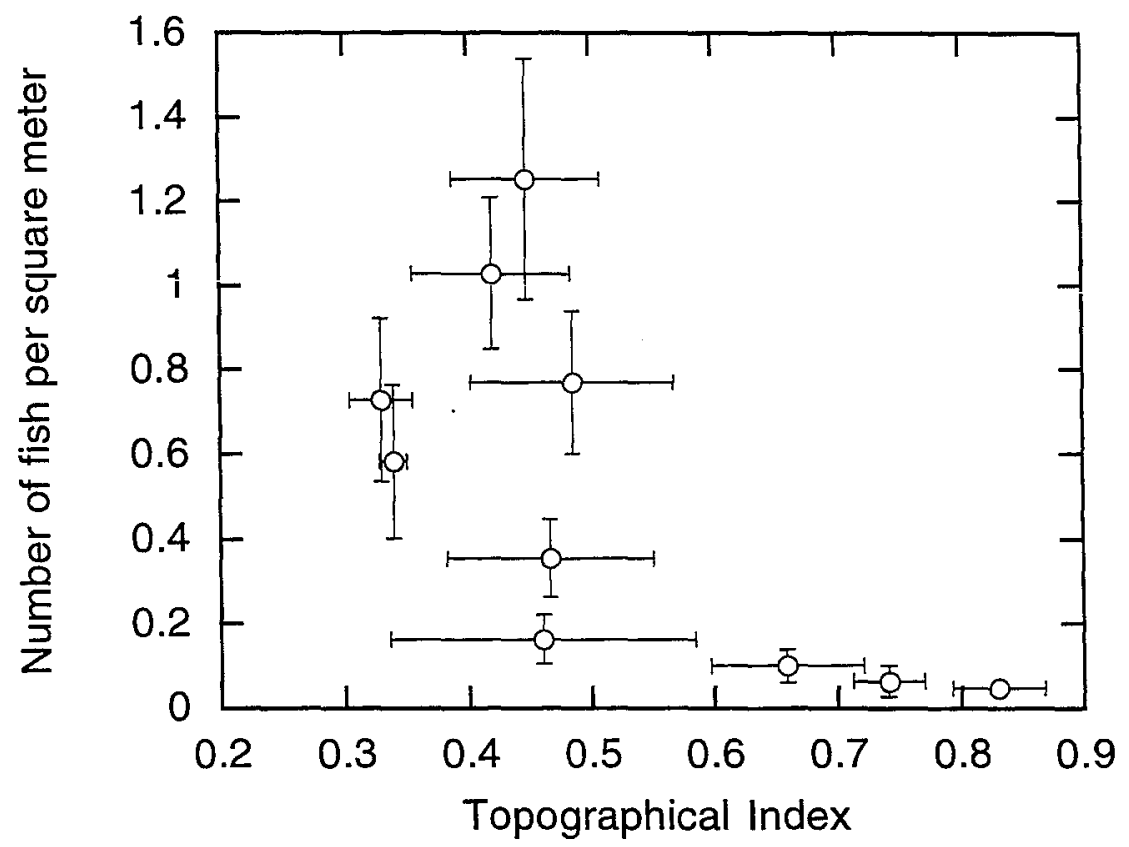


Figure 10. Relationship between prey abundance (Chlorurus sordidus and Acanthurus nigroris combined) and the presence of piscivorous predators (Caranx melampygus and Aphareus furca). Data points correspond to 15 -minute observation periods. A solid line indicates the linear regression between Caranx melampygus presence and prey abundance $\left(\mathrm{R}^{2}=0.55\right)$ 
Caranx melampygus

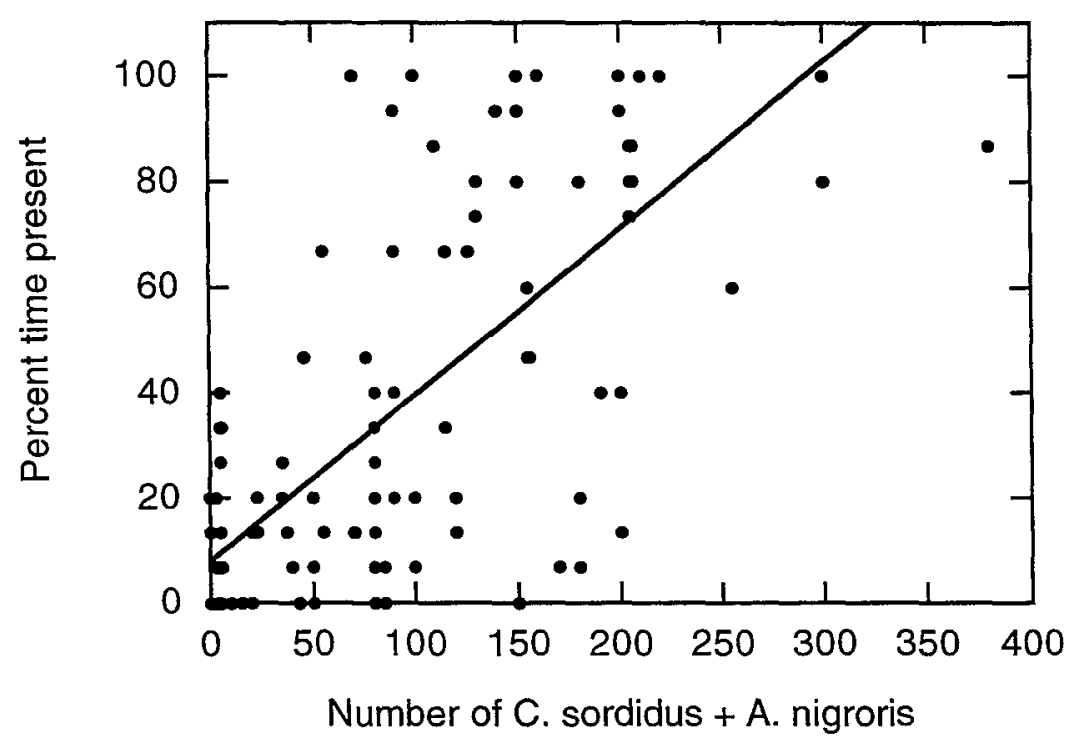

Aphareus furca

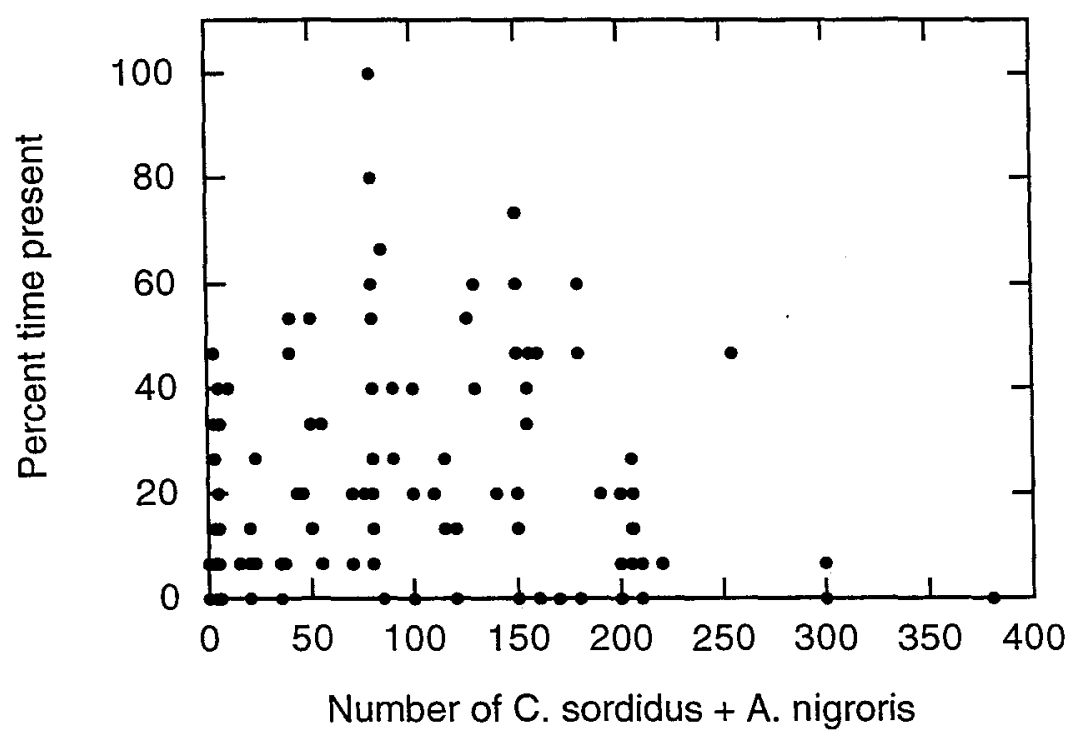




\section{CHAPTER 4}

Novel territorial ambushing behavior of the transient predator Caranx melampygus (Carangidae) 


\section{ABSTRACT}

The behavioral strategies used by the piscivore Caranx melampygus (Carangidae) while feeding on spawning aggregations of coral reef fishes were studied for two years at Johnston Atoll (Central Pacific). Visual behavioral observations revealed the existence of two different hunting behaviors employed by this predator. A 'midwater' hunting behavior, which consisted of midwater high speed attacks on spawning fishes, is typical of large sized transient predators and yielded a low capture success rate (2\%). An 'ambush' hunting behavior consisted of attacks on spawning fishes from hiding locations in the substrate, and yielded a much higher capture success rate $(17 \%)$. While ambushing their prey, C. melampygus displayed territorial aggressive behaviors toward other intruding conspecifics, defending a specific section of the reef. This specialized ambushing behavior is atypical of fast swimming carangids, but illustrates the behavioral flexibility of this predator. I suggest that the use of these two hunting behaviors by C. melampygus can potentially cause density-dependent mortality rates in prey communities, a demographic consequence previously attributed to the simultaneous action of various guilds of predatory species. 


\section{INTRODUCTION}

Predation is a major ecological force structuring various ecological systems, such as freshwater and rocky intertidal communities (Sih et al. 1985). In coral reef fish communities, post-settlement mortality in the benthic environment due to predation seems to be an important factor controlling populations (Hixon 1991). The abundance of predators and refugia have been proved important in determining the abundance and composition of reef fish populations (Hixon \& Beets 1989, Hixon \& Menge 1991, Caley 1993, 1995, Hixon 1993, Beets 1997). Recent experimental studies show that certain feeding behaviors of piscivores are crucial in achieving density-dependent mortality of fishes (Hixon \& Carr 1997), a key demographic condition that prevents prey populations from fluctuating widely and becoming extinct. The simultaneous predatory action of transient midwater piscivores, which swim above the substrate between reefs, and resident benthic piscivores, which are relatively sedentary and are closely related with the substrate, can produce density-dependent mortality (Hixon \& Carr 1997). Thus specific predatorprey behavioral interactions can have significant effects on reef fish communities at the population level.

Predator-prey relationships have been studied extensively among fishes in a variety of natural environments as well as in the laboratory (for reviews see Stouder et al. 1994, Godin 1997a). Piscivores exhibit a variety of search and pursuit tactics when feeding on reef fishes, such as stalking, ambush, rushing, and chasing attacks (Hobson 1968, Curio 1976, Parrish 1993). The efficiency of predatory attacks has been well studied in laboratory conditions and in freshwater environments (Juanes 1994, Godin 1997b), but few studies have actually quantified the success of attacks by piscivores under natural conditions in marine reef environments (Sweatman 1984, Moyer 1987, Parrish 1993). 
The jack family (Carangidae) is largely composed of mobile transient piscivores such as Caranx melampygus, a large-sized transient piscivore widely distributed across Indo-Pacific coral reefs (Myers 1991, Holland et al. 1996). This carangid feeds almost exclusively on small diurnal reef fishes, and is a major predator in coral reefs. A single individual is estimated to consume $48 \mathrm{~kg}$ of fish per year (Sudekum et al. 1991). Its success as a diurnal predator in very diverse locations and across a wide variety of coral reef habitats has been attributed to its behavioral flexibility (Potts 1980, Potts 1983).

The feeding behavior of large transient or free ranging piscivores is difficult to quantify in their natural environment due to their high mobility and rapid swimming (Holland et al. 1996). The existence of prey aggregations which occur predictably on certain reef areas allows researchers to observe the hunting behavior of transient piscivores at these locations (Moyer 1987, Parrish 1993). These predictable and patchy food sources are ideal circumstances for the appearance of aggressive territorial behaviors among predators competing for food (Milinski \& Parker 1991, Grant 1997). The adoption of territorial behaviors due to competition for food resources among fishes is common in coral reef environments (Grant 1997), but has not been shown to occur in large mobile piscivores.

This study focuses on two different hunting behaviors displayed by $C$. melampygus when feeding on spawning reef fishes, and is part of a larger effort to describe the predator-prey interactions between piscivores and reef fishes at a spawning aggregation site (Chapter 3). In this paper I will describe the two hunting tactics employed by this transient piscivore and quantify the success rates of each attack mode in order to evaluate the potential benefits of each behavior. Comparison with theoretical studies and other field studies will help me evaluate the consequences of this dual behavioral pattern on the mortality patterns of prey fishes. 


\section{METHODS}

Data were collected at Johnston Atoll, an isolated open atoll located $800 \mathrm{~km}$ south of the central Hawaiian Islands. Observations were made in a reef channel (Mustin's Gap) that intersected the northwest reef crest of the atoll. This reef channel was approximately $70 \mathrm{~m}$ long, $28 \mathrm{~m}$ wide and had an average depth of $4.5 \mathrm{~m}$. The substrate was a mixture of tabular coral formations (Acropora spp.), broken coral heads and fine coral rubble. Data were collected during the months of April and May, in both 1994 and 1995.

The channel of Mustin's Gap is utilized by various species of reef fishes as a spawning aggregation site (Chapter 2). Caranx melampygus (Carangidae) and Aphareus furca (Lutjanidae) are commonly observed to prey on spawning fishes at this location (Chapter 3).

Underwater behavioral observations of Caranx melampygus were done with SCUBA, always by the same observer (G. Sancho). Behavioral observations were made in a small rectangular sampling area $(14 \times 12 \mathrm{~m})$ located in the outer part of the channel, over a topographically complex substrate composed of live and dead coral structures (described in Chapter 3). The observer would lie down on the bottom always at the same location, $5 \mathrm{~m}$ away from ta single rectangle, annotating observations on underwater paper. Visibility always exceeded $20 \mathrm{~m}$, so the entire sampling area was visible.

In 1994, sampling was done throughout the day $(0700$ - 2000) for a total of 31 hours of observation. In 1995, observations were made during the afternoon (1300 $1630)$ and dusk (1900 - 2000) periods for 46.5 hours. I performed observations for 30 minutes at a time, recording any observed predatory attempts by $C$. melampygus occurring inside the sampling rectangle. For every attack observed, the identity of the intended prey, the behavior of the prey at the moment of the attack and the final outcome of the attack were recorded. Each attack was categorized as a 'midwater' or an 'ambush' attack. Midwater 
attacks by C. melampygus were initiated from a midwater swimming position (approximately 2 meters above the substrate). Ambush attacks were those performed from a stationary hiding position close to the substrate.

To estimate the presence of $C$. melampygus at the sampling area a one-zero sampling method was used (Altmann 1974), scoring the presence or absence of piscivores every 60 second period. Separate counts were kept for swimming (midwater behavior) and hiding (ambushing behavior) individuals. Even though the one-zero scoring method has certain limitations (Altmann 1974), its simplicity allowed the observer to simultaneously record and quantify the spawning behavior of reef fishes (Chapter 2), the presence of another co-occurring piscivore, Aphareus furca (Chapter 3), and to describe in detail the feeding behavior of $C$. melampygus.

\section{RESULTS}

\section{Midwater attacks}

This mode of attack has been described previously in great detail by Potts $(1980$, 1981, 1983). Individuals usually approached the spawning grounds by swimming 1 or 2 $\mathrm{m}$ above the substrate. When hunting, these individuals swam at medium speeds, frequently changing direction (zig-zag pattern). C. melampygus performed this hunting behavior alone and in gregarious groups of 2 to 5 individuals, displaying their usual lightsilver coloration mottled with blue specks. They typically approached their prey along the main axis of the channel from either direction (inwards and outwards of the lagoon). Midwater attacks were initiated from a swimming position above the substrate (Figure 1), and consisted of a sudden acceleration leading to a high-speed rush through a group of prey. Most of the attacks were directed towards reef fishes during their spawning rushes, when they were located in the water column away from the substrate (Chapter 3). Prey fish immediately darted towards the substrate in search of refuge in holes and crevices 
when an attack was detected. After the first rushing attack, jacks would occasionally pursue the fleeing prey, following individual fishes until the prey found cover among the coral heads. Jacks were often observed to charge into coral heads while trying to catch escaping prey, and frequently displayed fresh scratches and coral marks on their heads. Even though groups of $C$. melampygus occasionally approached prey, all attacks observed in this study were performed by single individuals and no simultaneous group attacks were observed.

\section{Ambush attacks}

On occasion, an individual C. melampygus would adopt a dark coloration, referred hereafter as 'pigmented' phase. This change in color was observed to occur in only a few seconds. Pigmented individuals hid underneath a large Acropora coral formation, maintaining a steady position against the current with the help of minor caudal and pectoral fin movements. At the observation area within the reef channel, most $C$. melampygus individuals used the same Acropora head as hiding location. This table-top coral formation had a large cavity open on three sides and was located approximately three meters away from an active spawning site used by group-spawning species. An ambushing jack was observed inside the sampling area hiding at a different location only once: during two consecutive sampling periods of 30 minutes a second pigmented jack was observed hiding behind some large broken pieces of coral located seven meters upstream from the normal hiding location, which at the time was occupied by another pigmented jack. These two pigmented jacks directed their attacks towards different sub-groups of spawning fishes, both within the sampling area. Pigmented $C$. melampygus showing ambushing behavior were also observed at other hiding locations within the reef channel of Mustin's Gap, but their activities were not quantified. The identity of the pigmented individuals hiding under the main Acropora head varied among different days (personal observation). 
Before launching an attack from the main Acropora hiding location, ambushing jacks turned their bodies slightly sideways, orienting themselves according to the shape of the frontal opening of the table-top coral head, through which a large jack did not fit in an up-right position. Attacks started with a fast rush initiated from underneath the coral head. The attacking jack would dart from beneath the coral head and accelerate upward, rushing through a group of fishes at the apex of their spawning rush (Figure 2). After this first ramming attack, jacks behaved as in midwater attacks, occasionally turning around and pursuing individual fleeing fishes.

When attacking, ambushing C. melampygus rushed from underneath the hiding location, accelerated, and rammed through a group of rushing fishes at speeds comparable to those of midwater attacks. A difference between ambushing and midwater attack behaviors was the angle of the attack rush, since ambushing jacks approached spawning fishes from below, thereby restricting the prey's access to refuges in the coral substrate.

Pigmented individuals displayed a very strong aggressive territorial behavior against conspecifics. Jacks approaching the spawning grounds while a pigmented individual was hiding elicited an immediate response by the pigmented fish. Upon locating the intruding fish or fishes, the pigmented jack would swim out of its hiding location and drive away the intruders, which always displayed a normal silvery-blue coloration (Figure 2). The pigmented jack would approach intruding conspecifics and nudge its head against their side. This behavior always caused intruders to turn around and leave the spawning site, and aggression never escalated past this point. After intruders had been driven away, the pigmented individual would return to its hiding position under the coral head and resume its ambushing hunting behavior. 


\section{Quantitative comparisons}

Abundance of hunting C. melampygus at the spawning grounds was generally highest during midday and early afternoon hours (Figure 3 ), the time when the most of the spawning activity occurs at Mustin's Gap (see Chapter 3). Display of ambushing behavior occurred less often than midwater hunting behavior, but both behaviors were most prevalent during early afternoon (Figure 3). Midwater hunting behavior was displayed during both inflowing and outflowing currents at the reef channel, while ambushing behavior only occurred while currents were outflowing.

A total of 149 midwater attacks were observed, while only 24 ambushing attacks occurred during the sampling intervals (Table 1). Only seven attacks succeeded in the capture of their intended prey. One other attack led to the capture of a non-spawning butterflyfish when a jack was pursuing fleeing parrotfishes above the substrate (Table 2). Because of its accidental nature, this successful attack was not considered in the analyses. Three of the successful attacks were categorized as midwater, and four as ambush attacks (Table 1). The success rate of ambush attacks $(16.7 \%)$ was significantly higher than of midwater attacks $(2.0 \%)$ (Table 1$)$.

Caranx melampygus preferentially attacked when their prey rushed into the water column to spawn (Chapter 3), but the proportion of attacks on rushing prey in midwater attacks (80\% directed to rushing prey) was significantly lower (Fisher's exact test; $\mathrm{p}=0.042$ ) than that of ambush attacks ( $95 \%$ directed to rushing prey). The majority of midwater attacks (93\%) and all of the ambush attacks were directed towards two prey species: Chlorurus sordidus (Scaridae) and Acanthurus nigroris (Acanthuridae). All the attacks directed towards rushing fishes occurred on group spawns (three or more fish involved), with the exception of one midwater attack on pair-spawning C. sordidus. By comparing the total number of attacks with the number of spawns observed for each 
species, $C$. melampygus was found to select these two prey species over other species spawning at Mustin's Gap (G-test of independence, $\mathrm{p}<0.001$ ), but no differences in prey selectivity were found between midwater and ambush attack behaviors (Fisher's exact test; $\mathrm{p}>0.05$ ).

Significant differences were found when comparing the 15-minute observation periods when ambushing behaviors occurred with those periods when ambushing behavior was absent. Sampling periods with ambushing had higher abundance of prey fishes than periods of no ambushing, with an average abundance at the observation area of spawning fishes of 80 individuals (Chlorurus sordidus and Acanthurus nigroris only) at times when no ambushing occurred, and of 163 individuals when ambushing jacks were present. This difference in prey abundance was significant (Mann-Whitney $U$ test; $p<0.001$ ) when considering all sample periods measured $(n=309)$, or just those restricted to the early hours of the afternoon $(\mathrm{n}=198)$ when C. melampygus was most active. Similarly, the 15minute periods when ambushing occurred had higher abundance of conspecific jacks displaying midwater hunting behaviors than in the time periods when no ambushing occurred (Mann-Whitney U test; $\mathrm{p}<0.001$ ).

\section{DISCUSSION}

The midwater hunting behaviors exhibited by Caranx melampygus at the spawning aggregation site of reef fishes in Johnston Atoll were equivalent to those displayed at a reef channel in Aldabra Atoll, where C. melampygus fed on schooling reef fishes (Potts 1980). While describing hunting behaviors of $C$. melampygus, Potts differentiated among passing, quartering, hunting and attacking behaviors (Potts 1983). What I refer to as midwater behavior accounts for the latter three behavioral categories, and ignores 'passing' behavior, since passing individuals seemed to be using the channel just for migratory purposes and displayed no interest in potential prey located along it. 
Midwater attacks on spawning fishes were similar to those observed in Aldabra on other non-spawning fish species (Potts 1980, Potts 1981). C. melampygus did not seem to orient to individual spawning fishes, but apparently rammed indiscriminately through spawning groups, which varied in size from 3 to 20 individuals. These apparently indiscriminate rushing attacks have been observed in other midwater predators feeding on schooling prey in the natural environment (Hobson 1968, Parrish 1993). Indiscriminate attack behaviors allow predators to avoid confusion effects produced by schools of prey (Ohguchi 1981, Pitcher \& Parrish 1993), since attacks are not directed towards individual prey but towards the whole group. Occasionally following a ramming attack against a specific spawning rush, C. melampygus would pursue individual fleeing prey as they swam for refuge among coral heads. This behavior is similar to that occasionally shown by various jack species (Caranx melampygus, C. ignobilis and C. caballus) when attacking tight schools of snappers, anchovies and herring respectively (Major 1978, Potts 1980, Parrish 1993),

Jacks using midwater hunting behaviors at Mustin's Gap displayed varying degrees of association with conspecifics. In experimental enclosures Caranx ignobilis showed a positive relation between the size of conspecific hunting groups and capture efficiency of schooling prey (Major 1978). The association patterns of $C$. melampygus were not directly measured in the reef channel in Johnston Atoll, but solitary hunting individuals seemed more abundant that groups of multiple individuals. In reef channels of Aldabra solitary hunting jacks were most common, occasionally seen hunting in groups of two or more individuals (Potts 1980), while on the reef slope of Aldabra most C. melampygus hunted in groups (Potts 1981). Different avoidance responses shown to solitary and group hunting jacks by potential prey in these two environments (Potts 1980, Potts 1983) indicate that conspecific associations of predators into hunting groups can have different adaptive advantages in different environments. Groups of jacks have been described dashing quasi- 
simultaneously into large schools of prey, even though after the initial approach, each individual predator behaved independently of the others while pursuing fleeing prey (Potts 1983, Parrish 1993). At Mustin's Gap, group attacks by C. melampygus were never observed, probably due to the different behavior of their prey. Spawning reef fishes will ascend up into the water column to spawn over locations with topographically complex substrates that offer them refuge from predators (Chapter 3). As soon as the first attack on a spawning rush occurred, all the fishes located in the vicinity would rush towards the substrate and hide among its crevices (personal observation), thus offering no targets for other predators to perform a group attack. Schooling midwater prey do not have access to a physical refuge, and confusion after an initial attack can be advantageous to other individual piscivores in subsequent group attacks (Potts 1983, Parrish 1993).

Caranx melampygus at Mustin's Gap performed ambushing attacks, which were very different than the midwater attacks previously discussed and have not been previously described for transient piscivores such as carangids. The success rate of ambush attacks was significantly higher than midwater attacks, indicating the advantage of an ambush behavior for feeding on spawning reef fishes.

The adoption by $C$. melampygus of an aggressive territorial behavior while ambushing their prey can be explained as a defense of a valuable resource (Milinski \& Parker 1991, Grant 1997). C. melampygus is typically a highly mobile transient predator (Holland et al. 1996), often showing gregarious behaviors while hunting (Potts 1980, Potts 1981, Potts 1983). The existence of an aggregation of vulnerable prey situated near a hiding location from which more successful ambush attacks can be launched is valuable enough to elicit the adoption of a territorial behavior to defend this resource. Intruding $C$. melampygus disrupted the normal spawning behavior of prey, which seemed essential for the successful completion of ambush attacks by ambushing individuals. The size of the 
territory was not quantified, but was estimated to cover an area of approximately $100 \mathrm{~m}^{2}$ around the ambushing location.

Territorial behaviors in response to feeding resources are hypothesized to be profitable when food items are found in high densities with a predictable spatially patchy distribution (Grant 1997). Group spawning fishes at Mustin's Gap form very dense spawning aggregations (Chapter 2) and use only certain areas of the channel as spawning locations (Chapter 3). Caranx melampygus individuals patrol large areas of reef during the daytime in search of prey (Holland et al. 1996). This behavior could allow jacks to detect any large accumulation of spawning fishes within their patrolling range, as indicated by the positive correlation found between abundance of C. melampygus and the abundance of group spawning prey species at Mustin's Gap (Chapter 3). The adoption of territorial behaviors by C. melampygus was limited in space, and only occurred during times of high abundance of spawning prey. Fish exposed to spatially clumped and predictable food sources will readily defend feeding territories to defend the resource (Magurran \& Seghers 1991, Barlow 1993).

The transformation of C. melampygus individuals into a pigmented phase occurred on every occasion that ambushing was observed. An hypothesis for this change is the potential cryptic benefit of a dark coloration while ambushing prey from beneath a coral head. A second hypothesis is the use of a dark coloration as a sign to conspecifics of the existence of a territory. This measure might be necessary for jacks since they only occasionally defend a territory, and it would express aggressive tendencies towards conspecifics (Archer 1988). Caranx melampygus has been observed establishing interspecific associations with the labrid Novaculichthys taeniourus (Potts 1980, G. Sancho personal observation). During these associations, the individual C. melampygus adopts a dark coloration, and will display aggressive behaviors towards other jacks approaching the labrid, in what seems to be a case of resource guarding behavior 
(Chapman \& Kramer 1996). The feeding behavior of $N$. taeniourus involves frequent overturning of rocks and pebbles along the substrate, and pigmented C. melampygus feed on crustaceans and small fish uncovered by the labrid. The behavior of $N$. taeniourus may provide a clumped and predictable food resource worth defending from conspecifics, and in this case, the dark coloration serves no cryptic function. Adoption of dark coloration during this association and also possibly during ambushing is therefore most likely an aggressive display signal directed at conspecifics.

All aggressive encounters between territorial dark C. melampygus and approaching light-colored conspecifics were resolved with a brief encounter and the fleeing of the intruding individuals. No serious aggressive escalation was observed among jacks. It was not clear if there was any size difference between territorial and intruding individuals. More studies are needed to address whether a dark coloration is an indication of the resource holding power of an individual, or if it just expresses aggressive intentions (Maynard Smith 1982).

The ambushing behavior displayed by C. melampygus probably kept the attacker out of sight from potential prey, while hiding a short distance from them. Fishes spawning in the absence of perceived predators typically left the substrate more readily than when predators were approaching, and would perform spawning activities farther up in the water column (personal observation). This behavior may increasie their risk of predation. Another potential benefit from using a hiding location situated close to a site used by spawning fishes is the reduction of the striking distance between predators and their prey (Dill 1973).

When compared with other studies measuring capture success rates of marine piscivores in the field, C. melampygus midwater attack success rates from Mustin's Gap were low $(2.0 \%)$, and similar to those measured for demersal stalking predators $(1.9 \%)$ feeding on spawning wrasses (Moyer 1987). These low capture rates indicate that rapid 
spawning rushes of reef fishes generally serve as a good defense against attacks of this predator. Ambushing increased the capture success of C. melampygus (16.7\%) to levels comparable to stalking lizardfishes $(12 \%)$ feeding on a variety of coral reef demersal fishes (Sweatman 1984) and two stalking predators (11-20\%) feeding on schooling herring (Parrish 1993). The only other field measurements of attack success by jacks showed high values (32- $48 \%$ ) for high-speed midwater attacks on schooling herring (Parrish 1993).

Caranx melampygus can act either as an ambush or a transient predator, according to the behavior, abundance and location of its prey. The higher success rate of ambush attacks by C. melampygus, which occur only at high prey densities, could produce negative density dependence in the survivorship of adult fishes (Hixon \& Carr 1997). Since C. melampygus is probably the most important large predator of diurnal reef fishes in the Indo-Pacific (Sudekum et al. 1991), the feeding behaviors adopted at specific locations by this piscivore can potentially have important effects on the mortality patterns of co-existing communities of reef fishes. This constitutes an example where specific predator-prey relations lead to behavioral modifications that could have effects at the population level. But more research is needed to address the occurrence of densitydependent mortality in prey populations that suffer both midwater and ambush attacks by C. melampygus. Knowledge on predator-prey behavioral relations will give insight to the importance of postrecruitment processes in adult coral reef fish community regulation, and will help predict the effects of changes in fisheries management of large predators in the populations of prey species. 


\section{BIBLIOGRAPHY}

Altmann, J. (1974). Observational study of behavior: sampling methods. Behavior. 49: $227-267$

Archer, J. (1988). The behavioural biology of aggression. Cambridge University Press, Cambridge

Barlow, G. W. (1993). The puzzling paucity of feeding territories among freshwater fishes. Mar. Behav. Physiol. 23: 155-174

Beets, J. (1997). Effects of a predatory fish on the recruitment and abundance of Caribbean coral reef fishes. Mar. Ecol. Prog. Ser. 148: 11-21

Caley, M. J. (1993). Predation, recruitment and the dynamics of communities of coralreef fishes. Mar. Biol. 117: 33-43

Caley, M. J. (1995). Reef-fish community and dynamics: an interaction between local and larger scale processes? Mar. Ecol. Prog. Ser. 129: 19-29

Chapman, M. R., Kramer, D. L. (1996). Guarded resources: the effect of intruder number on the tactics and success of defenders and intruders. Anim. Behav. 52: 8394

Curio, E. (1976). The ethology of predation. Springer-Verlag, Berlin

Dill, L. M. (1973). An avoidance learning sub-model for a general predation model. Oecologia. 13: 291-312

Godin, J.-G. J. (ed.) (1997a). Behavioral ecology of teleost fishes. Oxford University Press, Oxford

Godin, J.-G. J. (1997b). Evading predators. In: Godin, J.-G. J. (ed.). Behavioral ecology of teleost fishes. Oxford University Press, Oxford, p. 191-236

Grant, J. W. A. (1997). Territoriality. In: Godin, J.-G. J. (ed.). Behavioral ecology of teleost fishes. Oxford University Press, Oxford, p. 81-103

Hixon, M. A. (1991). Predation as a process structuring coral reef communities. In: Sale, P. F. (ed.) The ecology of fishes on coral reefs. Academic Press, San Diego, p. 475-508

Hixon, M. A. (1993). Predation, prey refuges, and the structure of coral-reef fish assemblages. Ecol. Monogr. 63: 77-101

Hixon, M. A., Beets, J. P. (1989). Shelter characteristics and Caribbean fish assemblages: experiments with artificial reefs. Bull. Mar. Sci. 44: 666-680

Hixon, M. A., Carr, M. H. (1997). Synergistic predation, density dependence, and population regulation in marine fish. Science. 277: 946-949 
Hixon, M. A., Menge, B. A. (1991). Species diversity, prey refuges modify the interactive effects of predation and competition. J. Theor. Biol. 39: 178-200

Hobson, E. S. (1968). Predatory behavior of some shore fishes in the Gulf of California. Research Report - U.S. Fish and Wildlife Service. 73: 1-92

Holland, K. N., Lowe, C. G., Wetherbee, B. M. (1996). Movements and dispersal patterns of blue trevally (Caranx melampygus) in a fisheries conservation zone. Fisheries Research. 25: 279-292

Juanes, F. (1994). What determines prey selectivity in piscivorous fishes? In: Stouder, D. J., Fresh, K. L., Feller, R. J. (ed.) Theory and application in fish feeding ecology. vol. 18. University of South Carolina Press, Columbia, p. 79-100

Magurran, A. E., Seghers, B. H. (1991). Variation in schooling and aggression amongst guppy (Poecilia reticulata) populations in Trinidad. Behaviour. 118: 214-234

Major, P. F. (1978). Predator-prey interactions in two schooling fishes, Caranx ignobilis and Stolephorus purpureus. Anim. Behav. 26: 760-777

Maynard Smith, J. (1982). Evolution and the theory of games. Cambridge University Press, Cambridge \& New York

Milinski, M., Parker, G. A. (1991). Competition for resources. In: Krebs, J. R., Davies, N. B. (ed.) Behavioural ecology: an evolutionary approach. Blackwell Scientific Publ., Oxford, p. 137-168

Moyer, J. T. (1987). Quantitative observations of predation during spawning rushes of the labrid fish Thalassoma cupido at Miyake-jima, Japan. Japan. J. Ichthyol. 34: 7681

Myers, R. F. (1991). Micronesian reef fishes: a practical guide to the identifiction of the inshore marine fishes of the tropical Central and Western Pacific. Coral Graphics, Guam

Ohguchi, O. (1981). Prey density and prey selection against oddity by three-spined sticklebacks. Advances in Ethology. 23: 1-79

Parrish, J. K. (1993). Comparison of the hunting behavior of four piscine predators attacking schooling prey. Ethology. 95: 233-246

Pitcher, T. J., Parrish, J. K. (1993). Function of shoaling behavior in teleosts. In: Pitcher, T. J. (ed.) The behaviour of teleot fishes. Chapman \& Hall, London, p. 363440

Potts, G. W. (1980). The predatory behavior of Caranx melampygus (Pisces) in the channel environment of Aldabra Atoll (Indian Ocean). J. Zool., Lond. 192: 323-350 
Potts, G. W. (1981). Behavioral interactions between Carangidae (Pisces) and their prey on the fore-reef slope of Aldabra, with notes on other predators. J. Zool., Lond. 195: $385-404$

Potts, G. W. (1983). The predatory tactics of Caranx melampygus and the response of its prey. In: Noakes, L. G., Lindquist, D. G., Helfman, G. S., Ward, J. A. (ed.) Predators and prey in fishes. Dr. W. Junk, The Hague, p. 181-191

Sih, A., Crowley, P., McPeek, M., Petranka, J., Strohmeier, K. (1985). Predation, competition and prey communities: a review of field experiments. Ann. Rev. Ecol. Syst. 16: 269-311

Stouder, D. J., Fresh, K. L., Feller, R. J. (eds.). (1994). Theory and application in fish feeding ecology. Belle W. Baruch Library in Marine Sciences, no. 18. University of South Carolina Press, Columbia, SC

Sudekum, A. E., Parrish, J. D., Radtke, R. L., Ralston, S. (1991). Life history and ecology of large jacks in undisturbed, shallow, oceanic communities. Fish. Bull. 89: 493-513

Sweatman, H. P. A. (1984). A field study of the predatory behavior and feeding rate of a piscivorous coral reef fish, the lizardfish Synodus englemani. Copeia. 1984: 187-194 
Table 1. Comparison between success rates of midwater and ambush attack behaviors.

\begin{tabular}{lll}
\hline & Midwater Attack & Ambush Attack \\
\hline Number of attacks & 149 & 24 \\
Number of kills & 3 & 4 \\
Attack success rate & $2.0 \%$ & $16.7 \% *$ \\
\hline
\end{tabular}

(*) Fisher's exact test; $p<0.01$ 
Table 2. Description of each successful attack by Caranx melampygus observed at Mustin's Gap.

\begin{tabular}{|c|c|c|c|}
\hline Date & Time & Behavior & Description of successful attacks \\
\hline 13 Apr 1994 & 1500 & midwater & $\begin{array}{l}\text { Midwater attack on group rushing Chlorurus sordidus (Scaridae), but during the pursuit } \\
\text { captured among the coral heads a Chaetodon trifascialis (Chaetodontidae), a territorial } \\
\text { butterflytish not involved in any spawning activities (accidental capture). }\end{array}$ \\
\hline 15 Apr 1994 & 1537 & ambush & $\begin{array}{l}\text { From an ambushing position attack on group rushing Acanthurus nigroris } \\
\text { (Acanthuridae). The same individual C. melampygus intermittently displayed } \\
\text { ambushing behavior from } 1435 \text { to } 1615 \text { hours. }\end{array}$ \\
\hline 27 Apr 1994 & 1508 & midwater & $\begin{array}{l}\text { Attack on group rushing Chlorurus sordidus. During this time Acanthurus nigroris was } \\
\text { dominant spawning species and the spawning grounds. }\end{array}$ \\
\hline 29 Apr 1994 & 1523 & ambush & $\begin{array}{l}\text { Ambushing attack on group rushing Acanthurus nigroris. The same C. melampygus } \\
\text { individual was observed ambushing between } 1405 \text { and } 1643 \text { hours. }\end{array}$ \\
\hline 13 Apr 1995 & 1934 & midwater & $\begin{array}{l}\text { While patrolling over spawning grounds, attack on a trio of rushing Ctenochaetus } \\
\text { strigosus. One of the few attacks observed at dusk. }\end{array}$ \\
\hline 28 Apr 1995 & 1516 & ambush & $\begin{array}{l}\text { Ambush attack on group rushing Chlorurus sordidus. Ambushing was only observed in } \\
\text { the } 1500 \text { to } 1530 \text { time period. }\end{array}$ \\
\hline 5 May 1995 & 1511 & ambush & $\begin{array}{l}\text { Attack on group rushing Chlorurus sordidus by an ambushing jack very involved in } \\
\text { driving away other conspecifics from the spawning site. The same individual pigmented } \\
C \text {. melampygus was observed ambushing intermittently between } 1511 \text { and } 1530 \\
\text { hours. }\end{array}$ \\
\hline 16 May 1995 & 1318 & midwater & $\begin{array}{l}\text { Midwater attack on group rushing Chlorurus sordidus by a patrolling fish while two } \\
\text { pigmented C. melampygus were ambushing in the sampling area. }\end{array}$ \\
\hline
\end{tabular}


Figure 1. Schematic representation of a midwater attack sequence by Caranx melampygus on spawning prey. Patrolling fish swim along the channel, can show gregarious behaviors, and display a light coloration. See results section for more details. 


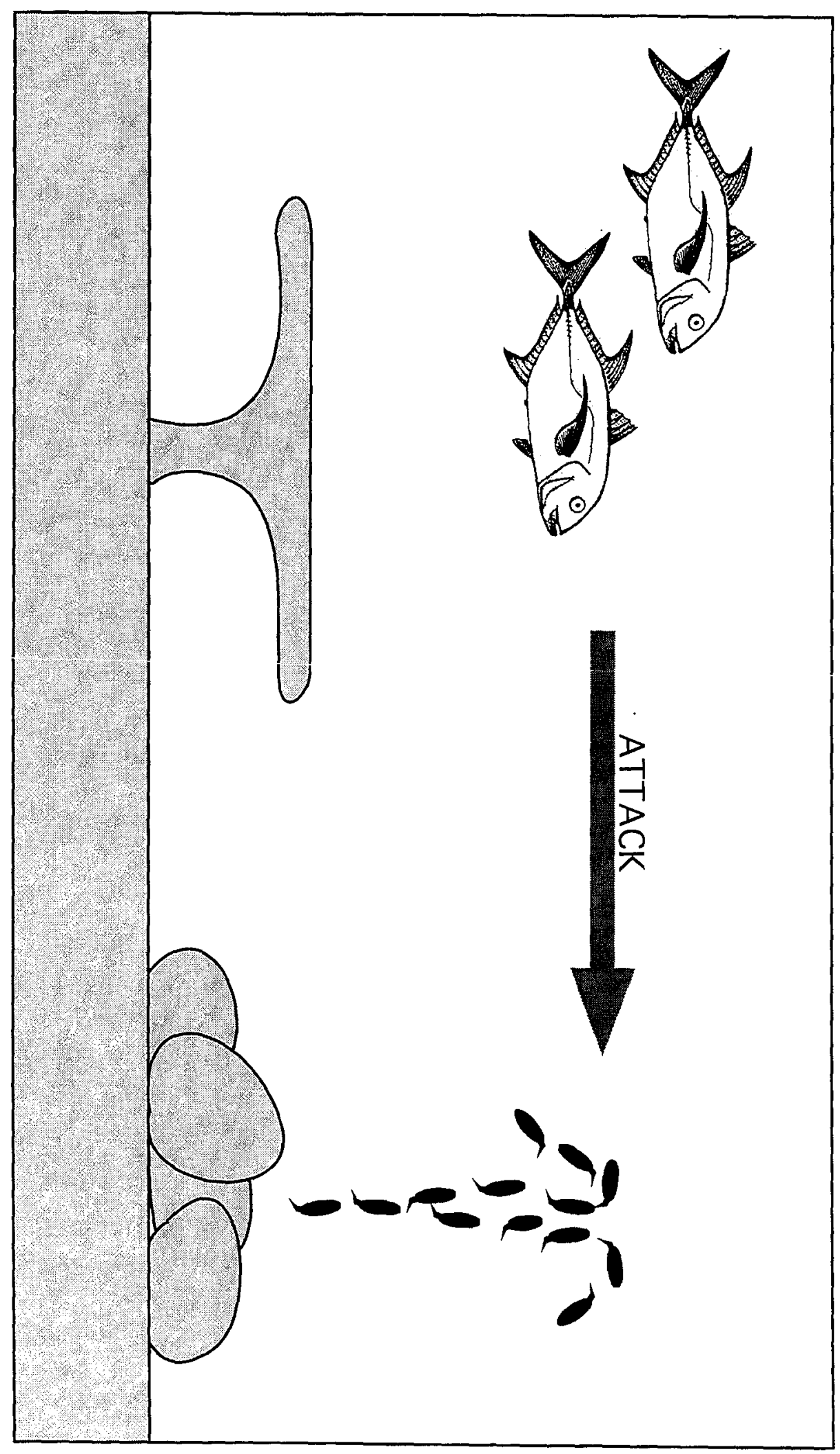


Figure 2. Schematic representation of an ambushing attack sequence by Caranx melampygus on spawning prey. Fish ambush their prey from underneath a coral head, show aggressive territorial behavior against conspecifics and adopt a dark coloration. See results section for more details. 


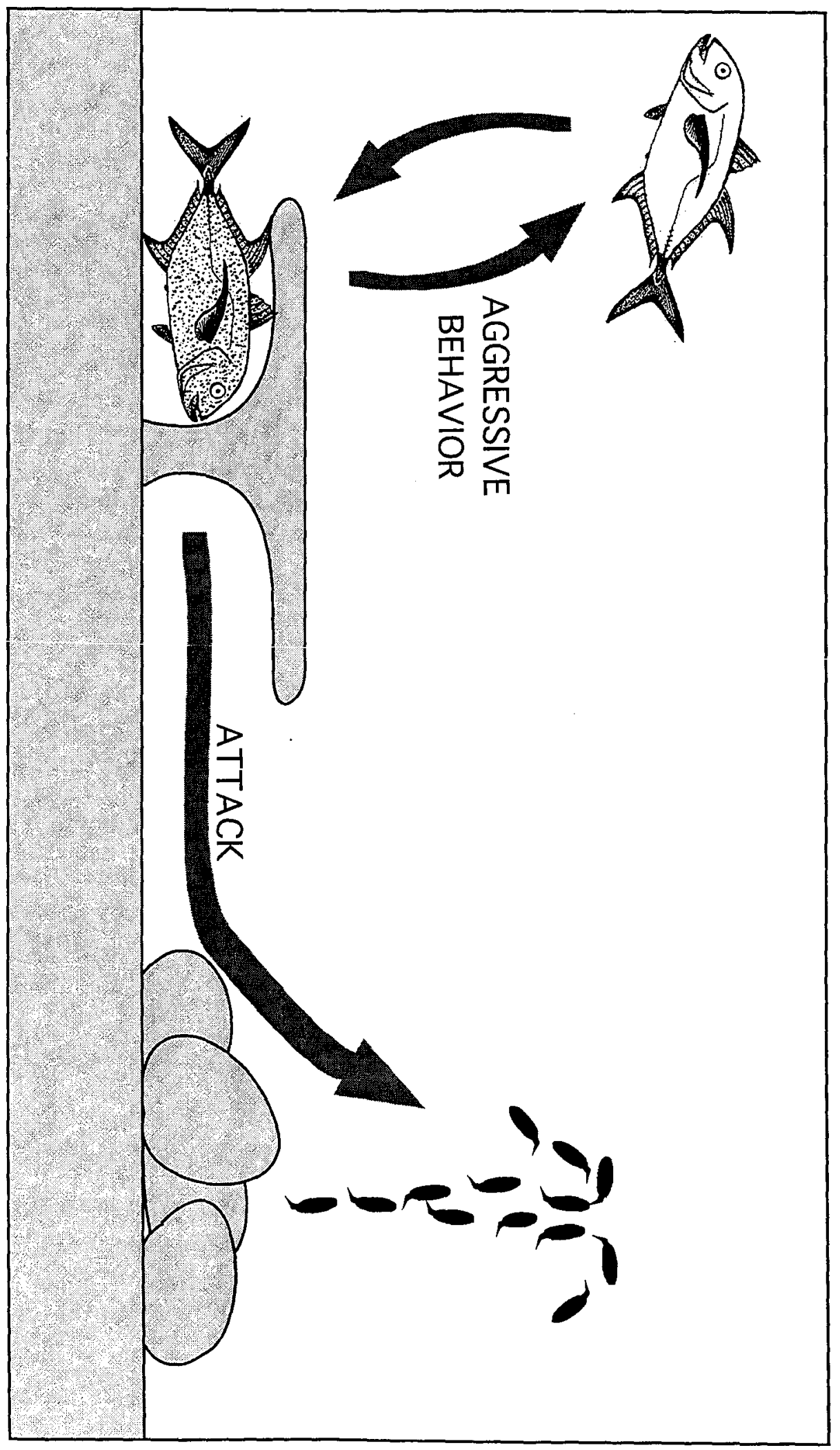


Figure 3. Diel distribution of hunting C. melampygus displaying midwater and ambushing behaviors, during 1994 (A) and 1995 (B). Presence of C. melampygus is expressed as the percentage of minutes they were observed at the sampling area. Data are averages per 15minute observation (+SE). 

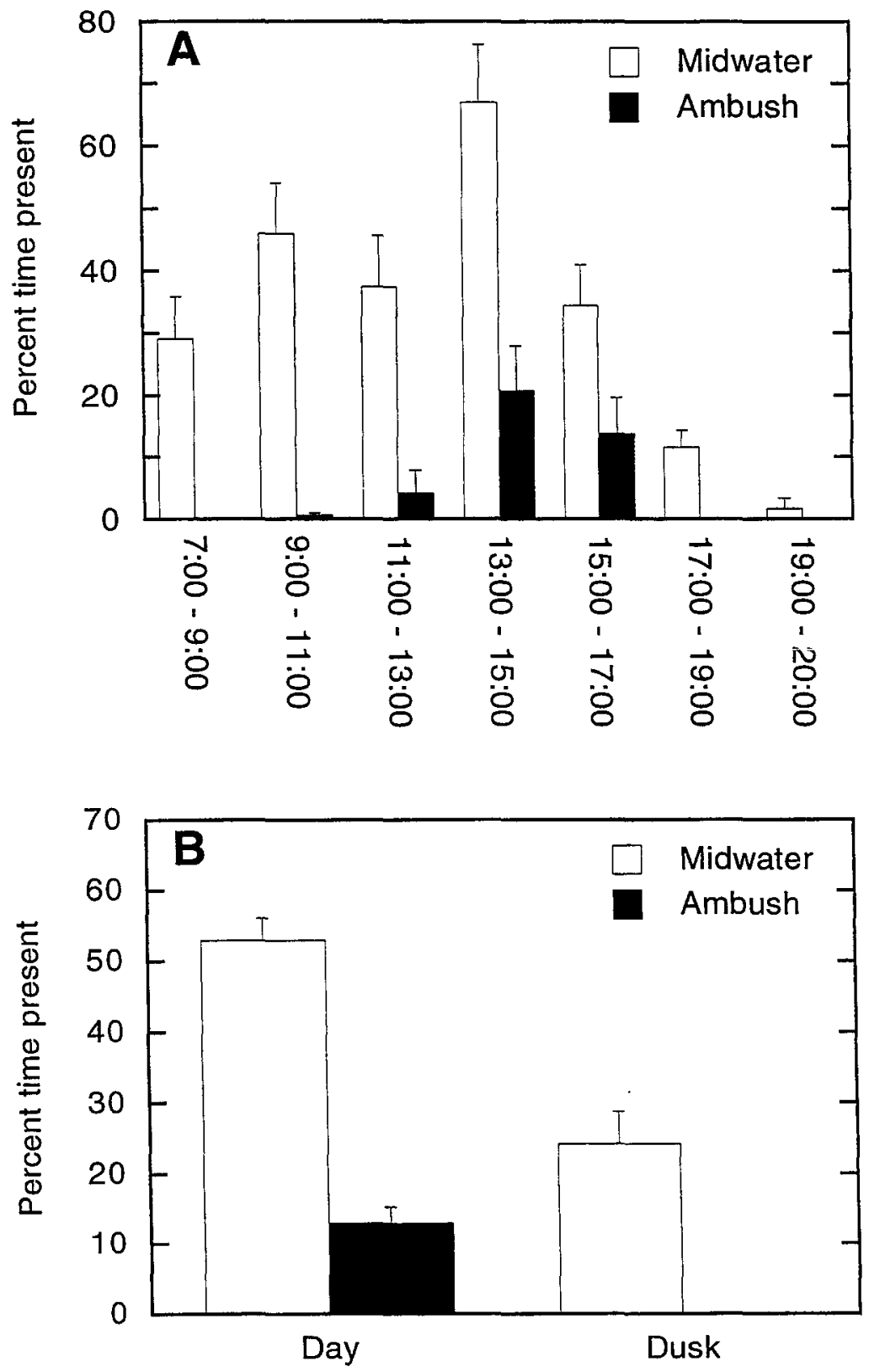


\section{CHAPTER 5}

Influence of predation and male competition on the height of spawning ascents in trunkfishes (Ostraciidae) 


\section{ABSTRACT}

Two species of trunkfishes (Ostraciidae) were observed spawning above a coral reef at Johnston Atoll (Central Pacific). This study analyzed the potential causes determining the difference in spawning ascent height in Ostracion meleagris $(3.3 \mathrm{~m}$ average) and $O$. whitleyi (1.5 $\mathrm{m}$ average). One hypothesis proposes that the risk of predation by piscivores influences how far each species can swim from the substrate, and that predation risk is greater for $O$. whitleyi than $O$. meleagris. Trunkfishes have an armoured exoskeleton and secrete an ichthyotoxic mucous under stress conditions, two defenses against predation. Because the two species used the same spawning grounds and spawned at approximately the same time, their size and toxicity levels were analyzed to assess their susceptibility to predation. Toxins were extracted from wild fishes and tested using a mosquitofish assay. Ostracion whitleyi was more toxic than $O$. meleagris, refuting the predation-risk hypothesis. A second hypothesis proposes that long ascents are a way for spawning pairs to avoid disturbances by other male conspecifics. Observations of the spawning behaviours of the two species showed that male $O$. meleagris were frequently involved in fighting episodes and showed high rates of male streaking (intruding nonpaired males attempting to fertilize eggs from spawning paired females), while none of these behaviours were observed in $O$. whitleyi. The larger spawning height from the substrate may be an attempt by pairs of $O$. meleagris to reduce the possibility of interference by other male conspecifics. Thus, the height of spawning ascents corresponds to the expectation from the male disturbance hypothesis, but not to the expectation of the predatory risk hypothesis. 


\section{INTRODUCTION}

Most coral reef fishes perform a spawning ascent into the water column to release their gametes. The function of this rushing behaviour has been hypothesized to reduce the predation on gametes by benthic filter-feeding invertebrates and small planktivorous fishes (Robertson \& Hoffman 1977, Johannes 1978). The height and speed of spawning rushes vary greatly among different species of reef fishes. The reasons for this variability are unclear, but the most common hypothesis states that the height of spawning results from two competing selective pressures: the risk of egg predation by benthic planktivorous organisms, and the risk of predation on adult fishes while spawning (for review see Thresher 1984). An alternative factor hypothesized to affect spawning ascent behaviours is the avoidance of sperm competition from males with alternative mating tactics (Myrberg et al. 1989).

By using a comparative approach, I examined which factors potentially influenced the spawning height of two trunkfish (Ostraciidae) species: Ostracion meleagris (Jenkins) and $O$. whitleyi (Fowler). Preliminary observations indicated that both species had equally slow spawning ascents, but $O$. meleagris released its gametes much higher in the water column than $O$. whitleyi. Because both species were observed spawning roughly at sunset, diel activity patterns of predators were expected to equally affect predation risks for the two species. The hypotheses analyzed in this study were:

Hypothesis 1. Spawning height is controlled by risk of predation on adults. Predatory pressures on adult fishes are expected to affect the spawning height of reef fishes, since they use the reef substrate as a refuge from predators (Hixon 1991), and piscivores preferentially attack spawning fishes during their spawning ascent (Moyer 1987). If predation risks on adults are important in determining the height of spawning, 
then species spawning high in the water column are expected to have stronger defenses against predation by piscivores than species spawning closer to the substrate.

The susceptibility of adult spawning fishes to predation can be affected by various factors, including body size and the existence of specific antipredatory adaptations (Godin 1997, Smith 1997). Large prey are more difficult for piscivores to ingest than small prey, and therefore, larger species might be expected to spawn higher in the water column than smaller ones. Based on the preliminary spawning height observations, I would predict that adult $O$. meleagris should be larger than $O$. whitleyi individuals. Trunkfishes have two obvious antipredatory adaptations: armoured exoskeletons and production of toxic secretions. The exoskeletons of $O$. meleagris and $O$. whitleyi are described as morphologically similar (Randall 1972), and therefore are expected to equally reduce predatory risks for both species. Trunkfishes have shown the ability to secrete ichthyotoxic substances through their skin in situations of stress (Thompson 1964) such as during an attack by a predator. Toxicity has been measured for $O$. meleagris (Thompson 1964, Boylan \& Scheuer 1967), but not for O. whitleyi. Differences in toxicity have been detected among trunkfish species in Australia (Goldberg et al. 1988), which were attributed to quantitative differences in both the amount of secretion produced and the chemical composition of the toxins. If predator responses to toxicity control the height of spawning of trunkfishes, I would predict that $O$. meleagris should be significantly more toxic than $O$. whitleyi.

Hypothesis 2. Spawning height is influenced by intraspecific male competition. Under circumstances of intense competition among male fishes, extended spawning ascents away from the substrate could be an avoidance response by pair-spawning fishes to spawning parasitism by conspecific males, referred to as "streaker" males (Warner et al. 1975). In pair-spawning fishes such as trunkfishes, streaker males rush from the substrate towards mating fishes and release sperm simultaneously with the spawning pair. 
Spawning far away from the substrate is expected to hinder the approach of streaker males, and reduce their chances of fertilizing the female's eggs. If long ascents away from the substrate serve as a mechanism to reduce spawning competition by streaker males, then spawning populations of $O$. meleagris are expected to have higher competition among males than $O$. whitleyi populations. This potential difference should be reflected by higher rates of male aggression and streaking events in $O$. meleagris than in $O$. whitleyi.

In order to test the above hypotheses regarding the factors controlling the height of spawning ascents of $O$. meleagris and $O$. whitleyi, I compared their relative sizes (Hypothesis 1), levels of toxicity (Hypothesis 1) and male-male aggression rates (Hypothesis 2).

\section{METHODS}

\section{Behavior}

All observations of Ostracion meleagris and Ostracion whitleyi took place at a reef channel along the NW reef crest of Johnston Atoll (Central Pacific). Within the reef channel, a sampling area of $170 \mathrm{~m}^{2}$ was monitored by an observer using SCUBA while laying on the substrate. Observations started approximately at $1900 \mathrm{~h}$, and lasted until all spawning activity by trunkfishes had ceased, approximately one hour after. Data were collected for 18 days during 1994 and 1995, totaling 990 minutes of observation.

Behavioral events of trunkfishes were recorded every minute on underwater paper. These events included successful spawnings, male-male aggressive encounters, and interrupted spawning ascents due to intrusions by streaker males or by planktivorous triggerfishes (Melichthys niger and M. vidua). For each successful spawning event, the number of fish involved in gamete release was recorded and the height off the substrate was estimated to the nearest meter. 


\section{Toxicity}

During 1995, a total of $14 O$. meleagris and $11 O$. whitleyi were captured for toxin extraction. Fish were captured while SCUBA diving with hand nets and transported live in buckets to the laboratory. Toxins are not found in dead trunkfishes, but are produced as a mucous secretion by epidermic multi-cellular glands in live fishes under distress conditions (Thompson 1964, 1968, Boylan \& Scheuer 1967). Toxins were extracted by placing newly-captured live fish in glass beakers with $70 \mathrm{ml}$ of distilled water. Fishes were continuously swirled around for two minutes and rinsed with distilled water to produce 100 $\mathrm{ml}$ of aqueous solution. To avoid bacterial detoxification, aqueous solutions were immediately heated $\left(100^{\circ} \mathrm{C}\right)$ after extraction and then frozen for preservation (Thompson 1964). After the toxin extraction, fish were weighed, measured (standard length) and placed in a large volume tank for observation. Fish showing normal swimming behaviour were released immediately, while those with erratic swimming patterns due to toxin overexposure were sacrificed following IACUC animal care guidelines.

Potency of the toxin extracts was measured through a bioassay modified after Coll et al. (1982), using common mosquitofish (Gambusia affinis) collected from warm brackish waters. Four mosquitofish were placed in each of six replicate glass jars containing $70 \mathrm{ml}$ of filtered seawater, to which $0.25 \mathrm{ml}$ of toxic solution were added. Assays were all done at a temperature between 19 and $21^{\circ} \mathrm{C}$. The amount of toxic excretion used in these assays $(0.25 \mathrm{ml})$ was chosen because in preliminary experiments it caused $50 \%$ mosquitofish mortality in approximately 30 minutes (Figure 1), thus avoiding the degradation of toxins at room temperature (Thompson 1964, Boylan \& Scheuer 1967). Assays were always done in pairs, simultaneously testing extracts from $O$. meleagris and O. whitleyi individuals. Toxicity for each of 12 trunkfishes tested (Table 1) was estimated through a toxicity index, calculated as the inverse of the average number of minutes 
necessary to reach $50 \%$ mosquitofish mortality, multiplied by the weight (kilograms) of each individual trunkfish (units $=1 / \mathrm{kg} \cdot \mathrm{min}$ ). On the three occasions when no mortality of mosquitofish occurred with toxic extracts from $O$. meleagris, a time equal to that of the least toxic individual (100 minutes) was used for toxicity estimation.

Non-parametric tests (Mann-Whitney U and Kruskall-Wallis $\mathrm{H}$ ) were used to compare differences between trunkfish species.

\section{RESULTS}

During the field component of this study, O. meleagris and $O$. whitleyi were observed spawning 85 and 6 times respectively. Each species spawned exclusively during the dusk period (Figure 2), but $O$. meleagris spawned on average ten minutes before $O$. whitleyi (at 6 and 16 minutes after sunset respectively; Mann-Whitney $U=72 ; p=0.003$ ). As preliminary observations indicated, O. meleagris spawned significantly higher in the water column than $O$. whitleyi (Figure 3A). The spawning height of $O$. meleagris remained constant (average of $3.3 \mathrm{~m}$ ) during the entire spawning period (Kruskall-Wallis $\mathrm{H}$ $=4.4 ; \mathrm{p}=0.351 ; \mathrm{n}=5$ categories), including the later times when $O$. whitleyi spawned (Figure 2).

The two trunkfish species had the same average size (Figure 3B), measured as weight (Mann-Whitney $U=58 ; p=0.112$ ) and standard length (Mann-Whitney $U=52.5$; $\mathrm{p}=0.180$ ). The toxicity assay indicated that $O$. whitleyi was more toxic than $O$. meleagris (Figure 3C), a result that was contrary to the prediction from the predation risk hypothesis.

No social male-male interactions were observed in $O$. whitleyi, but they were observed frequently among $O$. meleagris males. Aggressive encounters in $O$. meleagris consisted of circular swimming bursts and ramming events between two opposing males, which lasted for a few seconds. These encounters were observed both around coral heads and up in the water column. At total of 71 aggressive encounters were observed between 
O. meleagris males not involved in spawning ascents, the majority prior to the most active spawning period (Figure 4A).

Pairs of $O$. meleagris ascending through the water column to spawn were frequently intercepted by single males swimming from the substrate. These encounters typically resulted in midwater aggressive encounters between ascending and intruder males, while females abandoned the ascent and returned the substrate. Intruding males caused the interruption of 251 spawning ascents (Figure 4B). The interruption of the spawning was caused by females darting quickly away upon sighting an approaching intruder, and by intruder males directly attacking the ascending male. I observed spawning ascents that were interrupted repetitive times by multiple males, and females performed successive short ascents with different male fishes after each interruption. Observations of four and five fighting events during single ascent were not uncommon. Gamete release by $O$. meleagris took place in the characteristic spawning position of trunkfishes, with male and female side by side, both curling their caudal fins in opposite directions and facing away from each other (for pictures see Moyer 1979). While the pair were in spawning position, streaker males often quickly joined them, positioning their caudal area as close as possible to the caudal regions of the spawning pair. Streaking events usually involved one or two extra males, but up to five male fishes were observed simultaneously spawning with a single female $O$. meleagris, forming a "rosette" of fishes with their caudal regions in the center. Successful streaking was observed in 33 out of 85 O. meleagris spawns (Figure 4C), which constitutes a streaking rate of $39 \%$. On average, O. meleagris spawns in which streaker males were successful occurred later in the evening than uninterrupted pair-spawns (Mann-Whitney $\mathrm{U}=577 ; \mathrm{p}=0.011$; Figure 4c). The height of spawning events of $O$. meleagris did not vary with streaking (Mann-Whitney $\mathrm{U}=790$; $\mathrm{p}=0.807$ ).

The spawning sequence of $O$. whitleyi involved an approach by a male upon sighting a female among the substrate, a slow ascent into the water column with the male 
positioning his snout against the back of the female, and the adoption of a spawning position followed by the release of gametes. All these behaviours were done in a similar manner as $O$. meleagris.

\section{DISCUSSION}

The relative adult size and toxicity of the two trunkfish species did not support the hypothesis that differences in predation risks determine the spawning height in trunkfishes. The two species were the same size, and their differences in toxicity did not correspond to the predictions, since the most toxic species ( $O$. whitleyi) spawned closest to the substrate. Instead, the results are consistent with the hypothesis that high spawning ascents are a result of intraspecific competition among male fishes. The population of $O$. meleagris, the species which spawned highest in the water column, showed signs of intense competition among males during spawning, which were never observed in the population of $O$. whitleyi.

Predation on adults is generally considered an important selective mechanism in influencing the spawning behaviours of fishes (Lima \& Dill 1990). In razorfishes (Labridae), the perceived risk of predation has been shown to reduce their spawning height (Nemtzov 1994). Similarly, the height of spawning rushes of bucktooth parrotfish (Scaridae) is related to the size of the spawning female (Marconato \& Shapiro 1996). The apparent lack of influence of size and toxicity levels in determining the spawning ascent of trunkfishes indicates that the two trunkfish species from this study are probably relatively immune to predatory pressures. Independence from predatory pressure is an argument used to explain the spawning behaviour of certain toxic pufferfishes (Tetraodontidae) (Gladstone \& Westoby 1988). Adult trunkfishes are rarely found in gut content analyses of coral reef piscivores (Sweatman 1984, Shpigel \& Fishelson 1989, Kingsford 1992), but 
have been found in the stomachs of a few large carangids (Sudekum et al. 1991), indicating that their anti-predatory adaptations are not completely successful in avoiding predation.

A second explanation for the lack of correspondence between spawning ascent height and potential predation risks at Johnston Atoll could be that the overall activity of predators at the spawning grounds at dusk was minimal. Many piscivores that feed on reef fishes are generally diurnal (Sweatman 1984, Shpigel \& Fishelson 1989), and jacks and snappers feeding on spawning fishes at the location where this study took place had their lowest activity levels at dusk (Chapter 3 ). The abundance and variety of dusk-spawning fish species that have long spawning ascents also suggests that dusk is a period with low predatory risk for adult fishes (Thresher 1984).

Trunkfishes are generally territorial fishes, with males defending groups of females within a territory close to the substrate (Moyer 1979). Aggressive encounters between males have been observed in O. meleagris at other locations (Lobel 1996) and in other trunkfish species (Moyer 1979), but at much lower rates than those of O. meleagris described in this paper. Streaking behaviours have been observed in various families of reef fishes, but had never been described in trunkfishes. Although spawning streaker males successfully spawned with ascending pairs throughout the spawning period, these events were most frequent late in the evening. This pattern could be related to a higher tolerance of spawning pairs to intruders as light levels quickly decrease and the opportunities for spawning on a given day come to an end.

By releasing eggs far above conspecifics positioned close to the substrate, spawning pairs of $O$. meleagris could be attempting to hinder the action of streaker males. Trunkfishes are slow swimmers, so ascending high in the water column would give spawning pairs a chance to release their gametes before streaker males could locate and reach them. It is not clear which member of a spawning pair, the male or the female, determines when to conclude an ascent and begin gamete release. This decision could 
depend on the relative fitness costs caused by streaking and on the swimming characteristics of spawning pairs. By avoiding streakers, the principal spawning male ensures exclusive fertilization of the eggs released by the female. Females can benefit from avoiding streakers by maintaining control of mate selection (Gross 1996). But females could also potentially gain from allowing streaker participation, by achieving higher fertilization rates (Petersen 1991, Warner et al. 1995, Marconato \& Shapiro 1996, Marconato et al. 1997).

During the spawning ascent, males position their snout against the back of the female carapace, following her through the water column (personal observation). From this position the male would occasionally "bump" the female, a behaviour observed in other trunkfish species with long spawning ascents (Moyer 1979), which could force her to continue the ascent. If this is true, the male could partially determine the location of gamete release within the water column.

Ostracion whitleyi were less abundant at the spawning site than $O$. meleagris. I suspect their low population density resulted in the absence of obvious interspecific competition among males for spawning opportunities. I suggest that $O$. whitleyi pairs performed short ascents, spawning just one or two meters above the substrate, because of the absence of aggressive conspecific males.

Comparative studies at other locations where natural populations of different densities exist are necessary to determine the flexibility of spawning heights in response to spawning competition among males. The spawning heights of $O$. meleagris within populations where male competition does not occur are expected to be lower than those observed in this study. Similarly, spawning heights of $O$. whitleyi are expected to increase within dense populations, if this species develops aggressive behaviors similar to those of o. meleagris. Estimations of fitness costs of streaking behaviours, female mate choice and 
fertilization rates are not available, but will be necessary to fully understand the precise selective mechanisms influencing spawning behaviour in trunkfishes.

In conclusion, the observed patterns of spawning height of two species of trunkfishes did not conform to expectations based on their relative size and toxicity levels, but corresponded to those based on male-male competition patterns. I suggest that risk of predation is not a selective factor in determining the height of spawning in trunkfishes, but that male competition seems to influence the observed spawning patterns. 


\section{BIBLIOGRAPHY}

Boylan, D. B., Scheuer, P. J. (1967). Pahutoxin: a fish poison. Science. 155: 52-56

Coll, J. C., La Barre, S., Sammarco, P. W., Willimas, W. T., Bakus, G. J. (1982). Chemical defenses in soft corals (Coelenterata: Octocorallia) of the Great Barrier Reef: A study of comparative toxicities. Mar. Ecol. Prog. Ser. 8: 271-278

Gladstone, W., Westoby, M. (1988). Growth and reproduction in Canthigaster valentini (Pisces: Tetraodontidae): a comparison of a toxic reef fish with other reef fishes. Env. Biol. Fish. 21: 207-221

Godin, J.-G. J. (1997). Evading predators. In: Godin, J.-G. J. (ed.) Behavioral ecology of teleost fishes. Oxford University Press, Oxford, p. 191-236

Goldberg, A. S., Duffield, A. M., Barrow, K. D. (1988). Distribution and chemical composition of the toxin skin secretions from trunkfish (family Ostraciidae). Toxicon. 26: $651-663$

Gross, M. R. (1996). Alternative reproductive strategies and tactics: diversity within sexes. TREE. 11: 92-98

Hixon, M. A. (1991). Predation as a process structuring coral reef communities. In: Sale, P. F. (ed.) The ecology of fishes on coral reefs. Academic Press, San Diego, p. 475-508

Hobson, E. S. (1991). Trophic relationships of fishes specialized to feed on zooplankters above coral reefs. In: Sale, P. F. (ed.) The ecology of fishes on coral reefs. Academic Press, San Diego, p. 69-95

Johannes, R. E. (1978). Reproductive strategies of coastal marine fishes in the tropics. Env. Biol. Fish. 3: 65-84

Kingsford, M. J. (1992). Spatial and temporal variation in predation on reef fishes by coral trout (Plectropomus leopardus, Serranidae). Coral Reefs. 11: 193-198

Lima, S. L., Dill, L. M. (1990). Behavioral decisions made under the risk of predation: a review and prospectus. Can. J. Zool. 68: 619-639

Lobel, P. S. (1996). Spawning sound of the trunkfish, Ostracion meleagris (Ostraciidae). Biol. Bull. 191: 308-309

Marconato, A., Shapiro, D. Y. (1996). Sperm allocation, sperm production and fertilization rates in the bucktooth parrotfish. Anim. Behav. 52: 971-980

Marconato, A., Shapiro, D. Y., Petersen, C. W., Warner, R. R., Yoshikawa, T. (1997). Methodological analysis of fertilization rate in the bluehead wrasse Thalassoma bifasciatum: pair versus group spawns. Mar. Ecol. Prog. Ser. 161: 61-70 
Moyer, J. T. (1979). Mating strategies and reproductive behavior of Ostraciid fishes at Miyake-jima, Japan. Japan. J. Ichthyol. 26: 148-160

Moyer, J. T. (1987). Quantitative observations of predation during spawning rushes of the labrid fish Thalassoma cupido at Miyake-jima, Japan. Japan. J. Ichthyol. 34: 7681

Myrberg, A. A., Montgomery, W. L., Fishelson, L. (1989). The reproductive behavior of Acanthurus nigrofuscus (Forskal) and other surgeonfishes (Fam. Acanthuridae) off Eilat, Israel (Gulf of Aqaba, Red Sea). Ethology. 79: 31-61

Nemtzov, S. C. (1994). Intraspecific variation in sand-diving and predator avoidance behavior of green razorfish, Xyrichtys splendens (Pisces: Labridae): effect on courtship and mating suscess. Env. Biol. Fish. 41: 403-414

Petersen, C. W. (1991). Variation in fertilization rate in the tropical reef fish, Halichoeres bivittatus: correlates and implications. Biol. Bull. 181: 232-237

Pitcher, T. J., Turner, J. R. (1986). Danger at dawn: experimental support for the twighlight hypothesis in shoaling minnows. J. Fish Biol. 29: 59-70

Randall, J. E. (1972). The Hawaiian trunkfish of the genus Ostracion. Copeia. 4: 756767

Robertson, D. R., Hoffman, S. G. (1977). The roles of female mate choice and predation in mating systems of some tropical labroid fishes. Z. Tierpsychol. 45: 298320

Shapiro, D. Y., Hensley, D. A., Appledoorn, R. S. (1988). Pelagic spawning and egg transport in coral-reef fishes: a skeptical overview. Env. Biol. Fish. 22: 3-14

Shpigel, M., Fishelson, L. (1989). Food habits and prey selection of three species of groupers from the genus Cephalopholis (Serranidae: Teleostei). Env. Biol. Fish. 24: $67-73$

Smith, R. J. F. (1997). Avoiding and deterring predators. In: Godin, J.-G. J. (ed.) Behavioral ecology of teleost fishes. Oxford University Press, Oxford, p. 163-189

Sudekum, A. E., Parrish, J. D., Radtke, R. L., Ralston, S. (1991). Life history and ecology of large jacks in undisturbed, shallow, oceanic communities. Fish. Bull. 89: 493-513

Sweatman, H. P. A. (1984). A field study of the predatory behavior and feeding rate of a piscivorous coral reef fish, the lizardfish Synodus englemani. Copeia. 1984: 187-194

Thompson, D. A. (1964). Ostacitoxin: an ichthyotoxic stress secretion of the boxfish, Ostracion lentiginosus. Science. 146: 244-245

Thompson, D. A. (1968). Trunkfish toxins. Transactions from the drugs from the sea symposium, University of Rhode Island. Marine Technology Society, Washington D.C. 203-211 
Thresher, R. E. (1984). Reproduction in reef fishes. T.F.H. Publications, Neptune City. $399 \mathrm{pp}$

Warner, R. R., Robertson, D. R., Leigh, E. G. (1975). Sex change and sexual selection. Science. 190: 633-638 
Table 1. Toxicity of Ostracion meleagris and Ostracion whitleyi extracts used in toxicity tests. Two individuals of the same sex and different species were tested simultaneously. In each toxicity assay, $0.25 \mathrm{ml}$ of toxic extracts were added to six jars containing mosquitofishes. The number of minutes until the death of $50 \%$ of mosquitofishes in each jar $(n=6)$ was recorded, and their average $( \pm$ standard error) was calculated for each individual fish.

\begin{tabular}{|c|c|c|c|c|c|}
\hline \multicolumn{3}{|c|}{ Ostracion meleagris } & \multicolumn{3}{|c|}{ Ostracion whitteyi } \\
\hline Fish no. (sex) & weight $(\mathrm{g})$ & $\min \pm S E$ & Fish no. (sex) & weight $(\mathrm{g})$ & $\min \pm S E$ \\
\hline 1 (male) & 121.2 & (no deaths) & 1 (male) & 58.8 & $20.3 \pm 0.6$ \\
\hline 2 (female) & 22.2 & $99.7 \pm 9.4$ & 2 (female) & 25 & $43.3 \pm 3.2$ \\
\hline 3 (male) & 110.4 & (no deaths) & 3 (male) & 52.1 & $25 \pm 0.7$ \\
\hline 4 (female) & 53.1 & $60.7 \pm 3.6$ & 4 (female) & 53.8 & $33 \pm 1.4$ \\
\hline 5 (female) & 74.3 & (no deaths) & 5 (female) & 57.1 & $61.7 \pm 4.1$ \\
\hline 6 (male) & 44.6 & $42 \pm 1.5$ & 6 (male) & 41.1 & $30 \pm 1.7$ \\
\hline
\end{tabular}


Figure 1. Toxic effects of increasing amounts of toxic extracts of Ostracion meleagris and Ostracion whitleyi. The $\mathrm{X}$-axis represents the amount $(\mathrm{ml})$ of original toxic extract added to jars with mosquitofish in the toxicity assay (see methods). Toxicity Index (Y-axis) is calculated as the inverse of the product of trunkfish weight $(\mathrm{kg})$ by the number of minutes necessary to kill $50 \%$ of fishes in the mosquitofish assay. Both variables have been logtransformed and linear regression curves have been fitted to the data. 


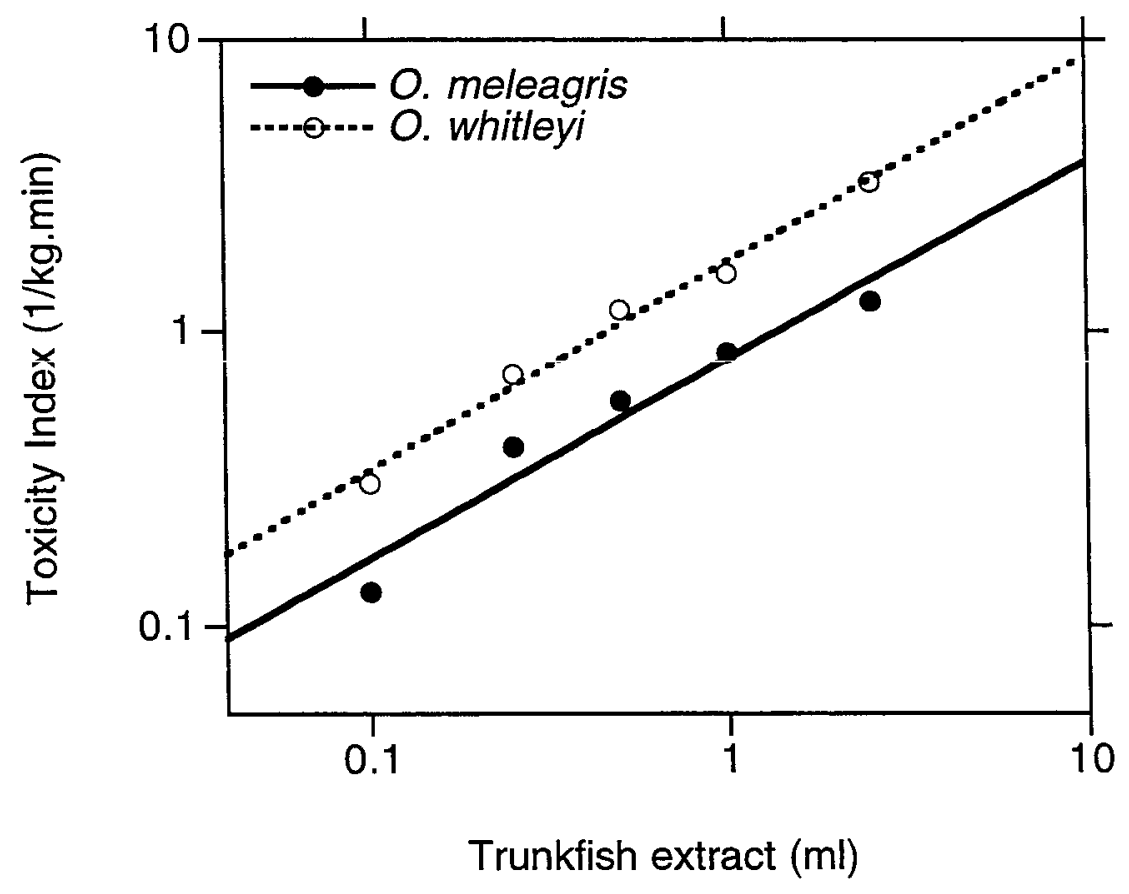


Figure 2. Timing of spawning by Ostracion meleagris and Ostracion whitleyi. Spawning effort is expressed as the percentage of total spawning by each species, while time is expressed as the number of minutes from sunset (negative values $=$ before sunset). 


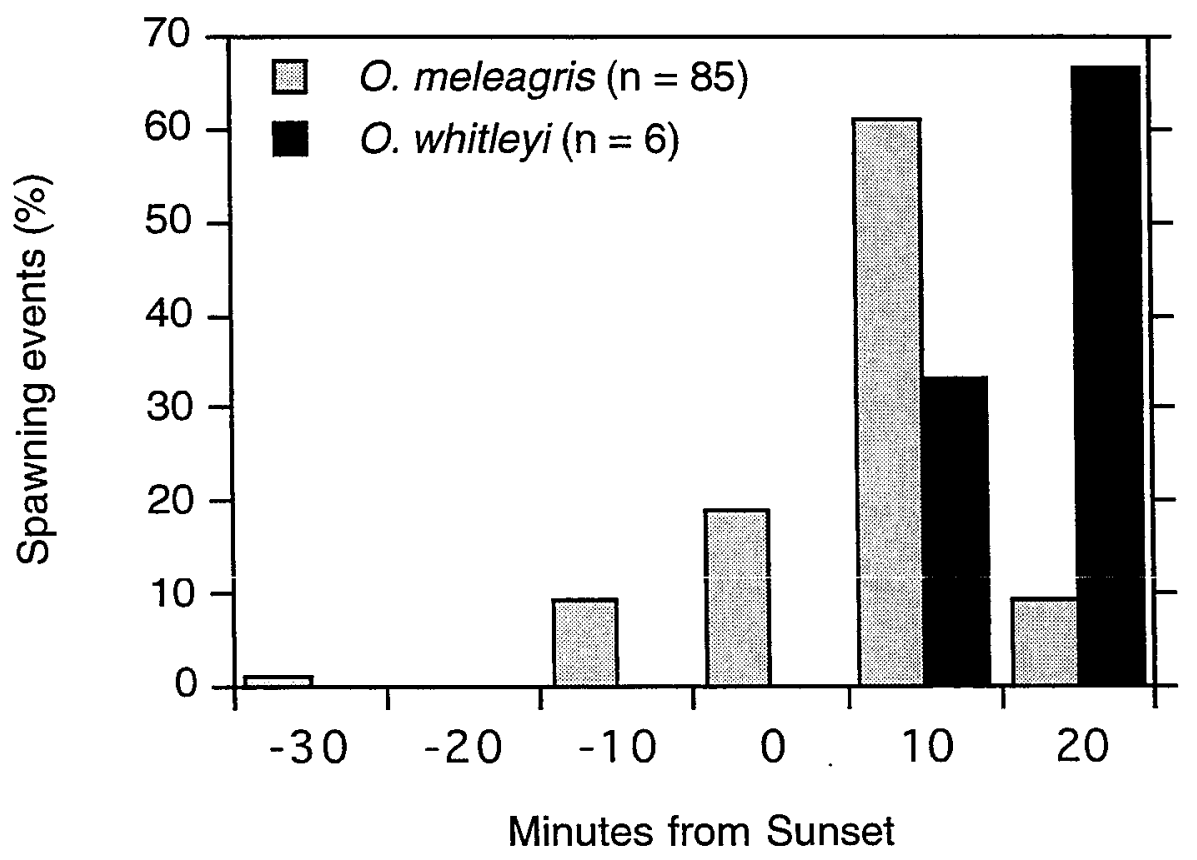


Figure 3. Comparison of spawning height (A), size (B) and toxicity (C) between Ostracion meleagris and Ostracion whitleyi ( \pm 1 standard error). Toxicity Index is calculated as the product of trunkfish weight by the number of minutes necessary to kill $50 \%$ of fishes in the mosquitofish assay (see methods). Asterisks indicate significant differences through a Mann-Whitney $U$ test for spawning height $(U=5 ; p<0.001)$ and Toxicity Index $(U=4 ; p$ $=0.009$ ). 


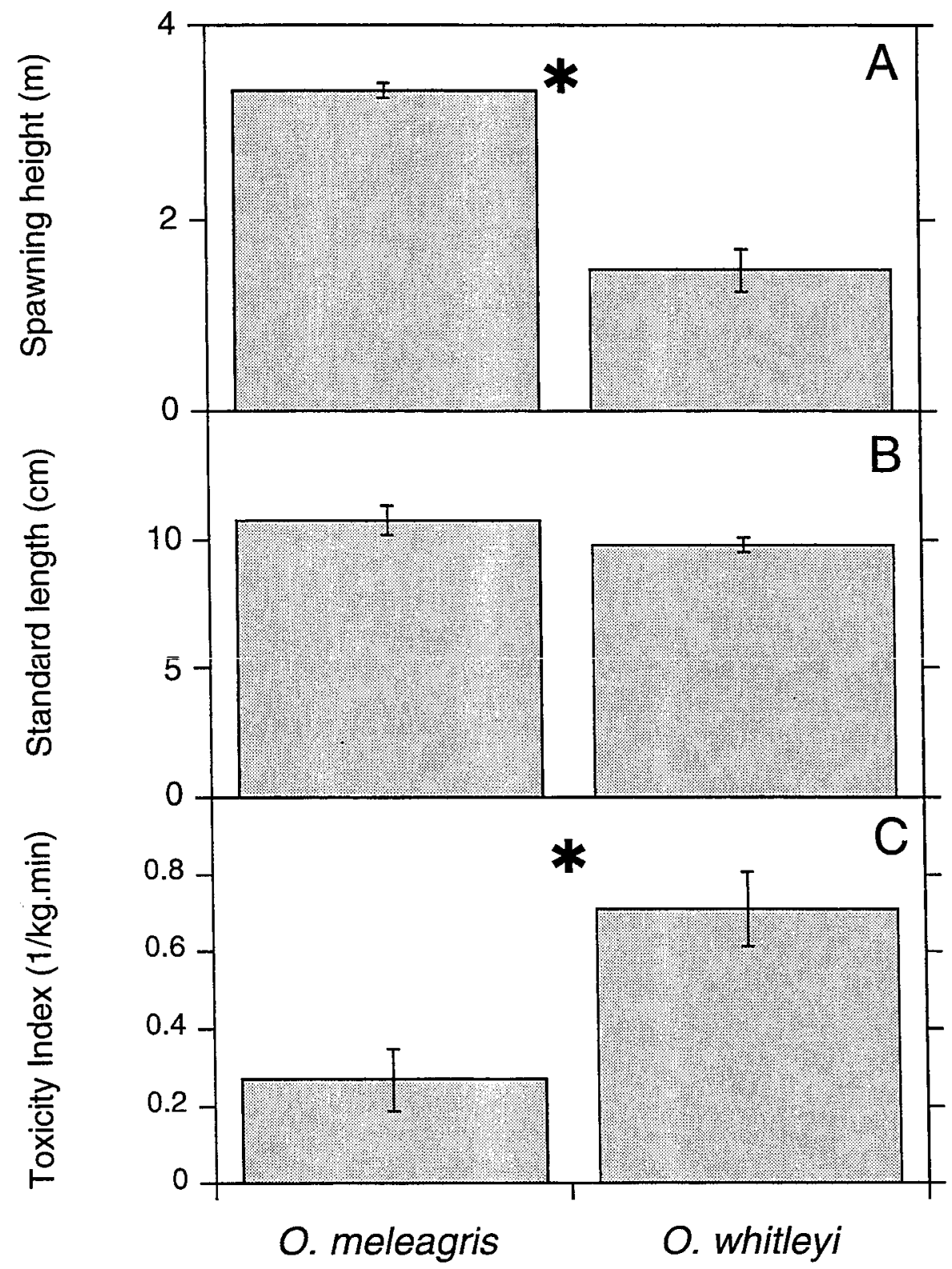


Figure 4. Timing of Ostracion meleagris behavioral events, including male fighting events (A), interrupted spawning ascents (B) and successful spawning events (C), observed over a total of 19 hours. Spawning ascents were interrupted by streaker males and planktivorous triggerfishes. Spawning events occurred in pairs, or with the presence of one or more streaker males. Time is expressed as the number of minutes from sunset (negative values $=$ before sunset). 


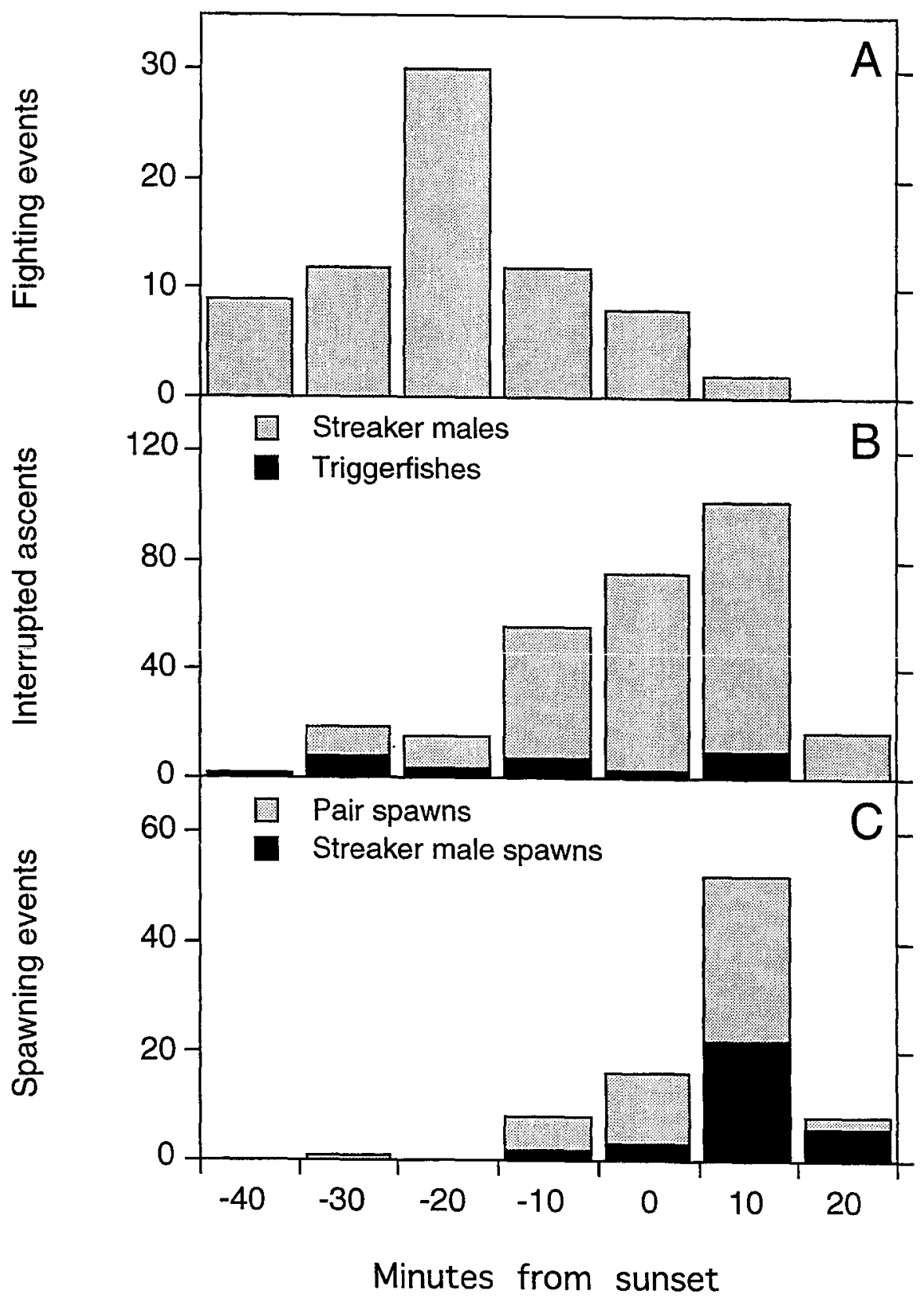




\title{
CHAPTER 6
}

\author{
Summary
}


An important objective of this thesis was to address various hypotheses explaining diel spawning patterns of reef fishes. These hypotheses propose that diel spawning patterns maximize dispersal of propagules (Barlow 1981), minimize predation of eggs by benthic planktivorous animals (Johannes 1978), are a response to predatory risks on adult fishes (Robertson \& Hoffman 1977) and are cued to tidal cycles to synchronize the spawning activities of adult populations (Colin \& Clavijo 1988). Different species of pelagic spawning fishes were found to have diverse responses to the environmental cues hypothesized to control diel timing of spawning. The time of the day when fish spawn seems to be a general fixed response for each species, which tend to spawn at the same time of the day at different locations. Spawning intensity of daytime spawning species was generally influenced by other environmental variables such as current direction and predator abundance, while dusk spawning species showed no correlation with these variables. Observations of spawning fishes responding to quick changes in current direction and predator abundance indicate that these environmental variables were detected by adult fishes at the time of spawning. Most daytime species selected outflowing currents for spawning, which will transport eggs away from the reef. This result supports hypotheses proposing the avoidance of predation of eggs by benthic reef predators (Johannes 1978) and the dispersal of eggs away from natal reefs (Barlow 1981) as selective mechanisms influencing the time of spawning. A few species of reef fishes showed low spawning intensities during times of high abundance of piscivores, indicating that spawning can be postponed due to high risks of predation (Robertson \& Hoffman 1977). Group-spawning fishes which migrate long distances to spawning aggregation sites could be using tides to help synchronize their spawning activities (Colin \& Clavijo 1988), but it seems like larval transport away from reefs is a more crucial factor determining spawning periodicity at locations with significant tidal amplitudes. 
It is significant that no single selective mechanism explained all the diel patterns observed. There is a great interspecific variability in behavioral responses, which indicates the complexity of the evolutionary and ecological mechanisms controlling timing of spawning of coral reef fishes.

The use of current meters permitted the correlation of spawning rates of fishes with the different current speeds occurring at the spawning grounds. Spawning during moments of maximum current speed has been hypothesized to reduce the time that eggs are exposed to benthic predators (Johannes 1978), but my data suggest that very few species selected high speed currents for spawning. Some species did avoid spawning at very low current speeds however. Studies on the effect of current speed on the predation rates of eggs by reef organisms and egg fertilization rates are needed to further understand how current speed might affect larval survival.

Many hypotheses consider the risk of predation as a potential factor influencing spawning patterns of reef fishes, but the behavior of predatory species at spawning aggregation sites was not well characterized (Robertson 1991) until the present study. Observations of diel activity patterns of two piscivorous species (Caranx melampygus and Aphareus furca) at the spawning aggregation site in Johnston Atoll showed that risks of predation are high during the daytime period, and are lowest at dusk. This result refutes hypotheses that propose crepuscular peaks of risk of predation in coral reef environments (Hobson 1973), and coincides with diurnal observations of piscivores feeding on nonspawning reef fish species (Sweatman 1984, Shpigel \& Fishelson 1989, Clifton \& Robertson 1993). Potential hypotheses explaining this daytime pattern of activity include the satiation of piscivores, diel changes in prey abundance and interspecific differences in prey spawning behaviors.

Piscivores selected to attack their prey during spawning ascents, a finding which confirms previous work by Moyer (1987). They also selected certain prey species over 
others at the spawning grounds. Selection of Chlorurs sordidus and Acanthurus nigroris as prey was hypothesized to be caused by predatory satiation processes, or by differences in spawning behaviors of prey species which affected their susceptibility to predation. The measured attack rates of piscivores on spawning fishes $(2.3 \%$ of spawning rushes by prey species were attacked), as well as capture rates ( $4 \%$ of all attacks were successful) indicate that spawning is a high-risk behavior for selected species. Based on these data, piscivory is expected to be an important cause of mortality for certain populations of group-spawning fishes, in particular for male fishes which spawn multiple times per day (Clifton \& Robertson 1993). Mortality due to predation of adult fishes during spawning should be considered as a potentially important mechanism regulating fish communities.

Predators can also affect the spawning behaviors of reef fishes by consuming recently released eggs. Planktivorous triggerfishes (Melichthys niger and M. vidua) had a high preference for attacking spawns from fishes which have large eggs, in comparison with much more abundant species which produce small eggs. Triggerfishes were more active at dusk, when species with large eggs usually spawned. Meanwhile, small planktivorous damselfishes (Dascyllus albisella) fed at similar rates during the daytime and dusk periods.

The interspecific variability in diel feeding patterns and prey selection by piscivores and planktivores shown in this study indicates that specific predator-prey interactions are important in determining the spawning patterns of reef fishes.

The choice of spawning locations by reef fishes has been hypothesized to reduce predation risks on adult spawners (Hugie \& Dill 1994). Group-spawning fishes were preferentially spwned from locations with high topographical complexity, which potentially offered refuge to adult spawners from piscivorous attacks, and avoided spawning over those stretches of reefs where holes and crevices did not exist. This result indicates that predation can affect the choice of spawning location for reef fishes. 
Ambushing and territorial behaviors were described for the first time for $C$. melampygus, which confirmed the behavioral flexibility of this piscivorous species (Potts 1983). These hunting behaviors provided C. melampygus with significantly higher capture success rates of adult spawning prey than the more common midwater hunting behaviors, indicating the potential advantage of ambushing behavior when prey concentrate at spawning aggregation sites. The behavioral flexibility of this piscivore could cause density-dependent mortality of its prey (Hixon \& Carr 1997), a key demographic condition for the regulation of fish populations.

Observations of two similar trunkfish species (Ostracion meleagris and O. whitleyi) releasing eggs at different heights from the substrate inspired the study of the selective factors influencing this behavior. The hypothesis tested states that risks of predation of adult fishes influence the height of spawning rushes (Robertson \& Hoffman 1977), relating long spawning ascents to low susceptibility of spawning fishes to predation. Examination of the size of both species and measurements of their relative toxicity revealed no differences in susceptibility to predation that might explain their spawning behaviors. However, O. meleagris, which spawned very high in the water column, had an extremely high rate of male competition during spawning, with abundant male-male aggressive interactions and high rates of streaking. Ostracion whitleyi spawned close to the substrate, and showed no indications of intraspecific male competition. Extended spawning ascents are interpreted as attempts to reduce the possibility of interference by streaker males. Thus, spawning height does not seem to be regulated by predatory risks in trunkfishes, but is more likely the result of competition among male fishes for matings. Future comparative observations are proposed to test this hypothesis.

The results from this thesis indicate that complex predator-prey interactions occur at spawning aggregation sites. Simple evolutionary hypotheses regarding the diel timing of spawning do not match the observed data well, since fish seem to interact in complex ways 
with different environmental variables. Predation of adult reef fishes at spawning aggregations can have important ecological consequences to the structuring and regulation of reef fish communities. 


\section{BIBLIOGRAPHY}

Barlow, G. W. (1981). Patterns of parental investment, dispersal and size among coralreef fishes. Env. Biol. Fish. 6: 65-85

Clifton, K. E., Robertson, D. R. (1993). Risks of alternative mating strategies. Nature. 366: 520

Colin, P. L., Clavijo, I. E. (1988). Spawning activity of fishes producing pelagic eggs on a shelf edge coral reef, Southwestern Puerto Rico. Bull. Mar. Sci. 42: 249-279

Hixon, M. A., Carr, M. H. (1997). Synergistic predation, density dependence, and population regulation in marine fish. Science. 277 : 946-949

Hobson, E. S. (1973). Activity of Hawaiian reef fishes during the evening and morning transitions between daylight and darkness. Fish. Bull. 70: 715-740

Hugie, D. M., Dill, L. M. (1994). Fish and game: a game theoretic approach to habitat selection by predators and prey. J. Fish Biol. 45 (Suppl. A): 151-169

Johannes, R. E. (1978). Reproductive strategies of coastal marine fishes in the tropics. Env. Biol. Fish. 3: 65-84

Moyer, J. T. (1987). Quaantitative observations of predation during spawning rushes of the labrid fish Thalassoma cupido at Miyake-jima, Japan. Japan. J. Ichthyol. 34: 7681

Potts, G. W. (1983). The predatory tactics of Caranx melampygus and the response of its prey. In: Noakes, L. G., Lindquist, D. G., Helfman, G. S., Ward, J. A. (ed.) Predators and prey in fishes. Dr. W. Junk, The Hague, p. 181-191

Robertson, D. R. (1991). The role of adult biology in the timing of spawning of tropical reef fish. In: Sale, P. F. (ed.) The ecology of fishes on coral reefs. Academic Press, San Diego, p. 356-386

Robertson, D. R., Hoffman, S. G. (1977). The roles of female mate choice and predation in mating systems of some tropical labroid fishes. Z. Tierpsychol. 45: 298320

Shpigel, M., Fishelson, L. (1989). Food habits and prey selection of three species of groupers from the genus Cephalopholis (Serranidae: Teleostei). Env. Biol. Fish. 24: $67-73$

Sweatman, H. P. A. (1984). A field study of the predatory behavior and feeding rate of a piscivorous coral reef fish, the lizardfish Synodus englemani. Copeia. 1984: 187-194 
228 


\section{APPENDIX 1}

Reproductive seasonality of four reef fishes at Johnston Atoll (Central Pacific) 


\begin{abstract}
The reproductive seasonality of four coral reef fish species was analyzed at Johnston Atoll. Specimens of Chaetodon multicinctus, Chlorurus sordidus, Ctenochaetus strigosus and Zebrasoma flavescens were collected at different times of the year, and their reproductive status was analyzed by calculating gonosomatic indices. All four species appeared to have a peak reproductive season during the late winter and spring months, even though interspecific variability was observed with respect to the beginning of the reproductive season. The spawning season at Johnston Atoll coincided with the general spawning pattern displayed by reef fishes in the Hawaiian Islands.
\end{abstract}




\section{INTRODUCTION}

Seasonal patterns in reproduction have been observed in most coral reef fishes studied (Munro et al. 1973, Johannes 1978, Thresher 1984, Sadovy 1996), and many factors have been hypothesized to control these seasonal spawning patterns (Robertson 1991). The principal hypotheses propose selective forces which will affect survivorship of pelagic larvae (larval-biology hypotheses) or the reproductive capacity of adults (adultbiology hypotheses). Larval-biology hypotheses propose temporal patterns of reproduction that have been selected to maximize larval survivorship in the pelagic environment and insure recruitment of juvenile individuals. Adult-biology hypotheses propose mechanisms that affect the reproductive capabilities and costs of reproduction of the adult fishes, and are independent of subsequent larval survivorship.

The objective of this study was to describe the spawning seasonality of four representative fish species from Johnston Atoll, in order to identify months of peak reproductive output. Later studies on the diel periodicity of spawning reef fishes were done during these peak reproductive months (Chapter 2). This study was not designed to investigate the environmental factors controlling spawning seasonality at Johnston Island, but data from this study will be compared with data from the Hawaiian Islands and other locations.

\section{METHODS}

Seasonality of reproductive activity was estimated from analyses of gonads from four different species of reef fishes: Chaetodon multicinctus (Chaetodontidae) a species endemic to the Hawaiian Islands and Johnston Atoll, and Chlorurus sordidus (Scaridae), Ctenochaetus strigosus and Zebrasoma flavescens (Acanthuridae), three species with pantropical Pacific distribution. All fish were collected from the same location in the lagoon of 
Johnston Atoll (east of North Island), characterized by large Acropora spp. coral formations. Collection dates $(n=9)$ were distributed between July of 1993 and June of 1994. All collections were done between $1600 \mathrm{~h}$ and $1800 \mathrm{~h}$ by four or five SCUBA divers using Hawaiian spears. Speared fish were kept on ice and, on the same night of collection, were measured, sexed and their gonads dissected. Measurements included fish weight (to $0.001 \mathrm{~g}$ ), gonad weight (to $0.001 \mathrm{~g}$ ) and fish standard length (to $1 \mathrm{~mm}$ ), measured as the distance between the snout of the fish to the point of insertion of the caudal fin rays.

Gonosomatic index (GSI) was calculated as the percentage of total body weight attributable to gonads. Because GSI values are dependent not only on stage of gonad development, but also on fish size (DeVlaming et al. 1982), only data from fishes which varied less than $15 \%$ in length were used in the analyses. Only females were used in the GSI analyses, to avoid potential variations in male testes size due to differences in sperm production within populations caused by different mating tactics of male fishes (Petersen et al. 1992, Warner et al. 1995, Marconato \& Shapiro 1996). A condition index (K) was calculated as $\mathrm{K}=$ constant $\mathrm{x}$ weight $/$ (standard length) ${ }^{3}$ (Anderson \& Gutreuter 1983) to assess the physical condition of fishes. A condition index was also calculated from weights and standard length measurements of fishes (Chaetodon multicinctus, Ctenochaetus strigosus and Zebrasoma flavescens) collected from the west coast of the Island of Hawaii in 1980 and 1981 by P.S. Lobel (1989).

\section{RESULTS}

Elevated gonosomatic index (GSI) values occurred during the late-winter and spring months at Johnston Atoll, but variations in this general pattern were observed among different species (Figure 1). Chaetodon multicinctus appeared to begin peak spawning in January and to continue through May, according to its GSI values. Chlorurus 
sordidus had enlarged ovaries between April and May, with intermediate GSI values observed in July and August. Ctenochaetus strigosus had high GSI values between February and April, and showed reduced GSI values by May. Zebrasoma flavescens had high GSI values from February through June.

The seasonal distribution of condition index $(\mathrm{K})$ values at Johnston Atoll indicated that all four species analyzed showed poor physical condition after the peak spawning season was over, in July and August (Figure 2). Annual minimum values of condition index occurred for all four species during these two summer months. Between October and May, the condition index remained relatively constant for all species. The condition index from fishes collected in the Island of Hawaii varied little among months (Figure 3). No common pattern was found for all three Hawaiian species analyzed, except for a small increase in condition in June.

\section{DISCUSSION}

A broad spring peak of spawning activity seems to occur for the four species studied at Johnston Atoll according to GSI analyses. This reproductive pattern coincided with the spawning season of three of these species (Chaetodon multicinctus, Ctenochaetus strigosus and Zebrasoma flavescens) measured by the same method in Hawaiian waters (Lobel 1989). More detailed comparisons between individual species from both studies are not attempted, due to the different sampling schedules employed and the coarse resolution of GSI analyses. No data on the reproductive seasonality of Chlorurus sordidus are available from the Hawaiian Islands, but this species seems to mainly spawn between April and August in the Ryukyu Islands (Yogo 1985) and was observed spawning between March and June in Enewetak Atoll (Colin \& Bell 1991). The only other reef fish for which data on reproductive seasonality have been collected at Johnston Atoll is Myripristis amaena (Myripristinae), which showed peak spawning in May and June (Dee \& Parrish 1994). 
The general spawning peak described for reef fishes in the Hawaiian Islands (Walsh 1987, Lobel 1989) coincides with the peak observed at Johnston Atoll, even though a few other species in Hawaii have different spawning seasons (Ross 1983, Walsh 1987). The general coincidence in spawning seasons indicates that whatever factors are responsible for establishing spawning seasonality, they are likely shared among various species in the Hawaiian Islands and Johnston Atoll, and possibly with these species at other Indo-Pacific locations within the northern hemisphere. Coral reef fishes from the southern hemisphere typically spawn during the austral spring (Montgomery \& Galzin 1993, Sadovy 1996), and display a weakening of spawning seasonality with decreasing latitude (Munro et al. 1973, Robertson 1991). A review of the potential factors hypothesized to control these seasonality patterns can be found in Robertson (1991), plus see Lobel (1989) for arguments in support of the larval biology hypotheses and Clifton (1995) for recent data supporting adult biology hypotheses.

The condition index $(\mathrm{K})$ is an estimate of body robustness. At Johnston Atoll the lowest condition indices occurred for all four species during the summer months, following the peak reproductive season. The occurrence of poor fish conditions during postreproductive periods has been observed in various surgeonfish species (Montgomery \& Galzin 1993), and was interpreted as an inability of feeding activity to supply energetic demands during the months following the reproductive season.

The condition indices of the three species analyzed from the Island of Hawaii did not vary seasonally as much as condition indices from fishes collected at Johnston Atoll. The different results from the fish populations of Johnston Atoll and Hawaii are most likely due to differences in the environment between the two locations. Condition differences between the samples could potentially be caused by (1) interannual differences in reef productivity between samples, (2) geographical differences in reef productivity between islands, (3) differences in reef habitats from where fish were collected or (4) differences in 
reef fish communities, which could affect competition and other ecological processes influencing physical condition of fishes. Genetic differences are less likely to cause the different seasonal condition patterns observed between Johnston and Hawaii, since both locations are part of the same Hawaiian faunal area and seem to be interconnected through larval dispersal (Randall et al. 1985, Lobel 1997). 


\section{BIBLIOGRAPHY}

Anderson, R., Gutreuter, S. J. (1983). Length, weight and associated structural indices. In: Neilsen, L. A., Johnson, D. L. (ed.) Fisheries techniques. American Fisheries Society, Bethesda, Md.

Clifton, K. E. (1995). Asynchronous food availability on neighboring Caribbean coral reefs determines seasonal patterns of growth and reproduction for the herbivorous parrotfish Scarus iserti. Mar. Ecol. Prog. Ser. 116: 39-46

Colin, P. L., Bell, L. J. (1991). Aspects of spawning of labrid and scarid fishes (Pisces: Labroidei) at Enewetak Atoll, Marshall Islands with notes on other families. Env. Biol. Fish. 31: 229-260

Dee, A. J., Parrish, J. D. (1994). Reproductive and trophic ecology of the soldierfish Myripristis amaena in tropical fisheries. Fish. Bull. 92: 516-530

DeVlaming, V. L., Grossman, G., Chapman, F. (1982). On the use of gonosomatic index. Comp. Biochem. Physiol. 73A: 31-39

Johannes, R. E. (1978). Reproductive strategies of coastal marine fishes in the tropics. Env. Biol. Fish. 3: 65-84

Lobel, P. S. (1989). Ocean Variability and the Spawning Season of Hawaiian Reef Fishes. Env. Biol. Fish. 24: 161-171

Lobel, P. S. (1997). Copmparative settlement age of damselfish larvae (Plectroglyphidodon imparipennis, Pomacentridae) from Hawaii and Johnston Atoll. Biol. Bull. 193: 281-283

Marconato, A., Shapiro, D. Y. (1996). Sperm allocation, sperm production and fertilization rates in the bucktooth parrotfish. Anim. Behav. 52: 971-980

Montgomery, W. L., Galzin, R. (1993). Seasonality in gonads, fat deposits and condition of tropical surgeonfishes (Teleostei: Acanthuridae). Mar. Biol. 115: 529536

Munro, J. L., Gout, V. C., Thompson, R., Reeson, P. H. (1973). The spawning seasons of Caribbean reef fishes. J. Fish Biol. 5: 69-84

Petersen, C. W., Warner, R. R., Cohen, S., Hess, H. C., Sewell, A. T. (1992). Variable pelagic fertilization suscess: implications for mate choice and spatial patterns of mating. Ecology. 73: 391-401

Randall, R. E., Lobel, P. S., Chave, E. H. (1985). Annotated checklist of the fishes of Johnston Island. Pacific Science. 39: 24-80

Robertson, D. R. (1991). The role of adult biology in the timing of spawning of tropical reef fish. In: Sale, P. F. (ed.) The ecology of fishes on coral reefs. Academic Press, San Diego, p. 356-386 
Ross, R. M. (1983). Annual, semilunar, and diel reproductive rhythms in the hawaiian labrid Thalassoma duperrey. Mar. Biol. 72: 311-318

Sadovy, Y. J. (1996). Reproduction of reef fishery species. In: Polunin, N. V. C., Roberts, C. M. (ed.) Reef Fisheries. vol. 20. Chapman \& Hall, London, p. 15-59

Thresher, R. E. (1984). Reproduction in reef fishes. T.F.H. Publications, Neptune City, NJ.

Walsh, W. J. (1987). Patterns of recruitment and spawning in Hawaiian reef fishes. Env. Biol. Fish. 18: 257-276

Warner, R. R., Shapiro, D. Y., Marconato, A., Petersen, W. (1995). Sexual conflict: males with highest mating success convey the lowest fertilization benefits to females. Proc. R. Soc. London B Biol. Sci. 262: 135-139

Yogo, Y. (1985). Studies on the sexual maturation and reproductive ecology in three protogynous fishes. Report of Fishery Research Laboratory, Kyushu University 7: $37-83$ 
Figure 1. Gonosomatic index for female Chaetodon multicinctus $(\mathrm{N}=101)$, Chlorurus sordidus $(\mathrm{N}=104)$, Ctenochaetus strigosus $(\mathrm{N}=64)$ and Zebrasoma flavescens $(\mathrm{N}=89)$. All fishes were collected at Johnston Atoll from July 1993 to June 1994. 


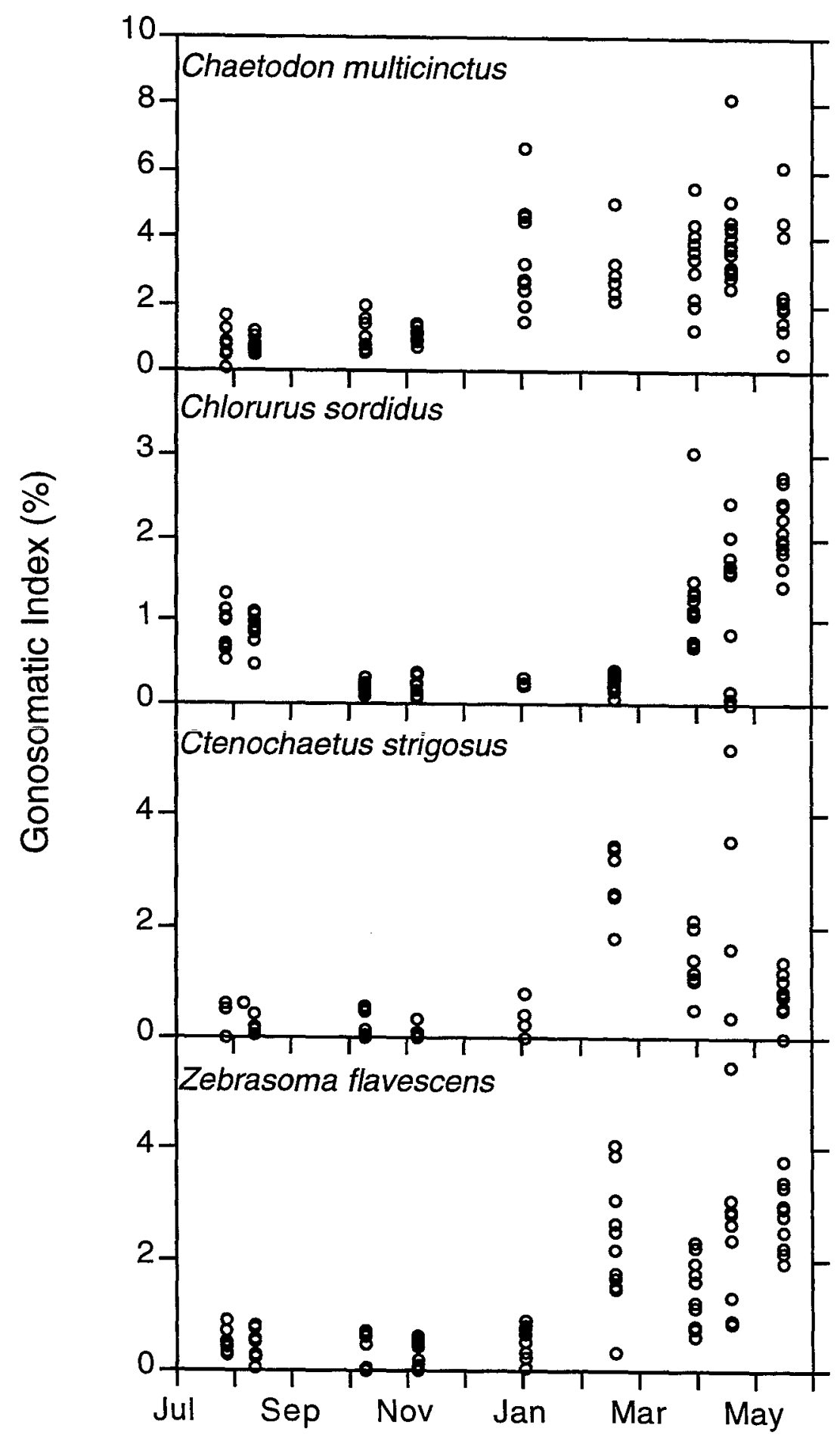


Figure 2. Average condition index (K) for female Chaetodon multicinctus $(\mathrm{N}=101)$, Chlorurus sordidus $(\mathrm{N}=104)$, Ctenochaetus strigosus $(\mathrm{N}=64)$ and Zebrasoma flavescens ( $N=89$ ). All fishes were collected at Johnston Atoll from July 1993 to June 1994. Error bars are \pm 1 standard deviation. 


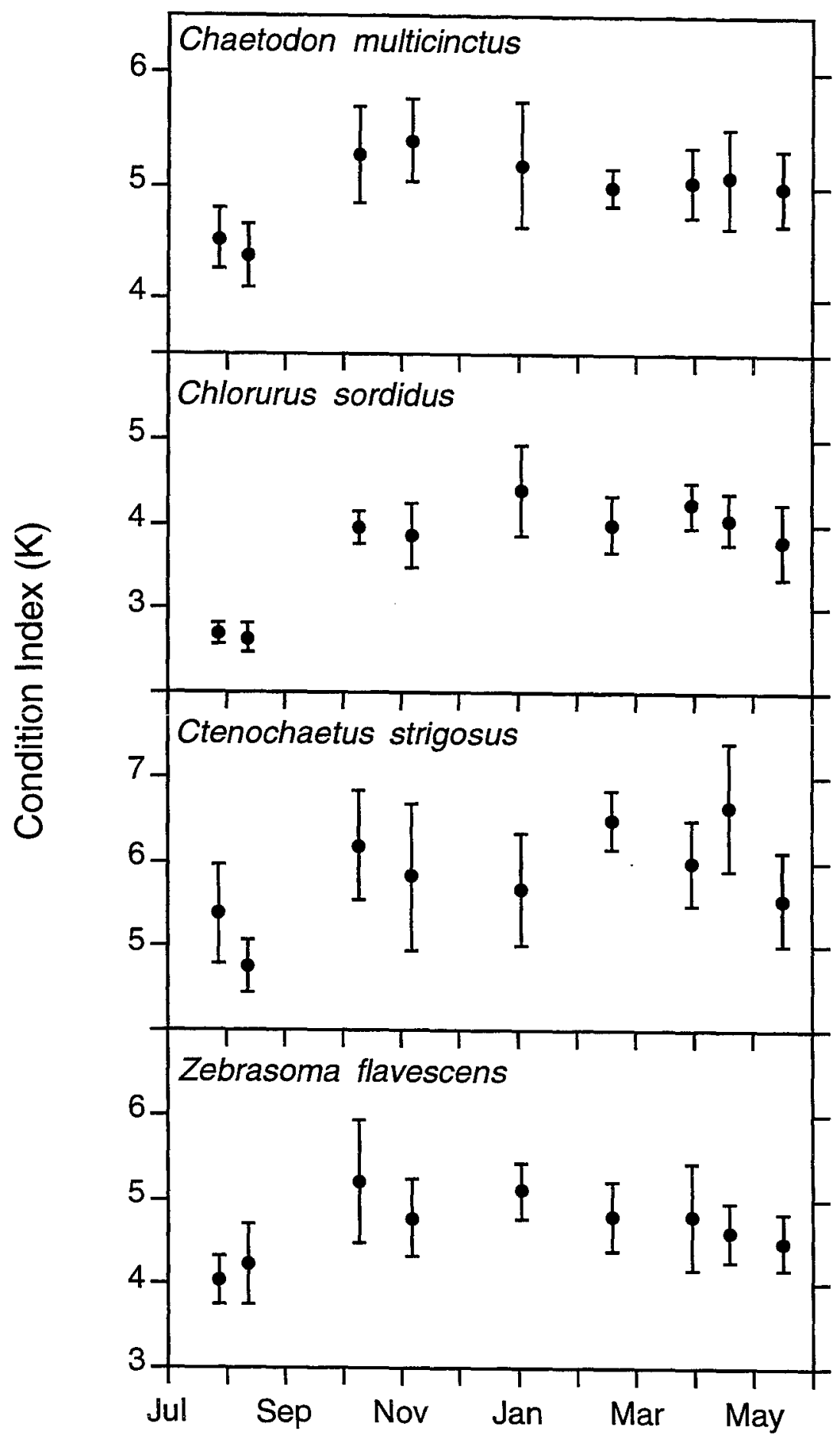


Figure 3. Average condition index (K) for female Chaetodon multicinctus $(\mathrm{N}=189)$, Ctenochaetus strigosus $(\mathrm{N}=105)$ and Zebrasoma flavescens $(\mathrm{N}=98)$ from Island of Hawaii. Data collected on different days within months were pooled into single month categories. Data for C. multicinctus and C. strigosus were collected from September 1980 to August 1981; data for Z. flavescens were collected from March 1980 to December 1980. Error bars are \pm 1 standard deviation. 


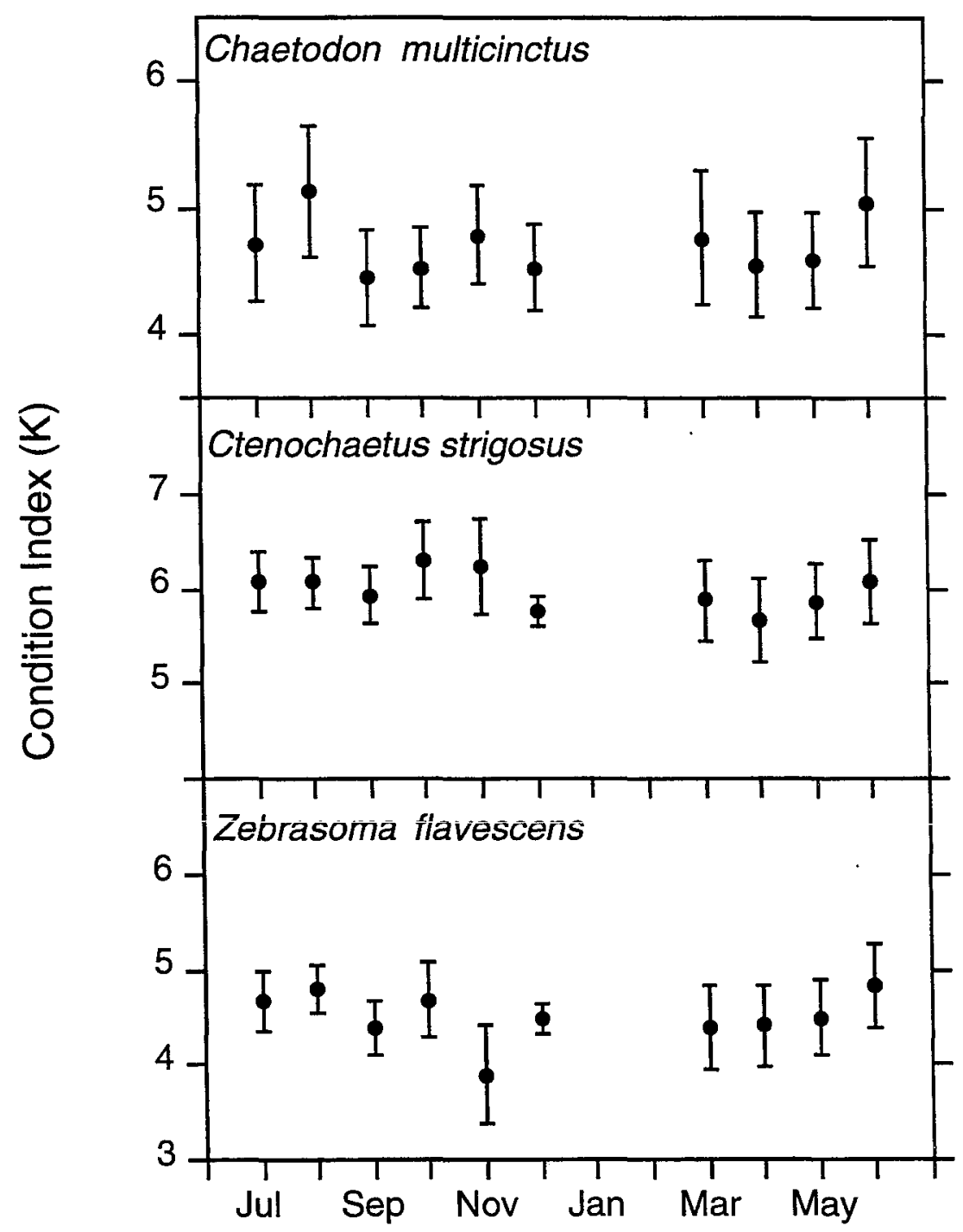




\section{APPENDIX 2}

\section{Graphic representations of some multifactorial analyses from Chapter 2}


Figure 1. Regression curves of group-spawning fish abundance (normalized data subjected to arcsin transformation) with significant independent variables of (A) current direction, $(\mathbf{B})$ time of day and (C) tide from multiple regression analyses (see Table 2 in Chapter 2). All graphs are from Mustin's Gap. 
A) Current direction
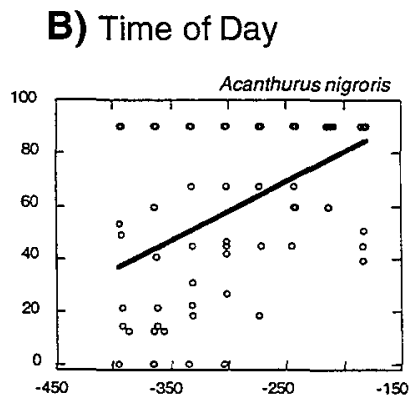

C) Tide
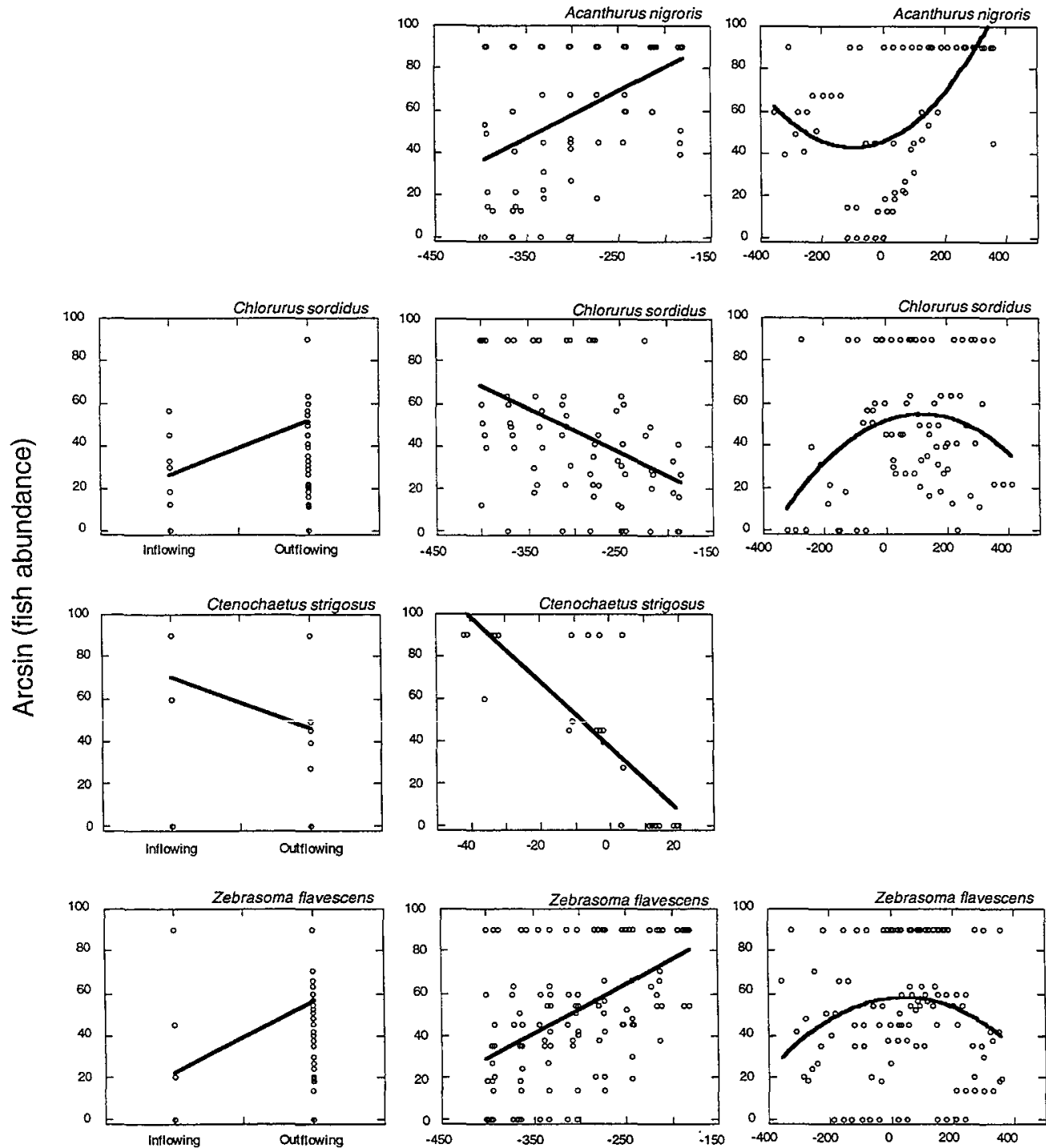

Current direction

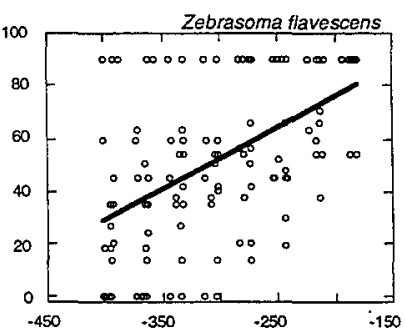

Minutes to sunset

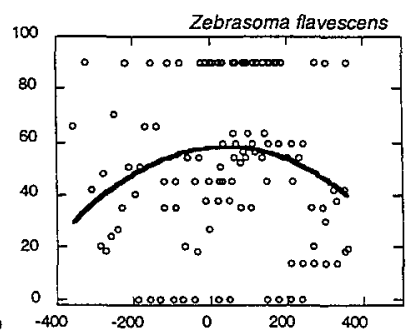

Minutes to low tide 
Figure 2. Regression curves of the number of spawns by group-spawning species (normalized data subjected to arcsin transformation) with significant independent variables of $\mathbf{A})$ predator presence, $(\mathbf{B})$ time of day and $(\mathbf{C})$ current velocity from multiple regression analyses (see Table 3 in Chapter 2). Predator presence is expressed as the percent of time predators were observed per 15-minute observation period, the predator identity is indicated in the lower-right corner of each graph. Graphs are from Mustin's Gap, except for one East Reef Edge graph in column (C). 

A) Predators
B) Time of Day
C) Current velocity
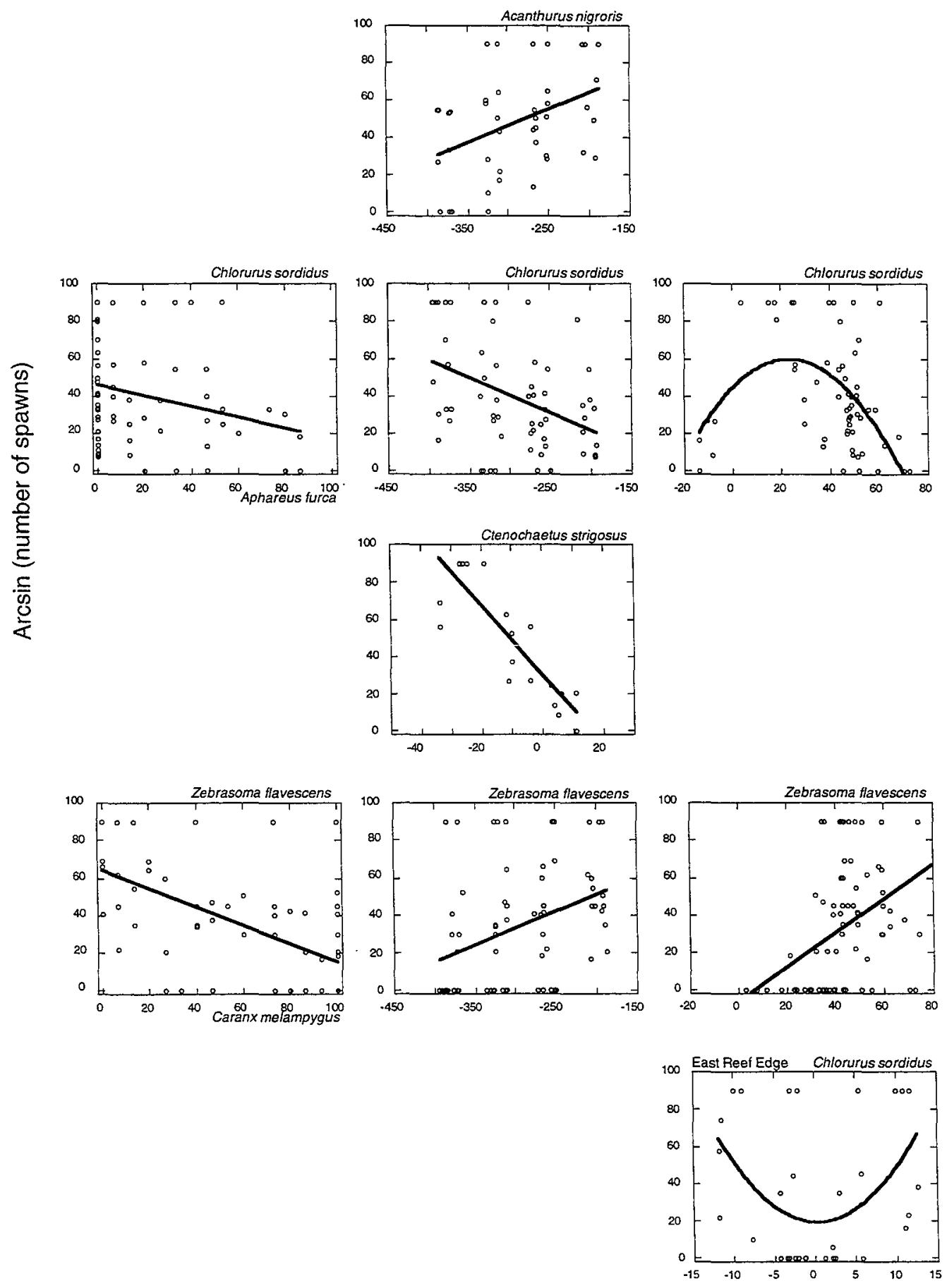

Predator presence (\%) Minutes to sunset

Current velocity $(\mathrm{cm} / \mathrm{s})$ 
Figure 3. Regression curves of the spawning intensity (number of spawns per fish present) of group-spawning species (log transformed) with significant independent variables of $\mathbf{A}$ ) predator presence, $(\mathbf{B})$ time of day and (C) current velocity from multiple regression analyses (see Table 4 in Chapter 2). Predator presence is expressed as the percent of time predators were observed per 15-minute observation period, the predator identity is indicated in the lower-right corner of each graph. Graphs are from Mustin's Gap, except for one East Reef Edge graph in column (C). 
A) Predators
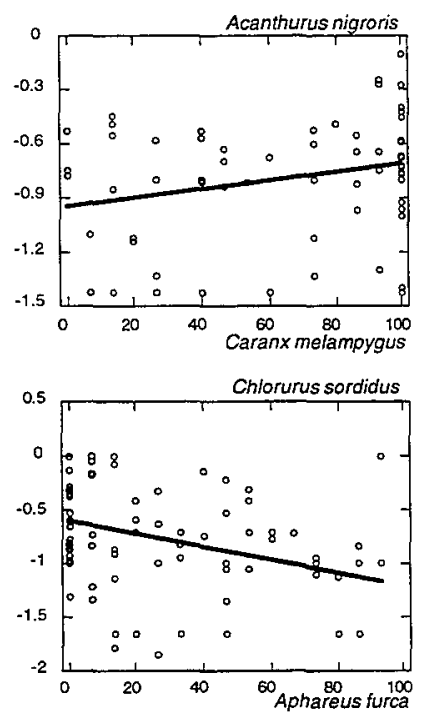

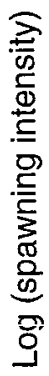
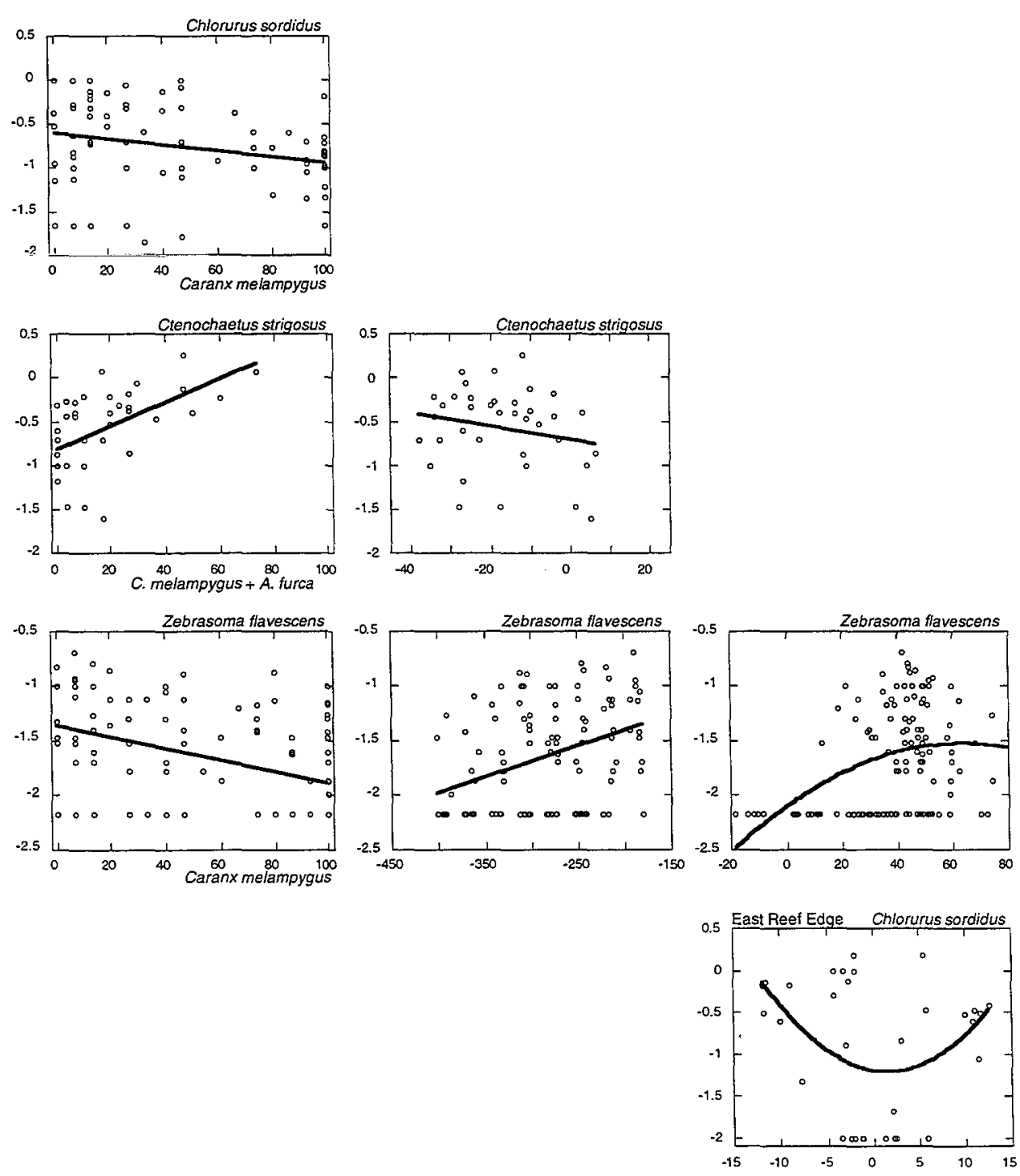

Predator presence (\%)

B) Time of Day

C) Current velocity
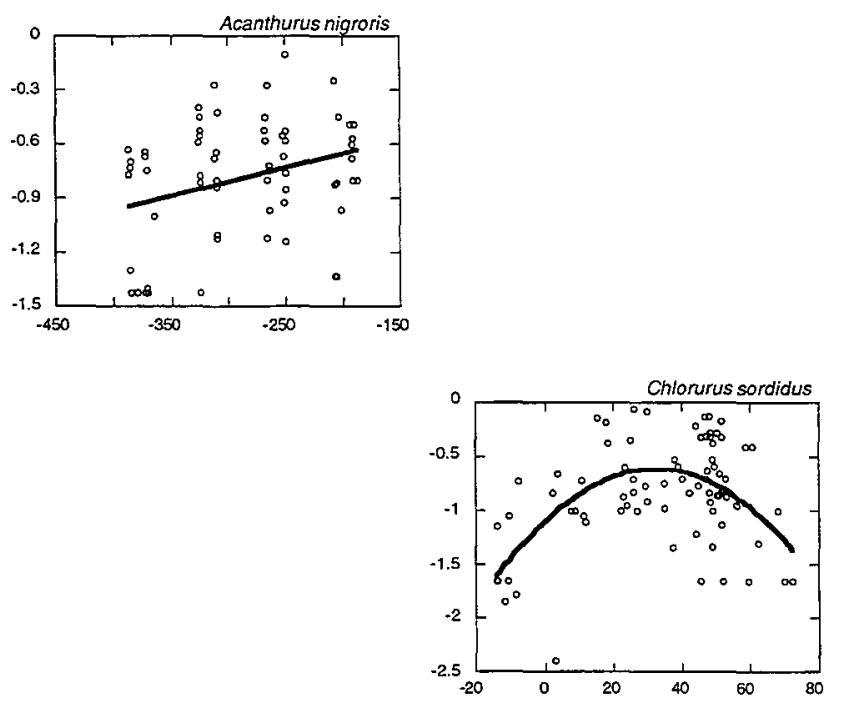
